\title{
TRANSDISCIPLINARIEDAD,
}

COMPLEJIDAD

\section{Y EDUCACIÓN}

Juan de Dios González Ibarra

Barbara Edith Orihuela Rosas Coordinadores
(9) COLEGIO DE MORELOS 


\section{TRANSDISCIPLINARIEDAD, COMPLEJIDAD Y EDUCACIÓN}




\section{TRANSDISCIPLINARIEDAD, \\ COMPLEJIDAD Y}

\section{EDUCACIÓN}

Juan de Dios González Ibarra

Barbara Edith Orihuela Rosas

Coordinadores 
Centro de Estudios de la Complejidad "Morelos".

El Colegio de Morelos, 2019.

1a. edición.

ISBN: 978-607-98493-5-1

Transdisciplinariedad, Complejidad y Educación

Obra arbitrada bajo el sistema de dobles pares ciegos.

D.R (C) 2019 Todos los autores

D.R (C) 2019 El Colegio de Morelos

Av. Morelos Sur 154 esq. Amates,

Col. Las Palmas, Cuernavaca, 62050,

Morelos, México.

(01 777) 3180125

www.elcolegiodemorelos.edu.mx

Proyecto realizado con financiamiento de la Secretaría de Educación Pública, Subsecretaría de Educación Superior, Dirección General de Educación Superior Universitaria.

Convenio registrado bajo el número 0708/19.

Este programa es público, ajeno a cualquier partido político.

Queda prohibido el uso para fines distintos a los establecidos en el programa.

\section{DIRECTORIO}

Dr. Juan de Dios González Ibarra

Rector de El Colegio de Morelos

Dr. Gustavo Arce Landa

Secretario General

Dr. Juan Carlos Tapia Rojas

Coordinador Académico

Lic. Jesús Antonio Hernández Flores

Coordinador Administrativo

Dra. Wendy Lucía Morales Prado

Directora Editorial

Efraím Blanco

Subdirector de Difusión y Vinculación

Ixshel Morales G.

Diseño y formación
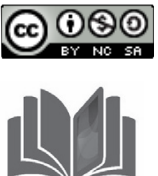

BNNIEM

Licencia Creative Commons Atribución

NoComercial-Compartir Igual 4.0 Internacional.

Registro ante la Cámara Nacional de la Industria Editorial Mexicana: 3948. 


\section{ÍNDICE}

LA HISTORIOGRAFÍA PEDAGÓGICA:

SUS MULTIDIMENSIONALIDADES

Graciela Sánchez Guevara

Universidad Autónoma de la Ciudad de México

COMPLEJIDAD EN LA ENSEÑANZA

DE LA CIENCIA JURÍDICA

Oscar Javier Apáez Pineda

Grupo de Investigación Desarrollo e Innovación:

Estudios sobre Justicia Social, Pobreza y Desigualdad

Barbara Edith Orihuela Rosas

El Colegio de Morelos

COMPLEJIDAD Y TRANSDISCIPLINARIEDAD

Juan de Dios González Ibarra

Carolina Peña Zepeda

El Colegio de Morelos

\section{LA COOPERACIÓN INTERNACIONAL EN}

LOS PAÍSES DE RENTA MEDIA DE AMÉRICA

LATINA Y EL CARIBE: UN BALANCE DE LOS

LOGROS DEL OBJETIVO 7 DE LA AGENDA

DE DESARROLLO 2015

Karen Ramírez González

Gustavo Arce Landa

El Colegio de Morelos

EL PENSAMIENTO COMPLEJO EN LA

COSMOVISIÓN DE LOS PUEBLOS INDÍGENAS

DE LA AMAZONÍA PERUANA

Rodrigo Severo Arce Rojas

Universidad Ricardo Palma 
PROCESOS SEMIÓTICOS DE LOS

MIGRANTES TRANSNACIONALES

Rosa María Macías Herrera

Universidad Autónoma de la Ciudad de México

CREACIÓN DE LA CIUDADANÍA DESDE EL

ECOSISTEMA DE LA PRENSA DEL MÉXICO

INDEPENDIENTE (1820-1829)

Tatiana Valdez Bubnova

Laura Campos Millán

Emiliano Canto Mayén

El Colegio de Morelos

LA RADIODIFUSIÓN UNIVERSITARIA EN COAHUILA:

ACCIÓN DISCURSIVA RADIOFÓNICA PARA LA

DIVULGACIÓN DE LA CIENCIA

Jorge Sadi Durón

Universidad Autónoma de Coahuila

ELEMENTOS PARA EL ESTUDIO Y ANÁLISIS DE LAS ORGANIZACIONES DESDE LA PERSPECTIVA DE LOS SISTEMAS DINÁMICOS COMPLEJOS

Pablo Guerrero Sánchez

Universidad Autónoma del Estado de Morelos

José Guerrero Grajeda

Universidad Nacional Autónoma de México

COMPLEJIDAD HUMANA EN LAS ORGANIZACIONES:

UN TEMA POCO CONSIDERADO EN EL

ESTUDIO ORGANIZACIONAL

Luis Canek Ángeles Tovar

El Colegio de Morelos 


\section{INTRODUCCIÓN}

El Primer Congreso Internacional "Transdisciplinariedad, Complejidad y Educación", que se celebró en la ciudad de Cuernavaca, Morelos, México, del 19 al 23 de noviembre de 2019, gracias al apoyo de la Secretaría de Educación Pública y de la Subsecretaria de Educación Superior, encabezada por el Dr. Francisco Luciano Concheiro Bórquez, logró reunir a los más grandes estudiosos del mundo, preocupados por el desarrollo del pensamiento complejo.

Se consiguió una gran participación y, a lo largo de las sesiones, se presentaron discusiones brillantes en el contexto de la educación, las ciencias sociales y las humanidades, con lo cual consideramos que nuestro país y estado aportaron no sólo la transmisión de conocimientos, sino construcción a partir de los postulados de la teoría de la complejidad. Igualmente, se buscó dar propuestas de solución a los grandes retos nacionales y globales, basadas en una panmetodología novedosa y transdisciplinaria, que permite la apertura hacia nuevos caminos para la mejora de nuestro país y todo el mundo. Gracias a los avances de este paradigma emergente, es posible abordar problemáticas desde el punto de vista de la multidiversidad, contando con el hermanamiento de todas las ciencias y saberes que la humanidad ha construido a lo largo de su historia, tanto de las llamadas ciencias duras como de las sociales.

La complejidad, aplicada a la educación, nos llevó a identificar sus posibilidades y límites frente a problemas como la falta de oportunidad, de calidad y equidad educativas, de modo que estos retos sean percibidos en relación al contexto social, político, económico, que traspasa los linderos de las aulas. Esto pone de relieve la necesidad de que las políticas en la materia, así como las propuestas pedagógicas, se gesten y desarrollen en un diálogo entre la Economía, Ética, Ecología, Ciencia y la vida en general, de modo que el derecho a la equidad y a la calidad educativa esté garantizado para todos. El objetivo estratégico de este pensamiento consiste en generar propuestas desde el enfoque de la complejidad y la transdisciplinariedad, que permitan aportar soluciones innovadoras a los desafíos educativos contemporáneos. 
Las ciencias sociales han sido eminentemente antropocéntricas y antropomórficas, con el consiguiente descuido de la naturaleza y la natursofía. En sentido tradicional, el objeto de las diversas ciencias y disciplinas sociales era el ser humano, de acuerdo con determinadas justificaciones, circunstancias, lenguajes o metodologías. Esta es, al mismo tiempo, su fortaleza y su debilidad, pues esta perspectiva ha impedido la consideración del deterioro que ha sufrido la naturaleza, así como la gran amenaza que representan las guerras nucleares y las centrales productoras de electricidad por medio de fisión atómica. Sin embargo, el tránsito desde el antropocentrismo hacia el reconocimiento del conjunto de desastres ecológicos -en el sentido más fuerte y amplio de la palabra- puso de manifiesto que, pensar en términos ecológicos es mucho más que pensar en términos de sociedad y naturaleza.

Así emergieron nuevos grupos de ciencias; propiamente hablando, de ciencias de frontera definidas a partir de problemas de la misma índole. El grupo más destacado de estas nuevas disciplinas incluye a las ciencias cognitivas, ciencias de la vida, ciencias de la salud, nanotecnología, inteligencia artificial, entre otras. Es aquí donde surge el objetivo del eje temático, ya que la teoría de la complejidad es el punto de partida para la resolución de las problemáticas presentes en cada una de las citadas ciencias, al buscar soluciones transdisciplinarias, reflexivas y de frontera.

La complejidad, la interculturalidad y las humanidades, marcan un cambio en la mentalidad de la época postmoderna; esto nos lleva a identificar sus capacidades y límites frente a diversos asuntos pendientes, como la falta del sentido de pertinencia de las humanidades (Filosofía, Estética, Artes y Letras), como elemento indispensable de desarrollo en la gestión cultural. En este sentido, un aspecto limitante, tanto creativo como reflexivo a resolver, es la carencia de transversalidad en las humanidades, que permita la resolución de problemas, así como la necesidad de responsabilidad fundada en una visión axiológica y en un paradigma de crecimiento comprometido con la realidad social y humana. El objetivo de este eje, que como flecha traspasa lo disciplinario, es dilucidar y coadyuvar en la realización de propuestas que vinculen a la complejidad y su carácter transdisciplinario con las humanidades, con la finalidad de generar propuestas que permitan avanzar hacia la solución de los grandes problemas nacionales y globales, dirigiéndonos a un mundo mejor. 


\section{LA HISTORIOGRAFÍA PEDAGÓGICA: SUS MULTIDIMENSIONALIDADES}

Graciela Sánchez Guevara

Universidad Autónoma de la Ciudad de México

\section{Introducción}

Comienzo con una verdad de Perogrullo: las historias escritas por mandato siempre están sesgadas por dos razones, una que obedecen a quien solicita que sean escritas, otra por la misma formación ideológica pasando por el tamiz de la pluma y del pensamiento de quien las escribe. Por ello, me propongo definir un modelo analítico que permita abordar epistemológica y analíticamente la historia oficial de México inscrita en los libros de texto gratuito. Me baso en la postura del pensamiento complejo y transdisciplinario que irrumpe las fronteras disciplinares, a fin de analizar el fenómeno de la escritura de la historia de manera integral, a partir de diversos campos del conocimiento, como la historia, la antropología, la literatura, la pedagogía, el diseño, el análisis del discurso y la semiótica de la cultura.

Con fundamento en la epistemología del pensamiento complejo, la unidad sujeto-objeto es requisito indispensable para la construcción de la historia oficial. Considero al sujeto como al objeto de manera colectiva en su multidimensionalidad. El punto de partida del análisis es el sujeto de la enunciación y del enunciado (sujeto cognoscente o, en términos complejos, sujeto conociente); en otras palabras, unos sujetos hacen la historia de un país, y otros la escriben para niños y niñas de educación básica.

A fin de sustentar una definición operativa de las categorías de discurso, texto verbo-visual y prácticas semiótico-discursivas, ofrezco una revisión general de los estudios que han abordado dichas categorías, destacando particularmente las tendencias que se retoman en esta investigación de larga data. Con base en ello, el discurso histórico se ubica en el tipo de discurso pedagógico de la historia oficial en dos dimensiones centrales, el de lo verbal-escrito y el de lo visual-estático. Aclaro que lo verbal lo identifico como discursivo y lo visual como semiótico; en ambas hay pro- 
ducción del sentido. Por último, planteo algunos criterios epistemológicos para una tipología compleja de la historia pedagógica de México. A continuación, el Modelo Operativo Transdisciplinario (MOT).

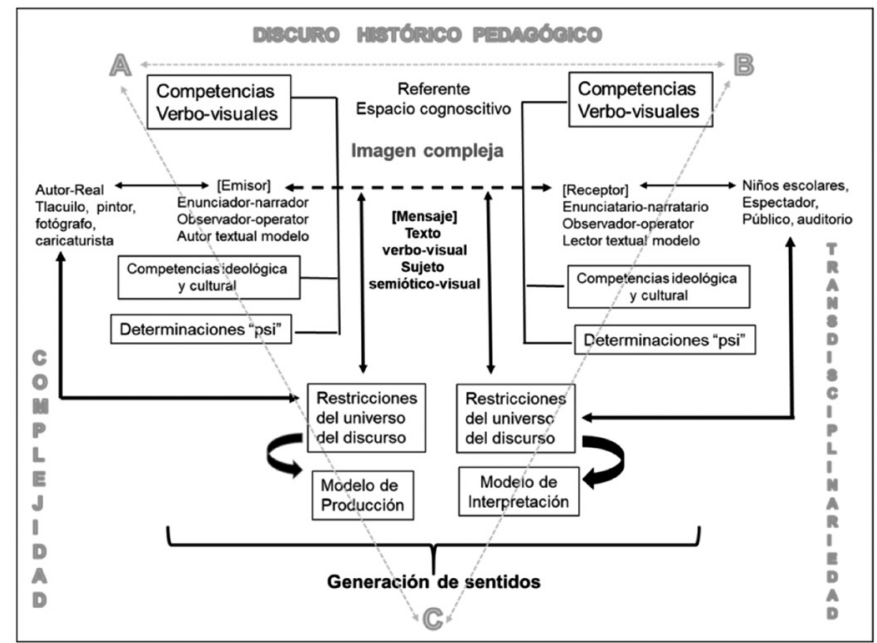

Cuadro 1.1

Modelo Operativo Transdisciplinario (MOT)

El Libro de Texto Gratuito Modelo elaborado por la autora

\section{Hacia una Pedagogía de la historia oficial}

Comprender la escritura de la historia oficial mexicana, en su multidimensionalidad, precisa, en primer lugar, definir pensamiento complejo y transdisciplinariedad, pues a la luz de esta epistemología proponemos un modelo acerca de la "complejidad aplicada" para la historia pedagógica. El siglo XXI, el bicentenario latinoamericano y la globalización económica y sociocultural, son aspectos que exigen cambios sustanciales tanto en la pedagogía como en la forma de concebir México inserto en el mundo; no de manera total, sino desde su complejidad.

La producción del conocimiento occidental ha tenido durante mucho tiempo, como base y fundamento, el pensamiento cartesiano que separa el sujeto del objeto. En el polo de la subjetividad en la que se instala la fi-

1 Edgar Morin, et al., Educar en la era planetaria, Barcelona, Gedisa, 2003. 
losofía y la investigación reflexiva, los sujetos se plantean problemas de su existencia, y en el polo de la objetividad se haya la investigación objetiva, la ciencia y el método científico, cuyos objetos de estudio están sometidos a observaciones, experimentaciones y verificaciones del dato. Esta manera rígida y fragmentada de mirar el mundo constituye un pensamiento reduccionista y simple, monodisciplinario, pues al parcelar el fenómeno, cualquiera sea su índole, en sus partes para su observación, genera, "dominios disciplinarios quebrados por el pensamiento disgregador, ${ }^{2}$ " lo cual limita el estudio del fenómeno de manera integral. El pensamiento simple y parcelado promueve las hiperespecializaciones que debilitan responsabilidades y solidaridad entre los seres humanos. ${ }^{3}$

Entonces, ¿qué significado tiene enseñar a los escolares la guerra de Independencia o la Revolución mexicana, si no se le mira en toda su complejidad, no sólo las causas que motivaron dichos movimientos sociales, sino los contextos o entornos socioculturales y económicos en todos los niveles? A los escolares habrá que enseñarles que la "[...] historia avanza, no de manera frontal como un río, sino por desviaciones que proceden de innovaciones o creaciones [o destrucciones] internas, o de acontecimientos o accidentes externos". ${ }^{4}$

Los principios ordenadores del pensamiento occidental tienen una finalidad fundamental, mediante la parcelación del conocimiento en disciplinas; constituir un sistema de control en la producción de discurso educativo, que fija sus límites por medio de la acción de una identidad que adopta la forma de una permanente reactivación de las reglas. ${ }^{5}$ Las disciplinas permiten gobernar y sujetar a los individuos a formas de pensamiento para reproducir el poder de los productores de conocimiento. Sin embargo, si se enseñara una historia más humanizada y religada no únicamente a la ciencia, sino a todo el acontecer humano y la naturaleza, quizá la población tendría mejores condiciones de vida y los gobernantes podrían gobernar mejor en conjunto con la sociedad. Una historia que manipula, aleja a quienes gobiernan de su oportunidad de gobernar.

Immanuel Wallerstein, en su texto Abrir las ciencias sociales, coincide con Edgar Morin, al hacer una severa crítica en la producción del conocimiento parcelado y disciplinario desde las burocracias educativas, ya sea

2 Edgar Morin, Introducción al pensamiento complejo, disponible en <http://www.pensamientocomplejo. com.ar/docs/files/MorinEdgar_Introduccion-al-pensamiento-complejo_Partel.pdf $>$.

3 "Educar en la era planetaria", en Edgar Morin et al., op. cit., p. 39.

4 Ibid., p. 77.

5 Cf. Michel Foucault, El orden del discurso, traducción de Alberto González Troyano, Buenos Aires, Tusquets Editores, 1969, p. 94. 
de educación básica o superior, reconoce que "los principales problemas que enfrenta una sociedad compleja no se pueden resolver descomponiéndolos en pequeñas partes que parecen fáciles de manejar analíticamente, sino más bien abordando estos problemas, a los seres humanos y a la naturaleza, en toda su complejidad y en sus interrelaciones". ${ }^{6}$

El pensamiento complejo no desconoce las disciplinas y las especializaciones; por el contrario, las reconoce e integra en un entramado de acciones y de otros conocimientos, para mirar y explicarse el mundo no como totalidad, sino en su complejidad; en otras palabras, explicar los fenómenos de manera integral y no fragmentariamente. Desde el siglo $\mathrm{XX}$, la producción del conocimiento se halla en crisis y se acrecienta a raíz de las grandes conflagraciones mundiales; por lo tanto, las investigaciones comienzan a cambiar de rumbo, cuando el sujeto 'conociente' toma conciencia de que el sujeto y el objeto no pueden estar separados, coexisten las dicotomías en un constante continuum, no se es únicamente sujeto o únicamente objeto, se es a la vez sujeto y objeto.

Niels Bohr, ${ }^{7}$ físico danés, premio Nobel de Física en 1922, fue quien introdujo por primera vez la epistemología de la complejidad al descubrir que el sujeto y el objeto no sólo son inseparables, sino que son complementarios, pero no dialécticamente; con esto, la idea determinista de la ciencia clásica llega a su fin, por tanto la observación se relativiza. Al respecto hay una pródiga producción de conocimiento sobre la complejidad y la transdisciplinariedad, ${ }^{8}$ cuyos autores desde sus campos de conocimiento coinciden en que los fenómenos de las ciencias naturales, básicas, humanas y artísticas deben estudiarse de manera integral como un todo y no en una sola de sus partes.

6 Immanuel Wallerstein, Abrir las ciencias sociales, México, Siglo XXI editores, 1996, 2006, p. 87.

7 "La confusión entre caos, complejidad y determinismo", en Edgar Morin et al., op. cit., p. 62.

8 Existe una gran producción teórica respecto de la complejidad desde diversas posturas epistemológicas, que se cita aquí de una manera muy sucinta: i) Ilya Prigogine (1979/1986), en el campo de la química. Fue precursor de la teoría del caos, y de la teoría de los procesos irreversibles en los sistemas biológicos; ii) Humberto Maturana y Francisco Varela (1984), en el de la biología. Sus aportes teóricos se relacionan con el principio de la auto-organización - autopoiesis- que se caracteriza por la capacidad que tienen los seres vivos de que frente a una situación de caos, logran la auto-organización; iii) Benoît Mandelbrot (1997), en el campo de las matemáticas, desarrolló la geometría fractal; iv) Heinz von Foerster (1979), en el campo de la cibernética, desarrolló la teoría del constructivismo radical y la cibernética de segundo orden. Jesús Ibáñez (1990) hace una recopilación de diversos textos acerca de la cibernética de segundo orden y su aplicación en las ciencias sociales; v) Geoffrey Chew, en el campo de la física subatómica, sus aportes teóricos fueron en relación con la interpretación bootstrap (tira de bota) de la mecánica cuántica; vi) Johnson Lakoff, en la lingüística y en las ciencias cognitivas; Luhman, en la sociología; y Capra, en la física (1996). Adicionalmente están los siguientes documentos en línea: Most (varios autores), Manual de iniciación al pensamiento complejo (varios autores). 
Edgar Morin, como científico social, ha estudiado al hombre como un individuo biológico, físico, psíquico, cultural y socio-histórico. Quiero pensar que el sociólogo ha considerado la producción artística dentro de lo cultural, ya que el arte, en sí, es el motor de la sociedad, donde explotan todas las posibilidades del ser humano. Todo este entramado constituye la base del pensamiento complejo que "está animado por una tensión permanente entre la aspiración a un saber no parcelado, no dividido, no reduccionista, y el reconocimiento de lo inacabado e incompleto de todo conocimiento". Se trata de comprender un pensamiento que separa y reduce, junto con el pensamiento que distingue y religa. No se trata de abandonar el conocimiento de las partes por el conocimiento de las totalidades, ni el análisis por la síntesis, sino hay que conjugarlos, como sugiere Morin. ${ }^{10}$ Además del pensador francés, otros autores como Jean Piaget, Eric Jantsch, Basarab Nicolescu, han abordado la teoría de la transdisciplinariedad para expresar, sobre todo en el campo de la enseñanza, la necesidad de transgredir las fronteras disciplinares. ${ }^{11}$

El análisis de la escritura de la historia oficial pedagógica en su multidimensionalidad, nos condujo a profundas reflexiones para formular, acorde a la complejidad-transdisciplinariedad, unos acercamientos epistemológicos que permita al estudioso de la historiografía construir-reconstruir-traducir los acontecimientos históricos que se imparten en la enseñanza básica. He tomado como base teórico-metodológica Los siete saberes de Edgar Morin, las cegueras del conocimiento, los principios de un conocimiento pertinente, enseñar la condición humana, enseñar la identidad terrenal, enfrentar las incertidumbres, enseñar la comprensión y la ética del género humano.

El sociólogo y filósofo ${ }^{12}$ sostiene que el conocimiento no es el espejo de las cosas o del mundo exterior; en todo caso, son traducciones y reconstrucciones que hace de la realidad el sujeto 'conociente' a partir de estímulos o signos captados y codificados por los sentidos. De ahí que distinga dos tipos de errores para la generación de conocimiento: el error de la percepción y el intelectual. El conocimiento al traducirse por medio de la palabra es el resultado de una traducción-reconstrucción mediada por el lenguaje y el pensamiento; ahí es donde radican los errores, razón por la cual, este autor insiste en que el conocimiento es ciego, con errores

9 Edgar Morin, Introducción al pensamiento complejo, Barcelona, Gedisa, 1998, p. 11.

10 Edgar Morin, Los siete saberes necesarios para la educación del futuro, Barcelona, Paidós, p. 43.

11 Véase Basarab Nicolescu, La transdisciplinariedad, Manifiesto, 1994, p. 3, disponible en <http:// www.ceuarkos.com/manifiesto.pdf $>$.

12 Los siete saberes necesarios..., en Edgar Morin, op. cit., pp. 21-22. 
e ilusiones. En este orden de ideas, el sujeto 'conociente' mira la realidad desde su lugar de batalla, tiene la incapacidad de ver y observar los otros lados de la realidad y por tanto en su ser 'conociente' tiene la ilusión que existan otras realidades similares a las que él conoce.

En el caso de la historia oficial pedagógica, mediante el estudio semiótico-discursivo, observamos que la selección de datos referentes a los grandes acontecimientos que se narran, describen y argumentan, responden a traducciones y reconstrucciones de la realidad histórica mexicana, dependiendo del lugar de producción del sujeto 'conociente', lo que trae como consecuencia una visión sesgada de los hechos.

Examinamos el discurso verbo-visual de la historia pedagógica, a partir de cuatro principios pertinentes para la educación: a) el contexto o entorno que da cuenta de las condiciones de producción de los discursos y de las semiosis, que es el que permite situar la información y datos seleccionados en su contexto para que produzcan sentido en los destinatarios; b) lo global da cauce a la relación entre el todo y las partes, se concibe a la sociedad como un todo organizador del cual los individuos formamos parte, de modo que la sociedad es más que un contexto; c) la multidimensionalidad toma en consideración dos unidades complejas: el ser humano que es biológico, psíquico, social, afectivo y racional, y la sociedad que comporta dimensiones históricas, económicas, sociológicas, religiosas y culturales; y d) lo complejo que implica el bucle individuo-sociedad-especie, y las prácticas socio-culturales-históricas-económicas-religiosas como un tejido interdependiente, interactivo e inter-retroactivo entre el objeto de conocimiento y su contexto, es decir, religa las partes y el todo y viceversa.

El basamento teórico-metodológico de esta investigación es el pensamiento complejo, la transdisciplinariedad en tanto que consideramos la ruptura de las fronteras disciplinares, pero por espacio no abordamos los niveles de realidad de la propuesta teórica de Nicolescu, además de algunos aspectos analíticos de la Escuela Francesa del Análisis del Discurso y de la Semiótica de la Cultura de la Escuela de Tartu. Con este andamiaje teórico-metodológico, analizamos a profundidad la escritura de la historia pedagógica oficial, en sus generalidades: los cortes temporales y espaciales de los acontecimientos, y en sus particularidades: la configuración de las diversas identidades y la cultura constituida por el conjunto de los saberes, saber-hacer, saber-ser, creencias, mitos, religio- 
nes que se transmiten de generación en generación, mediante el sujeto colectivo de la enunciación y del enunciado, y de los sujetos representados semiótico-discursivamente.

Abordamos la historia oficial pedagógica en su dimensión discursiva, con base en las teorías del sujeto, la enunciación, la deixis personal, temporal y espacial para ubicar al sujeto emergente, implícito, el nosotros inclusivo y exclusivo, en relación con las condiciones de producción, así como su vínculo con otras disciplinas como la historia, la pedagogía y los géneros discursivos como la narración, la descripción y la argumentación. Todo esto constituye un continuo diálogo constructivo de complejidad-transdisciplinariedad. Asimismo, analizamos la dimensión semiótica-visual de la imagen estática de los libros en su diseño, tipo de papel, de la distribución del discurso verbal del saber histórico en el espacio del libro, así como de las imágenes y su clasificación en códices, pintura de los siglos XVII, XVIII, XIX y XX, fotografías y caricaturas. Todo lo anterior implica una vinculación con los estudios culturales.

Para el análisis de la historiografía pedagógica tomamos en consideración los textos de historia de México, materiales educativos, socio-culturales e históricos, que son producto de dos coyunturas históricas significativas: las de los gobiernos de Luis Echeverría Álvarez y de Carlos Salinas de Gortari, correspondientes a la segunda y tercera reformas educativas. En estos materiales hay un interesante juego inter-subjetivo en estrecha relación con las prácticas y estrategias semiótico-discursivas pedagógicas. El análisis, tanto de la narración como de la argumentación, nos dejó ver cómo se construyen consciente o inconscientemente, objetos, campos y matrices semiótico-discursivas que conducen, necesariamente, a una nueva generación del sentido o de sentidos de la historia pedagógica y de la configuración de las diversas identidades.

Al plantear una nueva generación de sentidos nos referimos a que cada conjunto de libros expresa, en la estructura más profunda del discurso, conceptos de diversas identidades, aunque haga referencia a los mismos acontecimientos históricos. En todo caso, el nuevo sentido es asequible para el lector, porque se construye a partir de elementos de la tradición cultural y se materializa a través de la lengua socialmente compartida, reforzada por los textos visuales. El modelo de análisis transdisciplinario que se propone está conformado por tres grandes ejes: a) la tipología compleja semiótico-discursiva de la historia oficial, 
b) las condiciones de producción, circulación y recepción de los mismos y c) sus materialidades y funcionamientos semiótico-discursivos, con base en los cuatro principios del conocimiento pertinente.

Comenzamos con el análisis del discurso verbo-visual de la historiografía pedagógica de México, para llegar a conclusiones sobre el funcionamiento ideológico-cultural y de poder que se dinamizan y se consolidan en prácticas semiótico-discursivas, materializadas en los libros escolares en estudio. El sujeto de la historia pedagógica es bidimensional, se halla en el polo de la producción y de la recepción como un sujeto polifónico, ${ }^{13}$ en el que coexisten las posiciones subjetiva y objetiva. ${ }^{14}$ A diferencia del paradigma occidental cartesiano, que separa al sujeto del objeto, el pensamiento complejo concibe la unidualidad, que es igual a implicación-distinción-conjunción; es decir, que considera al sujeto como natural y cultural, a la vez, y como cerebral-psíquico.

El sujeto emisor colectivo está conformado por a) el conjunto de historiadores, quienes seleccionan los contenidos históricos a narrar; b) por los pedagogos, quienes establecen las estrategias discursivas pedagógicas para la enseñanza de ese saber histórico; c) por los editores y diseñadores, quienes son los encargados de dar forma al libro, en cuanto a la distribución del discurso pedagógico y de las imágenes que sirvieron para ilustrarlo. El conjunto de historiadores, como sujeto colectivo, que quiere observar la realidad histórica de manera objetiva, no obstante su subjetividad, emerge discursivamente en cualquier momento.

\section{El discurso verbo-visual}

A partir de la posición compleja-transdisciplinaria definimos la unidad analítica de discurso verbo-visual. Maingueneau ${ }^{15}$ precisa seis acepciones para definir el discurso: a) como sinónimo de habla saussureana; b) como una unidad lingüística de dimensión superior a la oración, -es una unidad transoracional en el nivel del enunciado-; c) como algo integrado al análisis lingüístico, tomando en cuenta el conjunto de reglas de encadenamiento de las sucesiones de oraciones que componen el enunciado; d) ligado a sus condiciones sociales de producción planteadas por la Escuela Francesa del Análisis del Discurso; e) como la lengua convertida en discurso a partir de la teoría de la enunciación; y f) como creatividad que toma en cuenta el contexto imprevisible concebido a

13 Mijaíl M. Bajtín, Estética de la creación verbal, Buenos Aires, Siglo XXI Editores, 1982, 2002 , p. 67.

14 Michel Pêcheux, "Formación social, lengua, discurso", en Arte, Sociedad, Ideología, No 5, México, 1997, p. 246.

15 Dominique Maingueneau, Introducción a los métodos de análisis del discurso, Buenos Aires,

Librería Hachette, 1980, p. 7. 
manera de sistema finito, campo de estudio de la pragmática. En el terreno de la lingüística, el término ha tenido un fuerte desarrollo que inicia con los estudios saussureanos en Europa, a los que le siguieron los de Bloomfield, con su teoría distribucionalista, y los de Chomsky, con la gramática generativista y transformacional, en Estados Unidos.

El problema presente en estos autores y sus teorías, es que ellos ven en la oración la unidad analítica de base. El análisis del discurso irrumpe estas fronteras para abrir las posibilidades de nuevas concepciones gracias a los movimientos que las ciencias del lenguaje han tenido. Desde esta última perspectiva teórica, es menester identificar las diferencias que se establecen al relacionar la categoría de discurso con la del lenguaje, del habla y del texto.

El discurso definido desde las condiciones sociales de producción, circulación y recepción, implica una serie de niveles de realidad, desde el pedestre hasta el inexplicable, el discurso emerge en el cotexto, contexto del sujeto conociente y emerge no sólo en las palabras, oraciones, párrafos, sino en todo un entramado complejo, en el cual puede o no adquirir sentido dependiendo del lugar y la coyuntura en el que se dice y se muestra ese discurso.

Para Pêcheux, "las formaciones discursivas están interrelacionadas con las formaciones sociales, ideológicas e imaginarias y determinan lo que puede y debe ser dicho en una posición y en un tiempo determinado". ${ }^{16}$ Por su parte, Regine Robin articula el discurso a la coyuntura, la cual impone censuras, tabúes, términos, sintagmas o enunciados. Además, obliga a hablar de algo e impide hablar de otras cosas, incluye y excluye discursos a la vez. ${ }^{17}$ Mientras que Foucault plantea que en toda sociedad la "producción del discurso está controlada, seleccionada y redistribuida"18 por un cierto número de procedimientos que tienen por función conjurar los poderes y peligros.

Con base en lo anterior, el discurso verbo-visual de los libros que estudiamos se articula en tres procesos:

16 “...nous apellerons dès lors formation discursive ce qui, dans une formation idéologique donné, cest á partir d'une position donné dans une conjonture donné determiné par létat de la lutte des classes, déterminée "ce qui puet doit éter dit...", en Michel Pêcheux, Les vérités de La Palice, Francois Maspero, Paris, 1975, p. 144.

17 Regine Robin "Discours Politique et Conjoncture", en Lanalyse du discours, discourse analysis, Centre Educatif et culturel Inc., Colection Langue et littérature/language and Literature, Montreal, 1976, p. 11.

18 Michel Foucault, "El orden del discurso", en op. cit., p. 67. 
A) El de producción, en el que tienen un funcionamiento importante las formaciones sociales, ideológicas e imaginarias de los grupos en el poder. El sujeto-emisor colectivo hace una selección de los acontecimientos a narrar, asimismo de las imágenes que sirven para ilustrar el discurso pedagógico, lo que determina qué puede y debe ser no sólo dicho, sino ilustrado, mediante las imágenes visuales. Vgr. la significativa exclusión de imágenes de personajes históricos como las de: Cuauhtémoc, Moctezuma, Nezahualcóyotl, Cuitláhuac, entre otros; y la incorporación de Malintzin, imagen asociada a la de Hernán Cortés. Lo anterior se debe a que la coyuntura impone censuras y tabúes que impiden hablar ilustrar o mostrar visualmente algo. El discurso verbo-visual responde al proceso de seleccionar, controlar y distribuir el saber histórico mediante el libro escolar, con el fin de controlar los poderes y evitar los peligros de formar niños pensantes y críticos.

B) El proceso de circulación: los libros de Ciencias Sociales $-3^{\circ} \mathrm{y}$ $4^{\text {o }}$ grados - correspondientes a la segunda reforma educativa promovida por el entonces presidente Luis Echeverría, llevada a cabo por su secretario de educación pública, Víctor Bravo Ahuja, tuvieron una circulación masiva. Se mantuvieron por 14 años, de 1971 a 1986 se tiraron aproximadamente 75 millones de ejemplares. Tomando en cuenta la primera edición y las subsecuentes reediciones, las cuales sufrieron algunos cambios con respecto a la prime ra edición, tanto en el texto verbal como en el visual, notamos que dichos cambios conservaron la misma tónica de la enseñanza de la historia desde la mirada de las ciencias sociales. En relación con los textos de Mi libro de historia de México $-4^{\circ}, 5^{\circ}$ y $6^{\circ}$ grados - correspondientes a la tercera reforma educativa propuesta por el ex presidente Carlos Salinas de Gortari, y - al frente de la SEP- Ernesto Zedillo Ponce de León, en 1992 tuvieron un solo tiraje de 1'325,000, 2'430,000 y 2'180,000, respectivamente, con un total de 5’935,000 millones de libros; cabe señalar que los libros de $5^{\circ}$ y $6^{\circ}$ grados tienen los mismos contenidos.

C) El proceso de recepción: la memoria histórica se guarda, recircula y se reproduce por los escolares, por los profesores e incluso por los padres de familia.

En síntesis, la categoría de discurso desde la perspectiva transdisciplinaria, rebasa las fronteras del enunciado sin que ello signifique soslayar el soporte básico de la lingüística. El discurso es, pues, una zona 
abierta que acepta, rechaza, omite, silencia u olvida y, a la vez, en forma continua, es nutrido por otros discursos, producidos y reproducidos en el seno de una formación social y de coyunturas determinadas.

\section{El texto verbo-visual}

El texto como producto en sí tiene la cualidad de ser polifónico, porque en él se cruzan muchas voces y se produce el sentido. ${ }^{19}$ Lotman articula texto, lenguaje y aspectos socio-culturales a la semiótica. El texto es definido como un mensaje multicodificado, están constituidos por subtextos en códigos diversos y no deducibles uno del otro. ${ }^{20} \mathrm{Vgr}$.: Una imagen con pie de foto constituye un texto, porque es el tejido de dos códigos, el de la lengua y el de lo visual, pero ninguno es deducibles del otro. En la fig. I.2 se ve cómo se articulan los códigos verbo-visuales, lo cual constituye una 'imagen compleja'. El texto verbal: "llegada de los españoles" es independiente del visual. Este último, a su vez, está constituido por diversos códigos como el color, líneas, formas, gestos y actitudes del o los sujetos representados, el tamaño de la ilustración, la combinación de elementos culturales de lo que se está narrando y describiendo visualmente; la ubicación espacial en el libro escolar, la cual se refiere al código de los editores y diseñadores.

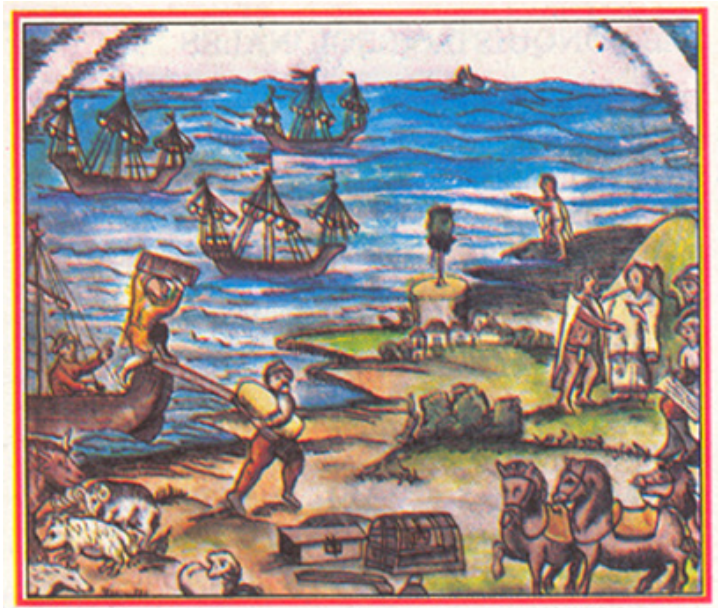

Fig. 1.2 CDS-II-HM-4 ${ }^{\mathrm{O}}$ - p. 25

Llegada de los españoles a Veracruz

19 Mijaíl M. Bajtín, "Estética de la creación verbal", en op. cit., p. 294 y ss.

20 Iuri Lotman, "La semiótica de la cultura y el concepto de texto", en La Semiosfera I, trad. Desiderio Navarro, Madrid, Frónesis Cátedra, 1996, p. 80. 
La imagen compleja está enmarcada por una línea roja. Es el código del diseñador, lo introduce para que el niño escolar identifique semióticamente el libro de $4^{\circ}$ - rojo - el de $5^{\circ}$-verde - de Mi libro de historia de México. En segundo lugar, la imagen está constituida por el avistamiento de la llegada de unos forasteros, en cuya escena se mira, del lado izquierdo, unas embarcaciones que llegan a tierra. Ellos visten pantalones, camisas y portan cascos. De las embarcaciones bajan caballos, cerdos y ovejas; también baúles, cajas y herramientas que se encuentran ya en la playa. Los hombres que reciben a los forasteros usan taparrabos y capas de manta; las mujeres, huipil y enaguas. Están descalzos a diferencia de los que arriban. Se muestra la escena de la "llegada de los españoles a Veracruz". Este enunciado constituye el texto verbal. Es el encuentro de dos culturas diferenciadas por los rasgos físicos. Unos son rubios y de piel blanca; los otros de piel morena y de cabellos negros. Por el ropaje, unos están vestidos; otros, semidesnudos; unos llegan a través de embarcaciones por el mar, que implica a su vez el movimiento y la transformación cultural que provocarán en los que están establecidos en tierra. El arribo significa la ruptura de la frontera ${ }^{21}$ entre una y otra culturas: hispana e indígena. Por lo tanto, la imagen constituye un texto con un alto grado de complejidad porque es multicódigo y a la vez polifónico-políglota, ya que en el sentido semiótico, los pensamientos materializados mediante las voces que cruzan el texto verbo-visual, son, como ya lo hemos mencionado, el sujeto-emisor colectivo que selecciona el texto verbo-visual; la voz de quien realiza el códice; y, por último, la del diseñador y del editor, quienes colocan estratégicamente dicho texto.

El texto es "un complejo dispositivo que guarda variados códigos, capaz de transformar los mensajes recibidos y de generar nuevos mensajes, es un generador informacional"; por lo tanto, es un generador de sentido. ${ }^{22}$ En este orden de ideas, la imagen compleja está constituida por dos unidades mínimas de sentido: la primera es la unidad mínima de sentido verbal de primer grado: "llegada de los españoles a Veracruz", la segunda unidad mínima de sentido es la visual de primer grado: la narración de hechos; estos dos aspectos en su conjunto constituyen la unidad compleja mínima de sentido de segundo grado. La imagen, acompañada de un enunciado escrito, conforma un texto

21 "La función de toda frontera se reduce a limitar la penetración de lo externo a lo interno, a filtrarlo y elaborarlo adaptativamente, mediante mecanismos de traducción", Cfr. Ibid, p. 26.

22 Ibid., pp. 77-82. 
verbo-visual, escrito por el historiador y diseñado por el diseñador. Por ello el texto es generador de sentidos y políglota, porque es recibido por diferentes lectores, quienes le dan lecturas diferentes.

Es también un espacio complejo semiótico, dentro del cual convergen otros sistemas semióticos: la lengua y los códices. Adquiere el carácter dinámico de heterogeneidad y homogeneidad semióticas; se establecen las relaciones de oposición: abierto-cerrado, sagrado-profano, vivo-muerto, homogéneo-heterogéneo, estático-dinámico, continuo-discontinuo, natural-artificial. ${ }^{23}$

Antes de la llegada de los españoles, los tlacuilos realizaron una serie de códices donde narraban con dibujos geométricos la vida cotidiana, sus costumbres, dioses, etcétera; a la llegada de los europeos las representaciones pictóricas son más figurativas, son los códices coloniales - la imagen analizada pertenece al Códice Florentino, para informar a los reyes, de cómo era la vida de los naturales, las cosas que los europeos habían encontrado en la nueva tierra, cómo había sido el encuentro entre ambas culturas-. Para ello necesitaban dibujar o pintar lo que había aquí y lo que aquellos traían. La heterogeneidad semiótica está en el nivel del texto visual de referencia.

El texto es un generador de sentido en cuanto hay una relación entre los emisores y los destinatarios, ${ }^{24}$ a través del habla directa entre ellos o mediante un libro, pintura, obra plástica, fotografía, que sirven de canales para establecer la comunicación entre el emisor y destinatario. Esto lleva a pensar, de acuerdo con Eco, que el texto es una máquina semántico-pragmática que pide ser actualizada en un proceso interpretativo, cuyas reglas de generación coinciden con las propias reglas de interpretación. ${ }^{25}$ En suma, se trata de un juego de actos de comunicación en los que tanto emisores como destinatarios producen continuamente textos, entendidos como "unidades de comunicación". ${ }^{26}$

Consideramos el texto verbo-visual como imagen compleja y como la manifestación real y concreta del sujeto de la enunciación, tanto en sus dos dimensiones, lo que no excluye la posibilidad de traspasar las fronteras del producto en sí mismo, porque no se cierra, sino que está en una constante tensión y continuum dialécticos, ya que abre y cierra sus fronteras para aceptar nuevos elementos que van a constituir el nuevo texto. Por ello, definimos texto de acuerdo con las premisas lotmanianas como: 1.

23 Iuri Lotman, Cultura y Explosión, Barcelona, Gedisa, 1999, pp. 16-17.

24 Santos Zunzunegui, Pensar la imagen, Madrid, Editorial Cátedra, 1998, p. 82.

25 Umberto Eco, La estructura ausente, Barcelona, Lumen, 1978ª, p. 69.

26 Lorenzo Vilches, La lectura de la imagen. Prensa, cine, televisión, Barcelona, Paidós, 1995, p. 31. 
Dispositivo de la memoria de la cultura; 2. Generador de sentido; 3. Heterogéneo y políglota; 4 . Soporte productor y reproductor de lo simbólico y 5. Dimensión del cambio cultural.

Terminamos este ítem con el siguiente texto, que es un claro ejemplo de las cinco premisas lotmanianas. Nos ilustra verbalmente la definición de texto verbo-visual. Aborda qué es y cómo se conserva la memoria histórico-cultural, por qué es generador de sentido, ya que la información pasa de generación en generación; también es heterogéneo y políglota, se cruzan varias voces de diferentes sujetos de enunciación, el de lo escrito, oral y visual; el por qué la instrucción sirve de soporte productor y reproductor de lo simbólico, y finalmente esta conservación de la memoria, ya escrita, oral, visual, permite el cambio cultural.

No se puede conservar de modo perfecto y absoluto la historia, sino se consigna por escrito; es sabido que nuestros primeros pueblos no tuvieron escritura propiamente dicha, sino que de la jeroglífica se valían; pero sus signos gráficos servían solamente para conservar el recuerdo y la fecha de los sucesos, los ayudaban con la tradición de los pormenores que oralmente se enseñaban, pues siempre se cuidó en las escuelas de los templos de instruir en ellos a la juventud, a fin de guardar viva la historia que de generación en generación iba pasando (sic). ${ }^{27}$

\section{Las prácticas-semiótico-discursivas de la historia pedagógica}

Desde la perspectiva del pensamiento complejo los libros de texto, en estudio, se pueden categorizar como prácticas semiótico-discursivas, pues generan sentidos en los niños lectores y puede impulsar el hacer-saber, hacer-hacer y el hacer-ser. Adicionalmente, se considera el funcionamiento ideológico estrechamente ligado al discursivo. Pêcheux sostiene que es mejor hablar de una 'intricación' de las formaciones discursivas en las formaciones ideológicas; en la 'intricación' es donde precisamente radica la interpelación. ${ }^{28}$ Por su parte, Foucault, concibe las prácticas discursivas como: "el conjunto de reglas anónimas, históricas, siempre determinadas en el tiempo y en el espacio, que han definido en una época dada, y para un área social, económica, geográfica o lingüística dada, las condiciones de ejercicio de la función enunciativa."29

27 Alfredo Chavero, México a través de los siglos, Tomo I: Historia Antigua, Barcelona, Espasa, 1882, p. IV.

28 '“.... qu'il en peut s'agir ni de'une pure équivalence (idéologie=discours) ni d'une simpli distribution de fonctions ( $<<$ practique discursive $>>\mid<<$ practique non discursive $>>$ ) Il conviendrait plutôt de parler d'une $<<$ intrication $>>$ des formations discursives dans les formations idéologiques, intrication dont le principe résiderait precisément dans l'<<interpellation $>>[\ldots]$ ", Les vérités de la Palice, en Michel Pêcheux, op. cit., p. 145.

29 El orden del discurso, en Michel Foucault, op. cit., p. 198. 
Las definiciones de Foucault y de Pêcheux se complementan con la de Robin, para quien las prácticas y los procesos discursivos dominantes y la jerarquización de las posiciones discursivas de los diversos agentes, y más ampliamente de los diversos grupos sociales, constituyen formaciones discursivas estrechamente relacionadas con las formaciones ideológicas. El proceso de intrication en el que se articulan formaciones ideológicas y discursivas para lograr el efecto de interpelación en los sujetos receptores, se produce cuando el sujeto-emisor logra interpelar al sujeto-receptor lo cual provoca la modificación o reafirmación de creencias, pensamiento, del hacer-hacer, y de su hacer-ser; así la función performativa adquiere sentido en los diferentes tipos de prácticas socio-culturales-histórico-políticas.

Para reforzar la identidad nacional, el sujeto-emisor colectivo ${ }^{30}$ recurre con frecuencia a juegos léxicos y a imágenes visuales a fin de interpelar al escolar. Así, cuando el sujeto de 'conociente' dice: "los lazos que nos unen a los mexicanos están representados por los símbolos que todos respetamos: la bandera, el escudo y el himno", el discurso verbal se ilustra con la imagen de la Bandera ondeando sobre el pedestal en la parte central de la escuela (fig. 1.3). En los sujetos receptores se produce el efecto de sentido en la articulación de las formaciones ideológico-discursivas. Esto es, mediante el uso del nosotros inclusivo (yo + tú = nosotros inclusivo), el sujeto-emisor interpela al escolar para que se asuma en la identidad nacional oficial que el aparato escolar construye. Con base en lo anterior, definimos las "prácticas semiótico-discursivas" de la historia oficial mexicana en virtud de las siguientes premisas:

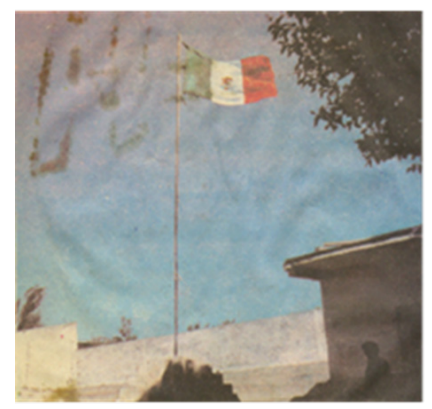

Fig. 1.3 CSD-1-CS-3 ${ }^{\circ}$-p. 104

30 Definimos sujeto-emisor-colectivo a aquel que está constituido por los historiadores, diseñadores, ilustradores, pedagogos y el sujeto que manda a hacer el libro de texto; es decir, el secretario de Educación Pública. 
1. Existe una estrecha relación entre las formaciones discursivas y las ideológicas en coyunturas específicas. Las huellas de la ideología se hacen evidentes en los juegos lexicales explícitos en el discurso, mediante las racionalizaciones, normas, valores, modalizaciones, aserciones que hacen intervenir al sujeto en su propio discurso; en otras palabras, son los mecanismos de selección-combinación entre unidades lexicales, ya peyorativos - terrible, dictador, destrucción-, ya meliorativos -libertad, igualdad, justicia, desarrollo, progreso-.

2. A través del discurso verbo-visual se producen, reproducen y transforman los modelos de la vida socio-cultural-económica-política-, proponiendo nuevos modelos a seguir.

3. Va dirigida a las y los niños escolares, quienes poseen un conocimiento previo, imprinting cultural, que obtuvieron mediante la información que les proporcionó la familia y reforzaron los medios masivos de comunicación, el entorno social, la Iglesia y la escuela.

4. Produce y reproduce las materialidades ideológico-culturales, de poder e histórica, mediante estrategias semiótico-discursivas para la producción y reproducción de la hegemonía y poder, que a su vez constituyen macro-modelos de la cultura nacional.

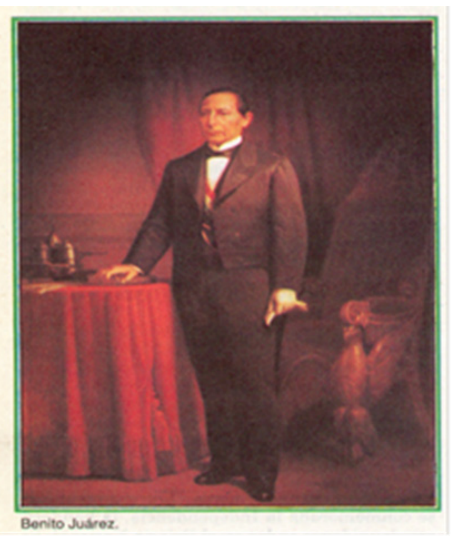

Fig. 1.4 CSD-II-HM-5ํ- p.84 
En el retrato al óleo de Benito Juárez ${ }^{31}$ (v. fig. I.4), elaborado por José Escudero y Espronceda, pintor oficial de finales del siglo XIX, retratista español establecido en México, de acuerdo con sus formaciones ideológicas e imaginarias, pinta a Juárez de cuerpo entero, vestido de levita, porta en el pecho la banda presidencial, del chaleco apenas se mira la cadena de un reloj de bolsillo, en la mano izquierda lleva un par de guantes blancos, y la derecha posa sobre un libro. Sus finas facciones rompen con las características propias del 'indio’ oaxaqueño. La escenografía de estilo europeo, alejada de todo pasado indígena, está constituida por una silla de respaldo alto, asiento y brazos forrados por un fino terciopelo rojo, de fina madera tallada que combina con un delicado mantel, también de la misma tela y color. Alrededor de este penden flequillos y borlas. Sobre la mesa hay un juego de cafetera y azucarera simulando ser de plata. Como fondo, una cortina larga que se adivina del mismo material que el mantel.

Desde las formaciones imaginarias del pintor español, se genera una nueva semiosis, en el sentido de eliminar todo vestigio indígena, incorporando elementos europeos, y blanqueando al personaje no sólo mediante los efectos de la luz sobre la cara y las manos, sino en todo su contexto. La pintura puede ser considerada un dispositivo del cambio cultural e impulsora de nuevos modelos a seguir. La pintura, aunque no se hizo ex profeso para ilustrar los libros gratuitos, ha sido seleccionada para ese fin. La imagen funciona como ilustración por la línea verde que enmarca la imagen que denota y connota el $5^{\circ}$ grado escolar de primaria. La hegemonía y el poder se materializan en la banda presidencial y en la levita. Se trata de una imagen compleja.

\section{La tipología semiótico-discursiva de la historia pedagógica}

Ubicar la historia oficial en sus tipos y subtipos, conforme a criterios epistemológicos, permite definir el tipo de discurso oficial, el cual es diferente dependiendo de dónde esté escrito y desde qué institución emane; También existen cuyos destinatarios pueden ser escolares de educación básica, media superior, superior o para un público lego.

Para examinar el discurso histórico que nos ocupa, es sustancial considerar las leyes institucionales, La Constitución, como un discurso incuestionable, en el cual se establece el tipo de educación que han de recibir los escolares mexicanos de educación básica. En esta ley surge el espacio y las prácticas simbólicas y de poder. La Secretaría de Educación Pública

31 El retrato se encuentra ubicado en la Suprema Corte de Justicia, Ciudad de México. 
funciona como un sujeto-emisor-colectivo, de donde emanan las leyes institucionales para la creación, tanto del aparato escolar, como de las herramientas - los libros gratuitos - que facilitan a los escolares el aprendizaje de la historia de México. Subyace al aparato escolar hegemónico, el control, la selección y la redistribución de los contenidos, que son oficiales; por lo tanto, implica una serie de exclusiones de ciertos acontecimientos; por ejemplo, en relación con el tema de los antiguos mexicanos, no se toca el asunto de la organización política y cultural, exiguamente se abordan los adelantos científicos de las culturas antiguas, ni siquiera de la mexica o maya que fueron unas de las más importantes. Visualmente se excluyen las figuras de Cuauhtémoc, Nezahualcóyotl y Cuitláhuac.

La exclusión voluntaria o involuntaria responde a lo que denomina Morin $^{32}$ las cegueras del conocimiento: error e ilusión. Los errores mentales hacen que el sujeto-emisor-colectivo olvide unos acontecimientos y recuerde otros, la mente es selectiva y esta operación lógica lleva al error de la razón, ya que desea el control del entorno, resistencia física del medio; el control de la práctica, la actividad verificadora del dato; el control de la cultura, referir el saber común y lo que se desea que los destinatarios deben aprender; el control del prójimo, los niños deben ver lo que yo veo y de esa manera 'ato' ideológicamente al sujeto de la historia, y evita que el escolar vea por sí mismo y se forme un juicio propio; por último, el control cerebral, en este punto, a través de la interpelación, el sujeto-emisor logra que el destinatario realice operaciones lógicas de la memoria de acuerdo con lo que ha aprendido.

El análisis comparativo de los discursos históricos oficiales permitió constatar las exclusiones de ciertos temas. En el conjunto semiótico-discursivo de Mi libro de Historia de México (CSD-HM) se excluye la bandera, el escudo y el himno como símbolos patrios laicos; por el contrario, hallamos la presencia de la Virgen de Guadalupe como símbolo de "unión de indios, mestizos y criollos" en diversas etapas históricas: la formación de la Nueva España, la Independencia, la Guerra de los Cristeros, tienen siete menciones, también como un importante elemento de identidad religiosa nacional. En el conjunto semiótico-discursivo de Ciencias Sociales, (CSD-CS) se excluyen todos los símbolos religiosos e incluyen los laicos.

32 Educar en la era planetaria, en Edgar Morin et al., op. cit., pp. 26-30. 
En la medida en que el discurso de la historia oficial hace juicios de valor de manera implícita, el discurso es evaluativo: "los mexicanos respetamos los símbolos patrios y nos sentimos orgullosos de ellos". ${ }^{33}$ En el enunciado "nos sentimos orgullosos" el sujeto 'conociente' emerge en el sujeto del enunciado mediante el verbo "sentimos" y en el adjetivo “orgullosos”, evaluamos nuestra emoción. El discurso metalingüístico de la imagen visual explica visualmente un hecho histórico. En este sentido, los discursos históricos oficiales son axiomáticos, con frecuencia explotan los valores para impregnar al destinatario el amor a la patria y sus símbolos; son descriptivos y narrativos; $y$, por ser didácticos, son expositivos semiótica-discursivamente; además, se caracterizan por ser deónticos, el deber-ser, el deber-hacer-ser. En el libro de $4^{\circ}$ grado de $\mathrm{Mi}$ libro de historia de México al final dice:

Resolver esos problemas es tarea de los mexicanos de hoy. Nuestra historia no está acabada...A ti te toca continuarla... es la historia que te toca vivir y hacer cambiar y mejorar. Es tu lugar en la historia de México. ${ }^{34}$

El deber-ser y el deber-hacer-ser están implícitos y emergen en los verbos "hacer cambiar y mejorar" y remata con "es tu lugar en la historia de México". Por ello, en el discurso se pasa la estafeta al niño para que se responsabilice de "los problemas" que sus padres y abuelos le han heredado.

La escritura de la Historia implica la narración en la que se dan cuenta los hechos ocurridos en forma cronológica, en el caso de los libros de historia de México, de fábula y de los de Ciencias Sociales. También es un discurso descriptivo el texto visual, aunque forma parte de un hilo narrativo, apoya predominantemente la descripción. Pertenece al subtipo pedagógico, pues se recurre a ciertas estrategias pedagógicas para hacer significativa la enseñanza, por lo cual es expositivo-didáctico, ya que en él se expone el 'saber autorizado' identificado con el verbo 'ser', y a la vez se articulan las funciones emotiva y modalizadora, que están centradas en el emisor, quien adjetiva los hechos a fin de interpelar al escolar. El discurso pedagógico de la historia está centrado en sus destinatarios: los niños escolares.

33 Libro de texto Ciencias sociales, 3er. Grado, Conaliteg, SEP, s/a, p. 105.

34 Libro de texto Mi libro de historia de México, $4^{\circ}$ Grado, Conaliteg, SEP, 1992, p. 79. 


\section{Tipología del discurso pedagógico de la historia}

Para la clasificación del discurso pedagógico de la historia, desarrollamos únicamente los siguientes criterios de clasificación: ${ }^{35} 1$. objetos semiótico-discursivos; 2. funciones del lenguaje de Jakobson, solo algunas; 3. aparatos ideológico-hegemónicos y 4 . la subjetividad,

1) Los objetos semiótico-discursivos corresponden a los temas o tópicos de la historia oficial. Distinguimos un macro-objeto semiótico-discursivo: "La historia oficial de México", la cual está constituida a su vez por objetos nucleares y objetos concretos. Los primeros dan cuenta de los acontecimientos históricos de acuerdo con los cortes temporales, según el criterio de los historiadores; los segundos, tienen que ver con la construcción de las diferentes iconósferas ${ }^{36}$ en función de los diferentes tipos de identidad que pasan por el sujeto.

2) Las funciones discursivas jakobsonianas — trabajadas también por Kerbrat-Orecchioni ${ }^{37}$ y por Reboul ${ }^{38}$ — son: la función emotiva o expresiva se centra en el sujeto-emisor que puede expresar sus emociones a través de lo visual o del discurso. ${ }^{39}$ La emoción del sujeto-emisor se manifiesta, implícita o explícitamente, a partir de su emergencia, tanto en el texto verbal como en el visual. Vgr., el sujeto-emisor colectivo emerge discursivamente a través del uso de adjetivos, participios, adverbios y sustantivos:

Como consecuencia de estas presiones, hubo pequeñas y grandes revueltas indígenas. Una de las mayores, la de los yaquis y mayos en Sonora, fue sofocada militarmente. La represión terminó con la deportación de miles de yaquis a Yucatán, destinados a trabajar en las haciendas henequeneras ${ }^{40}$.

En el texto anterior, el sujeto 'conociente' denomina "revueltas" a las rebeliones de los indios. Este término es definido por el Diccionario de la Real Academia como: "disturbio, alteración del orden público, riña, disputa entre varias personas". El sujeto-emisor minimiza el sentido de

35 Los criterios que siempre desarrollamos son: 1 . objetos semiótico-discursivos; 2. funciones del lenguaje; 3. aparatos ideológicos, hegemónicos; 4. la subjetividad; 5. géneros discursivos: narración, descripción y argumentación; 6 . discurso verbal oral-escrito y visual; 7. discurso formal/informal y semiosis.

36 Definimos iconósfera en analogía con el término semiósfera propuestgo por Lotman, como el espacio visual icónico fuera del cual es imposible la existencia misma de la semiosis del sentido.

37 Catherine Kerbrat-Orecchioni, L'enunciation. De la subjetivité dans le langage, París, Armand Colin, 1980, p. 45.

38 Olivier Reboul, Lenguaje e Ideología, México, Fondo de Cultura Económica, 1980.

39 En el caso de la historia oficial hay varios sujetos-emisores: el sujeto colectivo que es la secretaría de educación pública; el grupo de historiadores; los artistas plásticos, tlacuilos, fotógrafos, grabadores y caricaturistas.

40 Mi libro de historia de México, $4^{\circ}$ Grado, op. cit., p. 99. 
la lucha o rebelión de los indios yaquis y mayos ante las injusticias de que eran objeto por parte de "La política de progreso porfiriano". Cabe preguntar si sólo fueron revueltas, pequeñas o grandes, ¿por qué tuvieron que ser "sofocadas militarmente"? Se percibe una fuerte tensión entre los sentidos de los dos vocablos. El adverbio "militarmente" implica el funcionamiento del poder, cuya materialidad son las armas de fuego. Fernando Castro, en su pintura Henequén (fig. I.5), es el sujeto-emisor plástico, quien sintetiza una importante etapa histórica a través de una figura retórica, la metonimia. ${ }^{42}$

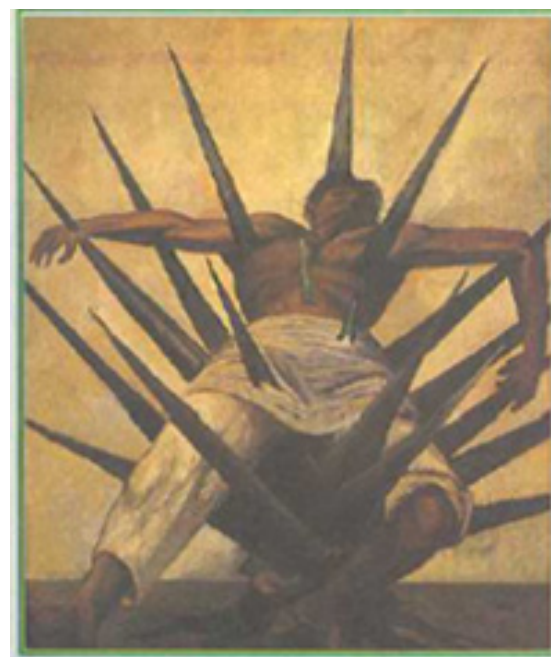

Fig. 1.5 CSD-II-HM-40- p.99

El protagonista representa plásticamente a un sujeto colectivo, los yaquis y mayos. La configuración metonímica en el cuerpo del yaqui muestra claros signos de desnutrición, se aprecia en la caja toráxica desnuda, la piel rojiza apenas cubre el sistema óseo. El hombre se identifica por su característico pantalón de manta. Yace atravesado por las hojas punzantes del henequén. Este, a su vez, representa la identidad regional del estado de Yucatán, lugar de donde es originario este cactus. De tal forma que dos regiones importantes mexicanas se unen en este cuadro, Sonora y Yucatán. Se mira el profundo dolor del pintor, porque expresa la vulnerabilidad del cuerpo semidesnudo, famélico, olvidado frente a las punzantes hojas del cactus, las cuales, en analogía con las bayonetas de los militares, dan un efecto de sentido del funcionamiento del poder. 
La función referencial remite al objeto discursivo, vgr. Las creencias prehispánicas desde la perspectiva de los frailes, eran "cosa del diablo" (enunciado axiomático), pues los naturales hacían sacrificios humanos. En la figura I.6, observamos a cinco sacerdotes realizando un sacrificio humano. El objeto discursivo de la religión colonial se representa mediante la imagen emblemática de la Virgen de Guadalupe (fig. I.7), cuya posición mística se manifiesta tanto en el piadoso gesto de la cara como en las manos juntas, dispuestas a la altura del pecho, que dan el efecto de sentido de la devoción.

3) Los aparatos ideológico-culturales hegemónicos tienen dos sentidos: uno restringido, como proceso de deformación y ocultamiento de la realidad social; ${ }^{43}$ otro, en un sentido más amplio, como la forma en que los hombres toman conciencia de los conflictos sociales, su concepción del mundo se materializa en prácticas sociales. ${ }^{44} \mathrm{El}$ fenómeno ideológico es un proceso complejo en el sentido que es un continuum, entre el ocultamiento de la realidad socio-política, y la toma de conciencia. La ideología ${ }^{45}$ se materializa en lo verbo-visual, también es un hecho del lenguaje como un medio social de comunicación y sus múltiples usos se intersectan con el poder, lo nutren, sostienen y decretan. La lengua no es coercitiva, pero algunas de sus coerciones están al servicio de un poder que puede ser de un grupo, una casta, una clase, una nación o un Estado. ${ }^{46}$ En la dimensión visual, la propuesta lotmaniana de la semiótica pone especial atención en el espacio semiótico, fuera del cual no existe semiosis o producción de sentido. Así, los 'lugares' o 'instituciones' son espacios semióticos ideológico-culturales donde la dirección intelectual y la moral se relacionan con la hegemonía y los juegos interpelatorios, los cuales controlan, de forma natural, a los sujetos-receptores.

43 Louis Althusser, Ideología y aparatos ideológicos del Estado, México, Ediciones Quinto Sol, 1970, p. 29.

44 Antonio Gramsci, Introducción a la filosofia de la praxis, Barcelona, Ediciones Península, 1972, p. 43.

45 En relación con la categoría 'ideología' hay una fuerte producción teórica a cargo de los siguientes autores, Althusser, 1970; Poulantzas, 1969; Giménez, 1980, 1981; Basáñez, 1990; Haidar, 1990, 1994a, 1994b; de Ipola, 1982; Gramsci, 1972 y Foucault 1972, 1980, 1988 entre otros.

46 Cfr. John B. Thompson, Ideología y Cultura Moderna, México, UAM Xochimilco, 1993, pp. 2-6.

Reboul, Olivier Reboul, Lenguaje e Ideología, México, Fondo de Cultura Económica, 1980, p. 36. 


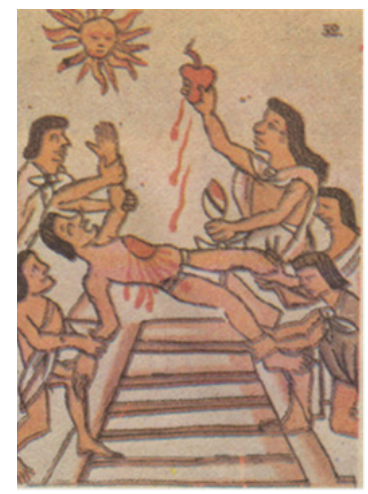

Fig. I.6 (CSD-I-CS-3ํ-p.52)

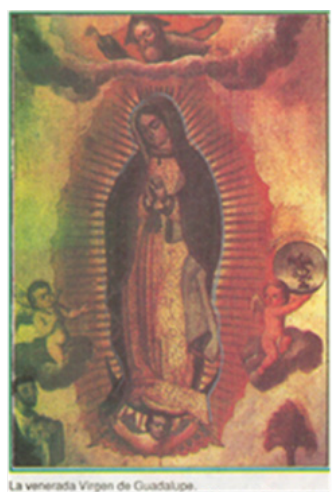

Fig. I.7 (CSD-II-HM-4º -p.58)

Izquierda: Fig. 1.6 CSD-I-HM-3ㅇ- p. 52.

Derecha: Fig. 1.7 CSD-II-HM-4- p. 58.

En esta aproximación, la Secretaría de Educación Pública, la Comisión Nacional del Libro de Texto Gratuitos (Conaliteg) y todas las instituciones gubernamentales públicas, son espacios semióticos-discursivos, por los cuales pasan las materialidades ideológico-culturales y del poder. El discurso pedagógico de la historia transmite 'saberes' irrefutables porque mantiene la autoridad pedagógica que le otorga el sistema escolar como institución legitimante y hegemónica de dicha autoridad, con la consecuente construcción de la identidad nacional entre otros tipos de identidades, de tal modo que el libro se convierte en un transmisor poliidentitario.

4) La subjetividad permite un mayor alcance explicativo en cuanto al sujeto semiótico-visual ${ }^{47}$ que se representa en los textos visuales. Distinguimos tres tipos de sujetos:

a) El sujeto-emisor-colectivo (en la dimensión de la enunciación): el conjunto de la SEP, el grupo de historiadores, artistas plásticos, tlacuilos, fotógrafos, grabadores y caricaturistas.

b) El sujeto del enunciado que emerge en una relación dialógica, a través de la deixis personal, yo-tú, nosotros inclusivo-nosotros exclusivo.

47 Graciela Sánchez Guevara, "Alteridad y semiótica visual: ustedes indios, nosotros ladinos", en Revista Cuicuilco, Núm. 25, México ENAH-INAH, 2000a, pp. 64-65; "La retórica visual novohispana: elemento fundamental para la construcción de la identidad nacional oficial", en La arquitectura del sentido, La producción y reproducción en las prácticas semiótico-discursivas, coord. Julieta Haidar, CONACULTA-INAH-ENAH, SES, PROMEP, México, 2005, pp. 302-303; "Los excesos sobre el cuerpo. Sus manifestaciones en el ciberespacio", en co-autoría con Margarita Alegría de la C., en Registros corporales, coord. Elsa Muñiz, Serie Estudios, Biblioteca de las Ciencias Sociales, México, UAM-Azcapotzalco, pp. 475-479. 
c) El sujeto semiótico-visual que se representa icónicamente por el 'otro', el cual construye al sujeto por sus características físicas, tomando en cuenta los espacios, tiempos y objetos que constituyen la realidad de este tipo de subjetividad de doble salida, la de quien representa y la del representado. La figura I.8 correspondiente al Códice Florentino, ${ }^{48}$ con el cual se ilustra la sección de la "Agricultura" en los libros de Ciencias Sociales 3er. Grado; el niño escolar observa a un hombre 'agricultor' semidesnudo, únicamente con taparrabo y una manta anudada al cuello, en la que carga las semillas del maíz. Su herramienta de trabajo es la coa con la que labra la tierra. Por la desnudez del hombre, se infiere que está en un clima tropical. Se sabe que los códices fueron elaborados por los tlacuilos, indios que sabían el arte de pintar. En la época colonial continuaron con esta tarea. Cabe hacer notar que la representación visual del agricultor posee unas características físicas que no tienen que ver con las de las diversas poblaciones originarias de México. El sujeto representado es al que llamamos sujeto-semiótico visual, porque desde las formaciones imaginarias $^{49}$ del sujeto representador, construye sujetos estereotipos.

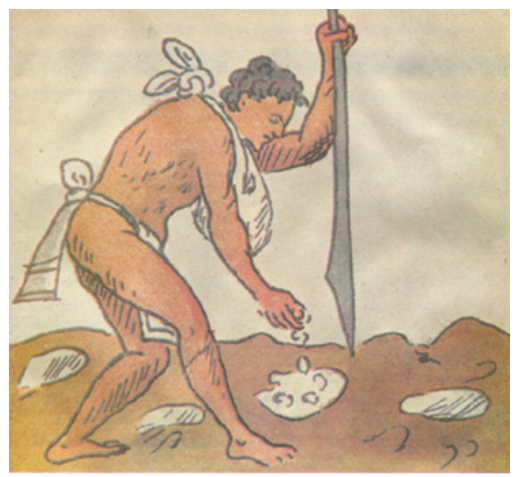

Fig. 1.8 CSD-II-HM-3ㅇ- p. 39

5) Los géneros discursivos: narración, descripción y argumentación. El discurso pedagógico de la historia se apoya en ellos en sus dos dimensiones básicas: la verbal escrita y la visual. Los acontecimientos históricos encuen-

48 En el Museo Nacional de Antropología e Historia se encuentra una copia facsimilar del Códice Florentino, el cual está compuesto por libros, volúmenes y láminas.

49 La categoría formaciones imaginarias ha sido trabajada por M. Pêcheux (1969). 
tran su materialidad en estos tres géneros discursivos. Los murales, cuadros y dibujos narran de una manera peculiar no sólo los grandes acontecimientos, sino también la vida cotidiana de los personajes colectivos, como el pueblo, los obreros, los niños y niñas, las familias, los gobiernos, las religiones y creencias. La argumentación verbo-visual subordinada a la narración, también da cuenta de la implícita persuasión pedagógica, a partir de la retórica visual y de recorridos inferenciales, donde halla su eficacia.

\section{Conclusiones}

El estudio del discurso pedagógico de la historia en dos coyunturas específicas, fundamentado en aportes teórico-metodológicos, nos condujo a las siguientes reflexiones:

1. El planteamiento transdisciplinario de esta investigación ha permitido definir el discurso histórico como un complejo proceso de producción-circulación-recepción desarrollado en determinadas condiciones socio-histórico-ideológico-culturales-políticas. Los sujetos-emisores colectivos están a cargo de la selección de los acontecimientos a narrar, así como de las estrategias semiótico-discursivas pedagógicas, con el propósito de interpelar al educando, quien, al término del estudio del libro escolar, tendrá presente su pertenencia al territorio, al idioma, a la religión oficial (el catolicismo), a los símbolos patrios y a los héroes, a partir de la construcción de la identidad nacional. Se unifica y uniforma la forma de pensar e incluso de sentir de los niños y niñas, y no se consideran otras creencias religiosas u otros símbolos para los pueblos originarios, cuyas lenguas vernáculas son distintas a la lengua oficial.

2. El discurso pedagógico de la historia cumple también con la función de ser una práctica semiótica-discursiva. Tanto en lo verbal como en lo visual existe una estrecha relación entre las formaciones discursivas e ideológicas, las cuales se manifiestan en los juegos lexicales y en los juegos visuales de las imágenes. De modo que en el discurso que estudiamos, juegan un papel muy importante los diversos códigos: el verbal, el visual, y el del diseño, que confluyen en la totalidad del libro gratuito. El discurso es una zona abierta que acepta, rechaza, silencia, olvida y simultáneamente, en forma continua, se nutre por otros discursos verbo-visuales, producidos y reproducidos por los sujetos-emisores y, sobre todo, por los receptores, en el seno de una formación social-histórica-ideológica-cultura-política, y de coyunturas determinadas. El discurso pedagógico de la historia tiene una profunda finalidad, constituir 
macro-modelos ideológico-culturales y de identidad nacional, para que el emisor colectivo se asegure de la continuidad de las prácticas emanadas por los aparatos hegemónicos.

3. El funcionamiento subjetivo del sujeto-emisor colectivo del aparato hegemónico es simbólico, debido a que dicho sujeto se asume en su proceso de enunciación de una forma autoritaria y totalitaria, estableciéndose así una estrecha relación entre el saber autorizado, universal e incuestionable, y el funcionamiento del poder.

\section{Referencias}

Althusser, Louis, Ideología y aparatos ideológicos del Estado, México, Ediciones Quinto Sol, 1970.

Bajtín, Mijaíl M., Estética de la creación verbal, Buenos Aires, Siglo XXI Editores, 1982-2002.

Chavero, Alfredo, México a través de los siglos, Tomo I: Historia Antigua, Barcelona, Espasa, 1882.

Eco, Umberto, La estructura ausente, Barcelona, Lumen, 1978.

Foucault, Michel, El orden del discurso, trad. Alberto González Troyano, Buenos Aires, Tusquets Editores, (1969), 1980.

Gramsci, Antonio, Introducción a la filosofía de la praxis, Barcelona, Ediciones Península, 1972.

Kerbrat-Orecchioni, Catherine, Lenunciation. De la subjetivité dans le langage, París, Armand Colin, 1980.

Lotman, Iuri, "La semiótica de la cultura y el concepto de texto", en La Semiosfera I, trad. Desiderio Navarro, Madrid, Frónesis-Cátedra, 1996.

, Cultura y Explosión, Barcelona, Gedisa, 1999.

Maingueneau, Dominique, Introducción a los métodos de análisis del discurso, Buenos Aires, Librería Hachette, 1980.

Riva Palacio, Vicente y Chavero, Alfredo, México a través de los siglos: Historia antigua y de la conquista, México, G.S. López, 1940, tomo I. 
Morin, Edgar, Introducción al pensamiento complejo, disponible en <http:// www.pensamientocomplejo.com.ar/docs/files/MorinEdgar_Introduccion-al-pensamiento-complejo_Parte1.pdf> et al., Educar en la era planetaria, Barcelona, Gedisa, 2003. , Los siete saberes necesarios para la educación del futuro, Barcelona, Paidós, 2001.

Nicolescu, Basarab, La transdisciplinariedad, Manifiesto, 1994, disponible en <http://www.ceuarkos.com/manifiesto.pdf >

Pêcheux, Michel, Les vérités de La Palice, Paris, Francois Maspero, 1975.

, Formación social, lengua, discurso", en Arte, Sociedad, Ideología, Número 5, México, s/a.

Reboul, Olivier, Lenguaje e Ideología, México, Fondo de Cultura Económica, 1980.

Robin, Regine, "Discours Politique et Conjoncture”, en L'analyse du discours, discourse analysis, Centre Educatif et culturel Inc., Colection Langue et littérature/language and Literature, Montreal, 1976.

Sánchez Guevara, Graciela, "Alteridad y semiótica visual: ustedes indios, nosotros ladinos", en Revista Cuicuilco, Núm. 25, México Escuela Nacional de Antropología e Historia-Instituto Nacional de Antropología e Historia, 2000.

"La retórica visual novohispana: elemento fundamental para la construcción de la identidad nacional oficial", en Haidar, Julieta coord., La arquitectura del sentido, La producción y reproducción en las prácticas semiótico-discursivas, Consejo nacional para la Cultura y las Artes-Instituto Nacional de Antropología e Historia-Escuela Nacional de Antropología e Historia-Promep, México, 2005.

Sánchez Alegría de la C, Margarita, "Los excesos sobre el cuerpo. Sus manifestaciones en el ciberespacio", en Elsa Muñiz, coord., Registros corporales, Biblioteca de las Ciencias Sociales, México, Universidad Autónoma Metropolitana-Azcapotzalco, Serie Estudios, 2008.

Secretaría de Educación Pública, Ciencias sociales, 3er. Grado, México, Comisión Nacional de Libros de Texto Gratuitos, Secretaría de Educación Pública, 1992.

, Mi libro de historia de México 4º Grado, México, Comisión Nacional de Libros de Texto Gratuitos, Secretaría de Educación Pública, 1992.

Thompson, John B, Ideología y Cultura Moderna, México, Universidad Autónoma Metropolitana- Xochimilco, 1993. 
Vilches, Lorenzo, La lectura de la imagen. Prensa, cine, televisión, Madrid, Paidós, 1995.

Wallerstein, Immanuel, Abrir las ciencias sociales, México, Siglo XXI editores, (1996) 2006.

Zunzunegui, Santos, Pensar la imagen, Madrid, Editorial Cátedra, 1998. 


\title{
COMPLEJIDAD EN LA ENSEÑANZA DE LA CIENCIA JURÍDICA
}

\author{
Oscar Javier Apáez Pineda \\ Grupo de Investigación Desarrollo e Innovación: \\ Estudios sobre Justicia Social, Pobreza y Desigualdad \\ Barbara Edith Orihuela Rosas \\ El Colegio de Morelos
}

\section{Introducción}

La enseñanza de la ciencia jurídica es un sistema complejo, caracterizado por la presencia de una gran multiplicidad de factores concurrentes, tanto en el nivel de procesos individuales (sujetos), como en los procesos interpersonales (enseñanza-aprendizaje) y en la cuestión organizativa (estructura dinámica de los sistemas educativos); por ello la presente investigación pretende dar a conocer las notas características y nuevas perspectivas que requiere la enseñanza de la ciencia jurídica desde el punto de vista de la complejidad, para combatir el reduccionismo positivista (social y jurídico) a simples sistemas mecánicos en los que imperan la previsión y la manipulación. Abordar el fenómeno educativo jurídico complejo supondrá dar cuenta de la innovación y movimiento, capaz de enfrentarse a realidades complejas, relacionadas mediante redes de sistemas, que necesitan formas nuevas de pensar la enseñanza jurídica.

Existe una fuerte e ineludible conexión entre el nacimiento de la filosofía occidental y las formas jurídicas, que hace inescindible el estudio de ambos dominios del conocimiento. Lo que está en el centro de la reflexión de la precitada conexión es la normatividad que históricamente puede ser reconstruida por medio de la formación de la mente. ${ }^{50}$ Lo que ha permitido generar conexiones que a lo largo de la historia han producido y producen aumentos de complejidad y, por otro lado, las prácticas propias de interacción cara a cara con constantes aumentos de complejidad.

50 Josúe Fossi, Derecho y Complejidad. Materiales para una Filosofía Epistemología y Metodología jurídica desde el enfoque (trans) complejo, Académica Española, Beau-Bassin, 2017, pp. 18-19. 


\section{Metodología}

Las notas características y nuevas perspectivas de la complejidad de la enseñanza de la ciencia jurídica revisten diversos aspectos teóricos que deben seguir un orden lógico en su exposición, para efectos de poder sustentar la hipótesis de este trabajo; en ese sentido, el método utilizado para conducir la argumentación es el deductivo, el cual se desarrolla con auxilio de la técnica documental para establecer las teorías.

En ese sentido, comenzaremos con la precisión de la enseñanza como sistema complejo, para posteriormente abordar el análisis de los factores concurrentes en la enseñanza jurídica, así como su impredecibilidad y caos. Posterior a ello, se analizará su retraducción educativa, partiendo del enfoque sistémico y autopiético, para dar paso a la transcomplejidad y transepistemología de la enseñanza jurídica. Por último, se presentan las conclusiones del presente trabajo que, como se mencionó, muestra los argumentos y perspectivas que se oponen al reduccionismo positivista de la enseñanza de la ciencia jurídica.

\section{La enseñanza de la ciencia jurídica como sistema complejo}

La teoría de sistemas introdujo una unidad de compresión del mundo que marcó una diferencia dentro de las formas filosóficas y epistemológicas tradicionales de Occidente. Al respecto, Bertalanffy estableció que el estudio de los sistemas sociales contrasta con dos concepciones: la del atomismo, que desatiende el estudio de las relaciones; y la del reduccionismo, que desdeña la especificidad de un sistema. ${ }^{1}$

Con el descubrimiento de la entropía (degradación de la energía, del orden, de la organización) y la física cuántica, el modelo clásico y determinable de forma absoluta de comprensión del mundo se vino abajo, con la introducción de una unidad dinámica de comprensión de la realidad. Esa unidad dinámica es lo que llaman hoy, complejidad. ${ }^{2}$

A propósito de ésta, Juan Manuel Juárez refiere que el pensamiento complejo rompe con la unilateralidad del pensamiento científico; teje conjuntamente elementos provenientes de una concepción sistémica, y se manifiesta a favor de que cualquier estudio de la experiencia humana se haga en forma multifacética y multirreferencial. ${ }^{3}$

1 Ludwig Bertalanffy, Teoría General de los Sistemas, 19a edición, México, Fondo Cultura Económica, 2012, p. 204.

2 Josúe Fossi, Derecho y Complejidad, op. cit., p.38.

3 José Manuel Juárez y Sonia Comboni Salinas, "Epistemología del pensamiento complejo" en Reencuentro. Análisis de Problemas Universitarios, no. 65, 2012, p. 42, disponible en <https://www. redalyc.org/pdf/340/34024824006.pdf>. 
Así, para Prigogine el sistema educativo es un sistema complejo, caracterizado por una gran multiplicidad de factores concurrentes, tanto en el nivel de los procesos individuales como en los procesos interpersonales y de carácter organizativo. ${ }^{4}$ En la ciencia jurídica esto lo encontramos de la siguiente forma (figura 1):

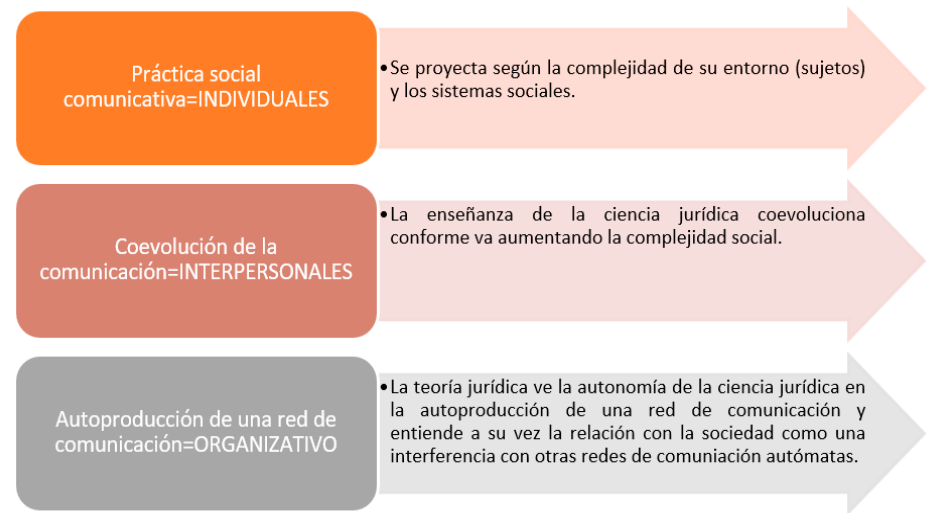

Figura 1

La multiplicidad de los factores concurrentes en la ciencia jurídica desglosados en la figura 1, muestran que la enseñanza de la misma está formada por un proceso autoorganizado con dinámicas fluctuantes permanentes e inestables. Ese sistema de fluctuaciones, que afecta el equilibrio, nos permite identificar bifurcaciones esenciales para analizar las reestructuraciones necesarias en el sistema de enseñanza de la ciencia jurídica.

Uno de los aspectos a resaltar en la enseñanza de las ciencias jurídicas consiste en que éstas se enfocan en interpretar el fenómeno jurídico bajo una visión positivista y reduccionista de la realidad, que establece sólo la posibilidad de un método excluyente de cualquier otro. Por lo que podemos observar en los argumentos vertidos hasta este momento, el sistema de enseñanza jurídica es, por su propia naturaleza, un sistema complejo, en el que concurren multiplicidad de factores que contrastan con la idea del paradigma de explicar el todo a través de la constitución de sus partes, sin reparar en el sistema y obviando su complejidad. 


\section{Multiplicidad de factores concurrentes en la enseñanza de la ciencia jurídica}

Para comprender la importancia de los factores presentes en la enseñanza de la ciencia jurídica, abordaremos cada uno de ellos de manera particular.

a) Como proceso individual — de acuerdo con Prigogine - tenemos a la práctica social comunicativa: en esta visualizamos a la ciencia jurídica desde la complejidad de su entorno; esto es, en palabras de Morales de Setién, se ve a la complejidad en sentido amplio como un motor de cambio social, ${ }^{5}$ en el que la enseñanza de la ciencia jurídica debe poner especial atención en los sujetos que participan en dichos cambios, por lo cual es necesario desarrollar esquemas conceptuales y métodos de análisis, que partan desde la transepistemología, capaces de analizar las nuevas situaciones.

b) Como proceso interpersonal tenemos a la coevolución de la comunicación: la enseñanza de la ciencia jurídica coevoluciona conforme aumenta la complejidad social; es decir, la complejidad al interior de los distintos sistemas de la sociedad (Economía, Derecho, Política) surge como consecuencia de tres factores que deben ser estudiados y analizados desde la enseñanza jurídica, siendo dichos factores, el orden como propiedad emergente de las interacciones entre los diversos sistemas de la sociedad y la ciencia jurídica; segundo, la auto-organización que se basa en la reconstitución de los procesos, tomando como dato la historia del sistema, esto en la ciencia jurídica se refiere al estudio de su estructura y de los procesos que desde la auto-organización permiten a la enseñanza de la ciencia jurídica coevolucionar; y tercero, la impredecibilidad, que proporciona a la enseñanza de la ciencia jurídica un punto de partida adecuado, para generar nuevos entrelazamientos entre los sistemas de la sociedad.

c) Como proceso organizativo tenemos a la autoproducción de una red comunicación, donde la teoría jurídica ve la autonomía de la ciencia jurídica en la autoproducción de una red de comunicación y entiende, a su vez, la relación con la sociedad como una interferencia con otras redes de comunicación

5 Carlos Morales de Setién, “La racionalidad jurídica en crisis”, en Pierre Bourdieu y Teubner, La fuerza del derecho, Bogotá, Siglo del Hombre Editores, 2000, p. 26. 
autómatas, ${ }^{6}$ esto significa que la ciencia jurídica es un medio de comunicación especial que, de acuerdo con Luhmann, se reproduce en los procesos auto-referenciales, con la finalidad de determinar si una comunicación es parte del sistema. ${ }^{7}$

El sistema de fluctuaciones que surge a partir de los factores o proceso citados, al afectar el equilibrio de la ciencia jurídica, nos permite identificar bifurcaciones esenciales para analizar las reestructuraciones necesarias en el sistema de su enseñanza, lo que de acuerdo con Prigogine provoca que el sistema ${ }^{8}$ —en este caso el sistema jurídico- fluctúe entre diversas alternativas que le permiten extenderse a todo el sistema, que de ahora en adelante se comporta como un todo más ordenado que el sistema inicial, y recupera así en la enseñanza de la ciencia jurídica sus equilibrios, superando el umbral de inestabilidad que se presentapor la aparición de comportamientos nuevos, lo que Prigogine denomina estructuras disipativas. ${ }^{9}$

Estas estructuras aluden que a partir del caos podemos encontrar estructuras ordenadas que no son lineales y pueden llevar a que un sistema se llene de situaciones cualitativamente muy diferentes de las que se encuentran cerca de su equilibrio. ${ }^{10}$

\section{La enseñanza de la ciencia jurídica: impredecible y caótica}

Gran parte de los procesos desarrollados en la enseñanza de la ciencia jurídica son impredecibles de dos maneras: la primera, por la dificultad de conocer y controlar la diversidad de variables implicadas en los procesos de enseñanza, aprendizaje, organización, etcétera; y segunda, por la constante modificación de las condiciones de actuación en las que se desarrolla su dinámica: cambios en la población, TICs, reformas sociales, interacciones imprevistas, entre otras.

Es por ello que, para aprovechar la impredecibilidad presente en la enseñanza de la ciencia jurídica, debemos valernos del factor coevolución de la comunicación, que nos permite estudiar a la ciencia jurídica como un sistema complejo adaptativo, ${ }^{11}$ nos auxilia en el estudio de las

6 Gunther Teubner, Law as an Autopoietic System, EE.UU., European University Institute, 2011, p. 39.

7 Niklas Luhmann, Complejidad y modernidad de la unidad diferenciada, Madrid, Trotta, 1998, pp. 25-29.

8 Ilya Prigogine, Las leyes del caos, México, Paidós, 2011, p. 42.

9 Ibid., p. 43.

10 Rafael Manrique Solana, "Estructuras disipativas, de la termodinámica a la psicoterapia familiar", en Revista de la Asociación Especialistas Neuropsiquiatría, Vol. VII, No. 11, 1987, p. 436.

11 J.B. Ruhl, "Law's Complexity: A primer", en Law Review, Georgia State University, vol.24, issue 4, EE.UU., 2008, pp. 885- 911. 
dependencias entre los agentes y los efectos en todo el sistema jurídico que producen, el sistema complejo adaptativo permite la coevolución con los otros sistemas de la sociedad que tiene por objeto regular $y$, por lo tanto, induce cambios (Véase figura 2).

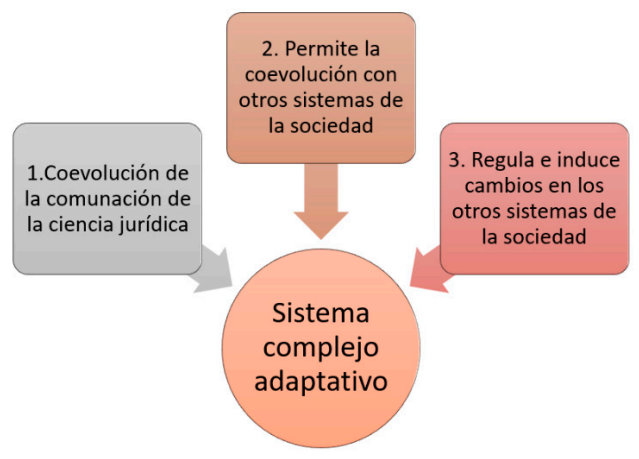

Figura 2

Por otro lado, nos referimos a que la enseñanza de la ciencia jurídica es caótica, porque, por un lado, se busca a través de ella integrar al hombre en el orden social y, por el otro, pretende aportar nueva información y reestructuración (desorden).

Asensio, desde la perspectiva caótica, menciona que a partir del desarrollo de las capacidades perceptivas, cognitivas y conductuales, se da el dinamismo de transformación de la enseñanza, por lo que una intervención educativa puede obtener resultados diversos. ${ }^{12}$ En el caso de la enseñanza de la ciencia jurídica, dicha intervención educativa se relaciona con influencias ideológicas disipativas, como moralismo religioso, positivismo kelseniano, activismo judicial, entre otros; también, existen cuestiones como la motivación, el interés y las actitudes que se generan en los ambientes educativos bajo los estímulos de resultados diferentes. ${ }^{13}$

De tal suerte que los procesos caóticos se dan tanto en el desarrollo de las personas como en las dinámicas educativas, siendo no suficiente la conjunción de desarrollo-educación para la enseñanza y evolución de la ciencia jurídica; por ello el aprendizaje de la ciencia jurídica debe ser objeto de análisis desde la teoría del caos; ante ello Davis y Sumara ${ }^{14}$ explican que la funcionalidad cognitiva se encuentra en el desarrollo interno de representación de una realidad que es percibida como algo externo e 12 Josep María Asensio Aguilera, Biología y educación, Barcelona, Ariel, 1997, p. 31.

13 Ibid., pp. 32-34.

14 Davis Brent y Dennis J. Sumara, "Cognition, complexity and teacher education", en Harvard Educational Review, EE.UU., 1997, Vol. 67, Issue 1, pp. 105-125. 
independiente del agente cognitivo, lo que genera una crítica ante las teorías conductistas y constructivistas del aprendizaje, que se basan en una retraducción del conocimiento en esquemas y materiales didácticos. ${ }^{15}$

Ante ello, la alternativa de Davis y Sumara es la teoría interpretativa, que se basa en un aprendizaje plural, complejo y comunitario, a través de múltiples fuentes de información que se proporcionan al estudiante para que pueda interpretar y posteriormente, crear.

Además, en la complejidad y en la desorganización se dan los procesos cognitivos más adecuados para el aprendizaje auto informado. ${ }^{16}$ Plantean una teoría para el aprendizaje complejo y para enseñar desde la complejidad, es decir, conforman un conocimiento vinculado con la realidad del sistema donde se actúa y del propio sujeto. Si el aprendizaje es ordenar y personalizar la información, las formulaciones mecanicistas de aprendizaje no aportan la capacidad de aprender, ya que lo hace - de acuerdo con ellos-, quien cognitivamente logra interpretar y ordenar el conocimiento desde la complejidad. ${ }^{17}$ Davis y Sumara proponen una teoría de la interpretación de la complejidad a través de la complejidad, a fin que sea el sujeto quien ordene el conocimiento adquirido, constituyendo una adaptación de la teoría del caos, para dar lugar a un modelo de aprendizaje que incide en la trasformación de la enseñanza.

En el caso de la enseñanza de la ciencia jurídica, podríamos tomar algunos elementos de la teoría de la interpretación de Davis y Sumara para generar un modelo desde la visión de la teoría del caos, consistente en lo siguiente:

Visualizando la figura 3, tenemos claro que la teoría del caos en la enseñanza de la ciencia jurídica nos abre un abanico de posibilidades de estudiar fenómenos jurídicos desconocidos, hasta el momento en su enseñanza, como la importancia y la influencia de los desórdenes en la enseñanza jurídica, las estructuras disipativas de los sistemas de la sociedad y la ciencia jurídica, la dialéctica orden-desorden, entre otras. Igualmente, la teoría del caos abre las puertas a la comprensión de la enseñanza jurídica como un cambio permanente, un proceso continuado de innovación, que produce un acercamiento más profundo a la sociedad tecnológica. ${ }^{18}$

18 Luís Ballester Brage y Antoni Colom Cañellas, Epistemologías de la complejidad y la educación, España, Octaedro, 2017, p. 93. 


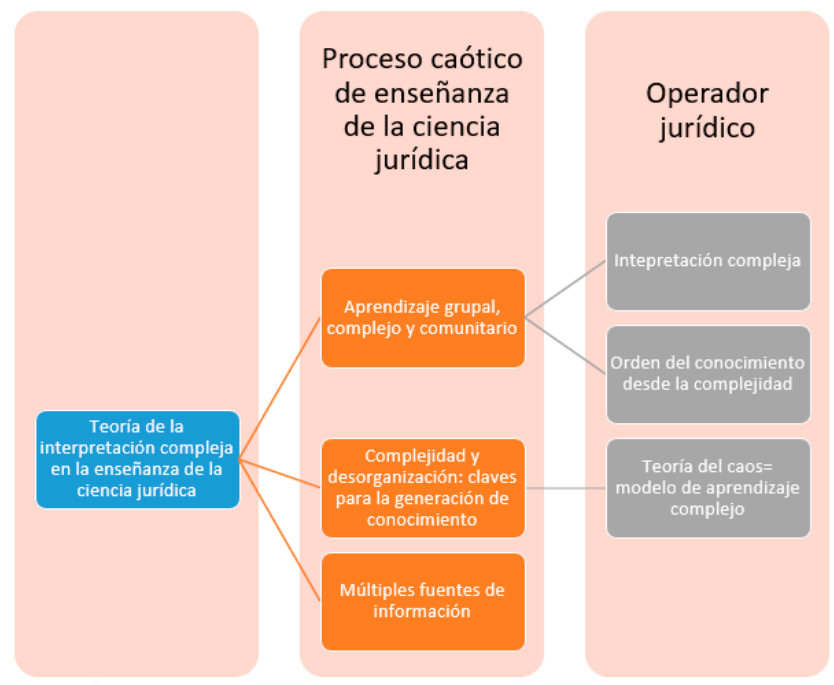

Figura 3

Por otro lado, los cambios sociales y la realidad jurídica oscilante a nivel estatal, nacional e internacional, obligan a la enseñanza de la ciencia jurídica a educar para la incertidumbre, porque las certezas cada vez son menos; además, para la contingencia, los órdenes y desórdenes que acontecen día con día en los cambios socioculturales con la finalidad de que el sujeto cognoscente de la ciencia jurídica, por medio de la creatividad, de lo imprevisible, lo aleatorio y complejo, pueda lograr sus propios órdenes. Una enseñanza de la ciencia jurídica desde la perspectiva de la teoría del caos es fundamental para generar nuevos órdenes que generarán nuevos conocimientos.

\section{Retraducción educativa de la ciencia jurídica desde una visión sistémica y autopiética}

Fritjof Capra, desde una visión epistemológica, realiza una retraducción pedagógica que se puede aplicar a la enseñanza de la ciencia jurídica. En su visión sistemática total e integral nos muestra una percepción del mundo de forma interdependiente, abierto y reticular, que permite al ser humano una nueva forma de pensar, percibir y entender el mundo. ${ }^{19} \mathrm{El}$

19 Fritjof Capra, La trama de la vida: una nueva perspectiva de los sistemas vivos, Barcelona, Anagrama, 2009, p. 29. 
paradigma propuesto por Capra se instala en el campo óntico y pasa por un planteamiento ecológico de carácter epistemológico, que analiza la vida, el hacer y el estar del ser humano.

Así, el paradigma ecológico de Capra se retraduce en comportamiento, que toma un modelo axiológico basado en el respeto a la vida en el planeta. ${ }^{20} \mathrm{~A}$ su vez, dicha axiología se retraduce en una forma de conducta y desarrollo de la vida del ser humano, actúa siempre en miras de la sostenibilidad del planeta, coloca en la cúspide axiológica a los valores ecológicos, naturales y ambientales, de tal suerte que el paradigma ecológico de Capra nos lleva a pensar y actuar coherentemente, llevándonos del pensamiento a la realidad y de la epistemología al comportamiento.

Es precisamente aquí donde Capra, ve en la educación el subsistema social capaz de posibilitar la difusión de la duplicidad mencionada, lograr así cambios en la forma de pensar y la transformación del comportamiento, siendo su objetivo pedagógico la implicación de los sistemas educativos en una forma de pensar sistémica; esto es, global, holística, interdependiente y reticular, a la par de un pensamiento ecológico.

Una concepción sistémica de la educación debe corresponder con un sistema de educación sistémico, ir de la mano de la práctica sistémica, si se aplica a la enseñanza de la ciencia jurídica, las facultades y escuelas de derecho deben enseñar a pensar sistémicamente, bajo perspectivas de totalidad e interdependencia.

Capra menciona que para desarrollar el pensamiento sistémico lo ideal es enseñar a ver el mundo de tal manera; es decir, estudiando los ecosistemas reales en la naturaleza, de tal suerte que la sostenibilidad, al formar parte de la escala axiológica, genera aportes sociales, tecnológicos y jurídicos de línea proteccionista al entorno ambiental. ${ }^{21}$

Bertalanffy apuntaba la realidad de esta visión sistemática, pues mencionaba que, si bien en el siglo XX se concibió al mundo como un caos, las nuevas disciplinas de la ciencia, como la cibernética, la teoría de sistemas, la teoría de juegos, de la decisión, de las colas y otras, coinciden en que deben ocuparse de sistemas, totalidades u organizaciones. ${ }^{22}$

Así, la visión sistémica en la enseñanza de la ciencia jurídica, partirá no sólo de la dualidad pensamiento-realidad ecológica (ontológico-epistémico), sino que se debe tomar en consideración — de acuerdo con Ca-

20 Fritjof Capra, Las conexiones ocultas: implicaciones sociales, medioambientales, económicas y biológicas de una nueva visión del mundo, Barcelona, Anagrama, 2005, p. 329.

21 Ibid., p. 225

22 Ludwig Bertalanffy, op. cit., pp. 196-197. 
pra- una dinámica compleja, no lineal, que se crea por una red social, que a su vez implica diversos bucles de retroalimentación, a través de los cuales los valores, creencias y normas se comunican, modifican y sostienen constantemente. (Véase figura 4).

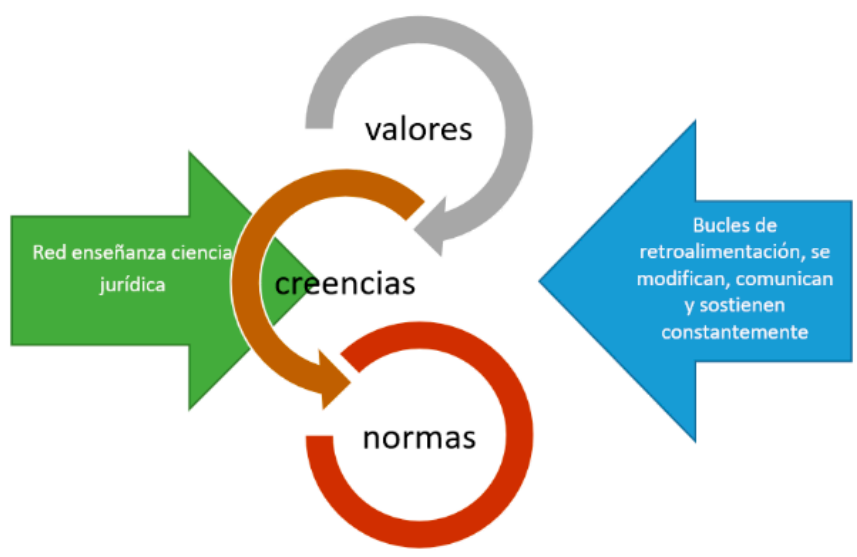

Figura 4

La pedagogía de la ciencia jurídica se modificará mediante una enseñanza integral, que contemplará varios rubros:

- Intelectual: la enseñanza de la ciencia jurídica debe ser sistémica y reticular de la realidad, desarrolla un nuevo pensamiento crítico que conozca las características sociales, culturales, ecológicas y jurídicas actuales del entorno en que se desenvuelve.

- Axiológico: parte de la base de la naturaleza como la cúspide de los valores y genera los medios necesarios para la toma de decisiones en favor del medio ambiente.

- Epistemológico: el desarrollo de una metapedagogía ecológica de la ciencia jurídica que busque generar un sentido de parentesco con el todo de la naturaleza del que formamos parte.

\section{La autopoiesis en la enseñanza de la ciencia jurídica}


La obra de Maturana y Valera El árbol del conocimiento, nos presenta el concepto de autopoiesis que, en palabras de Maturana, "captura el hecho de que los seres vivos son sistemas autónomos, como redes discretas de producciones moleculares en las que las moléculas producidas, con sus interacciones, constituyen la misma red que las que especifican su extensión en un ámbito de continuo flujo molecular". ${ }^{23}$ La palabra autopoiesis significa auto creación; etimológicamente autos en griego significa sí mismo, y poein, producir o crear. Tendría, entonces, un significado de sinónimo de circularidad, pues se pretende denominar con la autopoiesis a sistemas que se producen a sí y operan en sí mismos, y que son resultado de la operación sistémica del mismo sistema. ${ }^{24}$

Un sistema autopoiético es aquel se produce a sí mismo, abierto para intercambio de materia y cerrado en relación a la dinámica de las relaciones que lo producen. Maturana menciona que el individuo, en cuanto sistema cognitivo, se define con tres conceptos básicos: cuerpo, emoción y lenguaje. ${ }^{25}$ El cuerpo posibilita al lenguaje, que sirve para reconstruir el mundo mediante el propio lenguaje, pero además, las emociones forman parte del proceso de cognición, es decir, los seres humanos primero perciben y luego conocen desde una determinada emoción o estado emocional. ${ }^{26}$ Conocer la realidad es un acto autopoiético, mediatizado por el lenguaje y las emociones.

Del lenguaje surgen los diferentes mundos culturales, diversos y múltiples, mediatizados por las emociones. Aquí la circularidad cognoscente se hace presente, funda el punto de partida que nos permite dar explicación al conocimiento del conocimiento, sin caer en una actitud de certeza absoluta. ${ }^{27}$

23 Humberto Maturana Romesin, El árbol del conocimiento: las bases biológicas del entendimiento humano, Madrid, Debate, 1996, p. 14.

24 Luís Ballester Brage y Antoni Colom Cañellas, Epistemologías de la complejidad, op. cit., p. 128.

25 Humberto Maturana Romesin, Emociones y lenguaje en educación y política, Argentina, Granica, 2001, p. 26.

26 Ibid., p. 29 y ss.

27 Humberto Maturana Romesin, op. cit., p. 205 y ss. 
Agrega Maturana que el lenguaje constituye un fenómeno biológico relacional, que coexiste en las interacciones recurrentes bajo la forma de un fluir recursivo en coordinación con las cuestiones conductuales. Surge desde la complejidad un entrelazamiento entre el lenguaje y las emociones y genera redes de conversación.

En la enseñanza de la ciencia jurídica, lo anterior tiene cabida cuando Maturana afirma que las redes de conversación que surgen, se dan sobre un soporte emocional que aterriza en el campo jurídico en una conducta, lo que aporta herramientas a la pedagogía de la ciencia jurídica para lograr comprender y reflexionar, desde la esfera jurídica, el cambio de actitudes y conductas desde las emociones subyacentes en el lenguaje y la manera en que se modifican a través desde la conversación. Es más, la conversación genera, de acuerdo con Maturana, cambios culturales, sosteniendo que, "una cultura es una red cerrada de conversaciones, que el cambio de cultura ocurre como un cambio de conversaciones en la red de conversaciones, que la comunidad que cambia vive y que tal cambio surge, se sustenta y se mantienen en el cambio del emocionar de los miembros de la comunidad que cambia". ${ }^{28}$

En la conversación de la ciencia jurídica, las redes que se entrelazan surgen de los lenguajes entre las diversas cortes internacionales, los sistemas jurídicos y la doctrina jurídica; por ello es necesario tomar en consideración la autopoiesis o complejidad circular en la enseñanza de la ciencia jurídica, ya que de los diversos lenguajes citados, en conjunción con las emociones, se generan diálogos o conversaciones que interactúan de tal manera que producen nuevos diálogos, que se auto interpretan. Es aquí donde los estudiantes de las ciencias jurídicas requieren herramientas pedagógicas como la dialógica y la recursividad, que permitan el análisis y la interpretación circular de los diversos lenguajes y emociones, que convergen en la ciencia jurídica.

Como se observa, no escapa del principio de auto-eco-explicación, según el cual debe considerarse a la enseñanza de la ciencia jurídica en la lógica interna de su sistema como la lógica externa de su situación o entorno y que, en el paradigma de la complejidad, debe de ser una enseñanza ecologizada que, en vez de aislar el objeto estudiado, lo considere en y por su relación eco-organizadora con su entorno. ${ }^{29}$

28 Humberto Maturana Romesin y Gerda Verden-Zöler, Amor y juego. Fundamentos olvidados de lo humano. Desde el patriarcado a la democracia, Argentina, Granica, 2011, p. 11.

29 Sergio Osorio, "El pensamiento complejo y la transdisciplinariedad: Fenómenos emergentes de una nueva racionalidad", en Revista de la Facultad de Ciencias Económicas de la Universidad Militar, Nueva Granada, Vol. XX (1), junio 2012, pp. 269-291. 
Esta reflexión nos conduce a la necesidad de abordar la complejidad de la enseñanza de la ciencia jurídica a través de un método que explique qué es y cómo se constituye, además refiera la estrategia cognoscitiva para poner en circulación su comprensión y sea capaz de reintroducir al cognoscente en este proceso; es decir, que sea capaz de generar un "conocimiento del conocimiento".

\section{La transcomplejidad y la transepistemología en la enseñanza de la ciencia jurídica}

La complejidad es una propiedad emergente de un sistema relacional multidimensional, multi-causal, por el que se explica y comprende el Universo-Mundo-Sociedad-Comunidad que el hombre reproduce como visión del mundo. ${ }^{30}$ La complejidad es una propiedad emergente que selecciona un observador al reconstruir la realidad misma. En este sentido, la realidad no es transcompleja, lo transcomplejo es el modo en el que el observador trata esa complejidad que selecciona de la realidad. Por tanto, lo transcomplejo es el aparato epistemológico y metodológico que un observador utiliza para la comprensión y explicación de la complejidad que emerge de una selección de la realidad (Véase figura 5).
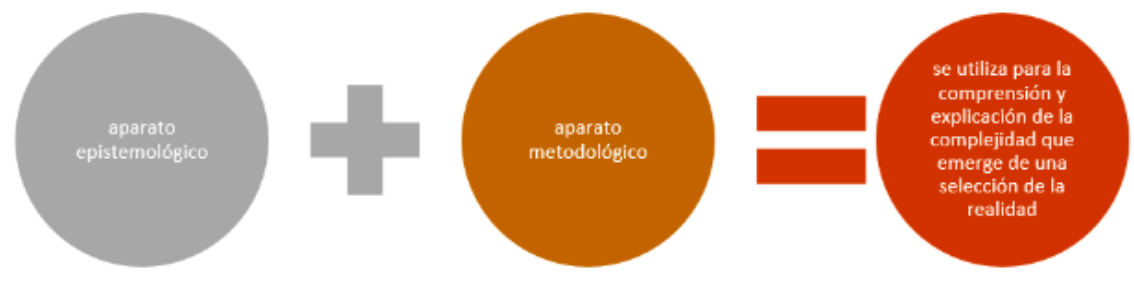

Figura 5

En la ciencia jurídica la visión transcompleja es de utilidad en su enseñanza, al permitirnos abordar de manera metodológica-epistemológica la complejidad de los supuestos jurídicos contenidos en la norma y adaptarlos a la realidad que corresponda, es decir, generar un diálogo que desemboque en la praxis jurídica (Véase figura 6).

30 Josúe Fossi, Derecho y Complejidad. Materiales para una Filosofía, epistemología..., op. cit., p. 51. 


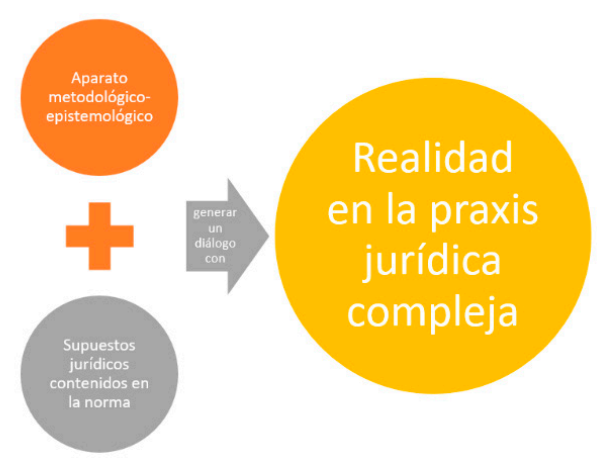

Figura 6

En este orden de ideas, la ciencia jurídica es además un sistema práxico, es decir, aquel cuya organización es activa con carácter organizacional. Que -como Maturana mencionaba al hablar de la autopoiesis-, se configura como autónomo, operacionalmente productor de sí, por medio de la metanorma de la producción jurídica, organizador de sí, reorganizador de sí, función que realizan las normas de competencia y las que confieren poderes. En este sentido, el derecho es autoreferencial debido a su autonomía organizacional, que a su vez determina una autonomía causal que crea una endo-causalidad no reducible al patrón causa-efecto. Es así que en el derecho como en otro sistema complejo, se da una endo-exo-causalidad, es decir, una causalidad mutua interrelacionada. ${ }^{31}$

\section{Transepistemología en la enseñanza de la ciencia jurídica}

La sociedad mexicana actual exige nuevos modelos de abordaje de las complejas relaciones que la praxis jurídica impone. Ese abordaje pasa por una comprensión clara del estatuto ontológico del Derecho, de la superación de las formas tradicionales de proyectar la realidad jurídica y de buscar nuevos modelos epistemológicos. Principalmente, la concientización de la multidimensionalidad de la realidad jurídica.

Para Maturana la realidad es una experiencia, un argumento en una explicación, la realidad surge como una proposición explicativa de nuestra experiencia de las coherencias operacionales en nuestra vida diaria y técnica. ${ }^{32}$ En este sentido, lo que se denomina realidad jurídica no es más que un subsistema de los sistemas deónticos o normativos, una creación de una praxis social comunicativa que configura redes de relaciones sociales. Tanto lo dado como lo construido (la realidad) de-

31 Josúe Fossi, Derecho y Complejidad. Materiales para una Filosofía, epistemología..., op. cit., pp. 54-55.

32 Humberto Maturana Romesin, Emociones y lenguaje, op. cit., p. 57. 
penden del modelo o imagen preconcebida por el sujeto, esto implica que los sujetos no sólo observan la realidad, sino que participan en ella, la construyen y alteran. Este modo de comprender la realidad es lo que Hawking denomina realismo dependiente del modelo, donde la idea de una imagen del mundo es un modelo y un conjunto de reglas que relacionan los elementos del modelo con las observaciones. ${ }^{33}$

La realidad jurídica es un hecho social, y como tal, estructuralmente complejo. La ciencia jurídica se comprende como parte del universo social y como su subsistema, que tiene como entorno otros, como el político o el económico. En palabras de Luhmann, sólo se pude concebir al Derecho como un sistema social, si se toma en cuenta el hecho que este sistema es un subsistema de la sociedad y existen otros. ${ }^{34}$

La estructura compleja de las sociedades modernas implica un modelo de reflexión mayor, que abarque el fenómeno de una forma global. Un abordaje de la realidad, construida con la integración de las distintas imágenes que pueden utilizarse para desarrollarlo. Concebir la experiencia jurídica se puede comprender a partir del principio de complementariedad. Este principio subraya la incapacidad humana de agotar la realidad con una sola perspectiva, punto de vista, enfoque, óptica o abordaje; con un sólo intento de captarla. La descripción más vasta de cualquier entidad, se lograría al integrar en un todo coherente y lógico los aportes de diferentes personas, filosofías, escuelas, métodos y disciplinas. Este principio epistemológico debe configurar una nueva sensibilidad y una nueva racionalidad, que ponga de relieve el carácter articulador y transdisciplinario, de perspectivas diversas que enmarcan y constituyen el contexto desde el cual se investiga, así como los aspectos aparentemente desvinculados y excluyentes. ${ }^{35}$

La visión transepistemológica descansa en la afirmación que la realidad es compleja y múltiple, o mejor: multidimensional, y se despliega por medio de cinco principios, como dispositivos de control para cualquier investigación. El primero es el de la complementariedad, que aparece como el dispositivo o principio rector para el análisis y la comprensión de la realidad. En las ciencias jurídicas operaría como un mecanismo de observación de los distintos niveles del conocimiento

33 Stephen Hawking y Leonard Mlodinow, El gran diseño, Madrid, Crítica, 2010, p. 83.

34 Niklas Luhmann, "El derecho como sistema social", en Carlos Gómez-Jara Diez, Teoría de sistemas y derecho penal: fundamentos y posibilidades de aplicación, Granada, Comares, 2005, pp. 126-150.

35 Crisálida Villegas, "Diálogos transcomplejos", Universidad Bicentenaria de Aragua-REDIT, Venezuela, 2011, consultado en: <https://es.calameo.com/read/000102258273e1d9178d5>, p. 7. 
jurídico y de las interpenetraciones del Derecho con otros dominios de los subsistemas sociales implica que cualquiera sea el fenómeno que se presente, no debe ser abstraído solo normativamente. ${ }^{36}$

La transepistemología propone como segundo principio la sinergética relacional, la cual opera como un sistema integrado de retroalimentación y producción de información. Este permite que se generen redes dinámicas y significativas que fortalezcan la indisoluble relación teoría-praxis en un ambiente cargado de sinergia; es decir, en la suma de energías individuales de los actores significantes que se convierten en razones comunes. Este principio obra como un sistema de mediación entre el aparato conceptual jurídico, organiza la forma como un sujeto o un conjunto de sujetos, que puede orientar la investigación mancomunada. ${ }^{37}$

El tercer principio que propone la transepistemología es la dialéctica recursiva, como un mecanismo de contrastación e interpretación no lineal de la realidad. Morin define a la dialógica como una unidad compleja entre dos lógicas, entidades o instancias complementarias, concurrentes y antagonistas que se alimentan la una a la otra; este principio opera en el Derecho como un dispositivo de transformación de la experiencia jurídica en una red interdependiente con saberes, aparentemente excluyentes, pero que posibilitan el curso de la construcción jurídica. ${ }^{38}$

La integralidad es el cuarto principio de la transepistemología, ella permite la organización y construcción de la realidad multidimensional. La integralidad trasciende al holismo y denota la necesidad de asumir que la realidad es múltiple, diversa, relacional, en construcción y construible. Este enfoque abre camino a lo interaccional, reticular y a la coproducción conjunta como fuentes constitutivas de la realidad compleja. La complejidad asociada al Derecho es tal que no puede abstraerse de la multiplicidad del contexto social con su respectivo recorte de saberes que lo proyecta. ${ }^{39}$

Por último, la transepistemología propone el principio de reflexibilidad profunda; es decir, un mecanismo de análisis y comprensión de los propios procesos de deliberación. Es un proceso complejo de deliberación del pensamiento sobre la interpretación de una experiencia para poder aprender de ella.

36 Niklas Luhmann, Complejidad y modernidad. De la unidad a la diferencia, Madrid, Trotta, 1998, p. 63 y ss.

37 Crisálida Villegas y Nancy Schavino, "La investigación: Un enfoque integrador transcomplejo", Congreso Iberoamericano de educación, Buenos Aires, 2010, consultado en <http://www.adeepra. org.ar/congresos/Congreso\%20IBEROAMERICANO/EIC/R0721_Schavino.pdf >, p. 10.

38 Edgar Morin, El método 6, Ética, Madrid, Cátedra, 2004, p. 230.

39 Ibid., p. 11. 


\section{Conclusiones}

La ciencia jurídica, como ciencia social, constituye un sistema complejo, en virtud de sus interrelaciones, que, además, se caracteriza por una gran multiplicidad de factores concurrentes. Por lo anterior, se puede concluir que la ciencia jurídica está formada por un proceso autoorganizado con dinámicas fluctuantes permanentes e inestables; sus interrelaciones motivan fluctuaciones de este tipo y sus factores concluyentes autorganizan su sistema.

Un ejemplo de lo anterior se puede encontrar en la evolución del referente lingüístico de la concepción de la enseñanza de las ciencias jurídicas y la nominación de los lugares destinados para llevarla a cabo; así, encontramos escuelas de leyes y jurisprudencias, de Derecho, facultades de Derecho, centros de investigación o institutos de investigaciones, que nominalmente permiten observar que el tipo de enseñanza que se imparte, proyecta la denominación institucional en atención a los enfoques y cómo éstos se materializan.

Esta nominación no necesariamente implica que se entienda la enseñanza de la ciencia jurídica como un sistema complejo; en las escuelas de leyes y jurisprudencia el paradigma reduccionista del positivismo impera, pero da cuenta de que en algunos de estos lugares la enseñanza va acorde a su nomenclatura, elegida en atención al momento paradigmático en el cual fue fundada y en atención a la posibilidad de llevar a cabo, o no, estudios complejos de transdisciplina, transcomplejidad o la transepistemología.

La posibilidad de que estas directrices sean implementadas en la enseñanza de las ciencias jurídicas, es susceptible de materializarse independientemente de la denominación que tenga la institución; aunque con frecuencia encontramos que es más factible que un instituto o centro de investigación sea el que cuente con mayor posibilidad de aplicar esta manera de enseñanza.

Lo que resulta esencial para poder implementar este tipo de estudios es la necesidad de que las instituciones comiencen a comprender que el sistema de enseñanza necesita vincularse con su entorno; un ejemplo de esta necesidad la podemos observar con la reforma en materia de derechos humanos en México, que ha provocado la conveniencia de actualizar planes de estudios, a través de procesos que, en el mejor de los casos, aplicarán a la generaciones venideras y no a las actuales, en atención a que los nuevos paradigmas que propone la visión de la 
precitada reforma, implica, como claro ejemplo de la complejidad del sistema, que ciertas materias se impartan considerando como adecuado el paradigma positivista reduccionista.

Esta situación no impide que la enseñanza de la ciencia jurídica se lleve a cabo; sin embargo, cada vez son más los abogados desplazados que no cuentan con herramientas para reinterpretar la ciencia jurídica o contemplar al Derecho como parte integrante de un sistema que se interrelaciona y exige la transcomplejidad y transepistemología para poder materializarse en un mundo donde el positivismo funciona en un nivel básico y para operaciones jurídicas de carácter técnico.

\section{Referencias}

Asensio Aguilera, Josep María, Biología y educación, Barcelona, Ariel, 1997.

Ballester Brage, Lluís y Colom Cañellas, Antoni, Epistemologías de la complejidad y la educación, España, Octaedro, 2017.

Bertalanffy, Ludwig, Teoría General de los Sistemas, 19a edición, México, Fondo de Cultura Económica, 2012.

Capra, Fritjof, La trama de la vida: una nueva perspectiva de los sistemas vivos, Barcelona, Anagrama, 2009.

, Las conexiones ocultas: implicaciones sociales, medioambientales, económicas y biológicas de una nueva visión del mundo, Barcelona, Anagrama, 2005.

Davis Brent, y Sumara, Dennis J., "Cognition, complexity and teacher education”, EE.UU., Harvard Educational Review, Vol. 67, Issue1, 1997.

Fossi Josué, Derecho y Complejidad. Materiales para una Filosofía, epistemología y metodología jurídica desde el enfoque (trans)complejo, Beau-Bassin, Editorial Académica Española, 2017.

Hawking, Stephen. y Mlodinow, Leonard, El gran diseño, Madrid, Crítica, 2010. 
Juárez, José Manuel, y Comboni Salinas, Sonia, "Epistemología del pensamiento complejo", en Reencuentro. Análisis de Problemas Universitarios, no. 65, 2012. Disponible en <https://www.redalyc.org/ pdf/340/34024824006.pdf>

Luhmann, Niklas, "El derecho como sistema social", en Gómez-Jara Diez, Carlos, Teoría de sistemas y derecho penal: fundamentos y posibilidades de aplicación, Granada, Comares, 2005.

Luhmann, Niklas, Complejidad y modernidad de la unidad diferenciada, Trotta, Madrid, 1998.

Manrique Solana Rafael, "Estructuras disipativas. De la termodinámica a la psicoterapia familiar", en Revista de la Asociación Especialistas Neuropsiquiatría, Vol. VII, No. 11, 1987.

Maturana Romesin, Humberto y Verden-Zöler, Gerda, Amor y juego. Fundamentos olvidados de lo humano. Desde el patriarcado a la democracia, Buenos Aires, Granica, 2011.

, El árbol del conocimiento: las bases biológicas del entendimiento humano, Madrid, Debate, 1996.

,Emociones y lenguaje en educación y política, Argentina, Granica, 2001.

Morales de Setién, C, "La racionalidad jurídica en crisis", en Bourdieu, Pierre y Teubner, Gunther, en La fuerza del derecho, Colombia, Siglo del Hombre Editores, 2000.

Morin, Edgar, La cabeza bien puesta. Repensar la reforma-reformar el pensamiento, Buenos Aires, Ediciones Nueva Visión, 2001ª.

,El método 6. Ética, Madrid, Cátedra, 2004.

Osorio, Sergio, "Camino hacia la transdisciplinariedad. La paradigmatología en Edgar Morin”, en Pensar desde la educación superior. Una reflexión transdisciplinar, Bogotá, Alvi Impresores-UMNG, 2010.

, "El desafío de la complejidad", en Bioética y pensamiento complejo II: Estrategias para enfrentar el desafío planetario, Bogotá, Archel publicidad-UMNG, 2008.

, "El pensamiento complejo y la transdisciplinariedad: Fenómenos emergentes de una nueva racionalidad", en Revista De La Facultad De Ciencias Económicas de la Universidad Militar Nueva Granada, Vol. XX (1), junio 2012. 
Prigogine Iliya, ¿Tan sólo una ilusión? Una exploración del caos al orden, Barcelona, Tusquets, 2009.

Ruhl, J.B., "Law's Complexity: A primer", en Law Review, EE.UU., Georgia State University, vol.24, issue 4, 2008.

Teubner, Gunther, Law as an Autopoietic System, EE.UU., European University Institute, 2011.

Velilla, Marco Antonio, Manual de iniciación pedagógica al Pensamiento complejo, París, ICFES/UNESCO, 2002.

Villegas, Crisálida y Schavino, Nancy, "La investigación: Un enfoque integrador transcomplejo", en Congreso Iberoaméricano de educación, Buenos Aires, 2010, consultado en <http://www.adeepra.org.ar/congresos/Congreso\%20IBEROAMERICANO/EIC/R0721_Schavino.pdf>

Villegas, Crisálida, Diálogos transcomplejos, Universidad Bicentenaria de Aragua-REDIT, Venezuela, 2011, consultado en <https://es.calameo.com/read/000102258273e1d9178d5>, p. 7. 


\section{COMPLEJIDAD Y \\ TRANSDISCIPLINARIEDAD}

Juan de Dios González Ibarra

Carolina Peña Zepeda

El Colegio de Morelos

\section{Introducción}

El paradigma emergente de la complejidad nos invita a reflexionar sobre él y, en este artículo, partimos de las preguntas de cuál es el referente básico y la metodología que se puede emplear para la construcción de un pensamiento complejo.

Comenzaremos señalando que el referente básico en la complejidad es el bucle moraniano, ${ }^{40}$ mientras que el concepto socrático es la unidad básica de la ciencia, el metaconcepto hegeliano-carrolliano es la unidad básica de lo epistémico; la anterior afirmación nos obliga a desarrollar lo que es el bucle y, sostenemos, que es como las olas del mar con el principio recursivo, donde todo efecto produce una causa y cada causa de nueva cuenta es efecto; lo poiético con su efecto autoconstructivo se aplica aquí, por ello podemos identificar al bucle como el ser lógico transdisciplinario que dinámicamente produce lo complejo, lo transdisciplinario conlleva bucles y recursivamente producen lo transdisciplinario en una renovadora retroalimentación incesante.

Lo transdisciplinario ${ }^{41}$ implica el cruce de las disciplinas como una flecha y también una translógica, la cual explicamos como aquella que maneja las diferentes lógicas disciplinarias integrando consecuentemente un tejido, en donde cada ciencia constituye un hilo que nos permite construir un lienzo con el que podemos explicar una realidad determinada. Una translógica que penetra y se mueve como una flecha en el tiempo disciplinario, lo rompe para crear una nueva dinámica que permite, desde el pensamiento complejo, comprender, a partir de un segundo orden, lo sujeto a comprensión y explicación.

40 Edgar Morín, Introducción al pensamiento complejo, Barcelona, Gedisa, 1990, p. 37.

41 Basarab Nicolescu, Manifiesto de la Transdisciplinariedad, Ediciones Du Rocher, consultado en $<$ http://www.ceuarkos.com/manifiesto.pdf>, 20 de mayo de 2019, p. 10. 
Así, si queremos comprender desde el pensamiento complejo al ser humano, necesitamos aceptar que es un ser racional, emocional, pasional, espiritual, instintivo y cultural; esto implica lo histórico y lingüístico, así como todas aquellas aportaciones que la humanidad ha hecho en su historia; aquí el legado de Freud ${ }^{1}$ es invaluable, al igual que Heidegger ${ }^{2}$ y Ludwig Wittgenstein ${ }^{3}$, para afirmar que si la muerte es un sueño eterno, la vida es un despertar de solamente $\boldsymbol{x}$ años.

Lo complejo es cuántico, no digital con su lógica binaria de 0 o 1 , sino que aquí el 0 y el 1 se hermanan, lo que nos lleva a lo infinito de recorrer del 0 al 1; luego cambia la lógica disciplinaria a transdisciplinaria, lo que gracias a pensadores como Edgar Morin e Ilya Prigogine ${ }^{4}$ la humanidad ha podido avanzar, mientras que las ciencias llegan hasta donde el ser humano ha logrado avanzar. Lo transdisciplinario como pensamiento complejo, genera un nuevo conocimiento que de acuerdo con la lógica mencionada del 0 y 1 nos conduce a una panlógica que cursa todas las lógicas disciplinarias, para poder llegar a un destino que integra lo transdisciplinario y lo niega dinámicamente, por lo que estamos ante un nuevo diálogo de todas las ciencias, técnicas, artes y tecnologías que la humanidad ha desarrollado, que nos permite situarnos en las fronteras de los conocimientos y lleva a un saber desde la complejidad.

Mientras en la epistemología de primer orden estamos en el campo del conocimiento del conocimiento, ${ }^{5}$ en la de segundo orden estamos ante lo sapiencial; entonces congruentemente debemos manejar el saber del saber y aquí nos ayuda Heidegger cuando menciona que la nada nadea, lo que es muy fácil de demostrar en nuestros alimentos envasados al alto vacío, lo que implica que la nada del oxígeno y otros gases, al eliminarse por el procedimiento del alto vacío, permiten evidentemente que la nada "nadee"; en el caso del 0 , también se presenta la nada que permite que una unidad con el 0 a la derecha eleve al número 10 la cantidad de entes que expresamos con ese 0 que no ejercería su función si estuviera a la izquierda, luego para que el cero nadee tiene que ir a la derecha.

El originario cero en maya-oriental es una negación-afirmación de lo abstracto-numérico, permite romper la barrera de la suma para poder pasar a otro orden lógico infinito en donde en el numero 10 o 20, la nada

1 Sigmund Freud, Obras Completas, Buenos Aires, Amorrortu Editores, 1978, p. 237.

2 Martín Heidegger, Ser y tiempo, trad. José Gaos, México, Fondo de Cultura Económica, 2013, p. 113.

3 Ludwig Wittgenstein, Tractatus lógico-philosophicus, Madrid, Tecnos, 2012, p. 86.

4 Ilya Prigogine, Las leyes de caos, Barcelona, Crítica, 1999, p. 56.

5 Juan de Dios González Ibarra y Carolina Peña Zepeda, Epistemología Jurídica, 6ta ed., México, Porrúa, 2019, p. 56. 
nadea con su potencia originaria. La lógica del cero nos permite pasar a un segundo orden, generado por la generatividad de lo originario; luego es la nada que nadea potenciando a una unidad para transformarla en 10 unidades, así el 1 se convierte en 10 manzanas, que no es una simple suma sino es otra lógica que dinámicamente en el 10, 30 se manifiesta gracias al poder originario del cero o la nada que nadea ${ }^{6}$ en todo su esplendor.

Lo sapiencial del segundo orden de la epistemología de esta calidad implica superar la epistemología del primer orden, la que nos permite manejar los conocimientos disciplinarios de cada ciencia que uno desea desarrollar, mientras que en el segundo se exige superar lo anterior, si el metaconcepto es la unidad básica de la epistemología del primer orden, como lo expresó $\mathrm{Hegel}^{7}$, que la pena es la negación de la negación del derecho, o siguiendo a Lewis Carroll ${ }^{8}$, no se pueden ni perder aquellos que no saben a donde quieren ir, o también cualquier camino es válido para quienes carecen de la voluntad de dirigirse hacia un destino determinado, ${ }^{9}$ podemos ver en quien está considerado por muchos como el mas grande crítico literario Harold Bloom, ${ }^{10}$ que cita a Paul Valéry (18711945), “nada es mas 'original', nada es más 'uno mismo’ que alimentarse de los demás. Pero hay que digerirlos, los leones están hechos de ovejas asimiladas", por lo que "decimos que un autor es original cuando ignoramos las transformaciones ocultas que otros han producido en él; queremos pues decir, que lo que hace ese autor es demasiado complejo e irregular en relación con lo que ya fue hecho". ${ }^{11}$

Afirma Bloom que Troilo y Crésida ${ }^{12}$ es la más compleja de las obras de Shakespeare, mientras que refiriéndose al Luis Vaz de Camões (15241580), quien escribió Los Lusiadas, ${ }^{13}$ cita que su episodio favorito está en el erótico canto 9, donde Camões escribió "que si heridas aun están viviendo, será para sentir que van muriendo", refiriéndose a las ninfas que han sido heridas mortalmente por las flechas lanzadas por Baco, también de Saramago ${ }^{14}$ toma lo siguiente, "tú, que le quitas lo mundo al mundo,

6 Martin Heidegger, El ser y el tiempo, op. cit., p. 98.

7 Georg W. F. Hegel, Enciclopedia de las ciencias filosóficas en compendio, trad. Ramón Valls Plana, Madrid, Alianza Editorial, 1997, p. 387.

8 Lewis Carroll, Alicia en el país de las maravillas, España, Alianza Editorial, 2010, p. 66.

9 Ibid., p. 72.

10 Harold Bloom, Genios, Un mosaico de cien mentes creativas y ejemplares, México, Anagrama, p. 247.

11 Ibid., p. 592.

12 William Shakespeare, Troilo y Crésida, España, Espasa, 2000, p. 65.

13 Luis Vaz de Camões, Los Lusiadas, Biblioteca Virtual Universal, consultado en: <http://portal. uc3m.es/portal/page/portal/ifibid/catedracamoens/luiscamoens/Las_Lusiadas_BVirtual_pdf >, el 15 de junio de 2019, p. 241.

14 Harold Bloom, Genios, op. cit., p.269. 
tú que eres la paz, tú que no existes, que solo eres la ausencia de la luz", lo que nos recuerda el nadear de Heidegger. Del premio Nobel de Literatura 1990, Octavio Paz (1914-1998), toma el poema "Piedra de sol", en donde el mexicano expresa "Amar es combatir, es abrir puertas, dejar de ser fantasma con un número, a perpetua cadena condenado por un amor sin rostro. El mundo cambia si dos se miran y se reconocen, amar es desnudarse de los nombres". ${ }^{15}$ En este aspecto es común que quienes se aman se nombren "cariño", "amor", "cielo", "corazón".

El segundo orden del conocimiento nos lleva a usar bucles que nos permitirán retroalimentarnos para que en un movimiento incesante, como es el mar, pasemos a un nivel donde lo disciplinario ha quedado atrás, y podemos, con una visión amplia, distinguir la sima y la cima de los conocimientos, lo que nos conduce a lo sapiencial; un ejemplo es el que Harold Bloom toma de John Ruskin ${ }^{16}$ (1819-1900), quien definió al poeta como "el hombre a quien hablan las cosas", entonces aquí podemos apreciar que éste puede recibir de todas las cosas sus saberes, por lo que la poesía puede ser transdisciplinaria.

\section{La transdisciplinariedad}

La visión clásica de un mundo que se rige por leyes universales, inmutables e ineludibles, ha encontrado en la complejidad su más grande cuestionador; ella abreva de la fuente que diluye las fronteras de la especialización, invade todo el espectro del saber, reta nuestra propia existencia y su sentido. El derrumbe de la pirámide construida con bloques disciplinares, ha permitido que el pensamiento de la humanidad tenga terreno para expandirse; sin embargo, este campo deberá explorarse con una visión que permita comprender la totalidad de los factores que este nuevo paradigma contempla, y, en caso de que esa tarea se considere ambiciosa o desmesurada, comprender al menos sus implicaciones.

En el paradigma de la complejidad no podemos pasar por alto el estudio de la transdisciplinariedad, teniendo uno de sus mayores exponentes en el doctor en Física cuántica, Basarab Nicolescu, cuyo pensamiento esbozado en su Manifiesto de la Transdisciplinariedad, afirma que dicho término, surgido apenas hace tres décadas, expresa la necesidad de una feliz transgresión de fronteras entre las disciplinas, de una superación de la pluri y de la interdisciplinariedad. ${ }^{17}$ Dicha transgresión, en el contexto

15 Octavio Paz, "Piedra de sol", en Lo mejor de Octavio Paz, Barcelona, Seix Barral, 1989, p. 95.

16 Harold Bloom, Genios, op. cit., p. 87.

17 Basarab Nicolescu, op., cit. p.3. 
de la cuarta revolución industrial. ${ }^{18}$ en particular de la revolución informática, podría, a consideración del autor, conducirnos a un "compartir de conocimientos" entre todos los seres humanos; sin embargo consideramos que "compartir de saberes" es un término más adecuado, pues como establecimos en líneas precedentes, en la epistemología de segundo orden nos situamos en el fértil campo de lo sapiencial.

Por su parte, el doctor en Pedagogía, Miguel Martínez, considera a la transdisciplinariedad como un movimiento que desea ir más allá de la uni-disciplinariedad (por su limitación), de la multi-disciplinariedad (que integra a una disciplina con los saberes de otra), y de la inter-disciplinariedad, (que lleva el orden epistémico y metodológico de una a otra), pues pretende superar la parcelación y fragmentación del conocimiento que reflejan las disciplinarias particulares y su consiguiente hiperespecialización, se detiene a revisar la intricada red de relaciones, nexos e interconexiones que las constituyen. ${ }^{19}$

Así tenemos que el conocimiento transdisciplinario se da entre, $a$ través y más allá de las disciplinas, funda su teleología en este más allá, pues busca comprender el mundo en el que vivimos, el mundo actual, cuyo imperativo fundamental es la unidad del conocimiento; por ello, la transdisciplinariedad no constituye una teoría, sino una nueva visión del mundo y de la racionalidad humana. ${ }^{20}$

Por su parte, Osorio García menciona que la transdisciplinariedad no es una invitación a desechar los conocimientos disciplinares, sino de buscar y encontrar una nueva forma de organizarlos, un paradigma de complejidad, una visión transdisciplinar para el conocimiento. ${ }^{21}$ Concluyendo, que la transdisciplinariedad es la forma de conocer la complejidad que somos y nos constituye; es la mejor estrategia cognoscitiva para poner en circulación el pensamiento complejo, capaz de complejizar la comprensión del mundo actual, que ayuda a su vez a buscar la unidad del conocimiento fragmentado en disciplinas y afrontar, desde una nueva racionalidad, el reto de la supervivencia planetaria. ${ }^{22}$

18 Klaus Schwab, La cuarta revolución industrial, España, Debate, 2018, p. 43.

19 Miguel Martínez Miguélez, "Transdisciplinariedad un enfoque para la complejidad del mundo", en Revista Visión docente con-ciencia, núm. 1, julio, 2003, p. 3.

20 Sergio Nestor Osorio García, "El pensamiento complejo y la transdisciplinariedad: Fenómenos emergenes de una nueva racionalidad", en Revista Facultad de Ciencias Económicas, Vol. XX (1), Junio 2012, p. 281.

21 Ibid., p. 289.

22 Ibid., p. 290. 
Encontramos acertada la afirmación que señala el peligro inminente que enfrenta la humanidad ante su autodestrucción, en tres diferentes dimensiones, lo material, biológico y espiritual ${ }^{23}$, aludiendo a lo ya establecido por Heidegger cuando afirmó "la ciencia no piensa", al establecer que "esta triple autodestrucción potencial es sin duda, el producto de una tecnociencia ciega pero triunfante, obedeciendo sólo a la implacable lógica de la eficacidad por la eficacidad". ${ }^{4}$

La transdisciplinariedad nos invita a dejar el confortable asiento que representa el pensamiento disciplinario, ideología predominante en la humanidad desde el siglo XIX, la cual genera la idea de continuidad al confiar ciega y religiosamente en la existencia de leyes, orden y estabilidad; dichas características tratan de convencernos de la posibilidad de prever situaciones futuras, de saber las consecuencias al conocer los factores que intervienen y sus interacciones, pues se fundan en la concepción que para llegar del punto $\mathrm{A}$ al punto $\mathrm{B}$, de manera indefectible, se debe recorrer un encadenamiento ininterrumpido de pasos. Así, según el autor, esta concepción determinista del mundo se irrigó del campo de la física al de otras ciencias, quienes gustosas acogieron la promesa seductora de las leyes; tal es el caso de la Sociología, la Historia, la Economía, etcétera, ésta última evidenciada en la ideología marxista que retoma los fundamentos de la Física clásica: continuidad, causalidad local, determinismo y objetividad. ${ }^{25}$

La complejidad, de la mano con la transdisciplinariedad, ha llegado a incomodar a una gran cantidad de ciencias y disciplinas que prometían conocer y dominar las "reglas del juego"; sin embargo, como lo esbozan los artículos cuarto y quinto de la Carta de la Transdisciplinariedad: "la piedra angular de la transdisciplinariedad reside en la unificación semántica y operativa de las acepciones a través y más allá de las diferentes disciplinas" y "la visión transdisciplinaria es definitivamente abierta en la medida en que trasciende el campo de las ciencias exactas las estimula para que dialoguen y se reconcilien, no solamente con las ciencias humanas sino también con el Arte, la Literatura, la Poesía y la experiencia interior", 26 estamos ante un nuevo modo de ver el mundo, las relaciones humanas, la Ética, la Lógica, la Economía, la Política y la Filosofía.

23 Basarab Nicolescu, op. cit., p. 7.

24 Idem.

25 Ibid., p. 11.

26 Ibid., pp. 121-122. 
El autor advierte, en esta misma carta, que: "rigor, apertura y tolerancia son las características fundamentales de la actitud y visión transdisciplinaria. El rigor en la argumentación que toma en cuenta toda la información disponible es la mejor barrera contra toda posible deriva. La apertura implica la aceptación de lo desconocido, lo inesperado y lo imprevisible. La tolerancia es el reconocimiento del derecho a las ideas y verdades opuestas a las nuestras". ${ }^{27}$

\section{¿Por qué es necesaria, en el siglo XXI, la sabiduría?}

Consideramos que ante las amenazas de guerras nucleares, las centrales atómicas y el daño a la naturaleza, la humanidad por primera vez se encuentra ante el panorama de su propia autodestrucción. Estamos en un viaje sin retorno; con la tecnología actual hemos llevado a cabo tal deterioro de la naturaleza, como son los mares de plástico que contaminan a nuestros océanos o la extinción de especies de la naturaleza, así como la pérdida de bosques en la tierra, tanto como los arrecifes coralinos en el mar.

Por nuestra parte, disentimos de Harold Bloom, en el sentido que no es correcto hablar de sabiduría, sino que procede mencionar sabidurías, así la sabiduría exige originalidad, honestidad, asombro, profundidad y modestia. En cada campo se requiere agregar una cualidad como, por ejemplo, la prudencia en el campo jurídico, lo que implica distinguir el bien del mal, en lo político el sentido del bien común, por encima del interés privado o de grupo, en la medicina, el respeto a la vida, pero también a una muerte digna, alejada de la distanasia; en lo económico la justicia social contemplada por Aristóteles; en nuestra relación con la naturaleza, el consumo prudente llamado decrecimiento; en la filosofía la profundidad del pensamiento y la acción congruente con la calidad del ser humano como Heidegger y Ortega y Gasset lo señalaron, al alertarnos en no ser Uno o el hombre masa que no piensa por sí mismo, sino que se deja llevar por las habladurías, los medios masivos de comunicación y los grandes intereses de las corporaciones; al respecto, debemos señalar que la sabiduría de Heidegger, con su andar filosófico ontológico, fue enorme, tanto que junto con Ludwig Wittgenstein está considerado como uno de los dos más grandes pensadores del siglo pasado; sin embargo, su sabiduría en el lenguaje fue enorme al crear nuevas palabras y filosofemas como Dasein, pero en términos morales y políticos fue nula, en virtud de que se

27 Ibid., p. 14. 
afilió al nazismo y fue amante de su alumna, Hanna Arendt, entre otras torpezas que cometió en su vida, como fueron sus rompimientos con su maestro Edmund Husserl y con varios de sus alumnos.

Lo mencionado anteriormente, es un señalamiento de que puede uno tener un tipo de sabiduría y carecer de otras; otro es el caso de Emmanuel Kant, quien al tener una gran sabiduría filosófica, al estudiar su vida, se da cuenta de la ausencia de ese impulso vital que es la libido; en Jenofonte, encontramos una gran sabiduría guerrera, sin embargo como alumno querido de Sócrates, los trabajos que nos han llegado muestran que su sabiduría filosófica no existió; en el caso de ese gran guerrero que fue Napoleón, sus carencias morales quedaron de manifiesto al traicionar los ideales universales de la Revolución francesa; también es pertinente señalar casos como los de Vincent Van Gogh o Paul Gauguin ${ }^{28}$ (aquí Bloom, aunque hizo varios intentos para explicar el caso de Van Gogh, definiéndolo como una personalidad con gran compresión emocional por nuestra parte, consideramos que el budismo zen ${ }^{29}$ nos da una mejor respuesta desde la filosofía oriental con la integración del pintor con la naturaleza o los objetos que pinta), quienes siendo poseedores de una gran sabiduría pictórica sus vidas fueron tragedias humanas.

En la música, nos encontramos con grandes artistas como Wolfgang Amadeus Mozart o Ludwig van Beethoven, ${ }^{30}$ que en lo económico padecieron muchas dificultades que no fueron de acuerdo con su sapiencia musical. Johann Wolfgang von Goethe abarcó la literatura con su Fausto, en la Administración pública, en el lenguaje, en el Teatro, en la Política y en la Filosofía; sin embargo, en el campo de las emociones, en concreto en el amor, la sapiencia brilló por su ausencia en el caso de Ulrike von Levetzow, pues a los 73 años quiso casarse con esta jovencita de 17 años, solicitó Goethe al gran duque de Saxe-Weimar-Eisenach, Carlos Augusto, que pidiera su mano, lo que la joven rechazó, con más sapiencia que el viejo Goethe, y la historia nos cuenta que ella nunca se casó; lo positivo de esta decisión insana de Goethe fue que en su dolor compuso la Elegía de Marienbad, uno de los poemas más bellos que logró escribir.

28 Cayetano Aranda Torres, Introducción a la estética contemporánea, España, Universidad de Almería, 2004 , p. 91.

29 D.T. Suzuki y Erich Fromm, Budismo Zen y psicoanálisis, México, Fondo de Cultura Económica, 1998, p. 123.

30 Juan Plazaola, Introducción a la estética. Historia, Teoría, Textos, Bilbao, Universidad de Deusto, 2007, p. 591. 
Conforme las biografías que tenemos de Albert Einstein, su vida familiar fue desastrosa; Georg Wilhelm Friedrich Hegel une sapiencia filosófica con estupidez racista y elitismo; de Edgar Allan Poe podemos mencionar su sapiencia literaria y su trágica vida personal, perdida en el alcoholismo.

Han existido en la historia de la humanidad seres humanos que han poseído varias sabidurías a la vez, como el caso de William Shakespeare, grandioso en la tragedia, en la comedia y en el manejo del lenguaje, pues se estima que manejó 21,000 palabras distintas, de las cuales 1,800 fueron creadas por él; o Leonardo Da Vinci, enorme en la pintura, escultura, ingeniería, anatomía, etcétera.

Desde la literatura, Harold Bloom en su libro ¿Dónde se encuentra la sabiduría?, obra que escribió muy enfermo y ante el temor muy elevado de una próxima muerte, ${ }^{31}$ se dio a la tarea de buscar en dónde está ella presente, y la encontró en diversos autores y libros como La Biblia, en especial en Job y el Eclesiastés; Homero y Platón, junto con Sócrates por lo que respecta a la Grecia antigua; Cervantes, Shakespeare, Montaigne y Francis Bacon, en el siglo XVI; Samuel Johnson, Goethe, Emerson y Nietzsche, en el siglo XIX; y Freud y Proust en el siglo XX; lo que encontramos en común en los escritores mencionados, es que lograron alcanzar el nivel sapiencial por medio de sus obras.

En el libro de Job, capítulo 28, 12-28 menciona "mas la sabiduría, ¿de dónde viene?, ¿Cuál es la sede de la Inteligencia? Ocúltase a los ojos de todo ser viviente... Mira, el temor del Señor es la Sabiduría, huir del mal, la Inteligencia". ${ }^{32}$ En Job la sabiduría se manifiesta como la confianza de él, en que su Dios no lo abandonará, a pesar de que sobre su persona habían caído todos los males, con su esposa en contra, quien le reclama lo poco que cuida de él Dios y le recomienda que se muera; sin embargo, Job, como una roca, no pierde ni un segundo su confianza en el Señor; al final, logra derrotar al enemigo real con el que se enfrentaba, que era el Diablo. Aquí la sabiduría proviene de Dios y es la primera afirmación con la que nos encontramos.

En el Eclesiastés, Salomón explica que ha aplicado su corazón a investigar y explorar con la sabiduría cuanto acaece bajo el cielo, afirma que posee una sabiduría grande y extensa, mayor que la de todos sus

31 Harold Bloom, ¿Dónde se encuentra la sabiduría?, trad. Damián Alou, Madrid, Punto de lectura, 2006, p. 65.

32 Francisco Serrano, El libro de Job. Fragmentos, consultado en <https://www.francisco-serrano.com/ translation/job.pdf>, el 16 de junio de 2019, p. 41. 
predecesores en Jerusalén, su corazón ha contemplado mucha sabiduría y ciencia, así como la locura y necedad, y concluye que "donde abunda la sabiduría, abundan penas y quien acumula ciencia, acumula dolor" ${ }^{33}$

Continúa el libro señalado con palabras sabias como "vanidad de vanidades, todo es vanidad"; de igual manera enuncia su tan conocido poema Tiempo de nacer y tiempo de morir:

... tiempo de llorar y tiempo de reír, tiempo de abrazarse y tiempo de separarse, tiempo de encontrar y tiempo de perder, tiempo de sembrar y tiempo de cosechar, tiempo de amar y tiempo de odiar, tiempo de guerra y tiempo de paz... ${ }^{34}$

Si para confirmar la sabiduría de Job hay que pagar un precio muy alto, en Salomón toda sabiduría se vuelve personal, fragmentos de una confesión que contempla igualmente matices de la sabiduría de la aniquilación, comparables con el propio Shakespeare en sus tragedias, como culminación de la literatura sapiencial. ${ }^{35}$

En la tradición literaria griega, con Platón, encontramos una disputa sobre la fuente de la sabiduría; él consideraba que los filósofos no necesitaban poesía, al condenarla por falta de realidad y por incitar el deseo erótico; en La República considera que Homero debe quedar fuera de toda sociedad. ${ }^{36}$ La sabiduría de Sócrates en Los Diálogos se manifiesta varias veces, su muerte es un ejemplo cuando se niega a escapar, pues considera que debe cumplir la ley, aunque sea injusta.

Con Cervantes y Shakespeare, los escritores occidentales considerados por Bloom como los maestros de la sabiduría, encontramos en sus obras cumbre, El Quijote y Hamlet, la supremacía que los distingue de todos los escritores desde el Renacimiento hasta nuestros días. Don Quijote es un espejo que no se pone delante de la naturaleza, sino del lector, constituyéndose como un paradigma universal. La verdad estética que prevalece en el Quijote hace que nos enfrentemos con la grandeza y lo considera como un sabio entre sabios. Por su parte, el prínci-

33 Salomón, El Eclesiastés o El predicador, consultado en <http://hopeinjesus.com.au/wp-content/ uploads/2014/02/21.-Eclesiastes.pdf>, el 16 de junio de 2019, p. 7.

34 Ibid., p.30.

35 Harold Bloom, op. cit., p. 30.

36 Platón, La República, Barcelona, Alianza Editorial, 2018, p. 78. 
pe Hamlet, inteligente más allá de la inteligencia, ${ }^{37}$ refleja la soltura de Shakespeare para crear el lenguaje y construir la realidad a través de los claroscuros de sus personajes.

Deseamos resaltar una idea extraordinaria que de la lectura ofrece Bloom, al mencionar que leemos para reparar nuestra soledad, pues en la práctica cuanto mejor leemos más solitarios nos volvemos; sin embargo, no considera la lectura como un vicio o una virtud, aunque la razón más profunda para leer tiene que ser la búsqueda de la sabiduría. ${ }^{38} \mathrm{La}$ sabiduría mundana, aclara, rara vez es sabia, o prudencial, aunque con Shakespeare tenemos al más sabio de los maestros, y lo apreciamos en $\mathrm{El}$ rey Lear, cuando se confronta con el ciego Gloster, mencionándole "Por eso pedí y se me concedió la prudencia; supliqué y me vino el espíritu de la sabiduría" ${ }^{39}$ ¿es entonces la sabiduría prudencia y humildad ? Lo que afirma el rey nos invita a reflexionar sobre esa pregunta.

La sabiduría de los sucesos, como los cataloga Bloom, los encontramos con Montaigne y Bacon, entendiendo a estos como los pensamientos plasmados en los ensayos personales, donde evidencia la abrumadora franqueza de su sabiduría. ${ }^{40}$ Lo que Montaigne ofrece va más allá de la sabiduría; invita a aumentar tu conocimiento sobre ti mismo. El autor reconoce que los ensayos son algo tan completo como nos parecen las obras de teatro y los poemas de Shakespeare, ${ }^{41}$ calificándolo como un mentor sabio que nos da fuerzas para vivir nuestra vida, pues los que busca sin cesar es la naturaleza del hombre. El autor asegura que Montaigne es sereno en su libertad de aprender sabiduría estudiándose a sí mismo, ${ }^{42}$ de ahí surge una de sus frases célebres: "yo mismo soy la materia de mi libro". ${ }^{43}$ Así, afirma que la sabiduría cura la melancolía, sólo con que seamos capaces de permitir que nuestro duelo y nuestro dolor se vean aliviados; ${ }^{44}$ sin embargo, con el padre del ensayo observamos un camino que se aleja de lo concebido por Job, sobre dónde encontramos la sabiduría, pues con su héroe, con su Sócrates, rescata la sabiduría humana del destierro celestial, quien activa una riqueza que ya es nuestra; no nos trae dialéctica ni virtud, sino un estado espiritual, que es una fuerza única, dirigida hacia sí. Esa fuerza, y no el temor a

37 Harold Bloom, ¿Dónde se encuentra..., op. cit., p.130.

38 Ibid., p. 132.

39 William Shakespeare, El Rey Lear, Madrid, Alianza Editorial, 2018, p. 124.

40 Harold Bloom, ¿Dónde se encuentra..., op. cit., p. 155.

41 Ibid., p. 159.

42 Michel de Montaigne, Los ensayos, Barcelona, Acantilado, p. 12.

43 Harold Bloom, Genios..., op. cit., p. 792

44 Harold Bloom, ¿Dónde se encuentra..., op. cit., p. 172 
Dios, es el comienzo de la sabiduría. ${ }^{45}$ Este estado espiritual que refiere, es precisamente lo que sostenemos como elemento de compresión del ser humano desde el pensamiento complejo, aunque disentimos que este sea el único componente sapiencial del hombre.

Con Francis Bacon, desde la percepción de Shelley, encontramos un lenguaje, cuyo ritmo dulce y majestuoso, satisface los sentidos del mismo modo que su sabiduría casi sobrehumana satisface el intelecto; ${ }^{46} \sin$ embargo, Bloom reconoce en Lord Bacon un escritor sapiencial valioso, aunque no comparable con Montaigne, cuando afirma que "Bacon era quizá tan desagradable como brillante, original e incapaz de amar a nadie" ${ }^{47}$ confirma la tesis, que sostenemos en párrafos precedentes, sobre la posibilidad del ser humano de poseer un tipo de sabiduría y carecer de otras, apoyado dicha aseveración tenemos la caracterización que del él hace Alexander Pope, calificándolo como "el más sabio, brillante y mezquino de los hombres". ${ }^{4}$ Su incapacidad manifiesta de sostener relaciones personales sanas, se refleja en su concepción del amor, al considerarlo como "la destrucción de la sabiduría".49

En Samuel Johnson tenemos a un sabio cristiano que, a consideración de Bloom, es el mejor de todos los críticos literarios, demostrando la naturaleza de dicha sabiduría en La historia de Rásselas, príncipe de Abisinia, donde el núcleo de su filosofía memorable y mordaz ${ }^{50}$ se condensa en el pensamiento de Imlac, exponiendo la tendencia del autor a la locura y profunda melancolía, cuando esboza "paulatinamente el reino de la fantasía se afianza; primero se hace poderosa y, con el tiempo, despótica. Luego las ficciones comienzan a obrar como realidades, los falsos prejuicios arraigan en la mente y la vida se pasa en sueños de arrobamiento o de angustia. Este, señor, es uno de los peligros de la soledad que, según confesó el eremita, no siempre fomenta la bondad, y que, como la desgracia del astrónomo ha probado, no es siempre propicia a la sabiduría". ${ }^{51}$

Confirmamos que se puede estar en posesión de la más elevada sabiduría literaria y estar privado de la que alegra el espíritu y reconforta el alma; Johnson temía a la agonía y muerte, a pesar de ser un devoto cristiano, pero

45 Podemos encontrar ese pensamiento en la Biblia, libro de Proverbios, versículos 9:10.

46 Percy B. Shelly, La necesidad del ateísmo y otros escritos de combate, trad. Julio Monteverde, España, Editorial Pepitas de Calabaza, 2015, p. 23.

47 Harold Bloom, ¿Dónde se encuentra..., op. cit., p. 185.

48 Ibid., p. 186

49 Alexander Pope, Ensayo sobre el hombre y otros escritos, trad. Ángeles García Calderón, Madrid Catedra, 2017, p. 65.

50 Harold Bloom, ¿Dónde se encuentra..., op. cit., p. 211.

51 Samuel Johnson, La historia de Rásselas, Príncipe de Abisinia, España, Ediciones del viento, 2017, p. 144. 
temía aún más una crisis de sus facultades intelectuales; a los setenta y cinco años su mente tenía más vitalidad que nunca; sin embargo, no consiguió aliviar sus angustias, ${ }^{52}$ por ello consideramos que con la vejez son necesarias la serenidad y prudencia.

En contraposición a Johnson, Bloom nos presenta a Johann Wolfgang von Goethe, de quien explora su sabiduría basada en el reconocimiento de que más importante es el misterio accesible, lo que puede sugerirse, pero no afirmarse..$^{53}$ Esta postura la traduce como la renuncia al deseo, arrojando la sugerente pregunta ¿es la sabiduría, entonces, nada más que otra renuncia a la apetencia? Esa "renunciación" tiene su escandaloso retrato en su Trilogía de la pasión, en donde plasma el profundo arrebato extático ${ }^{54}$ de su afán por desposar a Ulrike von Levetzow que contaba con 17 años cuando él era ya un septuagenario.

Alfonso Reyes reconoce la conveniencia de entender a Goethe como un caso de simultaneidad prodigiosa, pues dejó trazados mil senderos: el lirismo personal, el drama gótico, el romanticismo, la moderna tragedia, un nuevo clasicismo y el concepto de la "literatura mundial", así como el entendimiento filosófico de la ciencia. ${ }^{55}$ Sin embargo, su postura elitista, dice Bloom, lo coloca muy lejos de la humildad cristiana, esa cualidad que describimos al inicio de este trabajo.

En el siglo XIX nos encontramos con Ralph Waldo Emerson, quien después de abandonar su profesión como pastor unitario se dedicó a la escritura sapiencial, teniendo como inspiración los trabajos de Plutarco, Montaigne, Shakespeare, etcétera. "Leí en busca de esplendor" es una de las frases de Emerson más asiduamente citadas por el autor en su cátedra; reconoce que precisamente de esplendor llenó sus cuadernos. A pesar de reconocer la profundidad de lo esbozado en Confianza en sí mismo, en la heideggeriana frase "solo la vida nos es provechosa, no el haber vivido"; no obstante, debemos unirnos a Bloom en reconocer la genialidad de su ensayo Destino, perteneciente a La conducta de la vida, en donde plasma: "el hombre tampoco puede ignorar el libre albedrío. Para arriesgarse a la contradicción: la libertad es necesaria. Si deseas colocarte del lado del Destino, y decir: el Destino es todo; enton-

52 Harold Bloom. ¿Dónde se encuentra..., op. cit., p. 215.

53 Ibid., p. 228.

54 Ibid., p. 231.

55 Alfonso Reyes. Trayectoria de Goethe, México, Fondo de Cultura Económica, 2014, pp. 167-168. 
ces podemos decir, una parte de Destino es la libertad del hombre. En el alma siempre brota el impulso de elegir y actuar. El intelecto anula el destino. En la medida en que un hombre piensa, es libre" ${ }^{56}$

En Nietzsche reconoce una sabiduría miscelánea, que se vio eclipsada por la potencia cultural de Emerson y Goethe, causando que se redujera precisamente su confianza en sí mismo, aunque no por ello se desprendió de su calidad soberbia de escritor sapiencial; Bloom menciona que la suya es una sabiduría situada en el extremo. ${ }^{57} \mathrm{~A}$ pesar de lo cuestionable y trágica que fue la vida del filósofo, la conexión de su pensamiento con la Biblia hebrea y con Freud es el instinto de encontrar sentido en todo e interpretarlo. ${ }^{58}$ Una de sus aportaciones más perturbadoras es la sabiduría de la poética del dolor, argumentando que "el poema memorable por excelencia es aquel que tiene más de un sentido o da origen a más sentido, es el poema que produce más dolor" ${ }^{59}$

En el siglo XX, tomando en cuenta el criterio de Bloom, tenemos una figura que representan la sapiencia que mencionamos en párrafos precedentes de una manera singular; Sigmund Freud, el padre del psicoanálisis, quien no teniendo la calidad de poeta o filósofo, sino una inclinación evidente a la ciencia, fácilmente compite con Proust, Joyce y Kafka, ${ }^{60}$ situándose muy por encima de cualquier figura religiosa o erudito de este siglo. ${ }^{61}$ Apoyando dicha aseveración tenemos a Juan Rof Carballo, autor de Biología y psicoanálisis, quien, en la introducción al tomo primero de las Obras completas de Freud, menciona "es evidente que hay algo enigmático en esta poderosa vitalidad del pensamiento de Freud, en su fecundidad que ha llegado a penetrar por todos los resquicios de nuestra civilización y que se expresa en la novela, en la crítica literaria, en el cine, en la mentalidad de la gente, en la ciencia". ${ }^{62}$ La incapacidad que humildemente reconoce Bloom para caracterizar con precisión a Freud, se debe a que su ciencia, no siendo primordialmente poético-especulativa ni terapéutico-empírica, se halla en la frontera entre todas estas disciplinas. ${ }^{63}$

56 Harold Bloom, ¿Dónde se encuentra..., op. cit., p. 260.

57 Harold Bloom, ¿Dónde se encuentra..., op. cit., p. 263.

58 Ibid., p. 271.

59 Ibid., p. 275.

60 Sostiene Jürgen Habermas que Freud, en realidad, lo que hace es fundar una nueva ciencia humana, pero una ciencia humana que no deja nunca de ser ciencia natural. Sigmund Freud, Obras completas, tomo I, España, Editorial Biblioteca Nueva, 1973, p. XIX.

61 Harold Bloom, ¿Dónde se encuentra..., op. cit., p. 279.

62 Sigmund Freud, op. cit., pp. XIX-XX.

63 Ibid., p. 285. 


\section{La sabiduría en la literatura prehispánica y mexicana}

No podemos dejar de mencionar la sabiduría de nuestros grandes filósofos y pensadores, se considera oportuno el paralelismo que menciona Miguel León Portilla cuando afirma: "Sucede con los nahuas lo mismo que con los griegos, donde fueron precisamente los poetas líricos los que empezaron a tomar conciencia de los grandes problemas que rodean la comprensión del mundo y del hombre", ${ }^{64}$ iniciando con los tlamatinime $^{65}$, tenemos al rey tezcocano Nezahualcóyotl, a quien califica como un sabio preocupado sobre la fugacidad de lo que existe y sus ideas en relación con Tloque Nahuaque, el Dueño del cerca y del junto, esa fugacidad la refleja en su poema:

¿Acaso de verdad se vive en la tierra?,

No para siempre en la tierra: sólo un poco aquí,

Aunque sea jade se quiebra,

Aunque sea oro se rompe,

Aunque sea plumaje de quetzal se desagarra,

No para siempre en la tierra: sólo un poco aquíi ${ }^{\prime 6}$.

Comprobamos que la meditación sobre la transitoriedad de lo que sobre la tierra existe, fue tema fundamental y punto de partida de las elucubraciones del rey; sin embargo, es menester mencionar la profundidad de su pensamiento y su concepción de sabiduría reflejada en la erudita expresión "flor y canto". Dicha frase, reiteradamente mencionada en los poemas de diversos tlamatinimes, tiene un sentido profundamente sapiencial. Un análisis del modismo o complejo idiomático náhuatl, menciona Portilla, logra aclarar su genuino significado, "in Xóchitl y cuicatl", se le asigna como significado literal flor y canto, y como sentido metafórico el de poema. ${ }^{67}$ Esta metáfora la podemos entender como un peculiar modo de conocimiento, fruto de una auténtica experiencia interior. ${ }^{68}$ Afirma el autor que los tlamatinime llegaron a formular en sus poemas una auténtica teoría acerca del conocer metafísico, en contraposición a la transitoriedad universal, hay un modo de conocer lo verdadero: la poesía.

64 Miguel León-Portilla, La filosofía náhuatl estudiada en sus fuentes, México, UNAM, 2006, p. 5.

65 En náhuatl quiere decir los conocedores de las cosas.

66 Miguel León-Portilla, La filosofía náhuatl..., op. cit., p. 60.

67 Ibid., p. 143.

68 Idem. 
Sobre esta postura, León Portilla se apoya en García Baca, quien al comentar el libro de Heidegger, La Esencia de la Poesía, nota: "Metá-fora y Meta-física son el fondo y raíz una sola función: poner las cosas más allá (meta) plus ultra", ${ }^{69}$ por ello consideramos que la poesía en la cultura náhuatl era una expresión no solamente de conocimiento, sino de sabiduría pura.

Debemos mencionar el poema célebre que constituye la más alta expresión en sabiduría en Nezahualcóyotl; sin embargo, no deseamos omitir la mención de la gran polémica en torno a esta obra maestra; a consideración de muchos investigadores su autoría no se debe de reputar al gobernante en cuestión, por considerarlo un pensamiento con un trasfondo altamente cristiano, no obstante su carga simbólica lo hace merecedor de reconocimiento:

Amo el canto del cenzontle, pájaro de cuatrocientas voces Amo el color del jade y el enervante perfume de las flores, Pero amo más a mi hermano el hombre.

En el siglo XVII debemos reconocer la enorme sabiduría de Juana de Asbaje Ramírez, conocida posteriormente como Sor Juana Inés de la Cruz, extraordinaria mujer dedicada al estudio que supo reconciliar aquello que Platón repudiaba, la dulzura de la poesía a la hondura de la Filosofía. ${ }^{70}$ Poseedora de una de las bibliotecas más completas de su tiempo, con alrededor de 4000 volúmenes relativos a materas filosóficas, conocía a fondo no solamente la filosofía escolástica, sino también las ideas modernas de la filosofía, teniendo una poderosa influencia de Descartes. Su pensamiento condensado, que es de una hondura poco común, ${ }^{71}$ reflejan una gran prudencia y la colocan como uno de los bastiones del pensamiento feminista en Hispanoamérica, pues reconoce en sus versos la defensa a la libertad de crítica y el derecho de la mujer mexicana a la cultura. En Sor Juana Inés de la Cruz encontramos tanta sabiduría como modestia, lo cual constituye las dos caras de una misma moneda.

Otra de las figuras que vale la pena destacar en esta breve exégesis de intelectuales, es Ignacio Ramírez, "El Nigromante", quien a pesar de no ser un filósofo en estricto rigor, fue un indudable literato que lo llevo a ser considerado como uno de los grandes clásicos del siglo XIX, llegando a ser conocido como el "Voltaire Mexicano"y demostró su noble sapiencia en diversas posturas, en principio al ser uno de los pocos soldados

69 Juan David García Baca, "La esencia de la poesía en Heidegger", en Separata, Revista Nacional de Cultura, núm. 112, septiembre-diciembre, 1955, p. 146.

70 Antonio Ibargüengoitia, Filosofía Mexicana, México, Porrúa, 1967, p. 65.

71 Ibid., p. 66. 
de la República que, a pesar de apoyar las ideas liberales, sostuvo que se cometía una barbarie al fusilar a Maximiliano de Habsburgo, también albergó serias y sinceras preocupaciones por formar una patria nueva ${ }^{72}$ en la que se integrara a los indígenas, a los que el gobierno tenía olvidados. Encontramos en Ignacio Ramírez las mismas inquietudes en el que tal vez sea el filósofo más importantes de la historia, Aristóteles, pues apreciamos en sus Estudios Metafísicos, su interés por el ser, la sustancia y el tiempo cuando afirma: "El objeto eterno de todas las investigaciones, tanto las pasadas como las presentes, que se encuentran en esta pregunta: ¿Qué cosa es el ser? Se reduce a esta otra cuestión: ¿Qué es la sustancia?... La sustancia es un principio y una causa; de este punto de vista debemos partir...Es imposible que el movimiento haya comenzado o que termine algún día: lo mismo sucede con el tiempo pues si no existiese como actual, sería imposible como futuro y como pasado...." ${ }^{73}$

En el siglo XIX encontramos a Ignacio Manuel Altamirano, identificado como uno de los más brillantes ideólogos liberales, cuyos escritos literarios reflejan el profundo sentido filosófico de una sapiencia profunda, ${ }^{74}$ en su discurso, pronunciado en la sesión extraordinaria que celebró la Sociedad Mexicana de Geografía y Estadística, la noche del 24 de octubre de 1877, en honor de Thiers, ${ }^{75}$ afirma: "Hay, señores, vosotros lo sabeís bien, una cosa más grande que la vida física, y es la vida de las ideas. En ella Thiers es inmortal, su espíritu está con su pueblo y se complace hoy en recibir los homenajes que el género humano tributa a sus virtudes". ${ }^{76}$

Para Altamirano, las características que definen la sabiduría, enunciadas en líneas precedentes, también representaban una guía para clasificar a los hombres que la encontraban, por ello reconoce que “ $\mathrm{iLa}$ gloria que no puede ser patrimonio sino de los grandes hombres de bien! Thiers era un hombre de bien, era un genio, era un patriota. He aquí el por qué se hoy fraternizan en sus sentimientos e admiración, con el pueblo francés todos los pueblos" ${ }^{77}$

Con el campechano Justo Sierra Méndez, abogado de profesión, pero dedicado a las letras, al magisterio y a la política, tenemos una muestra de su pensamiento en uno de los actos culturales más importantes de

72 Ibid., p. 159.

73 Ignacio Ramirez, Estudios Metafísicos, México, El correo de México, 1867, p. 93.

74 Antonio Ibargüengoitia, op. cit., p. 171.

75 Adolphe Thiers (1797-1877) fue un historiador y político francés. Varias veces fue primer ministro en el reinado de Luis Felipe de Francia. Posterior a la caída del Segundo Imperio, se convirtió en presidente provisional de la Tercera República Francesa y ordeno la supresión de la Comuna de París en 1871.

76 Ignacio Manuel Altamirano, Discursos, París, Biblioteca de la Europa y América, 1972, p. VII.

77 Idem. 
nuestro siglo ${ }^{78}$, "La Universidad no puede ser una educadora en el sentido integral de la palabra; la Universidad es una simple productora de ciencia, es una intelectualizadora; solo sirve para formar cerebrales", ${ }^{79}$ por ello menciona que es tarea de nuestra "institución universitaria demostrar que nuestra personalidad tiene raíces indestructibles en nuestra naturaleza y en nuestra historia", ${ }^{80}$ debe indefectiblemente cultivar intensamente en los estudiantes "el amor puro de la verdad". ${ }^{1}$

Debemos reconocer que su sabiduría residía en la capacidad de plasmar, de manera estética, su sentir, cuando afirma que

la Universidad está encargada de la educación nacional en sus medios superiores, es la cima en que brota la fuente, clara como el cristal de la fuente horaciana; que baja a regar las plantas germinadas en el terruño nacional y sube en el ánima del pueblo, por alta que éste la tenga puesta ${ }^{82}$

Apreciamos su alta sensibilidad y se pone de manifiesto su fe en la acción creadora del pensamiento. Para Justo Sierra la sabiduría puede, y debe, buscarse en la escuela, ya que constituye "el peldaño más alto del edificio universitario, puesto así para descubrir en el saber los horizontes más dilatados, más abiertos, como ésos que sólo desde las cimas excelsas del planeta pueden contemplarse". 83

En el siglo XX no podemos dejar de hacer mención a una de las figuras que, a consideración del autor, encarnó la utilidad del trabajo del filósofo para la humanidad, José Vasconcelos, quien a lo largo de su fecunda vida intelectual, recorre el arduo camino que comienza en el positivismo, encontrándose después con el pensamiento espiritualista de Bergson y, en su marcha hacia la verdad, hacia un sistema organizado de pensamiento escribe sobre ética y metafísica. ${ }^{84}$ Procuró promover la figura de un mexicano con una perspectiva nueva, que asumiera como soporte la esencia de la patria, conociendo sus raíces hispanas e indígenas y a partir de esta sabiduría, plasmada en su teoría sobre Raza

78 Antonio Ibargüengoitia, op. cit., p. 183.

79 Justo Sierra, Inauguración de la Universidad Nacional, Biblioteca Virtual, consultado en <http://www. biblioteca.org.ar/libros/1287.pdf> el 19 de junio de 2019, p. 3.

80 Ibid., p. 5.

81 Idem.

82 Idem.

83 Ibid., p. 11.

84 José Vasconcelos, Tratado de metafísica, México, Trillas, 2009, p. 83. 
Cósmica, la que le abrió las puertas del Doctorado Honoris Causa en casi todas las universidades de América del Sur, ${ }^{85}$ pronunció a favor de todo lo humano en decididas maneras de superación.

\section{Edgar Morin}

¿Quién es Edgar Morin? Esta pregunta, formulada de maneras diversas a lo largo de la brillante conversación sostenida con Djénane Kareh Tager en el libro Mi camino, nos ayuda a comprender la sapiencia del padre de la complejidad, sus miedos, pasiones, amores y desamores, su singularidad y genialidad. Morin afirma que, ante todo, es hijo y temprano huérfano de su madre que murió en su infancia, de un padre que murió en su 63 aniversario, producto de sus propios actos que lo hicieron Edgar Morin, hijo de la tierra, de la Pachamama de los Incas. Como segunda respuesta aduce que es un ser medio, un espécimen no muy singular de la raza humana, lo que hace aparente su singularidad. Al decir que es un ser medio se refiere la propia conciencia de sus carencias, debilidades e idiotez, "por ello huyó a lo largo de sus diarios de edificar su propia estatua" ${ }^{86}$

Reconoce que esa calidad de hombre medio se fundamenta en varias características, la primera es una inteligencia media, sin genio particular, la segunda es su cultura universalista, ${ }^{87}$ a donde va no siente la extranjeridad de los otros que pueden verle como extranjero, pues prueba todas las diferencias. A la pregunta auto formulada: ¿quién soy?, afirma "soy yo, y al mismo tiempo todos los demás; soy todos los que he conocido, soy la humanidad". 8

Ante la interrogante que esboza la necesidad de conocer el conocimiento, Morin responde que este conlleva siempre un riesgo de error o de ilusión, afirmando que el conocimiento es el objeto mas incierto del conocimiento filosófico y el objeto menos conocido del conocimiento científico, ${ }^{89}$ sin embargo menciona que su libro El conocimiento del conocimiento, aborda sólo el estudio de una antropología del conocimiento, lo que debemos entender como respuesta a esta pregunta constituye el núcleo de El método, lo que plasma en Las ideas, pues afirma que

85 Antonio Ibargüengoitia, op. cit., p. 241.

86 Edgar Morin, Mi camino. La vida y obra del padre del pensamiento complejo, Barcelona, Gedisa, 2008, p. 280.

87 Ibid., p. 274.

88 Idem.

89 Ibid., p. 175. 
"las grandes ideas viven como los dioses, al igual que los dioses son producto de las mentes humanas, pero también, al igual que los dioses, adquieren potencia y realidad". ${ }^{0}$

Sobre Tierra-patria, el autor menciona que trató de concebir la era planetaria, noción que tiene como inspiración a Heidegger y pretende esbozar a la globalización, como una conciencia de interdependencia entre las diversas partes del mundo, calificándola, a su vez, como bárbara y civilizada. Sin embargo, Morin manifiesta que esta situación conlleva un mensaje, que es el de salvar las diversidades culturales, pero contemplando la unidad humana, y, como no podría ser de otra manera con el pensamiento de este autor, dicho mensaje es doble, pues esa unidad no deber ser solamente tecnoeconómica o monocivilizacional, ya que se trata de una unidad de tierra-patria, la que comprende el respeto de las diversidades. ${ }^{91}$

Para Álvaro Cepeda Neri, francés-universal erudito, amante de todo lo humano como sociólogo-antropólogo, no conoce límites para abordar el más amplio haz de temas de la cultura mundial. ${ }^{92}$ Desde nuestro punto de vista, para encontrarnos en posibilidad de comprender a Morin, debemos conocer su camino, tumultuoso por decir poco; el impacto de sus pérdidas; como la de su madre a los 10 años, hecho que marco profundamente su espíritu y circunstancia que lo llevo al reconfortante cobijo de los libros; debemos entender las dificultades de su adolescencia y juventud, envuelto en acciones militares como miembro de la Resistencia francesa, en donde llegó a ser teniente coronel, durante la Segunda Guerra Mundial; estudiar su incansable lucha social, como miembro del Partido Comunista Francés y su desilusión ante el estalinismo; bosquejar su vena combativa ante las injusticias, conocer sus amores, Violette Chapellaubeau, Joahnne y Edwige L. Agnes, y apreciar su inmenso cariño por la academia y sus alumnos, a la cual ha dedicado más de la mitad de su vida.

Estos antecedentes nos auxilian en la atrayente idea de conocer y comprender al padre del pensamiento complejo, pues al recorrer su vida a través de sus diversas biografías, logramos bosquejar la manera

90 Idem.

91 Edgar Morin, Mi camino..., op. cit., Barcelona, Gedisa, 2008, p. 196.

92 Álvaro Cepeda Neri, "Vida y obra del pensador inconformista Edgar Morin, por Emmanuel Lemieux", en Contralínea, disponible en <https://www.contralinea.com.mx/archivo-revista/2018/01/25/vida-obra-del-pensador-inconformista-edgar-morin-emmanuel-lemieux/> consultada el 1 de julio de 2019. 
en que Morin ve el mundo desde una perspectiva indisociable, apreciando el todo, las partes, los procesos que las retroalimentan y las conexiones que existen entre unas y otras.

\section{Metodología de la complejidad}

Harold Bloom, en una obra anterior a su infarto, intitulada Genios. Un mosaico de cien mentes creativas y ejemplares, ${ }^{93}$ explica que "el genio literario es difícil de definir y depende de una lectura profunda para su verificación", y lo relaciona con la creatividad originaria; sin embargo les faltan a estos seres en muchas ocasiones cualidades como la ética, prudencia y sencillez, que impiden que los consideremos como sabios conforme los elementos que señalamos como indispensables para llegar a alcanzar dicha calidad.

Edgar Morin irónicamente llamó El método a su obra cumbre de seis volúmenes, sin que en ninguno de ellos nos explique lo que es el método para la complejidad, ¿fue un olvido?; no, lo que ocurre es que conforme a la transdisciplinariedad de la complejidad no es posible hablar de un método, lo cuál sería contradictorio, sino que es necesario mencionar que para el pensamiento complejo el segundo orden aplica en todos los campos en los que queramos trabajar; dicho de otra manera, referirse a un método para lo complejo sería una contradicción en virtud que domina en este campo lo transdisciplinario, la manera de construir lo complejo se manifiesta de una forma multidimensional, así, si el referente elemental es el bucle, podemos construir lo complejo transdisciplinariamente, con tantos bucles como sean necesarios, formando un tejido dinámico que, valga la metáfora, nos dan una infinita tela en la cual tejemos, destejemos, cortamos, unimos, pegamos, de acuerdo con las necesidades de cada prenda sea una camisa, esmoquin, vestido, falda, en otras palabras no es válido hablar de un método para la complejidad, pero si de una dinámica que se retroalimenta, caótica, desordenada, ordenada, que nos permite construir transdisciplinariamente la complejidad conforme cada problema que se nos presente.

\section{Conclusiones}

Al principio de este artículo afirmamos que mientras en la epistemología de primer orden trabajamos con el conocimiento del conocimiento, en la epistemología de segundo orden hablamos de el saber del saber, lo que implica que necesitamos rebasar el pensamiento de Ernest Cassirer, Johannes

93 Harold Bloom, Genios..., op. cit., p. 122. 
Hessen y Jean Piaget, entre otros, para dirigirnos hacia lo sapiencial, ¿por qué hoy debemos realizarlo? Ante las amenazas de autodestrucción, producto del poder de las armas atómicas y la destrucción que hemos hecho de la naturaleza, hoy es el momento de utilizar lo mas elevado que el ser humano ha realizado en la historia de la humanidad: lo sapiencial.

El saber del saber que es lo sapiencial o, mejor expresado, los sapienciales como hemos argumentado, al identificar diferentes tipos de sabidurías, se construye con los elementos que hemos señalado que son humildad, honestidad, genialidad, creatividad, originalidad, profundidad y asombro, si el metaconcepto es la unidad de construcción de lo epistémico aquí implica una molécula que tenga todos los elementos anteriores, y a esa molécula la vamos a llamar $\mathrm{S}^{1} \mathrm{y}$ al conjunto de moléculas que construyen lo sapiencial lo llamaremos $S^{n}$. El problema de la sabiduría o de lo sapiencial es que o se ha visto con excesivo respeto o se ha negado su existencia, en ambos casos el ser humano se paraliza ante este ser y no puede avanzar en su construcción.

Aquí nosotros intentaremos simplemente manejarlo bajo la más sencilla de las formas de tratamiento; lo respetaremos, nos asombraremos ante él y haremos nuestro mejor esfuerzo para dirigirnos hacia ellas sabiendo que la distancia es enorme, pero que todo empieza con el primer paso. Así, con nuestra molécula sapiencial $\mathrm{S}^{1}$ intentaremos construir una malla que manifieste nuestra voluntad de proteger a este planeta como nuestra patria y ciudadanía ${ }^{94}$ y a la humanidad como una hermana querida que no deseamos que pase ni hambres, enfermedades, violencias o peligros de extinción.

Sólo con sabiduría o sabidurías podremos salvar a la naturaleza y a nosotros mismos, dándole a Martín Heidegger la razón cuando afirmó que "la ciencia no piensa humanísticamente", 95 con el agravante que se presenta como un ser neutral que favorece al ser humano y respeta a la naturaleza con un desarrollo sustentable, lo que es un oxímoron. ${ }^{96}$

94 Edgar Morin y Anne-Brigitte Kern, Tierra patria, España, Kairós, 2006, p. 55.

95 Martín Heidegger, Tiempo y ser, trad. Manuel Garrido, José Luis Molinuevo y Félix Duque,

Madrid, Tecnos, 2011, p. 96.

96 Juan de Dios González Ibarra y Bolívar Román Delgado, Derecho de los animales y constitucionalismo de la naturaleza, México, Fontamara, 2018, p. 46. 


\section{Referencias}

Altamirano, Ignacio Manuel, Discursos, París, Biblioteca de la Europa y América, 1891.

Aranda Torres, Cayetano, Introducción a la estética contemporánea, España, Universidad de Almería, 2004.

Bloom, Harold, ¿Dónde se encuentra la sabiduría?, trad. Damián Alou, España, Punto de lectura, 2006.

, Genios, Un mosaico de cien mentes creativas y ejemplares, Anagrama, México. Shakespeare, William, Troilo y Crésida, España, Espasa, 2000.

Carroll, Lewis, Alicia en el país de las maravillas, España, Alianza Editorial, 2010.

Cepeda Neri, Álvaro, "Vida y obra del pensador inconformista Edgar Morin, por Emmanuel Lemieux", en Contralínea, disponible en $<$ https://www.contralinea.com.mx/archivo-revista/2018/01/25/vida-obra-del-pensador-inconformista-edgar-morin-emmanuel-lemieux/>, consultado el 1 de julio de 2019.

Freud, Sigmund, Obras Completas, Buenos Aires, Amorrortu Editores, 1978.

García Baca, Juan David, "La esencia de la poesía en Heidegger”, en Separata, Revista Nacional de Cultura, núm. 112, septiembre-diciembre, 1955.

González Ibarra, Juan de Dios y Peña Zepeda, Carolina, Epistemología Jurídica, 6ta ed., México, Porrúa, 2019.

y Román Delgado, Bolívar, Derecho de los animales y constitucionalismo de la naturaleza, México, Fontamara, 2018.

Hegel, Georg W. F., Enciclopedia de las ciencias filosóficas en compendio, trad. Ramón Valls Plana, Madrid, Alianza Editorial, 1997.

Heidegger, Martín, Ser y tiempo, trad. José Gaos, México, Fondo de Cultura Económica, 2013.

Tiempo y ser, trad. Manuel Garrido, José Luis Molinuevo y Félix Duque, Madrid, Tecnos, 2011.

Ibargüengoitia, Antonio, Filosofía Mexicana, México, Porrúa, 1967.

Johnson, Samuel, La historia de Rásselas, Príncipe de Abisinia, España, Ediciones del viento, 2017.

León-Portilla, Miguel, La filosofía náhuatl. Estudiada en sus fuentes, México, UNAM, 2006. 
Martínez Miguélez, Miguel, “Transdisciplinariedad un enfoque para la complejidad del mundo, en Revista Visión docente con-ciencia, núm. 1, julio, 2003.

Montaigne, Michel de, Los ensayos, Barcelona,Acantilado, 2007.

Morin, Edgar y Kern, Anne-Brigitte Tierra patria, España, Kairós, 2006. , Introducción al pensamiento complejo, Barcelona, Gedisa, 1990. , Mi camino. La vida y obra del padre del pensamiento complejo, Barcelona, Gedisa, 2008.

Nicolescu, Basarab, Manifiesto de la Transdisciplinariedad, Ediciones Du Rocher, disponible en <http://www.ceuarkos.com/manifiesto.pdf $>$

Osorio García, Sergio Nestor, "El pensamiento complejo y la transdisciplinariedad: Fenómenos emergenes de una nueva racionalidad", en Facultad de Ciencias Económicas, Vol. XX (1), junio 2012.

Paz, Octavio, "Piedra de sol", en Lo mejor de Octavio Paz, Barcelona, Seix Barral, 1989.

Platón, La República, Barcelona, Alianza Editorial, 2018.

Plazaola, Juan, Introducción a la estética. Historia, Teoría, Textos, Bilbao, Universidad de Deusto, 2007.

Pope, Alexander, Ensayo sobre el hombre y otros escritos, trad. Ángeles García Calderón, Madrid, Catedra, 2017.

Prigogine, Ilya, Las leyes de caos, Barcelona, Crítica, 1999.

Ramírez, Ignacio, Estudios Metafísicos, México, El correo de México, 1867.

Reyes, Alfonso, Trayectoria de Goethe, México, Fondo de Cultura Económica, 2014.

Salomón, El Eclesiastés o El predicador, disponible en: http://hopeinjesus. com.au/wp-content/uploads/2014/02/21.-Eclesiastes.pdf.

Schwab, Klaus, La cuarta revolución industrial, España, Debate, 2018.

Serrano, Francisco, El libro de Job. Fragmentos, disponible en: https://www. francisco-serrano.com/translation/job.pdf.

Shakespeare, William, El Rey Lear, Madrid, Alianza Editorial, 2018.

Shelly, Percy B., La necesidad del ateísmo y otros escritos de combate, trad. Julio Monteverde, España, Editorial Pepitas de Calabaza, 2015.

Sierra, Justo, Inauguración de la Universidad Nacional, Biblioteca Virtual, disponible en <http://www.biblioteca.org.ar/libros/1287.pdf> 
Suzuki, D.T. y Fromm, Erich, Budismo Zen y psicoanálisis, México, Fondo de Cultura Económica, 1998.

Vasconcelos, José, Tratado de metafísica, México, Trillas, 2009.

Vaz de Camões, Luis, Los Lusiadas, Biblioteca Virtual Universal, disponible en: http://portal.uc3m.es/portal/page/portal/ifibid/catedracamoens/luiscamoens/Las_Lusiadas_BVirtual_.pdf.

Wittgenstein, Ludwig, Tractatus Lógico-philosophicus, Madrid, Tecnos, 2012. 


\section{LA COOPERACIÓN INTERNACIONAL EN LOS PAÍSES DE RENTA MEDIA DE AMÉRICA LATINA Y EL CARIBE: UN BALANCE DE LOS LOGROS DEL OBJETIVO 7 DE LA AGENDA DE DESARROLLO 2015}

Karen Ramírez González Gustavo Arce Landa El Colegio de Morelos

\section{Introducción}

La situación actual en América Latina y el Caribe (ALC), es una evidencia empírica de la evolución que se ha mantenido con los cambios de la política económica. Si bien en la década de 1940, la mayoría de los países se encontraban en un proceso de expansión de la política social, como una tendencia heredada de Occidente con la reestructuración de los Estados, a través de los Estados de Bienestar (Welfare State), en el periodo de 1970 hasta poco más de 1980, la política de sustitución de importaciones mantuvo un mercado cautivo y protegió la producción nacional, obteniendo el denominado crecimiento hacia adentro.

Con la flexibilización del mercado laboral y la proliferación de los tratados de libre comercio, las brechas de desigualdad se incrementaron a causa de las inequidades entre los países firmantes. Aunado a ello, los nuevos paradigmas teóricos con respecto al desarrollo, impregnados de una tendencia privatizadora y de focalización del gasto -como, por ejemplo, la teoría del derrame-, provocaron la agudización de las diferencias entre los países de bajos ingresos.

En consecuencia, la cooperación internacional hacia los países de Renta Media (PRM) ha tendido a disminuir, transfiriéndose la mayoría de los recursos a aquellos catalogados en extrema pobreza, tal como lo demostró el estudio titulado Cooperación con Países de Renta Media. El cual, es pionero por poner en tema de debate que la dismi- 
nución de la cooperación con los PRM es un error, y es de particular importancia que la comunidad internacional mantenga su asistencia a este grupo de países, debido a que:

1. En ellos vive al menos el $41 \%$ de la población pobre del mundo, que subsiste con menos de dos dólares al día.

2. Los logros económicos y sociales obtenidos son altamente vulnerables y con frecuencia, objeto de regresiones.

3. La aportación de este colectivo a la provisión de bienes públicos internacionales - especialmente ambientales-es decisiva.

4. Algunos de estos países tienen un elevado peso y liderazgo en su entorno regional, y

5. Porque es necesario construir un sistema de cooperación que sea incentivo-compatible con los propósitos de desarrollo. ${ }^{1}$

Además, la tendencia de crecimiento que ha experimentado la población de ALC desde 1950 hasta las estimaciones proyectadas a 2020, representa un incremento del 19.29 por ciento, implicando mayor requerimiento de recursos y provisión de bienes y servicios. Por estas razones, la cooperación internacional hacia los PRM es decisiva.

Este trabajo, a partir de la publicación anteriormente citada, encuentra especial interés en reactivar el debate en torno a la cooperación con los PRM, considerando los beneficios no sólo para el país destinatario, sino para aquellos que se encuentran en el rubro de ingresos bajos. El estudio tiene el propósito de presentar una versión actualizada de los datos ahí estimados, ya que, en general, este tipo de debates han sido escasamente abordados, priorizando los análisis de las economías menos desarrolladas. Sin embargo, hay esfuerzos notorios en tratar de explicar los beneficios anteriormente citados.

Con base en la revisión de la bibliografía reciente sobre la cooperación internacional en los PRM, se encontró que las principales investigaciones se centran en analizar la focalización los recursos en áreas estratégicas para producir desarrollo. En esta vertiente de investigación sobresalen los

1 José Antonio Alonso, Cooperación con Países de Renta Media, Madrid, Editorial Complutense, 2007, pp. 2-8. 
estudios de Restrepo, ${ }^{2}$ Otálora y Rouvinsky, ${ }^{3}$ Ripoll y Ghotme, ${ }^{4}$ Millán y Santander, ${ }^{5}$ entre otros. Una segunda vertiente se enfoca en los procesos de cooperación por regiones, en los cuales, son representativos los trabajos de Agudelo, ${ }^{6}$ Martín-Arnaiz, ${ }^{7}$ Tassara y, ${ }^{8}$ Sanahuja. ${ }^{9}$

Una tercera vertiente es aquella vinculada al desarrollo sostenible. Entre estos trabajos se encuentran los elaborados por Maldonado y López, ${ }^{10}$ Tezanos, ${ }^{11}$ Sanahuja, Tezanos, Kern y Perrotta y, ${ }^{12}$ Pellizzon. ${ }^{13}$ De la cual, esta disertación tiene relación en cuatro aspectos. Primero, analiza del papel prioritario de los PRM. Segundo, aporta nuevas líneas de investigación para el entendimiento de los avances y retrocesos en el marco del desarrollo sostenible en la región latinoamericana, en la Agenda 2015, apoyadas en la teoría de la complejidad. Tercero, contribuye desde la Ciencia Política a evaluar las políticas internacionales y su impacto por áreas estratégicas. Cuarto, motiva la creación de nuevas vertientes de investigación para entender los retos a los que se enfrenta la Agenda 2030 de Desarrollo Sostenible. Aspectos escasamente explorados en la academia mexicana.

2 Manuela Restrepo, "La cooperación internacional al desarrollo como herramienta de protección y promoción de los derechos humanos: el caso latinoamericano", en Revista Facultad de Derecho y Ciencias Políticas, vol. 42, núm. 116, 2012, pp. 271-295.

3 Lady Otálora y Rouvinski, Vladimir, "Cooperación internacional para el desarrollo en el Valle del Cauca: un estudio de percepciones”, en Estudios Gerenciales, volúmen 29, núm. 126, 2013, pp. 17-25.

4 Alejandra Ripoll y Rafat Ghotme, "La cooperación internacional: herramienta de desarrollo o de atraso", Revista Latinoamericana de Bioética, vol. 15, núm. 1, 2015, pp. 54-63.

5 Natalia Millán Acevedo y Guillermo Santander Campos, "Coherencia de políticas para el desarrollo y la cooperación Sur-Sur: reflexiones para una convergencia analítica", en OASIS, número 18, 2013, pp. 131-147.

6 Jairo Agudelo, "Cooperación para el desarrollo, relaciones internacionales y políticas públicas. Teorías y prácticas del diálogo Euro-Latinoamericano", en Documentos y Aportes en Administración Pública y Gestión Estatal, vol. 14, núm. 23, 2014, pp. 189-192.

7 José Martín-Arnaiz, "Vínculos entre la cooperación para el desarrollo y la educación en los países en desarrollo" Semestre Económico, vol. 20, núm. 42, 2017, pp. 143-160.

8 Carlo Tassara, "Diálogo, cooperación y relaciones euro-latinoamericanas", en Investigación y Desarrollo, vol. 21, núm. 1, 2013, pp. 2-21.

9 José Sanahuja, "La Unión Europea y el regionalismo latinoamericano: un balance", en Investigación y Desarrollo, vol. 21, núm. 1, 2013, pp. 156-184.

10 Marcela Maldonado y Santos López, "La visión del desarrollo dentro del contexto global y regional. El regionalismo a través de la Alianza del Pacífico y la Asociación Latinoamericana de Integración 2005-2014”, en Desafíos, vol. 29, núm. 1, 2013, pp. 13-48.

11 Sergio Tezanos, "Geografía del desarrollo en América Latina y el Caribe: hacia una nueva taxonomía multidimensional de los Objetivos de Desarrollo Sostenible", en Revista de la CEPAL N 125, 2018, pp. 7-28.

12 José Sanahuja, Sergio Tezanos, Alejandra Kern y Daniela Perrota, Perspectivas y propuestas para la cooperación al desarrollo entre la Unión Europea y América Latina y el Caribe, Cátedra de cooperación internacional y con Iberoamérica, Instituto Complutense de Estudios Internacionales, 2015.

13 Marco Pellizzon, "Cooperación internacional para el desarrollo: gobierno, economía y sociedad. evolución de las políticas y escenarios futuros. Desde la política hasta las OSC: interrogantes y respuestas para construir un futuro de desarrollo sostenible y global", en Investigación y Desarrollo, vol. 26, núm. 1, 2018, pp. 182-190. 
La investigación tiene como objetivo analizar la cooperación internacional hacia los PRM de ALC, en el marco del desarrollo sostenible, ya que estos países son decisivos para el logro de las metas del rescate al medio ambiente. Específicamente, explicando los avances obtenidos en la Agenda de los Objetivos de Desarrollo del Milenio (ODM), en el objetivo 7.

La pregunta que se trata de resolver a lo largo de esta disertación es si la cooperación internacional produjo un impacto positivo en los PRM en el logro del objetivo 7, que tenía establecido garantizar la sostenibilidad del medio ambiente. La hipótesis que subyace ante esta interrogante es la siguiente: el incremento de la cooperación internacional en los PRM de ALC, ha redituado en la disminución de la huella ecológica y, por consiguiente, en el aumento de los ecosistemas protegidos.

La metodología de este trabajo es mixta. En el aspecto cuantitativo para los PRM se realizará:

1. La proyección de las variaciones del coeficiente de Gini.

2. La estimación de la evolución de los ingresos.

3. El análisis del impacto de los ingresos en el combate a la pobreza y en el Índice de Desarrollo Humano (IDH).

4. El cálculo de la biocapacidad y de la huella ecológica.

5. El estudio de las estimaciones de la reducción de $\mathrm{CO}_{2}$ el mejoramiento de la calidad de la vivienda y el acceso a fuentes de agua potable.

6. El análisis de las variaciones del canje de deuda por naturaleza.

7. Lo anterior se combinará con el análisis cualitativo de los indicadores, del impacto de los convenios multilaterales en la protección medioambiental, y del balance general de la entropía del medio ambiente en los PRM. Con el propósito de materializar tales cometidos, esta investigación se divide en seis apartados. El primero expone el marco conceptual sobre la cooperación internacional y su relación con la teoría de sistemas y la complejidad. El segundo, analiza los criterios de clasificación de los PRM, establecidos por los organismos internacionales. 
El tercero se enfoca en la explicación de la relevancia de la cooperación internacional en los PRM. El cuarto, aborda la relevancia de los $\mathrm{ODM}$ en la protección ambiental. El quinto analiza los diversos convenios multilaterales ambientales, y, en especial, la conversión de deuda por naturaleza. El sexto, a modo de conclusión, realiza un cálculo sobre los alcances obtenidos en el objetivo 7.

\section{Complejidad, entropía y cooperación internacional}

Este apartado tiene por objetivo la explicación de la teoría de sistemas de Niklas Luhmann, para el análisis de los sistemas en general y de la entropía en la naturaleza, en lo particular. La teoría transforma las cuestiones fácticas en problemas y posee, entre otras características, la inter, multi y transdisciplina, y la no linealidad. Tiene un sinnúmero de aplicaciones entre las cuales destacan el análisis de la sociedad como sistema y el estudio de problemáticas diversas. En suma, es funcionalista, práctica y metódica.

Eguzki Urteaga, apoyado en Luhmann, refiere que la teoría de los sistemas es transdisciplinar, y considera tres tipos de sistemas: el sistema vivo, el sistema psíquico y el sistema social. El primero se vincula a la vida, el segundo a la conciencia y el tercero a la comunicación. ${ }^{14}$ Entre otros aspectos, parte de una metodología y una teoría singular. Critica y cuestiona conceptos como la causalidad, el determinismo y el reduccionismo. Pero, sobre todo, pretende la búsqueda del orden (resiliencia, neguentropía), partiendo del desorden (entropía). La fórmula para su cálculo, es la siguiente: ${ }^{15}$

\section{$\Delta \mathrm{eS}<\Delta \mathrm{iS}$}

Donde $\Delta \mathrm{eS}$ se refiere a la entropía por importación de sistemas externos, y $\Delta \mathrm{i} S$ a la generación de entropía por acciones propias del sistema medioambiental o de los subsistemas.

Para el análisis de la entropía medioambiental en los PRM, resulta imperativo tomar en consideración la teoría del caos, que tiene relación con la complejidad, y con la teoría de los sistemas. Nicolás Tenzer, considera que "el caos y el desorden se imponen a partir de la constatación de diversas crisis simultáneas". ${ }^{16}$ Para Luhmann, todo sistema genera

14 Eguzki Urteaga, "La teoría de sistemas de Niklas Luhmann", en Contrastes. Revista Internacional de Filosofía, vol XV, Departamento de filosofía, Universidad de Málaga, 2010, p. 304.

15 Felipe Lara-Rosano, Aplicaciones de las ciencias de la complejidad al diagnóstico e intervención en problemas sociales, México, Colofón, 2017, p. 237.

16 Javier Sánchez Galicia, coord., Treinta claves para entender el poder, Léxico para la nueva comunicación política, México, Piso 15 Editores, 2010, p. 207. 
decisiones colectivas coactivas que se traducen en formas de elección, que dependiendo de su tipología, aumentarán o no la entropía del sistema, o en su momento, el caos. En este sentido, el medio ambiente es el campo de la incógnita, el caos, desorden, lo indeterminado, impredecible y sobre todo lo enfrentado y disputado.

Para el análisis entrópico del medio ambiente, es necesario considerar, además, la teoría de la complejidad. La complejidad es un término que tiene tres significados básicos. El primero, implica la composición de diferentes elementos. El segundo, remite a lo difícil, enredado y articulado de una variedad de piezas. El tercero, constituye la unión de dos o más elementos. La complejidad, tiene un carácter objetivo; la unión o vínculo de elementos distintos, y un carácter subjetivo, lo que se traduce como difícil de comprender. ${ }^{17}$

Rosano acota que la complejidad, mediante una metodología adecuada, un marco conceptual pertinente y con apoyo en la transversalidad y transdisciplinariedad, permite identificar, comprender, prevenir y solucionar una gran variedad de problemas, y efectuar reflexiones científicas tomando en consideración "la teoría de los sistemas no lineales, los sistemas autoorganizados, los sistemas dinámicos adaptativos complejos, la teoría de las redes, las lógicas no clásicas, la teoría de las catástrofes, la teoría del caos y la lógica factual". ${ }^{18}$

Estas acotaciones conceptuales están relacionadas con la cooperación internacional, porque en primer orden, son decisiones colectivas, en el sentido propuesto por Luhmann. Segundo, el objetivo de incrementarla obedece a reducir la entropía en el medio ambiente, causado por la alteración de los ecosistemas. Tercero, porque para comprender la devastación medioambiental, se necesitan identificar las variables independientes que impiden su regeneración (neguentropía).

La cooperación es un término cuyo origen se remonta al siglo XIX con las asociaciones de trabajadores, de socorro, las cooperativas, de ayuda mutua, entre otras. Se concebía "como un conjunto de principios sociales, y por lo tanto, como un dispositivo que no era predominantemente económico". ${ }^{19}$ Otro de los antecedentes de su aparición, se encuentra en la ciencia social, como contraparte a la ideología económica del laissez-faire, redefiniéndose como "cooperación, ayuda

17 Esteban Ruíz Ballesteros y José Luis Solana Ruíz, Complejidad y ciencias sociales, Sevilla, Universidad Internacional de Andalucía, 2013, p. 23.

18 Felipe de Jesús Lara-Rosano, op. cit., p. 16.

19 Fernando Álvarez Uría y Julia Varela, Sociología, Capitalismo y Democracia. Génesis e Institucionalización de la Sociología en Occidente, Madrid, España, Morata, 2004, p. 80. 
mutua, fraternidad, sistema social, intereses comunitarios" ${ }^{20}$ Posteriormente, con la evolución de las relaciones sociales de producción, tuvo que entenderse en términos globales, como "una acción conjunta con un otro, u otros, con el propósito o motivada por la aspiración de lograr un fin común de mutuo beneficio". ${ }^{21}$

La cooperación surgió como una herramienta de reactivación económica para los países de Occidente, posterior a la Segunda Guerra Mundial (1948 a 1951), con el Plan Marshall, liderado por Estados Unidos. En dicho periodo surgen organizaciones internacionales para incentivar la cooperación internacional, como la Organización de Naciones Unidas (ONU), el Banco Internacional para la Reconstrucción y el Desarrollo (más adelante nombrado Banco Mundial), y la modernización de la Unión Panamericana, que posteriormente se llamaría Organización de Estados Americanos (OEA). A partir de ello, la cooperación internacional puede ser vista como una "transferencia de recursos humanos, tecnológicos y financieros de un Estado a otro (o de una agencia o empresa a otra) a fin de facilitar el logro de objetivos de interés común".22

Su propósito radica en dirigirse a las áreas que requieran inversión y monitoreo constante, con la finalidad de aminorar las brechas de desigualdad. Especialmente, a partir de la década de 1970, la cooperación ha tendido a la focalización, la incorporación de nuevas organizaciones provenientes de la sociedad civil y, desde el año 2000, no ha tenido grandes variaciones con respecto a los parámetros anteriores. Al contrario, con las crisis económicas de finales de 1990 y de 2008, el objetivo es disminuir la pobreza alimentaria, de capacidades y patrimonio. Las nuevas formas de cooperación se dirigirán a una clasificación basada en la renta por países, para destinar el apoyo de forma focalizada. Para una mejor comprensión del objeto de estudio, se analizarán los criterios de clasificación de los PRM.

\section{Criterios de clasificación de los PRM}

Tanto el Banco Mundial (BM), como el Programa de Naciones Unidas para el Desarrollo (PNUD), o el Comité de Ayuda al Desarrollo (CAD) de la Organización de Cooperación y Desarrollo Económico (OCDE), 20 Ibid., p. 106.

21 Carol Pinto- Agüero, "Globalización, Desarrollo y Cooperación Internacional", en La inserción internacional de las regiones y los municipios. Lecturas sobre gestión de cooperación descentralizada, Universidad de Viña del Mar, Chile, 2005, p. 218.

22 Ricardo Tichauer, "El rol de la Empresa Privada en la Cooperación Internacional", en La inserción internacional de las regiones y los municipios. Lecturas sobre gestión de cooperación descentralizada, Universidad de Viña del Mar, Chile, 2005, p. 275. 
y el Programa de Naciones Unidas para el Desarrollo (PNUD), identifican - con criterios más o menos similares - una amplia gama de países denominados de Renta Media. Para el año 2019, el BM establece como parámetro de clasificación los países Renta Media baja (PRMB), a aquellos con ingresos entre 1, 026 y 3, 995 dólares, y como países de Renta Media alta (PRMA), quienes cuenten con un ingreso per cápita de 3, 996 a 12, 375 dólares. ${ }^{23}$ Por su parte, el CAD de la OCDE fija como PRMA los que tengan ingresos de 3, 956 y 12, 235 dólares, y como PRMB, los que dispongan entre 1, 006 y 3, 955 dólares per cápita. ${ }^{24}$

Lo semejante de estos criterios es que, los recursos deben incidir positivamente en el coeficiente de Gini, ${ }^{25}$ que los situará como países "desarrollados" o en "desarrollo". El criterio de clasificación se basa en que los primeros pertenecerán a los ingresos altos de acuerdo al $\mathrm{BM}$, y los segundos, todos los que se encuentren entre ingresos medios y bajos. ${ }^{26}$

En el caso del PNUD, la clasificación varía no por niveles de ingreso, sino por su impacto en el IDH en tres rubros: salud y longevidad, reducción de las brechas educativas y una vida digna. Los valores se ubican entre 0 y 1 . Entre más cercano sean al 1 , mayor bienestar se traducirá en la población. De acuerdo a la última clasificación, se establecieron cuatro variantes: IDH muy alto ( 0,800 o más); IDH alto $(0,700$ a 0,799$)$; IDH medio (0, 550 a 0,699$)$; e IDH bajo (menor de 0,550$){ }^{27}$

La principal característica que surge de la clasificación de países por medio de su ingreso per cápita es la enorme heterogeneidad que presentan en su seno los PRM, pues no solamente los separan diferencias cuantitativas, como son de ingreso (US \$12, 375 a US \$1,026); de tamaño (Rusia, Brasil o China frente a Santa Lucía, Kiribati o Granada, por ejemplo) o de población (China, Brasil, México o Indonesia frente a Palau, Samoa, Tonga o San Vicente, entre otros), sino también cualitativas, como las disparidades acusadas en torno a las posibilidades de desarrollo o de logros económicos y sociales.

23 World Bank, World Bank Country and Lending Groups, disponible en <https://datahelpdesk. worldbank.org/knowled gebase/articles/906519>.

24 DAC List of ODA Recipients, <http://www.oecd.org/dac/financing-sustainable-development/development-finance-standards/DAC-List-of-ODA-Recipients-for-reporting-2018-and-2019-flows.pdf>

25 El coeficiente de GINI mide la paridad en los ingresos. Los valores de 0 o cercanos a él, corresponden a niveles de igualdad, mientras que los valores de 1 o cercanos a éste, indican perfecta disparidad. CEPALSTAT Bases de datos y publicaciones estadísticas <https://estadisticas.cepal.org/ cepalstat/web_cepalstat/estadisticasindicadores.asp>.

26 Sergio Tezanos, "Geografía del desarrollo en América Latina y el Caribe: hacia una nueva taxonomía multidimensional de los Objetivos de Desarrollo Sostenible", en Revista de la CEPAL, № 125, 2018.

27 Human Development Indices and Indicators 2018 Statistical Update, United Nations Development Programme, Communications Development Incorporated, Washington DC, USA, 2018. 
Un intento para resolver el problema de tal heterogeneidad ha sido la de reclasificar los PRM en seis regiones, de acuerdo a la clasificación de 2019 del Banco Mundial y de la cual, los principales organismos multilaterales toman como parámetro: ALC, que es la región que mayormente comprende PRM (24 países); Oriente Medio y África del Norte (11 países); África Subsahariana (20 países); Europa y Asia Central (20 países); Asia Oriental y el Pacífico (23 países), y Asia Meridional (6 países). Asimismo, el CAD de la OCDE incorpora a los PRM otra vertiente más: PRM no susceptibles de Ayuda Oficial al Desarrollo (AOD), que lo componen fundamentalmente los países de Europa del Este de reciente incorporación a la Unión Europea y Rusia.

En el caso de ALC, combinando las tres clasificaciones de las organizaciones anteriormente citadas, los países se ubicarían en los siguientes rangos de acuerdo a los datos de 2019:

Tabla 1: Países de Renta Media de América Latina y el Caribe

\begin{tabular}{|c|c|c|c|}
\hline País & $\mathbf{B M}$ & CAD & PNUD \\
\hline Argentina & PRMA & País en desarrollo & Muy Alto \\
\hline Belice & PRMA & País en desarrollo & Alto \\
\hline Brasil & PRMA & País en desarrollo & Alto \\
\hline Bolivia & PRMB & País en desarrollo & Medio \\
\hline Colombia & PRMA & País en desarrollo & Alto \\
\hline Costa Rica & PRMA & País en desarrollo & Alto \\
\hline Cuba & PRMA & País en desarrollo & Alto \\
\hline Dominica & PRMA & País en desarrollo & Alto \\
\hline Ecuador & PRMA & País en desarrollo & Alto \\
\hline El Salvador & PRMB & País en desarrollo & Medio \\
\hline Granada & PRMA & País en desarrollo & Alto \\
\hline Guatemala & PRMA & País en desarrollo & Medio \\
\hline Guyana & PRMA & País en desarrollo & Medio \\
\hline Honduras & PRMB & País en desarrollo & Medio \\
\hline Jamaica & PRMA & País en desarrollo & Alto \\
\hline México & PRMA & País en desarrollo & Alto \\
\hline Nicaragua & PRMB & País en desarrollo & Medio \\
\hline Paraguay & PRMA & País en desarrollo & Alto \\
\hline Perú & PRMA & País en desarrollo & Alto \\
\hline Santa Lucía & PRMA & País en desarrollo & Alto \\
\hline $\begin{array}{c}\text { San Vicente y las } \\
\text { Granadinas }\end{array}$ & PRMA & País en desarrollo & Alto \\
\hline
\end{tabular}




\begin{tabular}{|c|c|c|c|}
\hline Surinam & PRMA & País en desarrollo & Alto \\
\hline $\begin{array}{c}\text { República Bolivariana } \\
\text { de Venezuela }\end{array}$ & PRMA & País en desarrollo & Alto \\
\hline República Dominicana & PRMA & País en desarrollo & Alto \\
\hline
\end{tabular}

Fuente: Elaboración propia a partir de los datos del BM, el CAD y el PNUD.

* En el caso del PNUD, los últimos datos sobre el IDH fueron presentados en 2018.

* El diseño de esta tabla está inspirado en una primera versión presentada por Sergio Tezanos, en laRevista de la CEPAL, con datos de 2014 hasta 2017.

De allí que resulte anacrónico tomar medidas generales para aplicar al tratamiento de ciertos fenómenos en colectivos tan dispares, dado que desencadenan resultados igualmente diversos donde son aplicadas. Evidencia empírica de lo que produce la homologación de medidas, lo representan los cambios en el coeficiente de Gini (gráfico 1).

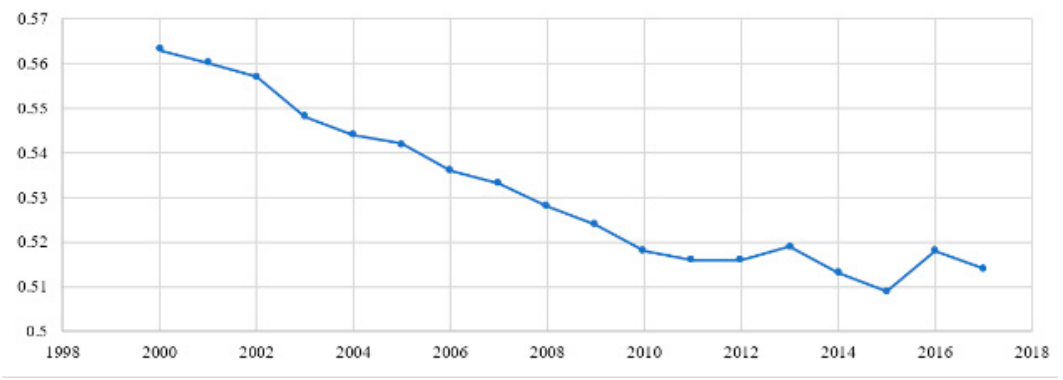

Gráfico 1: Coeficiente de Gini en America Latina y el Caribe.Fuente: Datos de CEPAL.

En el gráfico es posible observar las transiciones en la igualdad en ALC, por ingreso percibido en dólares corrientes. Desde 2000 a 2017, la tendencia se ha mantenido en 0.53 . Esto significa que, aunque ha tendido a mejorar el ingreso de los países de la región, la reducción de la pobreza y el incremento en los indicadores de la calidad de vida, el coeficiente de Gini se encuentra más cerca de la desigualdad.

Esto se puede explicar a partir de la tendencia histórica del promedio en las fluctuaciones en los ingresos mínimos de estos países. En el periodo de 1987 a 2019, ha sido de 3, 305.24 dólares per cápita. Mientras que el máximo oscila entre los 10, 157.90 dólares (gráfico 2). 


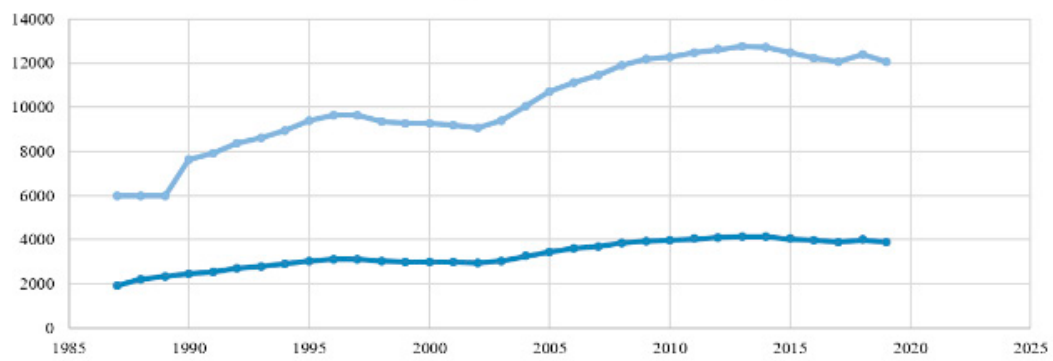

Gráfico 2 . Evolución del ingreso en los PRMA Fuente: Datos del Banco Mundial

En el caso opuesto, los PRMB han presentado en promedio de ingresos per cápita de 834.48 dólares, y un máximo de 3, 304.54 dólares. La diferencia sustancial se ubica en que los mínimos entre ambos países, es de 2, 470 dólares per cápita y el rango de los máximos corresponde a 6, 853 dólares (gráfico 3).

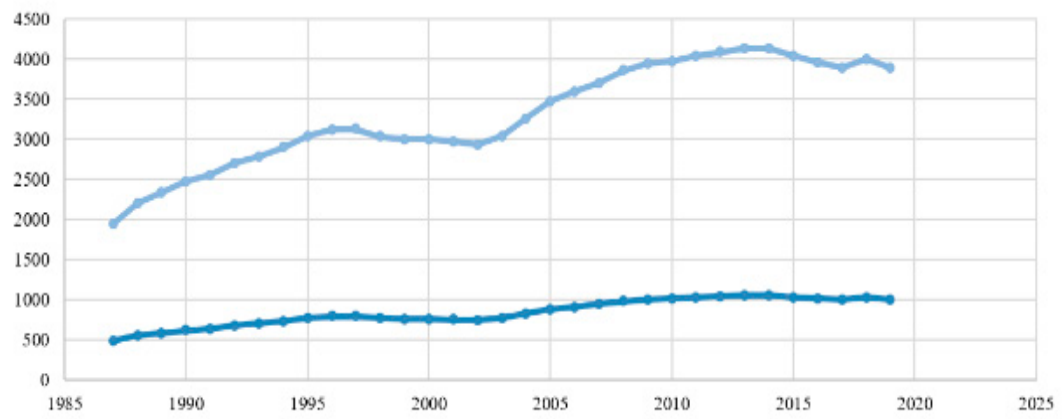

Fuente: Elaboración propia a partir de los datos del Banco Mundial

La interrogante que resulta de estos datos es, ¿cómo ha impactado las variaciones en el ingreso, en la pobreza de los PRM en el último sexenio? (gráfico 4) 


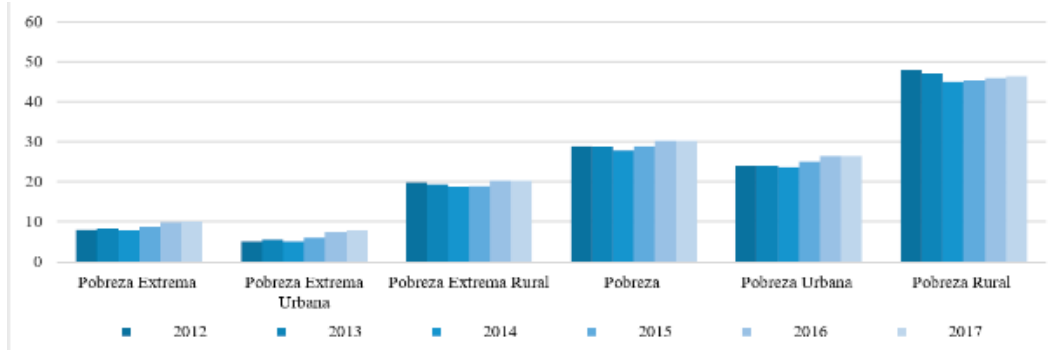

Gráfica 4. Fuente: Elaboración propia a partir de los datos de la CEPAL

Los resultados indican que del periodo 2012 al 2014, la tendencia a la reducción de la pobreza y la pobreza extrema, ha sido una constante. Sin embargo, en 2015 la pobreza incrementó un punto porcentual con respecto al año anterior, en los rubros nacionales, urbanos y rurales. Lo relevante de estos datos es que, la pobreza extrema se ha mantenido sin incrementos significativos.

Desde otra perspectiva, el impacto de la pobreza en la región en los PRM, se puede medir con el coeficiente de Gini (Gráfico 5).

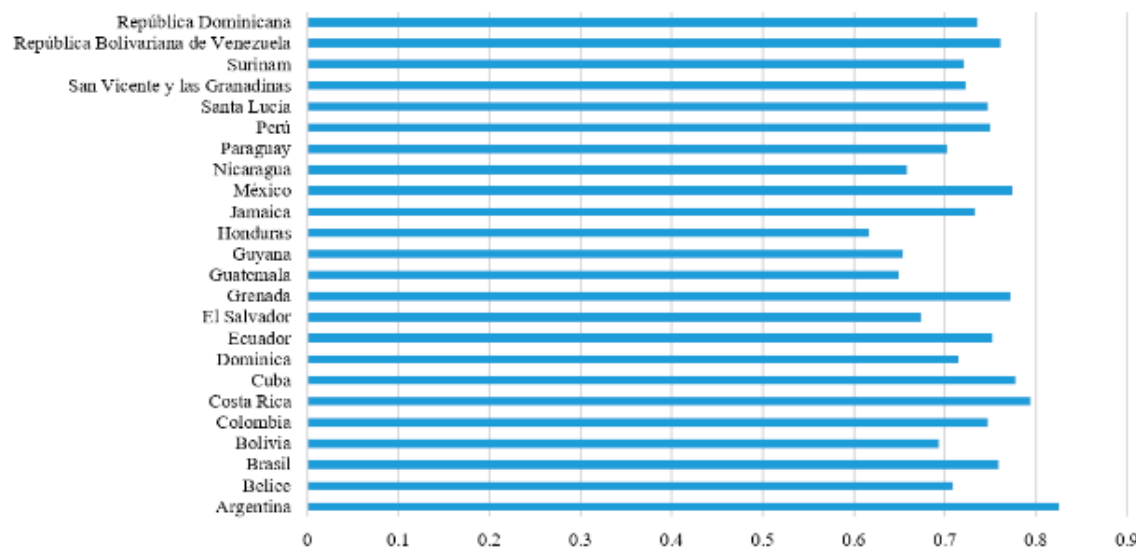

Gráfica 5. Fuente: Elaboración propia a partir de los datos del PNUD

En dicho gráfico se observa que de los 24 países clasificados como PRM en la región, 17 de ellos tienen un IDH alto, 6 un IDH medio y sólo Argentina tiene un IDH muy alto. Estos datos, junto con los de pobreza proyectados en el gráfico 4, pueden ser explicados por los flujos de AOD, las transformaciones del mercado laboral, el mejoramiento de los indicadores económicos y sociales de países como México, Costa Rica, Argentina, Granada, entre otros, que han permitido que el promedio de la región se vea 
beneficiada, y la adhesión y puesta en marcha de diferentes convenios para abatir la pobreza y garantizar la sostenibilidad de las comunidades, como se verá en el apartado subsecuente.

\section{La relevancia de la cooperación internacional con los PRM}

Durante el periodo 2000-2004, cerca de un tercio de la AOD bilateral, otorgada por el CAD, se destinó a los PRM. De la cual, cerca de un $90 \%$ fluyó hacia los PRMB y tan sólo un 10\% a los PRMA. ${ }^{28}$ Estas cifras para el periodo 2018 y 2019 variaron notablemente, puesto que se consideraron como sujetos de AOD países menos desarrollados, quienes recibieron $34.2 \%$ de la ayuda, así como los PRMA, que fueron receptores de $39.86 \%$, y los $\mathrm{PRMB}$, con una inversión recibida por organismos multilaterales de $25.87 \%{ }^{29}$

La inversión hacia los PRM es de gran relevancia, puesto que tienen mayor capacidad técnica e institucional, están en mejores condiciones que los países pobres para eludir alguno de los problemas que tradicionalmente condicionan la eficacia de la ayuda, como son: apropiación, promoción de la estabilidad de los flujos, coordinación de los donantes, condicionalidad, dependencia y capacidad de absorción y buenas prácticas. ${ }^{30}$

Ello sugiere que la ayuda siempre que esté bien orientada, puede lograr en los PRM mayores grados de eficacia que en otros países con elevadas carencias. El problema radica en que el esfuerzo que la cooperación internacional ha emprendido para dotarse de un marco de actuación en el caso de los países más pobres, no se ha acompañado de otro similar en el caso de los PRM, fundamentalmente en tres aspectos comunes a todos, a pesar del grado de heterogeneidad que los caracteriza, como son:

1. La consolidación de instituciones eficaces y creíbles, que les permita avanzar hacia la erradicación de la pobreza y la cohesión social.

2. La disminución de los niveles de vulnerabilidad de su inserción financiera internacional.

3. La mejora de su capacidad competitiva a través de la transformación productiva y el progreso tecnológico. ${ }^{31}$

28 José Antonio Alonso, Cooperación con Países de Renta Media..., op. cit. p.39.

29 DAC List of ODA, Recipients, http://www.oecd.org/dac/financing-sustainable-development/development-finance-standards/DAC-List-of-ODA-Recipients-for-reporting-2018-and-2019-flows.pdf

30 José Antonio Alonso, op. cit. p.39.

31 Idem. 
Toda vez que, los principales problemas del desarrollo en los PRM son: "la trampa de pobreza", ${ }^{32}$ que en un sentido lato implica que, al poseer incapacidad para el ahorro, no hay recursos propios para la inversión, con lo cual se ve seriamente dañada la generación de empleo. Esto nuevamente redunda en pobreza, o bien la inversión y, por tanto, la generación de empleo depende de recursos externos. Pero además se encuentra la "trampa de la gobernanza", ${ }^{33}$ que es un serio impedimento al desarrollo, ya sea por la debilidad de sus instituciones, o bien por el inadecuado control de la corrupción, y aunado a ello la "trampa de la deuda", ${ }^{44}$ y las dificultades que supone el cambio productivo.

La instrumentación de la cooperación con los PRM pasa por una activa presencia y contribución de los Bancos Multilaterales de Desarrollo en la cooperación Sur-Sur, en los ámbitos macroeconómico, de financiación del desarrollo y la cooperación técnica, que puede ser a través de esquemas de cooperación bilateral horizontal, cooperación bilateral triangular, regional y multilateral.

Las razones que se exponen, como es el hecho del porcentaje de pobreza que aún mantienen los PRM, la fragilidad de sus logros socio-económicos, la aportación de este colectivo a la provisión de bienes públicos internacionales, el liderazgo que algunos de estos países ejercen en su plano regional o sub regional, y la necesidad de construir un sistema de cooperación que sea compatible con los objetivos de desarrollo; justifican plenamente la asistencia a ellos. Además, por la solidaridad que debe imperar en una comunidad internacional libre de las ataduras, que traía consigo un mundo dividido por los antagonismos ideológicos del pasado y cuya evidencia empírica de esta solidaridad son los ODM.

\section{Los ODM y la protección al medio ambiente}

La Cooperación Internacional, a partir de la Declaración del Milenio y la posterior fijación de los ODM, traslada su centro de interés hacia la erradicación de la pobreza. Los objetivos "reconocen explícitamente la dependencia recíproca entre el crecimiento, la reducción de la pobreza y el desarrollo sostenible". ${ }^{35}$ Desde esta perspectiva, los recursos de cooperación se incrementan en mayor medida para paliar situaciones de pobreza extrema, como, por ejemplo, los resultados de las recurren-

32 Ibid., p. 103.

33 Ibid., p. 112.

34 Ibid., p. 116.

35 Programa de Naciones Unidas para el Desarrollo (PNUD), Objetivos de Desarrollo del Milenio, disponible en <http://www.undp.org/spanish/mdg/basics.shtml $>$. 
tes crisis que fundamentalmente azotan a los países más pobres que, hacia otras regiones del mundo en desarrollo, para consolidar precisamente los objetivos de desarrollo. En palabras de Sanahuja: "la ayuda, en particular, se justificaría por la existencia de "fallas de mercado" —en particular, la elevada concentración de la inversión directa en un puñado de "países emergentes"-, más que por el derecho al desarrollo, o por objetivos de equidad o de cohesión social a escala mundial". ${ }^{36}$

Una de las innovaciones al combate a la pobreza a través de estos objetivos, es la vinculación con la protección al medio ambiente, ya que tales reglas "exigen que a través del establecimiento de metas y objetivos de equidad social, se contribuya al desarrollo económico y a su vez se vele por la sustentabilidad ambiental". ${ }^{37}$ Dicho compromiso quedó estipulado en el objetivo 7: Garantizar la sostenibilidad del medio ambiente, a través del cumplimiento de 4 metas, divididas en diez indicadores (tabla 2).

Tabla 2. Objetivo 7: Garantizar la sostenibilidad del medio ambiente

\begin{tabular}{|c|c|}
\hline METAS & INDICADORES \\
\hline $\begin{array}{l}\text { Meta 7A: Incorporar los principios } \\
\text { del desarrollo sostenible en las po- } \\
\text { líticas y los programas nacionales e } \\
\text { invertir la pérdida de recursos del } \\
\text { medio ambiente. }\end{array}$ & $\begin{array}{l}\text { 7.1 Proporción de la superficie de las tierras cubiertas por } \\
\text { bosques } \\
\text { 7.2 Emisiones de dióxido de carbono totales, per cápita } \\
\text { y por } 1 \text { dólar PIB (PPA) } \\
\text { 7.3 Consumo de sustancias que agotan la capa de ozono } \\
\text { 7.4 Proporción de poblaciones de peces dentro de lími- } \\
\text { tes biológicos seguros }\end{array}$ \\
\hline $\begin{array}{l}\text { Meta 7B: Reducir la pérdida de } \\
\text { diversidad biológica logrando, para } \\
\text { 2010, una reducción significativa } \\
\text { en la tasa de pérdida. }\end{array}$ & $\begin{array}{l}\text { 7.5 Proporción de recursos hídricos totales usados } \\
\text { 7.6 Proporción de áreas terrestres y marinas protegidas } \\
\text { 7.7 Proporción de especies amenazadas de extinción }\end{array}$ \\
\hline $\begin{array}{l}\text { Meta 7C: Reducir a la mitad, } \\
\text { para el año 2015, el porcentaje de } \\
\text { personas que carezcan de acceso } \\
\text { sostenible a agua potable. }\end{array}$ & $\begin{array}{l}\text { 7.8 Proporción de la población que utiliza fuentes de } \\
\text { abastecimiento de agua potable mejoradas } \\
\text { 7.9 Proporción de la población que utiliza servicios de } \\
\text { saneamiento mejorados }\end{array}$ \\
\hline
\end{tabular}

36 José Antonio Sanahuja, “¿Más y mejor ayuda?: la Declaración de París y las tendencias en la cooperación al desarrollo", Anuario 2007-2008 del Centro de Educación e Investigación para la Paz (CEIPAZ), Madrid, 2007, p. 81.

37 Programa de Naciones Unidas para el Desarrollo (PNUD), op., cit. 
Meta 7D: Haber mejorado considerablemente, para el año 2020, la vida de por lo menos 100 millones de habitantes de tugurios.
7.10 Proporción de población urbana que vive en barrios de tugurios (La proporción real de personas que viven en barrios de tugurios se mide mediante una variable sustitutiva representada por la población urbana que vive en hogares con al menos una de las cuatro características siguientes: a) falta de acceso a un mejor abastecimiento de agua; b) falta de acceso a un mejor saneamiento; c) hacinamiento (3 o más personas por habitación); y d) viviendas construidas con material de corta duración).

Fuente: Elaboración propia, basada en los Objetivos de Desarrollo del Milenio.

El objetivo 7, surge de la acción colectiva y el apoyo institucional para llegar al desarrollo sostenible, que significa "[satisfacer] las necesidades del presente sin poner en peligro la capacidad de las generaciones futuras para atender sus propias necesidades" ${ }^{38}$ A partir de su decreto, surgieron toda clase de estudios para mejorar la calidad del medio ambiente. Entre los cuales sobresale La Evaluación de los Ecosistemas del Milenio $^{39}$, en la cual se determinó que:

1. El ser humano en la segunda mitad del siglo XX, transformó más rápidamente los ecosistemas que en cualquier otra fase de la historia, y cuya consecuencia es el daño irreversible.

2. El daño está intrínsecamente ligado al crecimiento económico y al incremento de los recursos financieros.

3. Los recursos naturales podrían experimentar tal degradación que, en la primera mitad del siglo XXI, provocarían la imposibilidad de la reducción de la pobreza, del mejoramiento de la sanidad mundial y de una mayor provisión de los servicios elementales de la población.

4. El daño a los ecosistemas puede ser controlado de forma gradual, bajo el auspicio de las instituciones, transformaciones en las políticas públicas, y por consiguiente, en las prácticas sociales.

38 Organización de Naciones Unidas, Medio Ambiente y Desarrollo Sostenible, disponible en $<\mathrm{http}: / /$ www.cinu.org.mx/temas/des_sost.htm>.

39 Evaluación de los Ecosistemas del Milenio, disponible en <http://www.millenniumassessment.org/ documents/document.439.aspx.pdf>. 
Lo anterior pone en evidencia que el crecimiento económico como producto del incremento en las exportaciones, ha provocado la división marcada entre el aprovechamiento equilibrado de los recursos naturales y la generación constante de servicios para abastecer las demandas de la población. La huella ecológica, según estimaciones de Living Planet Report ${ }^{40}$ en el 2008, se superó en 1980 y para el 2005 era 30\% mayor del nivel sostenible.

Resulta relevante identificar a los países que estén por debajo de su capacidad de recuperación ecológica (huella ecológica), o por el contrario, en posibilidades de consumo y regeneración de los recursos naturales (capacidad biológica o biocapacidad), para conocer los efectos de la cooperación internacional en los PRM de ALC incluidos en este estudio para el periodo de $2019 .{ }^{41}$

Los resultados son alarmantes si se considera que más de la mitad de los PRM (Belice, Costa Rica, Cuba, Dominica, República Dominicana, Ecuador, Granada, Guatemala, Jamaica, México, Santa Lucía, El Salvador y Honduras), han excedido su capacidad de regeneración y, por tanto, la huella ecológica es mayor. En contraparte, Argentina, Brasil, Colombia, Guyana, Paraguay, Perú, Surinam, Venezuela, Bolivia y Nicaragua, tienen indicadores positivos.

\section{Gráfico 6. El impacto ambiental en los PRM de América Latina y el Caribe}

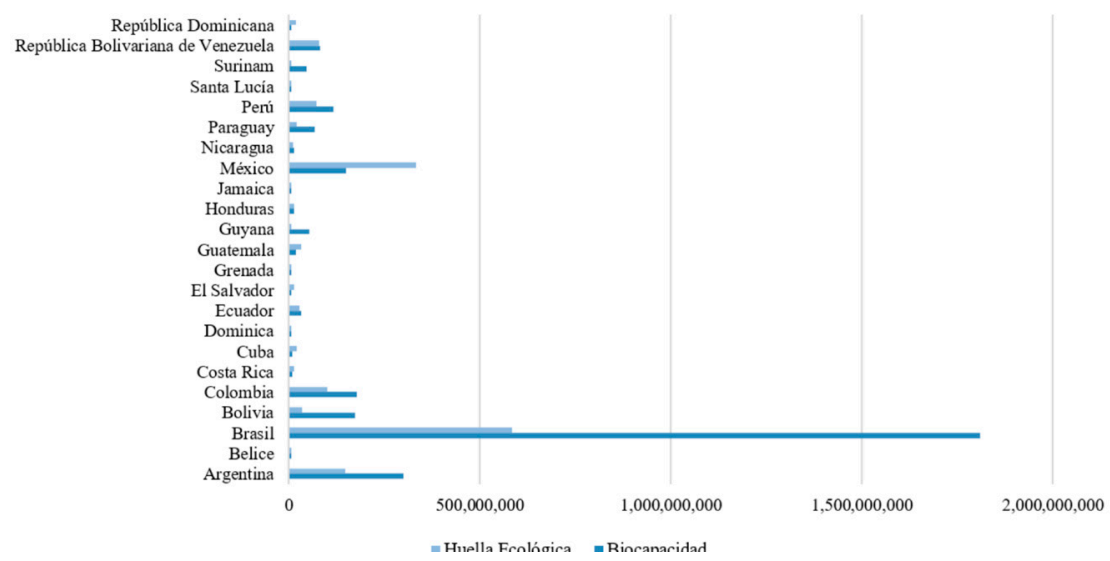

Fuente: elaboración propia a partir de los datos de Global Footprint Network.

40 Living Planet Report 2008, disponible en <http://assets.panda.org/downloads/living_planet_report_2008.pdf>

41 Global Footprint Network 2018, disponible en <https://www.footprintnetwork.org/>. 
Según los resultados obtenidos por los países en el cumplimiento del objetivo 7,42 las acciones de ALC en los PRM, con respecto a la disminución de la contaminación no han tenido avances. En 1990 de 4.6\% en la emisión de CO2, aumentó a 5.3 en el 2002, y también el consumo y uso de fertilizantes en áreas agrícolas, aproximadamente en 13, 230 toneladas en 2005. Esto repercute en que el promedio desde 1990 a 2010 en toneladas de $\mathrm{CO} 2$ por habitante, ha sido de 2.75 .

En lo que respecta a la protección de áreas naturales de tipo terrestre y marítimo, en 1990 era de $12.8 \%$, y en 2005, de $17.7 \%$. Sin embargo, al calcular el promedio desde 1990 a 2014, el total de áreas protegidas representó el 11.2 por ciento, ya que, en 2010, redujeron $7.1 \%$, y, en 2014 repuntó $6.3 \%$.

Uno de los logros de las metas del objetivo 7 se observa en el acceso a agua potable. En 1990 era de 83\%, y en 2004 de $91 \%$. El saneamiento pasó de $69 \%$ en 1990 a $77 \%$ en 2004 . En total, el promedio nacional de acceso a fuentes mejoradas de agua potable desde 1990 a 2015, es de $73.8 \%$. A nivel urbano es de $96.08 \%$ y en el plano rural, $74.72 \%$. Sin embargo, aún resta disminuir el porcentaje de habitantes de los tugurios, ya que en 1990 vivían 110.8 millones de personas y en 2005 aumentó la cifra a 134.3 millones. Por lo tanto, el promedio de personas que mejoró sus niveles de vivienda entre los años de 2000 a 2014 fue equivalente al 8\%.

Como los logros han sido minúsculos, se han tomado medidas en el combate al deterioro ambiental mediante acuerdos multilaterales, que representan un consenso internacional para realizar acciones conjuntas. En el capítulo siguiente se analizará la cooperación internacional, a través de los convenios multilaterales ambientales y el canje de deuda por naturaleza.

\section{Los convenios multilaterales ambientales y el canje de deuda por naturaleza}

Una primera forma de cooperación internacional en ALC, es el compromiso con el resto de los países para la protección del medio ambiente, a través de la firma de convenios multilaterales desde 1970 a la actualidad (tabla 3). Infiriendo que, al menos en lo que respecta al interés internacional de vincular a los países con objetivos comunes del desarrollo sostenible, se ha avanzado considerablemente; sin embargo, en la realidad los logros se han materializado de forma escasa.

42 Comisión Económica para América Latina y el Caribe (CEPAL), El séptimo Objetivo de los ODM, disponible en <http://www.cepal.org/mdg/Documentos/graficos/ODM7/FICHA_ODM7.pdf >. 


\section{Tabla 3. Convenios Multilaterales Ambientales}

CONVENIOS

Ramsar: Convención de Ramsar relativa a los humedales de importancia internacional, especialmente como hábitat de aves acuáticas de 1971.

CITES: Convención sobre el Comercio Internacional de Especies Amenazadas de Fauna y Flora Silvestres de 1973.

Convenio sobre la protección del patrimonio mundial, cultural y natural. Entró en vigor en 1975.

Especies migratorias: Conservación de las especies migratorias de animales silvestres, 1979.

Derecho del mar: Convención de las Naciones Unidas sobre el Derecho del Mar, 1982.

Protocolo de Montreal: Relativo a las sustancias que agotan la capa de ozono establecidas en la Convención de Viena de 1987.

Convenio de Basilea: Control de los movimientos transfronterizos de los desechos peligrosos y su eliminación, 1989.

Cambio Climático: Convención Marco de las Naciones Unidas sobre el Cambio Climático, 1992.

Diversidad Biológica: Convenio sobre la Diversidad Biológica de 1992.

Desertificación: Convención de las Naciones Unidas de Lucha contra la desertificación en los países afectados por sequía grave o desertificación, en particular en África, 1994.

Protocolo de Kyoto: Convención Marco de las Naciones Unidas sobre el Cambio Climático, 1997.

Protocolo de Cartagena: Seguridad de la Biotecnología del Convenio sobre la Diversidad Biológica, 2000.

Convenio de Estocolmo: Contaminantes orgánicos persistentes (COPs), 2001.

Rotterdam: plaguicidas y productos químicos peligrosos objeto de comercio internacional, 2004.

Convenio de Minamata: Acuerdo para reducir los efectos adversos del mercurio, 2013.

Acuerdo de París: Convenio para la reducción de los gases efecto invernadero, 2015.

Acuerdo Escazú: Acuerdo Regional sobre el Acceso a la Información, la Participación Pública y el Acceso a la Justicia en Asuntos Ambientales en América Latina y el Caribe, 2018.

Fuente: elaboración propia a partir de los datos de la CEPAL.

En esta tabla es posible advertir la evolución de la cooperación internacional con respecto al desarrollo sostenible. Desde las primeras firmas de convenios de la década de 1960 "empezaron a concertar acuerdos y diversos instrumentos jurídicos para evitar la contaminación marina".

La Conferencia de Estocolmo de 1972 incorporó variables relacionadas con el crecimiento económico, el desarrollo y la degradación del medio ambiente. Ello condujo a que en la década de 1980 "los Estados Miembros mantuvieron negociaciones históricas sobre cuestiones ambientales como las relativas a los tratados para la protección de la capa de ozono y el control de los traslados de desechos tóxicos." ${ }^{34}$ Sin em-

43 Organización de Naciones Unidas, Medio Ambiente y Desarrollo Sostenible, disponible en $<\mathrm{http} / / /$ www.cinu.org.mx/temas/des_sost.htm>.

44 Ibid. 
bargo, hasta 1987 se introdujo por primera vez el concepto de desarrollo sostenible en el informe presentado por la Comisión a la Asamblea General, como una percepción teórica contraria al crecimiento económico sin restricciones. Poniendo en especial línea de acción, el involucramiento de las naciones en la contribución para la disminución de la degradación de la biosfera.

Finalmente, en la Conferencia Mundial sobre Desarrollo Sostenible, celebrada en Johannesburgo en septiembre de 2002, se observó que las distintas realidades de los países no han permitido lograr los objetivos en materia de cooperación al medio ambiente, y se concluyó que "no existe verdadero desarrollo sin preservar y mejorar las bases ambientales sobre las que éste se sustenta. Ni tampoco es posible mantener la salud ecológica de la biosfera sin garantizar el desarrollo integral (económico, social y cultural) de la sociedad humana en su conjunto, en especial de esa mayoría sumida en la vergonzante marginación de la pobreza" ${ }^{45}$

Una de las causas del incumplimiento de estos convenios en los PRM de ALC, se debe a que no son susceptibles de AOD, salvo para proyectos específicos:

La AOD, para el desarrollo sostenible de los océanos y los mares, la protección de la atmósfera, la agricultura sostenible y la lucha contra la deforestación ha declinado. La participación de la AOD en esas esferas se redujo de 25\% en 1996 a 17\% en 1999. En 2000, América Latina y el Caribe recibió asistencia equivalente a $0.34 \%$ de su PIB, menor que el promedio recibido por los países en desarrollo (1.04\%). Esta cifra contrasta con la de 1992 (0.43\% para América Latina y el Caribe y 1.13\% para los países en desarrollo). ${ }^{46}$

Los países deben invertir gran parte de sus presupuestos para el logro de los objetivos medioambientales. Es por ello que en las posteriores reuniones internacionales - como la realizada en noviembre de 2008 en la que participaron los países pertenecientes al G-20, se reiteró la importancia de la cooperación para el logro de los Objetivos del Milenio,

45 Luis Jiménez Herrero, Cooperación Mundial para el Desarrollo Sostenible, disponible en <http:// www.cima.org.es/archivos/Areas/cooperacion/4-cooperacion.pdf>.

46 Alicia Bárcena, "Financiamiento para el desarrollo sostenible en América Latina y el Caribe. De Monterrey a Johannesburgo", en Cumbre Mundial sobre el desarrollo sostenible, 2002, disponible en $<$ http://www.eclac.org/publicaciones/xml/9/10879/lcr2098e.pdf>. 
de la sostenibilidad de la deuda externa, pero, sobre todo se enfatizó en un crecimiento justo y sostenible para todos, vinculando el binomio de desarrollo y protección ambiental.

Las medidas establecidas por el G-20 reactivaron una forma de cooperación internacional denominada conversión de deuda por naturaleza. Su origen se remonta al periodo de la agudización de las crisis económicas de la década de 1980, en donde el endeudamiento externo se incrementó. En ALC se inició una oleada de solicitudes de financiamiento a través de las instituciones internacionales (principalmente el Fondo Monetario Internacional (FMI) y el BM). Ello provocó que la naciente infraestructura internacional de carácter público dedicada al desarrollo ambiental, detuviera su crecimiento debido al escaso apoyo político en materia de inversión. Los recursos eran destinados a otras áreas, o al pago de la deuda externa.

El pago de la deuda acaparó los recursos de los gobiernos de los países sin solvencia ni liquidez monetaria, teniéndose que desarrollar estrategias que permitieran no generar intereses como producto del incumplimiento en los pagos, surgiendo así, la conversión de deuda por naturaleza:

El canje o conversión de deuda se define como la cancelación de parte de la deuda externa del gobierno deudor a cambio de un compromiso de movilizar recursos nacionales, en moneda nacional u otro activo, para un propósito acordado. Los objetivos principales de los canjes son reducir la deuda de los países e incrementar los recursos que pueden destinarse a la conservación. ${ }^{47}$

Este tipo de cooperación consiste en que "el gobierno acreedor condona deuda pendiente a un gobierno deudor y éste se compromete a destinar una cantidad acordada - normalmente menor que el valor nominal de la deuda - de fondos de contrapartida en moneda nacional a la conservación del medio ambiente. Estos fondos pueden canalizarse a través de instituciones públicas o privadas". ${ }^{4}$ Una variante de ello, es la interacción con tres actores participantes, conocido como el modelo a tres bandas:

Consiste en que una organización conservacionista, generalmente del país deudor, entra en contacto con representantes de instituciones internacionales interesadas en dar apoyo financiero a una actividad de gestión ambiental que también sea de interés para el país deudor. Luego la organización internacional 
aporta los fondos para la adquisición de una parte de la deuda, que compra en el mercado secundario con un valor inferior al nominal, y negocia la cancelación. ${ }^{49}$

Los primeros casos de conversión de deuda por naturaleza, aparecieron en 1987, con el gobierno de Bolivia y la organización Conservación Internacional. En el mismo año, Costa Rica y Ecuador se integraron, siendo un modelo efectivo hasta finales de 1980. A partir de entonces, "estas transacciones han continuado y se estima que han superado los 1 500 millones de dólares y abarcan a más de 20 países del mundo, número que sigue incrementándose" ${ }^{50}$

Tabla 4. Canje de deuda por naturaleza en millones de dólares

\begin{tabular}{|c|c|c|c|c|c|}
\hline Fecha & País & $\begin{array}{c}\text { Comprador o } \\
\text { donante }\end{array}$ & Valor nominal & $\begin{array}{c}\text { Costo de la } \\
\text { deuda }\end{array}$ & $\begin{array}{c}\text { Fondos de } \\
\text { conservación }\end{array}$ \\
\hline 1987 & Bolivia & CI & 0.65 & 0.10 & 0.25 \\
\hline 1987 & Ecuador & WWF & 1.00 & 0.35 & 1.00 \\
\hline 1988 & Costa Rica & NPF & 5.40 & 0.92 & 5.40 \\
\hline 1988 & Costa Rica & Países Bajos & 33.00 & 5.00 & 9.90 \\
\hline 1989 & Costa Rica & TNC & 5.60 & 0.78 & 1.70 \\
\hline 1989 & Costa Rica & Suecia & 24.50 & 3.50 & 17.10 \\
\hline 1989 & Ecuador & $\mathrm{WWF} / \mathrm{TNC} / \mathrm{MBG}$ & 9.00 & 1.10 & 9.00 \\
\hline 1990 & $\begin{array}{l}\text { República } \\
\text { Dominicana }\end{array}$ & TNC / PRCT & 0.56 & 0.12 & 0.58 \\
\hline 1990 & Costa Rica & WWF / TNC / Suecia & 10.80 & 1.90 & 9.60 \\
\hline 1991 & Jamaica & EAI & 271.00 & n.a & 9.20 \\
\hline 1991 & Bolivia & EAI & 38.40 & n.a & 1.80 \\
\hline 1991 & Costa Rica & Rainforest Alliance & 0.60 & 0.36 & 0.54 \\
\hline 1991 & México & $\mathrm{CI}$ & 0.25 & 0.18 & 0.25 \\
\hline 1991 & México & $\mathrm{CI}$ & 0.25 & 0.00 & 0.25 \\
\hline 1991 & Guatemala & TNC & 0.10 & 0.08 & 0.09 \\
\hline 1991 & Jamaica & TNC / AID & 0.44 & 0.30 & 0.44 \\
\hline 1992 & México & CI / AID & 0.44 & 0.36 & 0.44 \\
\hline
\end{tabular}




\begin{tabular}{|c|c|c|c|c|c|}
\hline 1992 & Ecuador & WWF & 1.00 & n.a & n.a \\
\hline 1992 & Panamá & TNC & 30.00 & 7.50 & 30.00 \\
\hline 1992 & Guatemala & CI / AID & 1.30 & 1.20 & 1.30 \\
\hline 1992 & Bolivia & TNC/WWF & 11.50 & 0.00 & 2.80 \\
\hline 1992 & Chile & EAI & 15.90 & n.a & 1.40 \\
\hline 1992 & Brasil & TNC & 2.20 & 0.75 & 2.20 \\
\hline 1992 & Ecuador & Japón & n.a & n.a & 1.00 \\
\hline 1992 & Ecuador & Bélgica & 6.50 & 6.50 & 6.50 \\
\hline 1993 & México & CI & 0.25 & 0.28 & 0.25 \\
\hline 1994 & México & CI & 0.28 & 0.24 & 0.28 \\
\hline 1994 & México & CI & 0.48 & 0.40 & 0.48 \\
\hline 1994 & México & CI & 0.29 & 0.25 & 0.29 \\
\hline 1994 & Ecuador & Suiza & 40.0 & 10.00 & 10.00 \\
\hline 1995 & México & CI & 0.49 & 0.25 & 0.34 \\
\hline 1996 & México & CI & 0.39 & 0.19 & 0.25 \\
\hline 1996 & México & CI & 0.50 & 0.33 & 0.44 \\
\hline 1996 & México & CI & 0.67 & 0.44 & 0.56 \\
\hline 1997 & México & CI & 0.27 & 0.19 & 0.24 \\
\hline 1997 & México & CI & 0.31 & 0.24 & 0.30 \\
\hline 2002 & Belice & EE.UU-LOBT-TNC & 9.00 & 7.20 & 7.20 \\
\hline
\end{tabular}

Fuente: Elaboración propia a partir de la información de la Comisión Económica para América Latina y el Caribe (CEPAL), El séptimo Objetivo de los ODM.

En la tabla anterior, se muestra la relación del canje de deuda por naturaleza de Bolivia, Ecuador, Costa Rica, República Dominicana, Jamaica, México, Guatemala, Chile, Brasil y Belice. Se observa que, en los primeros años de funcionamiento este programa, Costa Rica es uno de los países que realizó mayor canje. Sin embargo, entre 1991 y 1997, México es uno de los principales receptores, auspiciado por Conservation International.

Una objeción que se hace en este canje de deuda, es la pérdida de soberanía por parte de los gobiernos, al ceder parte de la responsabilidad a las organizaciones no gubernamentales en la toma de decisiones para la protección del territorio, aunado a los problemas que deriven al afectar a 
las poblaciones que habiten en la extensión territorial protegida, así como al desarrollo de proyectos de infraestructura, como se ha visto en el caso mexicano en los últimos sexenios. Particularmente en el gobierno actual, se ha reducido el presupuesto para la conservación ambiental, se han revocado los acuerdos de áreas protegidas, y se han puesto en marcha políticas públicas para la siembra de árboles frutales y maderas finas, incrementando el incentivo para la tala indiscriminada de bosques y prácticas inapropiadas de siembra para obtener financiamiento público.

\section{Conclusiones: el balance general de la entropía en el medio ambiente}

Las conclusiones a las cuales llega este trabajo, revelan la importancia de las crisis económicas en la contracción de cooperación internacional. Cuanto mayores sean los problemas y el impacto generado en los PRM, mayores serán los requerimientos de asistencia, lo cual incidirá negativamente en las metas del desarrollo sostenible.

Este estudio señala una propuesta de solución ante ello: la transferencia tecnológica Norte-Sur y la cooperación Sur-Sur para mejorar la situación productiva, permitir la transición hacia tecnologías e infraestructuras limpias, innovadoras y eficientes en el uso de los recursos. Esto fomentará medidas que permitan la creación de economías sostenibles y mayor facilidad de acceso a los mercados de los países desarrollados; toda vez que esto genera empleo, crecimiento y aumento de los ingresos per cápita en los PRM y menor dependencia de la AOD.

Por lo tanto, la hipótesis planteada en este trabajo, se refuta. Esto es porque la entropía en el medio ambiente llega a un sistema de equilibrio cuando no existe intervención humana, exceptuando cuando existen catástrofes naturales. Cuando el ser humano tala, cava, o construye ciudades, genera orden para producir neguentropía en su entorno. Esto afecta al medio ambiente, porque la entropía liberada de las ciudades, se traduce en sustancias químicas, caza furtiva, erosión del territorio, entre otras, liberadas en energía negativa a la naturaleza. Este estudio pudo comprobar que el nivel neguentropía, en el medio ambiente de los PRM, es menor a la entropía producida. Veamos por qué. 
A pesar de existir desde 1971 al 2018, casi una veintena de acuerdos multilaterales para la protección al medio ambiente y el desarrollo sostenible, de los cuales los 24 PRM analizados son firmantes, y un incremento exponencial del canje de deuda por naturaleza, la biocapacidad sólo es posible en Argentina, Brasil, Colombia, Guyana, Paraguay, Perú, Surinam, Venezuela, Bolivia y Nicaragua. Por el contrario, Belice, Costa Rica, Cuba, Dominica, República Dominicana, Ecuador, Granada, Guatemala, Jamaica, México, Santa Lucía, El Salvador y Honduras, tienen una huella ecológica superior, a pesar de ser los países con más canje de deuda por naturaleza contratada.

Asimismo, las emisiones de $\mathrm{CO}_{2}$ aumentaron, contabilizándose 2.75 toneladas por persona, a finales de 2015, así como el incremento en el uso y consumo de fertilizantes equivalentes a 13, 230 toneladas. En cuanto a las áreas marítimas y terrestres protegidas, disminuyeron. En 2005 se había alcanzado el 17.7\%, y para 2014, el porcentaje era de $11.2 \%$. Sin embargo, se observan indicadores positivos en el acceso a fuentes mejoradas de agua. En el nivel urbano, el $96.08 \%$ de la población tenía acceso a agua potable, y en el rural, el 74.72\%. Por el contrario, la tendencia en las condiciones de la vivienda ha ido en detrimento, ya que hasta 2015, sólo el 8 por ciento mejoró.

A partir de la evidencia recabada, se concluye que el canje de deuda externa por naturaleza no es la única herramienta para transitar al desarrollo sostenible. La solución estaría más cerca en el cambio de las prácticas sociales del estilo de vida de los países, ya que la tendencia es generar una privatización de los recursos naturales en aras de la reducción de la deuda externa. Sin una cultura de protección medioambiental, aunque se incremente el flujo de capital, se mantendrá el deterioro de los países, ya que los habitantes no han logrado incorporar las herramientas del desarrollo sostenible en los procesos productivos.

Es importante reconocer que, a pesar de las críticas, este tipo de cooperación internacional ha resultado innovadora, debido a que permite la utilización de los recursos financieros de forma más adecuada y, al mismo tiempo, logra avances en la contribución de la protección del medio ambiente, y de acuerdo a lo observado, es un tanto más efectivo con respecto a los convenios multilaterales ambientales. 


\section{Referencias}

Agudelo, Jairo, "Cooperación para el desarrollo, relaciones internacionales y políticas públicas. Teorías y prácticas del diálogo Euro-Latinoamericano", en Documentos y Aportes en Administración Pública y Gestión Estatal, vol. 14, núm. 23, 2014.

Alonso, José Antonio, Cooperación con Países de Renta Media, Editorial Complutense S.A. Madrid, 2007.

Álvarez Uría, Fernando y Varela, Julia, Sociología, Capitalismo y Democracia. Génesis e Institucionalización de la Sociología en Occidente, Madrid, España, Morata, 2004.

Bárcena, Alicia, "Financiamiento para el desarrollo sostenible en América Latina y el Caribe. De Monterrey a Johannesburgo", en Cumbre Mundial sobre el desarrollo sostenible, 2002, disponible en <http:// www.eclac.org/publicaciones/xml/9/10879/lcr2098e.pdf>.

Cepal, (Comisión Económica para América Latina y el Caribe), El séptimo Objetivo de los ODM, disponible en <http://www.cepal.org/mdg/ Documentos/graficos/ODM7/FICHA_ODM7.pdf>.

DAC List of ODA Recipients, <http://www.oecd.org/dac/financing-sustainable-development/development-finance-standards/DAC-List-ofODA-Recipients-for-reporting-2018-and-2019-flows.pdf>.

Evaluación de los Ecosistemas del Milenio, disponible en >http://www.millenniumassessment.org/documents/document.439.aspx.pdf >.

Human Development Indices and Indicators 2018 Statistical Update, United Nations Development Programme, Communications Development Incorporated, Washington DC, USA, 2018.

Jiménez Herrero, Luis, Cooperación Mundial para el Desarrollo Sostenible, disponible en <http://www.cima.org.es/archivos/Areas/cooperacion/4-cooperacion.pdf $>$.

Lara-Rosano, Felipe, Aplicaciones de las ciencias de la complejidad al diagnóstico e intervención en problemas sociales, México, Colofón, 2017.

Living planet report 2008, disponible en $<$ http://assets.panda.org/downloads/living_planet_report_2008.pdf >.

Maldonado, Marcela y Lopez, Santos, "La visión del desarrollo dentro del contexto global y regional. El regionalismo a través de la Alianza del Pacífico y la Asociación Latinoamericana de Integración 20052014", en Desafíos, vol. 29, núm. 1, 2013. 
Martin-Arnaiz, José, "Vínculos entre la cooperación para el desarrollo y la educación en los países en desarrollo", Semestre Económico, vol. 20, núm. 42, 2017.

Millan Acevedo, Natalia y Santander Campos, Guillermo, "Coherencia de políticas para el desarrollo y la cooperación Sur-Sur: reflexiones para una convergencia analítica, en OASIS, núm. 18, 2013.

ONU (Organización de Naciones Unidas), Medio Ambiente y Desarrollo Sostenible, disponible en $<$ http://www.cinu.org.mx/temas/des_sost.htm>.

Otálora, Lady y Rouvinski, Vladimir, "Cooperación internacional para el desarrollo en el Valle del Cauca: un estudio de percepciones". Estudios Gerenciales, vol. 29, núm. 126, 2013.

Pellizon, Marco, "Cooperación internacional para el desarrollo: gobierno, economía y sociedad. evolución de las políticas y escenarios futuros -Desde la política hasta las OSC: interrogantes y respuestas para construir un futuro de desarrollo sostenible y global", en Investigación y Desarrollo, vol. 26, núm. 1, 2018.

Pinto, Agüero, Carol, Globalización, Desarrollo y Cooperación Internacional, en La inserción internacional de las regiones y los municipios. Lecturas sobre gestión de cooperación descentralizada, Chile, Universidad de Viña del Mar, 2005.

Pnud (Programa de Naciones Unidas para el Desarrollo), Objetivos de Desarrollo del Milenio, disponible en <http://www.undp.org/spanish/ $\mathrm{mdg} /$ basics.shtml>.

Restrepo, Manuela, "La cooperación internacional al desarrollo como herramienta de protección y promoción de los derechos humanos: el caso latinoamericano", en Revista Facultad de Derecho y Ciencias Políticas, vol. 42, núm. 116, 2012.

Ripoll, Alejandra y Ghotme, Rafat, "La cooperación internacional: herramienta de desarrollo o de atraso", en Revista Latinoamericana de Bioética, vol. 15, núm. 1, 2015.

Ruiz Ballesteros, Esteban y Solana Ruiz, José Luis, Complejidad y ciencias sociales, Sevilla, Universidad Internacional de Andalucía, 2013.

Sanahuja, José, "La Unión Europea y el regionalismo latinoamericano: un balance”, en Investigación y Desarrollo, vol. 21, núm. 1, 2013.

, José Antonio, “¿Más y mejor ayuda?: la Declaración de París y las tendencias en la cooperación al desarrollo", en Anuario 2007-2008 del Centro de Educación e Investigación para la Paz (CEIPAZ), Madrid, 2007. 
José, Tezanos, Sergio, Kern, Alejandra y Perrota, Daniela, Perspectivas y propuestas para la cooperación al desarrollo entre la Unión Europea y América Latina y el Caribe. Cátedra de cooperación internacional y con Iberoamérica, Instituto Complutense de Estudios Internacionales, 2015.

Sánchez Galicia, Javier (coordinador), Treinta claves para entender el poder, Léxico para la nueva comunicación política, México, Piso 15 Editores, 2010.

Tassara, Carlo, "Diálogo, cooperación y relaciones euro-latinoamericanas", en Investigación y Desarrollo, vol. 21, núm. 1, 2013.

Tezanos, Sergio, "Geografía del desarrollo en América Latina y el Caribe: hacia una nueva taxonomía multidimensional de los Objetivos de Desarrollo Sostenible" en Revista de la CEPAL N 125, 2018.

Tichauer, Ricardo, "El rol de la Empresa Privada en la Cooperación Internacional", en La inserción internacional de las regiones y los municipios. Lecturas sobre gestión de cooperación descentralizada, Chile, Universidad de Viña del Mar, 2005.

Urteag, Eguzki, "La teoría de sistemas de Niklas Luhmann”, en Contrastes. Revista Internacional de Filosofía, vol XV, Departamento de filosofía, Universidad de Málaga, 2010, p. 304.

World Bank, World Bank Country and Lending Groups, disponible en<https://datahelpdesk.worldbank.org/knowledgebase/articles/906519>. 


\section{EL PENSAMIENTO COMPLEJO EN LA COSMOVISIÓN DE LOS PUEBLOS INDÍGENAS DE LA AMAZONÍA PERUANA}

Rodrigo Severo Arce Rojas

Universidad Ricardo Palma

\section{Introducción}

La crisis ambiental, producto de la confluencia de un marco epistemológico disyuntivo, reductivo, lineal y determinista, un sistema económico que privilegia el mercado y el crecimiento sin límites, y un sistema político que privilegia el interés individual antes que el bienestar general, provoca que el planeta esté amenazado por el cambio climático, la pérdida de biodiversidad, la extinción acelerada de las especies, entre otras manifestaciones, que afecta la calidad de vida de las poblaciones más vulnerables.

El pensamiento neoliberal está poniendo en cuestión la viabilidad de la vida en el planeta tierra; no obstante, tiene un gran predominio en la institucionalidad mundial y en la mayoría de Estados. Contradictoriamente, el pensamiento indígena amazónico que, en su esencia, se sustenta en una estrecha relación entre el ser humano y la naturaleza y plantea una nueva forma de expresar el desarrollo (buen vivir, vivir bien o vida plena), también es erosionado por lo valores de una economía depredadora de la naturaleza. En tal sentido, es importante la propuesta de ontologías relacionales que reconoce la diversidad de formas de relación entre la sociedad y la naturaleza, y está más acorde con las alternativas al desarrollo que recogen la pluralidad, la ecología de saberes, la ética y el cuidado de la tierra. Ello permitirá avanzar hacia auténticos procesos de diálogo intercultural basados en el respeto a la diversidad. 
Aunque el pensamiento indígena es catalogado como "pensamiento salvaje", propio de estados inferiores de conciencia humana a través de la historia, encierra en sus propuestas nuevas formas de vivir la sustentabilidad más allá de propuestas de desarrollo -o incluso-, de desarrollo sostenible, cuyos fundamentos económicos de crecimiento, basado en una visión de la naturaleza como una canasta ilimitada de recursos, que deben explotarse sin ningún tipo de remordimiento.

Las cosmovisiones de los pueblos indígenas de la Amazonía peruana, en tanto no forman parte de la tradición epistemológica occidental, mantienen sus propias y particulares manifestaciones. De acuerdo con Ventrella, existe una estrecha correspondencia entre los paradigmas, pensamientos, sentimientos, actitudes, discursos y narrativas. Por ello, es posible derivar el pensamiento indígena amazónico a través de la identificación de sus cosmovisiones, ${ }^{1}$ que se expresan a través de los mitos y ritos. ${ }^{2}$

Es preciso señalar, no obstante, que las cosmovisiones, como la cultura, no son estáticas, pues están sujetas a una serie de influencias, producto de la aculturación producida a través de la articulación al mercado y a la ciudad, la escolarización estatal, los medios de comunicación, las religiones, nuevos patrones de ocupación espacial del territorio, entre otros factores. Muchos grupos étnicos han integrado en sus vidas diversos elementos de la economía global de mercado y de las sociedades nacionales con mayor o menor referencia a sus antecedentes culturales. ${ }^{3}$ En tal sentido, existen diferentes grados de pérdida o dilución de las cosmovisiones originarias. La pérdida de las cosmovisiones se traduce también en pérdida de referentes de códigos de conducta. ${ }^{4}$ Por todo ello, San Román se pregunta: ¿cuál será la capacidad de los indígenas y del pueblo amazónico en general para integrar a su racionalidad una cosmovisión tan opuesta a la suya? Indica que sólo la historia dará la respuesta. ${ }^{5}$

1 Scott Ventrella, El Poder del Pensamiento Positivo en las Empresas 10 Rasgos para lograr Resultados óptimos, Bogotá, Grupo Editorial Norma, 2001, p. 264.

2 Beatriz Huertas y Mauricio Chanchari Lancha, Agua, cultura y territorialidad en el pueblo Shawi del río Sillay, Lima, TERRA NUOVA, 2011, p. 154.

3 Anika Schroeder y Volker von Bremen, Pueblos indígenas y protección de bosques a través de REDD+ y medidas similares Fundamentos para un diálogo, Berlín, Pan para el Mundo - Servicio Protestante para el Desarrollo, Organización Protestante para Diaconía y Desarrollo, 2013, p. 44.

4 Michael Valqui, Conrad Feather y Roberto Espinoza, Haciendo visible lo invisible. Perspectivas indígenas sobre la deforestación en la Amazonía peruana, Lima, Asociación Interétnica de Desarrollo de la Selva Peruana AIDESEP y Forest Peoples Programme FPP, 2014, p. 362.

5 Jesús San Román, Perfiles Históricos de la Amazonía Peruana, Iquitos, Centro de Estudios Teológicos de la Amazonía Centro Amazónico de Antropología y Aplicación Práctica Instituto de Investigaciones de la Amazonía Peruana, 1994, p. 281. 
En tanto que Arce ensaya una aproximación a un núcleo conceptual del pensamiento complejo.

En tal sentido, señala que el pensamiento complejo es una filosofía, estrategia, método, actitud y práctica orientada al abordaje de problemas de frontera, que se encuentran entre los comportamientos regulares y predecibles y los comportamientos irregulares e impredecibles, con el propósito de entender y dar explicaciones de la realidad de manera totalizadora, integradora, dialogante con el entorno, constructiva y transformadora a partir de la comprensión de las estructuras complejas en las que se verifican la emergencia de nuevos comportamientos y la auto organización. Este núcleo conceptual servirá de base para esta investigación. ${ }^{6}$

Es necesario señalar que el pensamiento complejo reconoce la racionalidad, pero no se aferra únicamente a ella, porque está más abierta a la intuición, a las emociones y mitos como fuentes diversas de conocimiento.

El conocer no es sólo una función cerebral, sino que implica la actividad de todo el ser en su medio, incluyendo la acción. Estas características del pensamiento complejo hacen que su aproximación a las cosmovisiones se realice sin apremios de incertidumbre.

No existe una única definición para la cosmovisión, pero en líneas gruesas la mayoría de autores coincide en señalar que es la manera cómo los grupos humanos ven e interpretan su realidad tanto de lo visible como lo invisible, como de lo perceptible y de aquello que no puede ser directamente sensible; esto lo han desarrollado ampliamente las últimas dos décadas, entre otros, Espino, ${ }^{7}$ Rueda, ${ }^{8}$ Huertas y Chanchari, Mayor y Bodmer, ${ }^{9}$ Broda y Báez. ${ }^{10}$ La cosmovisión permite establecer valores y

6 Rodrigo Arce, "Aportes del pensamiento complejo a la facilitación de grupos" Congreso Mundial por el Pensamiento Complejo Los desafíos en un mundo globalizado París, 8 y 9 de diciembre, 2016, disponible en <https://www.reseau-canope.fr/fileadmin/user_upload/Projets/pensee_complexe/ arce_aportes_del-pensamiento_complejo.pdf> , consultado el 27 de mayo de 2019.

7 Gonzalo Espino, "Literatura indígena amazónica Shipibo-conibo y el kené de la palabra de Lastenia Canayo", Estudios Filológicos, 2018, 247-267, disponible en <http://revistas.uach.cl/index.php/efilolo/article/view/4179>, consultado el 30 de mayo de 2019.

8 Paulino Rueda. "Las Comunidades Nativas de la Amazonía peruana y el cumplimiento de los incisos c) y d) del artículo 10 del Convenio sobre Diversidad Biológica. Situaciones Análogas En La Unión Europea", Vox Juris, 26(2), 2013, pp. 155-196.

9 Pedro Mayor y Richard Bodmer, Pueblos indígenas de la Amazonía peruana, Iquitos, Centro de Estudios Teológicos de la Amazonía CETA, 2009, p. 339.

10 Johanna Broda y Félix Báez, Cosmovisión, ritual e identidades de los pueblos indígenas, México, Fondo de Cultura Económica, 2001, p. 527. 
normas que guían las prácticas cotidianas, según ha establecido Gardi$\mathrm{ni}^{11}$, $\mathrm{y}$, finalmente, tiene que ver con la sistematización del tiempo, espacio y la ubicación de los seres como sujetos interrelacionados. ${ }^{12}$

El pensamiento salvaje es conocido también como mentalidad primitiva, pensamiento prelógico, falsa conciencia, pensamiento mágico-religioso, mito, bricolaje, ciencia de lo concreto, intuición, imaginación, percepción, según lo han establecido Goody ${ }^{13}$ y Olavarría. ${ }^{14}$ Claude Lévi-Strauss aclara que se refiere al pensamiento en estado salvaje, distinto del pensamiento culto o domesticado con miras a algún rendimiento propio de pueblos "ágrafos". ${ }^{15}$ Por su parte, Barandiarán señala que el pensamiento salvaje se refiere a la inteligencia de los pueblos primarios u originarios y no primitivos, como suele hacerse. ${ }^{16}$ Gómez toma como base la obra de Lévi-Strauss y explica que el pensamiento salvaje:

Se trata del pensamiento espontáneo, el que opera en la magia, en el rito, en el mito, el mismo que se maneja en la vida ordinaria, en las opiniones, en la concepción del mundo, en la ideología política; es a la vez analítico y sintético; es capaz de pensarlo todo y encuadrarlo dentro de una totalidad coherente; se eleva desde las cosas concretas hasta relacionarlas e integrarlas en sistemas abstractos; etc. ${ }^{17}$

El propósito de la presente investigación es conocer en qué medida las cosmovisiones indígenas se corresponden con los principales atributos del pensamiento complejo.

Tanto el pensamiento complejo como las cosmovisiones indígenas amazónicas, comparten el paradigma de la complejidad y es necesario conocer el grado de esta correspondencia.

11 Llery Gardini et al., Informe de identificación de pueblos indígenas u originarios en el ámbito del lote 181, Informe técnico, 2015, p. 77.

12 Manuel Calle, El conocimiento ambiental Shipibo-Konibo en la programación curricular de $V$ ciclo de las instituciones educativas bilingües del distrito de Yarinacocha, región Ucayali (Tesis para optar al Grado Académico de Maestro en Ciencias de la Educación con mención en Educación Ambiental y Desarrollo Sostenible), Universidad Nacional de Educación Enrique Guzmán y Valle, 2018, p.165.

13 Jack Goody, La domesticación del pensamiento salvaje, Madrid, Ediciones Akal, 2008, p. 192.

14 María Olavarría, "El pensamiento salvaje y la importancia de ser imperfecto", en Alteridades, 7 (13): 33-38.

15 Claude Levi Strauss, Mito e significado, Lisboa, Portugal, Edições 70, 1978, p. 66.

16 Agustín Barandiarán, "La lógica del Bricolaje y las Piezas sueltas", en Revista Conclusiones analíticas, (s.f.), <http://sedici.unlp.edu.ar/bitstream/handle/10915/48336/Documento_completo. pdf? sequence $=1$ \&isAllowed $=y>$, consultado el 2 de junio.

17 Pedro Gómez, La antropología estructural de Claude Levi-Strauss Ciencia, filosofía, ideología, Madrid, Editorial Technos, 1981, p. 384. 
Con la emergencia de la propuesta de ontologías relacionales, ${ }^{18}$ la ecología de saberes ${ }^{19}$ y de alternativas al desarrollo, cobra sentido la recuperación y revaloración de las cosmovisiones indígenas como un aporte a una construcción de una sustentabilidad fuerte, aquella que está motivada por un respeto profundo a la vida y no subalterna a los imperativos del crecimiento económico ilimitado. ${ }^{20}$ En esa dirección, el pensamiento indígena tiene muchos elementos aún no suficientemente comprendidos ni atendidos por la ciencia normal, porque escapa largamente a sus presupuestos epistemológicos.

\section{Métodos}

Para realizar la investigación se usó un esquema que presenta los principales atributos del pensamiento complejo y con este fundamento se realizó una búsqueda bibliográfica relativa a la cosmovisión de los pueblos indígenas de la Amazonía peruana. ${ }^{21}$ Ello permitió identificar qué elementos de las cosmovisiones indígenas se corresponden con los atributos del pensamiento complejo.

Se señala que el análisis se hizo tratando de encontrar rasgos comunes de las diferentes cosmovisiones amazónicas y cuando existieran particularidades que destacar se haría la mención del grupo étnico correspondiente. Se reconoce que el mundo de las cosmovisiones de los indígenas amazónicos es intrincado y no es posible identificar todas sus expresiones, por ello se pone énfasis en las más relevantes.

La pregunta de investigación que se plantea es: ¿en qué medida el pensamiento complejo está presente en el pensamiento indígena de los pueblos indígenas de la Amazonía peruana? En tal sentido, la hipótesis de la investigación es que el pensamiento indígena contiene elementos significativos propios de un pensar complejo y, por tanto, su revaloración forma parte del enriquecimiento de propuestas alternativas al desarrollo.

18 Arturo Escobar, Sentipensar con la tierra. Nuevas lecturas sobre desarrollo, territorio y diferencia, Medellín, Ediciones UNAULA, 2014, p. 184.

19 Boaventura de Sousa Santos, Descolonizar el saber. Reinventar el poder, Montevideo, Ediciones Trilce, 2010, p. 113.

20 Eduardo Gudynas, "Debates sobre el desarrollo y sus alternativas en América Latina: Una breve guía heterodoxa”, en Más Allá del Desarrollo, Miriam Lang, y Dunia Mokrani, comp., Quito, Ediciones Abya Yala, Universidad Politéctica Salesiana, Fundación Rosa Luxembrugo, 2011, disponible en <http:// rio20.net/wp-content/uploads/2012/07/masalla-del-desarrollo_30.pdf $>$, consultado el 3 de junio de 2019).

21 Rodrigo Arce, "Respuestas del pensamiento complejo al pensamiento simplificante", en Horizontes $y$ Raíces, Volumen 6, Número 1 (Enero-Junio), 2018, p. 32-41, disponible en <http://www.hraices. uh.cu/index.php/HorR/ article/view/140>, consultado el 27 de mayo de 2019). 
Una limitación para la realización de la investigación consistió en que tanto la complejidad como el pensamiento complejo no tienen definiciones precisas y se les debe entender desde sus atributos o principios. Tampoco existe una convención que señale con precisión cuáles son los principios definidos del pensamiento complejo, pero se toma como base los enunciados por Morin (1998): principio sistémico, principio dialógico, de recursividad y hologramático. ${ }^{22}$

\section{Resultados. Principio sistémico}

Uno de los principales aspectos que comparten el pensamiento complejo y las cosmovisiones indígenas se refiere al enfoque sistémico, totalizador y holístico. El principio de la totalidad significa que las personas, los demás seres vivos y sus espíritus están en permanente interrelación activa conformando el todo del cosmos. Se podría afirmar que el pensamiento indígena amazónico es un pensamiento ecologizado. Alarcón-Cháires señala al respecto que

Los conocimientos y saberes locales son sistemas de carácter dinámico, evolutivo, adaptativo, heurístico y práctico. Su construcción y validación solo es posible bajo los contextos y particularidades que los originan. ${ }^{23}$

Un rasgo común en la cosmovisión de los pueblos indígenas amazónicos es la concepción de una humanidad muy extendida a través de la cual otros elementos de la naturaleza son también considerados humanos. ${ }^{24}$

Es necesario señalar que la condición original común a humanos y animales no es la animalidad, sino la humanidad. ${ }^{25}$

Para los pueblos indígenas amazónicos los humanos, los no humanos, las deidades, los aspectos biofísicos, las costumbres, mitos, leyendas, historias, entre otros aspectos tangibles y no tangibles, forman parte de un único entramado interdependiente, conocido también como territorio, según los estudios de Olórtegui, ${ }^{26}$ el Fondo Indígena, ${ }^{27}$ y el ministerio de

22 Edgar Morin, Introducción al pensamiento complejo, Barcelona, Gedisa Editorial, 1998, p. 108.

23 Pablo Alarcón, Epistemologías otras: Conocimientos y saberes locales desde el pensamiento complejo México, Tsíntani, AC/Instituto de Investigaciones en Ecosistemas y Sustentabilidad - Universidad Nacional Autónoma de México, 2019, p. 274.

24 Andrea Calmet, Contribución de los pueblos indígenas a la conservación de la Amazonía peruana, Lima, Sociedad Peruana de Derecho Ambiental, 2018, p. 35.

25 Philippe Descola, "Las cosmologías de los indios de la Amazonia", Zainak, 17 (1998), pp.219-227, disponible en $\langle$ https://dialnet.unirioja.es/servlet/articulo? codigo=1368836>, consultado el 27 de mayo de 2019.

26 Julio Olórtegui, "La naturaleza en la cosmovisión de los pueblos originarios de la Amazonía peruana", Ponencia magistral en el XV Congreso Nacional de Filosofía, Puno, 26 al 30 de octubre del 2015.

27 Fondo Indígena, Módulo de Historia y Cosmovisión Indígena, Guía de aprendizaje colectivo para organizaciones y comunidades, La Paz, Fondo Indígena, 2007, p. 112. 
Salud, ${ }^{28}$ Ello lleva a la necesidad de conocer el todo, de acuerdo a las aportaciones de Lévi-Strauss ${ }^{29}$ y de Gómez. ${ }^{30}$ Por ello, se puede afirmar que la cosmovisión indígena está signada por el pensamiento relacional. Así, las mujeres Awajún llaman a sus cultivos "hijas", y los hombres consideran a los animales que cazan como "cuñados".

Este conjunto de elementos entrelazados está en equilibrio armónico y no debe ser alterado. ${ }^{31}$ El principio de energía del pueblo Shipibo Konibo refiere a que existe una fuerza central que regula el orden del mundo y la relación del hombre con la naturaleza, el cual suena muy similar a la autoorganización de los sistemas complejos. Asimismo, el hecho que los indígenas amazónicos consideren que todos los seres del universo tienen un dueño, contribuye al equilibrio en la relación con la naturaleza. ${ }^{32}$

Ahora bien, una diferencia respecto al pensamiento sistémico es que en las cosmovisiones indígenas amazónicas el territorio no tiene límites como en el concepto de sistemas, sino que todo conforma una continuidad ${ }^{33}$ como han advertido Tamariz y García. ${ }^{34}$ Este territorio es el espacio de encuentro y relación entre la gente, entre la gente con otros seres y de todos con la naturaleza. ${ }^{35}$

Otro aspecto que resalta en las cosmovisiones indígenas amazónicas es la multidimensionalidad. Así, en las diferentes cosmovisiones indígenas coexisten diferentes mundos, generalmente compuestos por el mundo del Agua, de la Tierra y el de arriba, entendido como Cielo, Nubes o Sol. Desde la física cuántica, la concepción de los pueblos in-

28 Perú Ministerio de Salud (MINSA), Análisis de la Situación de Salud del Pueblo Achuar, (Lima, Dirección General de Epidemiología, 2006, p. 294.

29 Claude Levi Strauss, El pensamiento salvaje, Bogotá, Fondo de Cultura Económica, 1997, p. 413.

30 Pedro Gómez, La antropología estructural de Claude Levi-Strauss Ciencia, filosofía, ideología, Madrid, Editorial Technos, 1981, p. 384.

31 Carlos Viteri, 2002, "Visión indígena del desarrollo en la Amazonía", en Polis [En línea], 3 (2002), disponible en $\langle$ http://journals.openedition.org/polis/7678>, consultado el 27 de mayo de 2019).

32 Militza Seminario, Centro de investigación científico en la Reserva Tambopata-Candamo, Tesis para optar el grado de Arquitecto, Universidad de Ciencias Aplicadas, 2003.

33 Organización Regional de los Pueblos Indígenas de la Amazonía Norte del Perú-ORPIAN-P y Centro Amazónico de Antropología y Aplicación Práctica (CAAAP), Territorio Integral Tajimat Awajún Fundamentos legales, antropológicos y políticos, Lima, Perú, ORPIAN-P, CAAAP, 2018, p. 47.

34 Katherine Tamariz y Luis García. "Comunidades nativas y derechos de propiedad: una aproximación desde la selva central” (s.f.), disponible en <http://www.desco.org.pe/recursos/site/files/CONTENIDO/1132/PH_15_Tamariz_Garc\%C3\%Ada.pdf $>$, consultado el 3 de junio de 2019.

35 James Regan, "Los awajún y wampís contra el Estado: una reflexión sobre antropología política", en Investigaciones Sociales, Universidad Nacional Mayor de San Marcos/Instituto de Investigaciones Histórico Sociales, Vol.14, No 24, 2014, pp. 19-35, disponible en <https://doi.org/10.15381/is. v14i24.7278>, consultado el 26 de mayo de 2019. 
dígenas de los multimundos se parece a la teoría del todo, la teoría del campo unificado o la teoría de las cuerdas. ${ }^{36}$ La tabla 1 muestra los diversos mundos en la cosmovisión de algunas etnias amazónicas:

\section{Tabla 1: Mundos, lugares o espacios en algunas etnias de la Amazonía peruana.}

\begin{tabular}{|c|c|}
\hline Etnia & Mundos, lugares o espacios \\
\hline Kichwa del Pastaza & $\begin{array}{l}\text { El lugar donde está la tierra sin vegetación, las nubes, el aire y la } \\
\text { lluvia; lugar de los muertos; y el lugar de Yaya (Dios), el sol, la luna } \\
\text { y las estrellas. }\end{array}$ \\
\hline Achual (Achuar) & $\begin{array}{l}\text { El mundo está dividido en cinco espacios: Agua, donde no hay vida } \\
\text { y que sirve para sostener la tierra; Debajo del agua, donde viven los } \\
\text { Tsungki; Tierra, lugar donde vivimos nosotros; lugar donde habitan } \\
\text { las nubes y estrellas; y lugar de los hombres Karakam. El lugar donde } \\
\text { está el sol no se cuenta porque nadie ha llegado allí. }\end{array}$ \\
\hline Wambisa y Wampis & $\begin{array}{l}\text { Existen tres espacios fundamentales: Entsa, el espacio del agua; } \\
\text { Nunka, el espacio de la tierra; y Nayaim, el espacio del cielo. }\end{array}$ \\
\hline Jebero & $\begin{array}{l}\text { Dek, el mundo del agua; Lupak, el mundo de los seres humanos y ani- } \\
\text { males terrestres; y Kekiluktek, el mundo de los espíritus y las estrellas. }\end{array}$ \\
\hline Bora Huitoto & $\begin{array}{l}\text { La tierra está formada por tres mundos: de la Tierra, del Agua y } \\
\text { de las Almas. En el mundo de la Tierra, donde vivimos. }\end{array}$ \\
\hline Shawi (Chayahuita) & $\begin{array}{l}\text { El mundo está conformado por espacios: el espacio de abajo, el espacio } \\
\text { del agua, espacio de la tierra, espacio del aire, espacio de viento y lluvia y } \\
\text { el espacio de muerte y vida. }\end{array}$ \\
\hline Harakbut & $\begin{array}{l}\text { El mundo Wäwëri o mundo del agua, Numberi o mundo del bosque, } \\
\text { Kurudneri o mundo del aire y Serawë o mundo subacuático. }\end{array}$ \\
\hline Kukama Kukamiria & $\begin{array}{l}\text { Los mundos se clasifican en tres espacios: la tierra, el cielo y el mundo } \\
\text { del agua. En este último habitan diferentes seres, como el yacuruna, la } \\
\text { sirena, los bufeos y, además, la gente que vive dentro del agua. }\end{array}$ \\
\hline
\end{tabular}

Es necesario señalar que no todas estas dimensiones son equiparables, pues en ocasiones el mundo de la tierra es ocupada por humanos o por humanos y animales terrestres, el mundo del agua puede referirse a aguas superficiales o al mundo subacuático, los Kichwa del Pastaza tienen un lugar específico para los muertos; mientras que los Shawi tienen un espacio para la muerte y la vida, entre otras especificidades. Para la comunicación entre estos mundos destaca el papel que cumplen los chamanes ${ }^{37}$.

36 Fondo para las Naciones Unidas para la Infancia Unicef, Valores de los pueblos y nacionalidades indígenas de la Amazonía (Bolivia, Ecuador y Perú), Lima, Unicef, 2008, p. 192.

37 Gerald Weiss, Campa Cosmology: The word of a forest tribe in South America, New York, Anthropological Papers of the American Museum of Natural History, 52 (5), 1975, pp. 217-588. 
En los Wachiperi se verifica la multidimensionalidad del "cuerpo" entendido como la colectividad de cinco organismos o energías: el cuerpo físico, el cuerpo mental, el cuerpo emocional, el cuerpo espiritual, y el cuerpo sexual. ${ }^{38}$

También es importante señalar la valoración del proceso en las cosmovisiones indígenas. Al pensamiento amazónico le interesa el curso de la vida, es observador de cómo las cosas nacen, crecen y se reproducen, siguiendo su propio curso, como se ha visto en estudios de Olórtegui. Asimismo, es interesante señalar que, en la cosmovisión indígena amazónica, el tiempo no es lineal, sino cíclico, de ahí que para el indígena amazónico el pasado está siempre presente, pues le permite seguir existiendo con todo el cúmulo de experiencias de sus ancestros, los cuales lo acompañan.

\section{Principio dialógico}

El principio de la comunión es la integración armónica entre el hombre y la naturaleza y alude al hecho que la naturaleza está dotada de vida y es posible entablar el diálogo con ella. Este es un diálogo entre personas o paisanos, humanos y no humanos, que buscan vivir complementariamente en armonía. Por ello no se busca dominar la naturaleza, como se ha visto en los estudios de Mayor y Bodmer ${ }^{39}$ y Olórtegui.

A diferencia del pensamiento disyuntivo del paradigma simplificante de occidente, el pensamiento indígena es articulador, religante y sintético, como lo han determinado diversos autores, entre ellos, Mayor y Bodmer y Lévi-Strauss. En tal sentido, integra la naturaleza y la cultura, lo abstracto y lo concreto, el objeto y el sujeto, el cuerpo y el espíritu, la animalidad y la humanidad. ${ }^{40}$

Una particularidad en la que se manifiesta la distinción en el pensamiento indígena refiere el caso de los Matsigenka y Wachiperi en los que se cree que el individuo está compuesto por una dualidad: cuerpo físico y alma, bajo ciertas condiciones tiene capacidad de separarse, según ha notado Sever. ${ }^{41}$

38 Alison Sever, El Ícaro Cambiante: Lenguaje y Curación en Santa Rosa de Huacaria, Independent Study Project (ISP) Collection, 1323, 2012, disponible en <https://digitalcollections.sit.edu/isp_collection/1323>, consultado el 4 de junio de 2019.

39 Mayor, Pedro y Richard Bodmer, op. cit.

40 Idem.

41 Alison Sever, op. cit. 


\section{Principio de recursividad}

Es interesante señalar que para los pueblos indígenas amazónicos las categorías naturaleza y cultura aluden a configuraciones de relaciones, perspectivas cambiantes. ${ }^{42}$ Bajo esta perspectiva, los seres humanos se pueden convertir en animales y se pueden convertir en humanos, tal como lo atestiguan numerosos mitos amazónicos. ${ }^{43}$ También, es posible que las personas se conviertan en plantas, silvestres y cultivadas y, éstas, en personas, como en los Kichwa lamistas. Esta característica, señalada por Calmet, alude al alto grado de animicidad propia de la cosmovisión indígena:

Lo que implica que el mundo está lleno de seres etéreos que se presentan como divinidades, espíritus benévolos y espíritus malévolos, capaces de adquirir una apariencia material -a través de los animales, las plantas y las montañas, entre otros- y hacerse visibles ante el ojo humano. ${ }^{44}$

Asimismo, los animales depredadores y los espíritus, ven a los humanos como animales de presa, mientras que, los animales de presa ven a los humanos como espíritus o como animales depredadores ${ }^{45}$.

\section{Discusión}

Es interesante reconocer que los principios básicos del pensamiento complejo centrados fundamentalmente en el principio sistémico y principio dialógico tengan amplia correspondencia con la cosmovisión de los pueblos indígenas amazónicos. Incluso, la definición de sistemas complejos tiene expresión concreta en las cosmovisiones indígenas amazónicas. Así, los sistemas adaptativos complejos refieren a estructuras que están constituidas por numerosos, múltiples y heterogéneos elementos, tangibles e intangibles, que dan cuenta de la materia/masa, energía, información y sentido de la realidad. Estos elementos están interrelacionados, son interdependientes, son interdefinibles y presentan capacidad de autoorganización y de generación de comportamientos o propiedades emergentes. Como sistemas, son no descomponibles, irreversibles, irreductibles, impredecibles y de naturaleza multidimensional, multiescalar, multitemporal. Estos sistemas consideran la flecha del tiempo, por lo que importan los procesos, el contexto y el tiempo,

42 Mayor y Bodmer, op. cit., p. 83.

43 Philippe Descola y Gisli Pálsson, coords., Naturaleza y sociedad. Perspectivas antropológicas,

México, Siglo XXI Editores, 2001, p. 360.

44 Andrea Calmet, op. cit.

45 Mayor, Pedro y Richard Bodmer, op. cit. 
como han señalado Rodríguez Zoya y García. Como se puede apreciar, la mayoría de los elementos señalados en la definición de los sistemas complejos están presentes en las cosmovisiones indígenas.

Los mundos y sus diferentes dimensiones en los pueblos indígenas amazónicos remiten al concepto de pluriverso que aluden a las ontologías no dualistas o relacionales que mantienen muchas comunidades amazónicas. ${ }^{46}$ Así, el carácter ontológico está presente, no sólo en los seres humanos, sino en los seres no humanos, incluso en deidades y en elementos “inertes" de la naturaleza. De esta manera, es posible reconocer múltiples subjetividades. ${ }^{47}$

El pensamiento complejo y las cosmovisiones indígenas amazónicas superan las dualidades que han caracterizado al pensamiento occidental. ${ }^{48}$ No obstante, aquí habría que identificar algunos matices en las cosmovisiones indígenas amazónicas. Una de ellas, se refiere a un diálogo en perspectiva ontológica de seres distintos e intercambiables y a otra perspectiva, que alude a una continuidad donde simplemente no hay tal distinción y se forma una sola unidad.

Los pueblos indígenas amazónicos han desarrollo su propio proceso cultural, al margen de influencias del pensamiento disyuntivo de la sociedad occidental, por lo que las relaciones estrechas entre la naturaleza y sociedad, categorías que además son occidentales, se corresponden a sus vivencias. ${ }^{49}$ Como señala Alarcón, la cosmovisión indígena no está influenciada por la tradición del conocimiento occidental. Por ello, no es de extrañar que la ontología desarrollada corresponda a la necesidad de alcanzar una relación más armoniosa con la naturaleza. Visto desde esta perspectiva, es posible entender por qué la alta diversidad biológica corresponde con la alta sociodiversidad de las regiones tropicales. Desde una perspectiva conservacionista, las cosmovisiones indígenas amazónicas son respetuosas con el ambiente porque en la práctica, no hay separación entre el ser humano y la naturaleza, ambas forman una continuidad, ambos reúnen los atributos y cualidades de humanidad y ambos se merecen respeto y cuidado mutuo. ${ }^{50}$

46 Arturo Escobar, op. cit. p 37.

47 Mayor, Pedro y Richard Bodmer, op. cit., p. 165.

48 Fritjof Capra, El tao de la física, Barcelona, Editorial Sirio, 2007, p. 478

49 María Pérez, "Concepciones de biodiversidad: una mirada desde la diversidad cultural”, en $\mathrm{Ma}$ gis, Revista Internacional de Investigación en Educación, 6 (12) Edición especial Enseñanza de las ciencias y diversidad cultural (2013), pp. 133-151, disponible en <https://revistas.javeriana.edu.co/ index.php/MAGIS/article/view/7207>, consultado el 12 de junio de 2019).

50 Andrea Calmet, op. cit., p. 56. 
Paradójicamente, usando una escala evolutiva de la conciencia occidental, implicaría que los pueblos indígenas de concepción animista se encontrarían en un grado inferior de conciencia que, según la perspectiva positivista, aún no ha entrado al mundo de la racionalidad y la eficiencia del mercado. Sin embargo, es importante señalar que en la humanidad ha ido emergiendo una ética ambiental distinta a la de la dominación de la naturaleza que reivindica la relación afectiva y de cuidado mutuo entre el ser humano y la naturaleza. Es ahí donde las cosmovisiones indígenas amazónicas cobran especial relevancia en la búsqueda de una sustentabilidad profunda.

La siguiente paradoja es que mientras sectores de occidente empiezan a apelar una ética de la tierra, los pueblos indígenas se encuentran en una gran tensión entre mantener los valores de la cultura que les ha permitido conservar la naturaleza, pero que los mantiene en una situación económicamente difícil, a la luz de las nuevas necesidades y la tendencia a articularse al mercado, aún a costa de sacrificar los bosques. Aunque la propuesta política de los pueblos indígenas apunta a recuperar y revitalizar las cosmovisiones indígenas, a nivel de las comunidades existe una tendencia creciente a acelerar su incorporación a la economía de mercado. El gran problema de fondo, es que muchas de las cosmovisiones indígenas amazónicas se están perdiendo dramáticamente, quedan rezagadas o simplemente en algunas comunidades se han perdido o tergiversado. En 2013, según el Ministerio de Cultura del Perú, de 47 lenguas indígenas que se hablan en el país, tres están en peligro y 18 en serio peligro de desaparecer y se estima que 35 lenguas ya han desaparecido. ${ }^{51}$

Los resultados de la investigación demuestran que las cosmovisiones de los pueblos indígenas amazónicos tienen elementos consistentes con el pensamiento complejo, lo cual refuerza la tesis de Descola de 1998, en su planteamiento que el pensamiento indígena amazónico no está en inferioridad de condiciones respecto del pensamiento occidental y también al señalar que es necesario un diálogo fluido entre ambas perspectivas. Asimismo, esta propuesta es congruente con la ecología de saberes que promueve Santos desde el pensamiento del sur. ${ }^{52}$ En este caso específico, la revaloración de las cosmovisiones

51 Perú Ministerio de Cultura (MINCUL), 10 cosas que debes saber sobre las lenguas indígenas del Perú y sus hablantes, Lima, Ministerio de Cultura, 2013, disponible en <https://www.cultura.gob.pe/ sites/default/files/paginternas/tablaarchivos/2013/05/10cosasquedebessabersobrelenguasindigenas. pdf $>$, consultado el 27 de mayo de 2019).

52 Santos, Boaventura de Sousa, Descolonizar el saber. Reinventar el poder, Montevideo, Ediciones Trilce, 2010, p. 88. 
indígenas amazónicas tiene lugar en un mundo que está en la búsqueda de legítimos caminos de sustentabilidad ${ }^{53}$. El planeta ya no soporta más apuestas por una sustentabilidad discursiva que está afectando su biocapacidad.

Por su parte, el pensamiento complejo demuestra que tiene expresiones de aplicación concretas y que, incluso, han surgido antes de que se acuñara la categoría de "pensamiento complejo". En tal sentido, el pensamiento complejo es útil, no sólo porque permite recuperar y revalorar razonamientos ancestrales, sino que tiene todas las potencialidades de transformación a partir de la perspectiva de religancia.

Finalmente, se debe señalar que el pensamiento indígena no tiene pretensión intelectual desde una perspectiva académica, sino que, simplemente, fluye en la cotidianeidad de la convivencia con la naturaleza. No obstante, como lo señala Alarcón, ${ }^{54}$ las formas de pensamiento indígena ponen a prueba y análisis definiciones y conceptos aparentemente inamovibles, así como los conocimientos y saberes locales que finalmente representan la reivindicación de otras formas de conocer el mundo; eso se ha dado en llamar "rebeldía epistémica". El pensamiento complejo, por su parte, busca explícitamente entender y comprender la realidad para transformarla. En tal sentido, el diálogo entre ambas formas de pensamiento es una forma de contribuir a la sustentabilidad.

\section{Conclusiones}

La cosmovisión de los pueblos indígenas amazónicos presenta correspondencia con los principios del pensamiento complejo, especialmente, en lo que se refiere al principio sistémico, al dialógico y al de recursividad. El pensamiento indígena, al igual que el pensamiento complejo, rompen la dualidad cartesiana y ambos pueden ser explicados desde los sistemas complejos que aluden a diversos elementos heterogéneos, tangibles e intangibles, que se encuentran estrechamente interrelacionados y son interdependientes. El pensamiento indígena, visto así, no corresponde a un estadio prelógico, sino a una condición particular de relación con los diversos mundos de la realidad americana que le ha permitido desarrollar una relación de convivencia con la naturaleza. Los procesos acelerados de globalización y la articulación a los mercados están erosionando aceleradamente los valores de la cosmovisión indígena. Se requiere que los procesos de diálogo intercultural pongan

53 Ferdinand Hagiwara, "Cosmogonía y cosmovisión en la racionalidad y el pensamiento Cocama Cocamilla”, en Phainomenon, Vol 13 N¹, Ene. - Dic, 2014, p. 67.

54 Pablo Alarcón, op. cit., p. 234. 
en igualdad de condiciones ambos tipos de pensamiento y que la sociedad occidental sea más permeable a otras perspectivas que contribuyan a una sustentabilidad fuerte.

\section{Referencias}

Alarcón, Pablo, Epistemologías otras: Conocimientos y saberes locales desde el pensamiento complejo, México, Tsíntani, AC/Instituto de Investigaciones en Ecosistemas y Sustentabilidad, Universidad Nacional Autónoma de México, 2019.

Arce, Rodrigo, "Respuestas del pensamiento complejo al pensamiento simplificante", en Horizontes y Raíces, Volumen 6 Número 1 (Enero-Junio) (2018a), pp.32-41, disponible en <http://www.hraices.uh.cu/index.php/HorR/article/view/140>, consultado el 27 de mayo de 2019).

, "La complejidad en la gestión de cuencas", Lima; SERVINDI (2018b), disponible en <https://www.servindi.org/actualidad-noticias/27/07/2018/la-complejidad-en-la-gestion-de-cuencas $>$, consultado el 27 de mayo de 2019).

, "Aportes del pensamiento complejo a la facilitación de grupos" Congreso Mundial por el Pensamiento Complejo, Los desafíos en un mundo globalizado París, 8 y 9 de diciembre, 2016 disponible en <https://www.reseau-canope.fr/fileadmin/user_upload/ Projets/ pensee_complexe/arce_aportes_del-pensamiento_complejo.pdf $>$, consultado el 27 de mayo de 2019).

Barandiarán, Agustín, "La lógica del Bricolaje y las Piezas sueltas", Revista Conclusiones analíticas, (s.f.), http://sedici.unlp.edu.ar/bitstream/ handle/10915/48336/ Documento _completo.pdf? sequence=1\&isAllowed $=\mathrm{y}$ (Consultado el 2 de junio de 2019).

Broda, Johanna y Jorge Báez, Cosmovisión, ritual e identidades de los pueblos indígenas, México, Fondo de Cultura Económica, 2001.

Calle, Manuel, El conocimiento ambiental Shipibo-Konibo en la programación curricular de $V$ ciclo de las instituciones educativas bilingües del distrito de Yarinacocha, región Ucayali, Tesis para optar al Grado 
Académico de Maestro en Ciencias de la Educación con mención en Educación Ambiental y Desarrollo Sostenible, Lima, Universidad Nacional de Educación Enrique Guzmán y Valle, 2018.

Calmet, Andrea, Contribución de los pueblos indígenas a la conservación de la Amazonía peruana, Lima, Sociedad Peruana de Derecho Ambiental, 2018.

Capra, Fritjof, El tao de la física, Barcelona, Editorial Sirio, 2007.

Cardoso, Andrea, "El pueblo Harakbut frente a los extractivismos en la Amazonia del Sur de Perú", en Ecuador Debate 105, Devenires actuales del extractivismo, diciembre, 2018, pp. 109-124.

Descola, Philippe y Gisli Pálsson, coords., Naturaleza y sociedad. Perspectivas antropológicas, México, Siglo XXI Editores, 2001.

Descola, Philippe, "Las cosmologías de los indios de la Amazonia”, en Zainak 17, (1998), pp. 219-227.

Escobar, Arturo, Sentipensar con la tierra. Nuevas lecturas sobre desarrollo, territorio y diferencia, Medellín, Ediciones UNAULA, Colección Pensamiento vivo, 2014.

Espino, Gonzalo, "Literatura indígena amazónica Shipibo-conibo y el kené de la palabra de Lastenia Canayo", en Estudios Filológicos, 2018, pp. 247-267.

Fondo para las Naciones Unidas para la Infancia Unicef, Valores de los pueblos y nacionalidades indígenas de la Amazonía (Bolivia, Ecuador y Perú), Lima, Unicef.

Fondo Indígena, Módulo de Historia y Cosmovisión Indígena Guía de aprendizaje colectivo para organizaciones y comunidades, La Paz, Fondo Indígena, 2007.

García, Rolando, Sistemas complejos. Conceptos, método y fundamentación epistemológica de la investigación interdisciplinaria, Madrid, Editorial Gedisa, 2006.

Gardiny Llery, Isabel Ráez, Bruno Mendoza y Oscar Flores, Informe de identificación de pueblos indígenas u originarios en el ámbito del lote 181, Informe técnico, 2015.

Gómez, Pedro, La antropología estructural de Claude Levi-Strauss. Ciencia, filosofía, ideología, Madrid, Editorial Technos, 1981.

Goody, Jack, La domesticación del pensamiento salvaje, Madrid, Ediciones Akal, 2008. 
Grados, Claudia y Eduardo Pacheco "El impacto de la actividad extractiva petrolera en el acceso al agua: el caso de dos comunidades kukama kukamiria de la cuenca del Marañón (Loreto, Perú)", en ANTHROPOLOGICA/Año XXXIV, N. ${ }^{\circ} 37$, (2016), 33-59, disponible en $<$ https://doi.org/10.18800/anthropologica.201602.002>.

Gudynas, Eduardo, "Debates sobre el desarrollo y sus alternativas en América Latina: Una breve guía heterodoxa", en Más Allá del Desarrollo, Miriam, Lang, y Dunia Mokrani, comp., Grupo Permanente de Trabajo sobre Alternativas al Desarrollo, Quito, Ediciones Abya Yala - Universidad Politéctica Salesiana, Fundación Rosa Luxembrugo, 2011, disponible en <http://rio20.net/wp-content/uploads/2012/07/ masalla-deldesarrollo_30.pdf $>$.

Hagiwara, Ferdinand, "Cosmogonía y cosmovisión en la racionalidad y el pensamiento Cocama Cocamilla”, en Phainomenon, Vol 13 ํo1, (Ene. - Dic) (2014), pp. 55-68.

Huertas, Beatriz y Mauricio Chanchari, Agua, cultura y territorialidad en el pueblo Shawi del río Sillay, Lima, Terra Nuova, 2011.

Levi Strauss, Claude, Mito e significado, Lisboa, Edições, 1978.

, El pensamiento salvaje, Bogotá, Colombia, Fondo de Cultura Económica, 1997.

Llamazares, Ana y Carlos, Martínez (eds.), El lenguaje de los dioses, Arte, chamanismo y cosmovisión indígena en Sudamérica, Buenos Aires, Biblos, 2004.

Mayor, Pedro y Richard Bodmer, Pueblos indígenas de la Amazonía peruana, Iquitos, Centro de Estudios Teológicos de la Amazonía, 2009.

Morin, Edgar, Introducción al pensamiento complejo, Barcelona, Gedisa Editorial, 1998.

Olavarría, María, "El pensamiento salvaje y la importancia de ser imperfecto", en Alteridades, 7 (13), 1997, pp 33-38.

Olórtegui, Julio, "La naturaleza en la cosmovisión de los pueblos originarios de la Amazonía peruana”, Ponencia magistral, XV Congreso $\mathrm{Na}$ cional de Filosofía, Puno, 26 al 30 de octubre del 2015.

"Racionalidad amazónica y racionalidad occidental" en Thémata, Revista de Filosofía, Núm. 39, Iquitos, UNAP, 2007. 
Organización Regional de los Pueblos Indígenas de la Amazonía Norte del Perú - (ORPIAN-P) y Centro Amazónico de Antropología y Aplicación Práctica (CAAAP), Territorio Integral Tajimat Awajún Fundamentos legales, antropológicos y políticos, Lima, ORPIAN-P, CAAAP, 2018.

Pérez, María, "Concepciones de biodiversidad: una mirada desde la diversidad cultural" en Magis, Revista Internacional de Investigación en Educación, 6 (12), Edición especial Enseñanza de las ciencias y diversidad cultural, 2013, pp. 133-151.

Perú Ministerio de Cultura (MINCUL), 10 cosas que debes saber sobre las lenguas indígenas del Perú y sus hablantes, Lima, Ministerio de Cultura, 2013, disponible en <https://www.cultura.gob.pe/sites/default/ files/paginternas/tablaarchivos/2013/05/10cosasquedebessabersobrelenguasindigenas.pdf $>$.

Ministerio de Salud (MINSA), Análisis de la Situación de Salud del Pueblo Achuar, Lima, Dirección General de Epidemiología, 2006.

Regan James, "Los awajún y wampís contra el Estado: una reflexión sobre antropología política”, en Investigaciones Sociales, Universidad Nacional Mayor de San Marcos/Instituto de Investigaciones Histórico Sociales, Vol.14, $\mathrm{N}^{\circ}$ 24, (2014), 19-35.

Rodríguez Zoya, Leonardo, "Desafíos educativos para enseñar a pensar la complejidad en la ciencia y la sociedad" [Archivo de video], 2015, disponible en <https://youtu.be/fFRK_tX9MVM>, consultado el 27 de mayo de 2019.

Rueda, Paulino, "Las Comunidades Nativas de la Amazonía peruana y el cumplimiento de los incisos c) y d) del artículo 10 del Convenio sobre Diversidad Biológica. Situaciones Análogas En La Unión Europea”, en Vox Juris, Lima, 26(2), 2013, pp. 155-196.

San Román, Jesús, Perfiles Históricos de la Amazonía Peruana, Iquitos, Centro de Estudios Teológicos de la Amazonía, Centro Amazónico de Antropología y Aplicación Práctica Instituto de Investigaciones de la Amazonía Peruana, 1994.

Santos, Boaventura de Sousa, Descolonizar el saber. Reinventar el poder, Montevideo, Ediciones Trilce, 2010. 
Schroeder, Anika, Volker von Bremen, Pueblos indígenas y protección de bosques a través de REDD+ y medidas similares Fundamentos para un diálogo, Berlín, Pan para el Mundo - Servicio Protestante para el Desarrollo, Organización Protestante para Diaconía y Desarrollo, 2013.

Seminario, Militza, Centro de investigación científico en la Reserva Tambopata-Candamo, Tesis para optar el grado de Arquitecto, Universidad de Ciencias Aplicadas, 2003.

Sever, Alison, "El Ícaro Cambiante: Lenguaje y Curación en Santa Rosa de Huacaria" en Independent Study Project (ISP) Collection, 1323, 2012, https://digitalcollections.sit.edu/ isp_collection/1323.

Tamariz, Katherine, Luis García, Comunidades nativas y derechos de propiedad: una aproximación desde la selva central, (s.f.), disponible en <http://www. desco.org.pe/recursos/site/files/ CONTENIDO/1132/PH_15_Tamariz_ Garc\%C3\%ADa.pdf>.

Valqui, Michael, Conrad Feather, Roberto Espinoza, Haciendo visible lo invisible. Perspectivas indígenas sobre la deforestación en la Amazonía peruana, Lima, Asociación Interétnica de Desarrollo de la Selva Peruana (AIDESEP) y Forest Peoples Programme (FPP), 2014.

Ventrella, Scott, El Poder del Pensamiento Positivo en las Empresas. 10 Rasgos para lograr resultados óptimos, Bogotá, Grupo Editorial Norma, 2001.

Viteri, Carlos, "Visión indígena del desarrollo en la Amazonía”, en Polis [En línea], 3, 2002, publicado el 19 noviembre 2012, disponible en <http:// journals.openedition.org/polis/7678>, consultado el 28 mayo 2019.

Weiss, Gerald, Campa Cosmology: The word of a forest tribe in South America, New York, Anthropological Papers of the American Museum of Natural History, 52 (5), 1975. 


\title{
PROCESOS SEMIÓTICOS DE LOS MIGRANTES TRANSNACIONALES
}

\author{
Rosa María Macías Herrera \\ Universidad Autónoma de la Ciudad de México
}

Si el agua es una fuerza de la
naturaleza, entonces la migración
es una fuerza de la historia
George Alagaih

\section{Introducción}

Desde tiempos antiguos los seres humanos se han mantenido en tránsito. El fenómeno migratorio se ha convertido una experiencia que no es exclusiva de unos pocos; pasó de ser un momento excepcional a una actividad cotidiana en el mundo actual. La migración internacional es uno de los fenómenos de mayor relevancia en nuestros días, su crecimiento y consecuencias está impactando de manera global. Hasta 2017 el número de migrantes en el mundo asciende a 258 millones de personas comparado con 177 millones en el año 2000. Ello corresponde al 3.4\% de la población mundial, el $2.8 \%$ en el año 2000 y el $2.3 \%$ en el año 1980 de acuerdo a la Departamento de Asuntos Económicos y Sociales de la ONU.

Entre ellos 68 millones son desplazados por la fuerza, 25 millones de refugiados, 3 millones solicitando asilo en algún país y 40 millones de desplazados internos dentro de los países.

Las causas para el desplazamiento de las personas corresponden a múltiples causas como búsqueda de trabajo, mejores condiciones económicas, persecuciones políticas, terrorismo, violación a derechos humanos, reunificaciones familiares, crecimiento intelectual, mejores condiciones sociales, desastres naturales e incluso consecuencias por el cambio climático, en muchas ocasiones la migración no sólo es producto de una de ellas sino de diversas causas acumuladas.

Del total de migrantes 124 millones son mujeres, 15 millones trabajadores, 36 millones niños, 25 millones refugiados y 4.8 millones estudiantes (ONU). 
En cuanto a su lugar de nacimiento, un tercio de todos los migrantes internacionales proceden de sólo diez países. El país líder en este apartado es India, con 18 millones de personas, seguidos a una distancia considerable por los 12 millones de mexicanos que viven en el extranjero, junto a 11 millones de chinos y 10 millones de rusos.

La Organización Internacional para las Migraciones (OIM) define a un migrante como cualquier persona que se desplaza o se ha desplazado a través de una frontera internacional o dentro de un país, fuera de su lugar habitual de residencia independientemente de: 1) su situación jurídica; 2) el carácter voluntario o involuntario del desplazamiento; 3) las causas del desplazamiento; o 4) la duración de su estancia. ${ }^{1}$

Se visibilizarán los migrantes a partir del establecimiento del Estado-nación, posterior a la Edad Media, que consistió en la creación de los países, la aparición del ciudadano, los derechos de nacimiento, la edificación de fronteras que tuvo como consecuencia la movilidad reglamentada y en gran medida esto constituye una dificultad para las personas.

Posteriormente, con la llegada de la Globalización en el término económico (ya que muchos autores ubican el nacimiento de la Globalización con el descubrimiento de América o encuentro de dos mundos); sin embargo, es hasta la aparición del las empresas transnacionales y acuerdos económicos entre los países a través de flujos de capitales, bienes y servicios, la aparición del internet y las nuevas tecnologías que caracteriza la Globalización en nuestros días; todo lo anterior trajo como consecuencia que sea más visible la diferencia entre países pobres y ricos, las personas conocen donde hay mejores oportunidades y ello ha provocado en muchos casos que se incremente la movilidad humana entre los países.

Los estudios de migración internacional han sido abordados desde una perspectiva disciplinar y han tenido como principal fin medir el impacto económico y demográfico del fenómeno desde la visión macrosocial perdiendo de vista el dinamismo subjetivo del actor.

Es por ello, por lo que el estudio de la migración nos exige un alcance más profundo a través de la complejidad para conocer su realidad.

La migración académica es una de las alternativas adoptada por las nuevas generaciones de profesionales para enfrentar las condiciones de la revolución tecnológica, las transformaciones en las formas de organización del trabajo y las nuevas condiciones de espacio y tiempo y también una estrategia de competitividad y cualificación. Los flujos de migración

1 Información disponible en <https://www.un.org/es/sections/issues-depth/migration/index.html $>$. 
calificada están adquiriendo una importancia significativa en los investigadores y requiere ser desarrollada con mayor profundidad con el fin de lograr la comprensión de este dinámico y complejo proceso.

Si en 1990 los migrantes calificados suponían 29.9 por ciento del total, en 2000 representaban 35 por ciento. En cambio, los migrantes con nivel educativo bajo descendieron su participación relativa de 49.1 por ciento a 43.1 por ciento, aunque tuvieron un crecimiento absoluto de cinco millones de personas. Los migrantes con nivel educativo medio también tuvieron un crecimiento absoluto importante (de aproximadamente cuatro millones de individuos), pero en este caso se mantuvo constante la participación porcentual

El fenómeno de la migración se hace presente formalmente dentro de los estudios sociológicos, antropológicos, demográficos y económicos, desde hace varios años y pone de manifiesto los problemas de empleo, problemas socioeconómicos, culturales, históricos y de integración; abordándolo como un proceso de movilidad social generado en la transición de una sociedad con escaso desarrollo socioeconómico a otra desarrollada de manera mayoritaria.

Sin embargo, el estudio de los fenómenos sociales requiere el cruce e intersección de disciplinas para comprender la realidad. La migración es un fenómeno multifacético y de interés multidisciplinario. Los estudios de migración internacional han sido abordados por muchas disciplinas, la mayor parte de ellos han sido dirigidos por los intereses políticos y económicos de los países receptores y poco se ha profundizado en el protagonista del fenómeno. La migración es un fenómeno que no se puede fragmentar porque estudiarla de manera disciplinar implica ignorar el contexto que le da sentido y significado debido a su complejidad se requiere de un estudio transdisciplinario. Los estudios deben reconocer la dimensión humana, debe ser el elemento central del debate, abandonar el enfoque limitado de gestión de los flujos o sus impactos exclusivos en consecuencias económicas o demográficas, para avanzar hacia el reconocimiento de la migración con un elemento clave en el enriquecimiento cultural y social, que brinde dinamismo a las sociedades.

La transdisciplina es una forma de organización de los conocimientos que busca trascender las disciplinas, abarca lo que está entre ellas, lo que las atraviesa, incluso lo que está más allá de ellas. ${ }^{2}$

2 Edgar Morin, Introducción al pensamiento complejo, México, Gedisa, 1990 p. 37. 
Su objetivo es nutrirse de los conocimientos científicos de cada una de las disciplinas y brindar una mirada global, que permita observar el mundo en su unidad diversa, que no lo divida, pero sí que evidencie sus diferencias.

El estudio y análisis del fenómeno de la migración requiere una mirada completa, y la transdisciplina le permite dialogar con la diversidad de los saberes humanos, un conocimiento relacional y complejo que no se acaba nunca y con el compromiso del diálogo y recisión permanente.

Volvemos entonces a la imperiosa necesidad de proponer, vivir, aprender y enseñar un pensamiento complejo, que vuelva a tejer las disciplinas como posibilidad de humanidad en completud; y que sólo de esta manera se vencería la eterna limitación del sujeto separado de sí mismo en la búsqueda del conocimiento. ${ }^{3}$

Es a partir de esta realidad actual que surgen corrientes teóricas que estudian el fenómeno de los migración desde la perspectiva compleja como el transnacionalismo, analizando procesos como lo transnacional y la transculturalidad.

Los migrantes académicos son aquellos que deciden dejar su país por una ambición personal y deseo de superación, aunque es de destacar que en la mayoría de los casos confluyen varias causas de manera simultánea que los impulsa a la decisión de migrar.

La migración calificada ha ido en aumento según los datos publicados por la Organización para la Cooperación y el Desarrollo Económico (OCDE), incluso comparada con la migración en general.

El término "fuga de cerebros" fue acuñado en 1963 por la Real Academia de Ciencia para explicar y describir el flujo masivo de especialistas y científicos a los Estados Unidos, causado en primer lugar por las guerras mundiales en Europa que se continuó durante el periodo de la Guerra Fría, proceso de inserción que fue facilitado particularmente por los Estados Unidos. El concepto ha ido adaptando con el tiempo nuevas significaciones como circulación de conocimientos (Brain Circulation) ganancia de cerebros ( Brain Gain), bajo esta propuesta se les designa migrantes académicos con la finalidad de centrarnos en el actor del proceso y no en las ventajas económicas que ofrece al país de acogida.

3 Nicolescu Basarab, Manifesto de transdisciplinariedad, París, Ediciones du Rocher, 2002, p. 35. 
La migración académica es un universo heterogéneo y diverso, ha conducido a profundizar en identificar y reconocer los patrones de movilidad y sus transformaciones y consecuencias en distintos niveles, se parte desde las condiciones estructurales hasta la comprensión de la experiencia subjetiva de los actores que la han llevado a cabo.

\section{Métodos utilizados}

Esta ponencia describe una investigación realizada desde la perspectiva compleja con apoyo del transnacionalismo y la semiótica de la cultura de Lotman para lograr entender el proceso desde varias aristas, se busca comprender a profundidad al migrante a través del análisis de las redes y comunidades transnacionales que construyen en su camino, así como entender cómo realizan el proceso de semiosis que realiza a través de traducciones interculturales e intersemióticas. Es una investigación cualitativa de carácter descriptivo y analítico que tiene como propósito la reflexión en torno a su importancia y su complejidad, ello nos permite comprender los procesos subjetivos y simbólicos que acompañan a los migrantes académicos, así como los determinantes socioculturales y estructurales asociados al proceso. La investigación describe los resultados obtenidos de una encuesta y una epístola aplicada a nueve migrantes-académicos procedentes de Chile, Argentina, España, Cuba, Colombia, Uruguay y Chile, asentados en México y que laboran en la misma institución educativa universitaria, son un recorte pequeño de la complejidad del proceso.

\section{Resultados}

México a través de la historia se ha distinguido como un país expulsor de migrantes más que como receptor de los mismos.

México es el principal país de migración en el mundo, más de 11 millones de personas viviendo en el extranjero, cerca de $10 \%$ del total de su población (OIM 159). El corredor de migración entre México y Estados Unidos de América es el más importante del mundo, con 9.3 millones de migrantes. ${ }^{4}$

De manera simultánea México ha sido tradicionalmente una nación de acogida de refugiados, asilados y trabajadores inmigrantes procedentes de distintos países y regiones del mundo, quienes han encontrado en su territorio un lugar nuevo de residencia y de trabajo. 
Si bien el número de inmigrantes permanentes en el país siempre ha sido pequeño, respecto del total de la población nacional, los datos censales muestran que dicha población creció progresivamente a 961 mil en 2010.

No podemos dejar de reconocer las aportaciones de los movimientos migratorios a México como el exilio español o chileno, entre algunos de los destacados en las últimas décadas.

Asimismo, México se ha convertido en un país que recibe grandes flujos migratorios de carácter irregular en tránsito hacia Estados Unidos. El Instituto Nacional de Migración estimó para 2010 alrededor de 140 mil eventos de tránsito por México, predominando entre ellos los ciudadanos provenientes de Centro y Sudamérica. Los desplazamientos temporales de trabajadores guatemaltecos que se dirigen a las localidades urbanas y rurales de la región fronteriza del sur del país constituyen otra forma de la inmigración en México.

En los estudios migratorios tradicionales se asume que los migrantes se trasladan a otro país para quedarse y pierden de manera progresiva su relación con su país de origen, ello es producto de una concepción binaria que niega su complejidad en la actualidad. Los inmigrantes en estos tiempos mantienen regularmente lazos, redes, actividades e incluso ideologías que engloban de manera simultánea sociedades de origen y destino.

Los estudios de migración de acuerdo con Faist ${ }^{5}$ se dividen en tres generaciones:

1. Se dedica a explicar los orígenes y causas de la migración, desde las disciplinas económicas y políticas describiendo flujos y causas internas. Profundiza en el análisis de los factores de atracción y expulsión. Dando respuesta a pregunta como: por qué se migra desde las causas objetivas, sin considerar las motivaciones y decisiones individuales de los sujetos.

2. La segunda generación intenta profundizar más que sólo las explicaciones causales generales, estudia las redes sociales que implica considerar que intervienen más elementos en la decisión de migrar, como económicos, sociales, políticos y legales.

3. La tercera generación corresponde al enfoque transnacional que sostiene que existe una relación entre los mundos de los migrantes entre el país de origen y de acogida, atiende de manera simultánea ambas dimensiones.

5 Thomas Faist, The Volume and Dynamics of International Migration and Transnational Social Spaces, Oxford, Clarendon Press, 2000, p. 121. 
A continuación, un recorrido del estado del arte sobre los estudios de migración hasta la actualidad.

Cuadro de dimensiones, teorías, y autores del fenómeno migratorio

\begin{tabular}{|c|c|c|}
\hline Dimensión & Teorías & Autores \\
\hline $\begin{array}{l}\text { Inicio y causas del } \\
\text { movimiento } \\
\text { migratorio } \\
\text { (causas económicas) }\end{array}$ & $\begin{array}{l}\text { - Mercado dual } \\
\text { - Orientación marxista } \\
\text { - Sistema mundial }\end{array}$ & $\begin{array}{l}\text { - Ravestein (1889) } \\
\text { - Piore (1979) } \\
\text { - Castles y Kosack (1982) } \\
\text { - Wallenstein (1974) } \\
\text { - Stark (1985) }\end{array}$ \\
\hline $\begin{array}{l}\text { Mantenimiento de los } \\
\text { movimientos } \\
\text { migratorios } \\
\text { (costo-beneficio) }\end{array}$ & $\begin{array}{l}\text { - Redes sociales } \\
\text { - Institucional } \\
\text { - Causación acumulativa } \\
\text { - Sistemas migratorios }\end{array}$ & $\begin{array}{l}\text { - Massey (1990) } \\
\text { - Myrdhall (1959) } \\
\text { - Zlotnik (1992) }\end{array}$ \\
\hline $\begin{array}{l}\text { Funciones de las } \\
\text { migraciones } \\
\text { (contenido-alcance) }\end{array}$ & $\begin{array}{l}\text { - Del consenso } \\
\text { - Del conflicto } \\
\text { - Del conflicto sostenido }\end{array}$ & - Zlotnik (1992) \\
\hline $\begin{array}{c}\text { Efectos sobre de los } \\
\text { migrantes } \\
\text { (sociocultura-institucional) }\end{array}$ & $\begin{array}{l}\text { - Asimilación } \\
\text { - Crisol de culturas } \\
\text { - Pluralismo } \\
\text { - Interculturalidad }\end{array}$ & $\begin{array}{l}\text { - Maalouf (2007) } \\
\text { - Sartori (2000) } \\
\text { - Kymlycka, (1966) } \\
\text { - Taylor (2009) } \\
\text { - Pérez Tapias, (1995) } \\
\text { - Panikkar, (1964) } \\
\text { - Fornet Betaconcourt (1994) } \\
\text { - Kearney (1991) } \\
\text { - Portes (1990) }\end{array}$ \\
\hline
\end{tabular}

Fuente: elaboración propia.

Como se puede observar, las disciplinas en su quehacer epistemológico han desarmado el fenómeno migratorio limitando su observación a una porción del fenómeno, sin lograr comprender su complejidad. 
El problema fundamental de estas visiones es que se concentran en los efectos de la movilidad humana bajo la perspectiva del nacionalismo metodológico con una lógica binaria, país de origen- país de acogida, emigrante-inmigrante, lo nacional- lo extranjero. Lo propio- lo ajeno; cuando el fenómeno es mucho más complejo que eso, para analizar la migración se debe partir del centro que es el migrante, la persona que vive la experiencia y que permite romper esta visión tradicional de abordarlo, requiere una visión dinámica que incluya al emigrante y el inmigrante de manera simultánea, el que se siente aquí y allí, porque rebasa las fronteras entre los países a través de las tecnologías, en sus imaginarios, emociones y afectos.

Los objetos de estudio de la investigación presentada, que son los migrantes académicos procedentes de países hispanoamericanos como Chile, Argentina, Cuba, Colombia, Uruguay y España, que emigraron por causas estructurales, políticas y reunificación familiar, experimentaron el proceso en tres fases: el de preparación, acto de migrar y asentamiento, que denota dinamismo; es decir, muchos cambios en su situación económica, social, política y en su situación emocional y psicológica.

Para comprender la complejidad del fenómeno de la migración se optó por la perspectiva del transnacionalismo que es un campo de estudio que propusieron las antropólogas Nina Glick, Linda Basch y Christina Blanc-Szanton, ${ }^{6}$ para estudiar el fenómenos de la migración en la actualidad, a través de sus trabajos analizaron el dinamismo entre los migrantes debido que sus vidas transcurren con una conexión de dos sociedades en un sólo campo social y las corrientes teóricas tradicionales estudiaban al sujeto migrante, meramente como personas que viven un proceso de asimilación de la sociedad receptora.

Así, las actividades transnacionales se ubican en un espacio desterritorializado, ajenas a localidades y naciones preexistentes; por lo tanto, con capacidad para erosionar y derrumbar al actual sistema del Estado nación que trascienden. ${ }^{7}$

Definimos transnacionalismo como los procesos a través de los cuales los inmigrantes construyen campos sociales transnacionales que conectan su país de origen y su país de asentamiento, Los inmigrantes que construyen campos sociales son designa-

6 Glick Schiller, N.; Basch, L. y Blanc-Szanton, C, “Transnationalismus: Ein neuer analytischer Rahmen zum Verständnis von Migration", en Kleger, H. (Ed.), Transnationale Staatsbürgerschaft, Frankfurt, 1992.

7 Kearney, Michael, The local and the global: the anthropology of globalization and Transnationalism, Oxford, Rowman and Littlefield, 1995. p. 556. 
dos "transmigrantes". Los transmigrantes desarrollan y mantienen múltiples relaciones familiares, económicas, sociales, organizacionales, religiosas, políticas- que sobrepasan fronteras. Los transmigrantes actúan, toman decisiones y se sienten implicados, desarrollan identidades dentro de redes sociales que les conectan a ellos con dos o más sociedades de forma simultánea. ${ }^{8}$

Por lo anterior, las categorías como territorialidad e identidad desde una visión simple se vuelven limitadas, ya que no consideran que sean fluidas, dinámicas y contextualizadas. El transnacionalismo identifica las prácticas e identidades de las personas en varios espacios sociales que van más allá de las fronteras y nos obliga a replantear el espacio físico en que se producen los fenómenos sociales.

El transnacionalismo rebasa el nacionalismo metodológico, ya que se limita el estudio de la migración al estado-nación, tomando como unidad de análisis las fronteras para explicar procesos como integración, inclusión y exclusión.

De acuerdo con Glick, Basch y Blanc-Szanton, el transnacionalismo considera cuatro premisas:

1. La migración transnacional está ligada al capitalismo global, por lo cual, ser analizada en el contexto de las relaciones globales entre capital y trabajo.

2. Es el proceso por el cual los migrantes crean campos sociales a través de fronteras nacionales e internacionales.

3. No puede analizarse mediante categorías limitadas de ciencias sociales que combinan el desplazamiento físico, la cultura y la identidad.

4. Contribuye a la construcción de dos o más Estados-nación. ${ }^{9}$

La migración transnacional realiza una labor «liberadora» precisamente por eludir las limitaciones del status quo. Es decir, presupone una ausencia de referentes sociales específicos y la perpetuación de la identidad de origen, ambos motivos más que suficientes para crear la falta de integración de los migrantes en las sociedades receptoras. ${ }^{10}$

10 Cristina Blanco, Las migraciones contemporáneas, Madrid, Alianza, 2018, p. 18. 
Los migrantes inmersos en redes y actividades transnacionales, en continuo contacto referencial y práctico con sus comunidades de origen, tienden a crear verdaderas dificultades para asimilarse en las sociedades receptoras.

Los migrantes académicos no son ajenos a vivir dificultades para asimilarse, aun cuando en México, reconoce el valor que representa la educación y que la capacidad innovadora que trae un migrante académico es siempre una ganancia.

Sin embargo, los migrantes académicos también viven los procesos revelan la definición de Hienaux y Zárate del transnacionalismo: “como una serie de procesos sociales, económicos políticos y culturales que involucran más de un espacio estado-nación”. Los migrantes también tienden a no desconectarse con su origen; en sus actividades profesionales y sociales, los «transmigrantes» mantienen, construyen y refuerzan múltiples lazos que les unen a sus lugares de origen, generando, de este modo, verdaderas "comunidades desterritorializadas». ${ }^{11}$

Los migrantes transitan entre diferentes naciones con la finalidad de ampliar sus conocimientos, habilidades y experiencias, relacionadas con la comprensión de expandir su cosmovisión cotidianamente viven "dependiendo de las múltiples y constantes interconexiones a través de las fronteras nacionales y cuyas identidades se configuran en relación con más de una nación Estado".12

Los transmigrantes actúan, toman decisiones, se sienten implicados, y "desarrollan identidades dentro de redes sociales que les conectan a ellos con dos o más sociedades de forma simultánea". ${ }^{13}$

Se identifica entonces, que el transnacionalismo rebasa al territorio, la de identidad, pues los contextos de intercambio lo van cambiando pues el espacio físico ha perdido los límites de antaño y ya no delimita los fenómenos sociales actuales. Para Portes, las actividades transnacionales deben incluir:

- Ocupaciones y actividades que requieren contactos sociales, periódicos y sostenidos a lo largo del tiempo y a través de las fronteras nacionales para su implantación.

- Prácticas cotidianas de los individuos en comunidades transnacionales. 
- Las actividades transnacionales no se limitan a las políticas regulatorias de la migración de los países de origen, tránsito o destino, sino están basadas en las redes de parentesco y relaciones, otros factores que influyen son la distancia geográfica, la disponibilidad de tecnologías e infraestructuras de transporte y comunicación, la condición económica y el estatus social de los migrantes. ${ }^{14}$

Los migrantes académicos van construyendo sus propios campos sociales trasnacionales que van disgregando la cultura, aumentando, restando como un proceso dialéctico de dos vías. Lo expresa diciendo que con estas dinámicas la sociedad multicultural es continua en movimiento y en identidades, se vuelve las relaciones se vuelven una red elástica de identificaciones cruzadas y siempre mutuamente dependiente de una situación determinada. ${ }^{15}$

El migrante una vez que abandona el país donde nació ya lleva consigo una diversidad cultural heredada a través de los siglos en su lugar de origen, y la incorpora en los campos sociales que inicia a construir en el otro país "cuando se interviene en un mundo interconectado, uno siempre es, en distinta manera, 'inauténtico’: está atrapado entre algunas culturas, implicado en otras". ${ }^{16}$

El transnacionalismo es una globalización desde abajo, que no requiere necesariamente de las instituciones para mantener contacto simultáneo con dos naciones y tiene al menos tres dimensiones:

1. Económica: a través de comerciantes, pequeños negocios, inversiones, turismo, bancos para migrantes, comunidades bursátiles.

2. Política: comité cívico del pueblo, apoyo a candidatos desde el exterior, doble nacionalidad, migrantes elegidos para país de origen o acogida, funcionarios consulares, candidatos que hacen campaña en países donde hay muchos migrantes.

14 Alejandro Portes, Conclusion: towards a new world: the origins and effects of transnational activities, en Ethnic and Racial Studies, 22 (2), 463-477, p. 296.

15 Zygmunt Bauman, La Globalización. Consecuencias humanas, Buenos Aires, FCE, 2001, p. 148. 16 James Clifford, Dilemas de la cultura, Barcelona, Gedisa, 2001, p. 50. 
3. Sociocultural: competencias deportivas entre migrantes y del país de origen, música folclórica, radios de comunidades indígenas en país de acogida, sacerdotes que visitan a creyentes en el extranjero, artistas que actúan en otros países, fiestas en embajadas.

El transnacionalismo migratorio es una forma de globalización de abajo a arriba, ya que nace de la institucionalización de prácticas fundamentadas en la vida cotidiana de individuos en comunidades transnacionales. Mientras anteriormente, el éxito económico y el estatus social dependían en forma exclusiva de una rápida aculturación y del ingreso al ámbito dominante de los círculos de la sociedad receptora, en la actualidad éstos dependen cada vez más del cultivo de redes sociales sólidas a través de las fronteras nacionales.... ${ }^{17}$

El alcance del fenómeno del transnacionalismo va más allá de concebir el Estado-nación como contenedor y en donde la vida social de los migrantes no está confinada a las fronteras territoriales. Por lo tanto, los migrantes construyen y reconstruyen sus vidas de forma simultánea en varias sociedades en un mundo altamente globalizado. Por ello, es necesario observar su impacto en los fenómenos sociales más allá de los límites de las fronteras nacionales. El migrante es una frontera simbólica; a través de él se permea la cultura, por ejemplo, el migrante académico a través de sus acciones como docente transmite su cultura de origen a los estudiantes de la cultura de acogida, pero a su vez preserva su propia cultura en su casa. Al mismo tiempo, sus estudiantes le influyen con sus acciones y respuestas el modo cultural que el migrante académico también transmite a su familia. Este intercambio es un intercambio constante y mutuo es un primer nivel de influencia del transnacionalismo.

En muchas ocasiones existe discrepancia entre "lo que se espera y "y lo que se encuentra en las naciones receptoras, es uno de los factores que determinan que los migrantes sufran de serios problemas de adaptación y aun en algunos casos de marginación en las sociedades de acogida. ${ }^{18}$

17 Alejandro Portes et al., La globalización desde abajo: transnacionalismo migrante y desarrollo, FLACSO, México, Porrúa, 2003, p. 32.

18 Méndez, Alejandro, ¿Emigrar para volver?, Problemas del desarrollo 38(148):99-126 · March 2007, 2015, p. 115. 
En la investigación se identificó que las redes transnacionales académicas fueron factor clave para lograr su movilidad, así fue en el caso de la española, chilena, argentina, uno de los cubanos entrevistados e inclusive el colombiano, en el caso de la uruguaya, argentino y otro cubano fueron redes transnacionales familiares las que les facilitaron el proceso.

También se ha visto cómo la sociedad mexicana ha tenido un vínculo directo con la migración al corroborar que es un país atravesado por el fenómeno de migración, tanto de origen como de destino.

Otro campo de estudio que ha contribuido a comprender la complejidad del proceso de migración, es la semiótica de la cultura de Lotman; su postura surge de la experiencia personal del estoniano de vivir en la frontera, lo que le permitió observar la movilidad de las personas de un país a otro y comprender al migrante; por lo tanto, su postura es el marco para caracterizar este fenómeno como un derivado de sentido dinámico y relacional, por lo tanto, también imprevisible.

Para el estoniano, cultura es "inteligencia colectiva" y "memoria colectiva", la "cultura es la información no hereditaria que recogen, conservan y transmiten las sociedades humanas expresada en un determinado sistema de obligaciones y prescripciones". ${ }^{19}$ La cultura involucra una identificación dinámica de los fenómenos de significación, por lo tanto, la conformación textual, es un proceso constante. Es decir, Lotman se preocupa por el estudio de textos y no de signos de manera particular, aplicado al fenómeno de la migración, para él es un proceso que se da en la intersección con los signos adoptados de la cultura de origen y los signos de la cultura de acogida, el texto ocupa el lugar del signo como unidad cultural que teje la interacción de sistemas semióticos mediante una variada tipología de textos, con diferentes grados de organización y con exclusiones o combinaciones de diferentes lenguajes, lo que ayuda a comprender el fenómeno de la migración. ${ }^{20}$

Toda cultura revierte el carácter "acultural" del mundo, donde se inserta el hombre al encerrarlo en un ámbito de sentido. De acuerdo con la concepción precedente, para alejar el problema que supone la antinomia: "cultura-no cultura", se podría acotar que la última arista implica,

19 Iuri Lotman et al., Sobre el mecanismo semiótico de la cultura, en La semiosfera: semiótica de las artes y la cultura, Madrid, Cátedra, Frónesis, 2000, p. 37.

20 Rosa María Macías, El problema semiótico del fenómeno de la migración, disponible en Academia, edu, $<$ https://www.academia.edu/33701231/El_problema_semi\%C3\%B3tico_del_fen\%C3\%B3meno_de_ la_migraci\%C3\%B3n_una_mirada_desde_Lotman_y_la_filosof\%C3\%ADa_de_la_cultura $>, 2012, p .1$. 
simplemente, a un marco, contexto o ámbito de la realidad que no ha sido semiotizado o incorporado a un esquema de sentido producido por agentes competentes. ${ }^{21}$

Para ilustrar una significación de cultura, por ejemplo, Lotman llama al lenguaje "sistema modelizante primario" y considera que se trata de un modelo que va delimitando la realidad y que se encuentra en el centro de la cultura funcionando como un elemento que brinda estructura, ya que define las reglas o códigos de los signos que se encontrarán tanto dentro como fuera del sistema.

Aplicada esta noción para el caso de los migrantes sean académicos o no, se nota cómo su "cultura de origen" marca su visión, es donde originalmente se "modela" su estructura de valores, creencias y símbolos que le dan sentido y lo lleva más allá de su país al enfrentar el cambio de cultura como un proceso de adaptación a su nueva casa y en el mejor de los casos se convertirá en un proceso de integración.

Además, Lotman, hace la división del espacio cultural entre centro y periferia y plantea que la zona de la periferia es la zona más sensible a los cambios, debido a su inestabilidad fronteriza y a la carencia de normas rígidas que la guíen; por el contrario, en el centro existe una constante estructuralidad, como resultado de esta situación, el cambio proviene casi siempre de esta zona periférica por su mayor impredictivilidad. ${ }^{22}$

Lotman conceptualiza a la cultura como algo más acotado que "el estudio de ese todo que rodea al hombre y aún de su espacio cultural"; por el contrario, aunque reconoce estos espacios, trata a la cultura como el producto de un trabajo de distinción permanente que conforma sus propias fronteras a partir del sentido compartido o el acuerdo comunicativo (estructuras significantes).

De esta forma, Lotman por medio de los múltiples emisores y destinatarios presentes en un entorno determinado que dejan de ubicarse como polos de un proceso de intercambio de información, pasan a caracterizarse como "sujetos competentes capaces de interactuar en un marco o sistema y significar generando estructuras semánticas y, por tanto, identitarias”.

Se puede considerar el universo semiótico como un conjunto de distintos textos y de lenguaje cerrados unos con respecto a los otros. Entonces todo el edificio tendrá el aspecto de estar constituido de

21 Gustavo Garduño Oropeza et al., "La semiótica de Lotman en la caracterización conceptual y metodológica de la organización como cultura”, en Revista de Ciencias Sociales, 2002, p. 221.

22 Macías, op. cit., p. 13. 
distintos ladrillitos. Sin embargo, parece más fructífero el acercamiento contrario: todo el espacio semiótico puede ser considerado como un mecanismo único (si no como un organismo). ${ }^{23}$

Una aportación fundamental de la semiótica de Lotman es la idea de que cualquier sistema sígnico que presente niveles de convencionalidad o socialización y que, por lo tanto, esté delimitado es, por lo mismo, susceptible de ser entendido como "cultura". ${ }^{4}$

Para Lotman, la cultura es el espacio semiótico fuera del cual es imposible la existencia misma de la semiosis. Por el contrario, sólo la existencia de tal universo - de la semiosfera - hace realidad el acto sígnico particular. "Así como pegando distintos bisteces no obtenemos un ternero, pero cortando un ternero podemos obtener bistecs, sumando actos semióticos particulares no obtendremos un universo semiótico". ${ }^{25}$

Una de las preocupaciones de la semiótica de la cultura es el problema de la generación del sentido. La formación de sentido no tiene lugar en un sistema estático. Para que ese acto se haga posible, se debe introducir algún mensaje nuevo en el sistema comunicativo que detone un proceso de traducción interna, de intercambio semiótico entre sus subestructuras. La comunicación y el intercambio cultural resultan de un mecanismo de traducción que opera tanto entre los propios textos de la cultura (semiosfera) como para los textos que provienen de sistemas culturales externos.

La semiótica de la cultura resulta útil para explicar los procesos migratorios como procesos de intercambio entre distintos sistemas semióticos, debido a que el migrante se enfrenta a un intercambio de culturas y produce de manera permanente un proceso de traducción entre las culturas que provoca la transformación de ambas culturas de forma continua.

23 Luri Lotman, op. cit., p. 28.

24 Gustavo Garduño, op. cit., p. 222.

25 Lotman, Idem. 


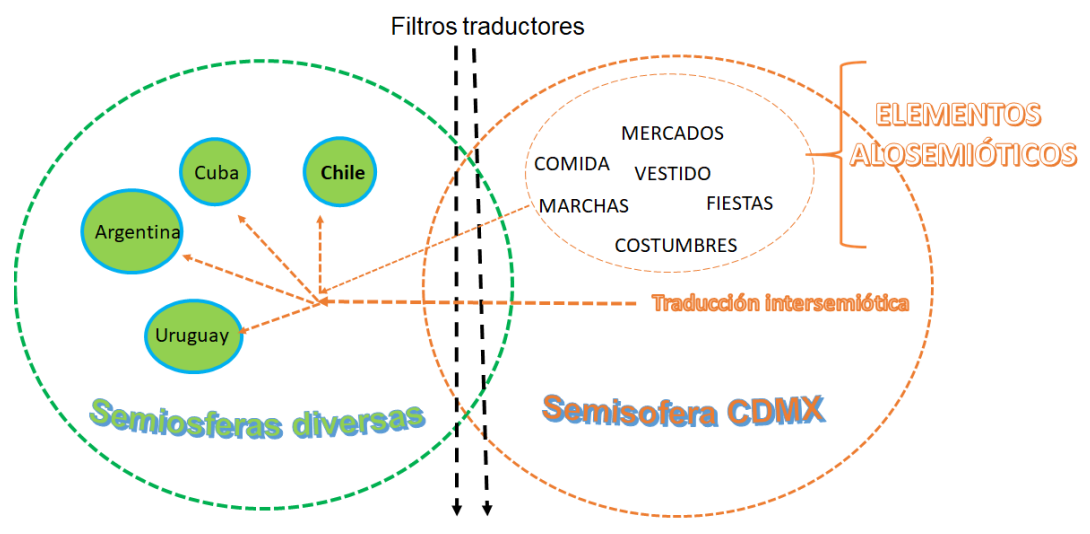

\section{Gran semiosfera del migrante}

La gran semisofera del migrante es la suma de todos los procesos significación y de cada una de las estructuras significantes que incluyen los aspectos tanto materiales como sociales que van conformando y regulando la vida a través de las experiencias vividas que construyen el entorno del migrante pero que al mismo tiempo construyen y reconstruyen la identidad del migrante en un proceso dinámico. También se incluyen las relaciones con otras culturas; por consiguiente, todo lo que signifique o pueda significar en el migrante en el tiempo y en el espacio comprende parte de la semiosfera del migrante. A considerar que ese espacio al que se enfrenta (culturas distintas) no es homogénea, que no es trivial ni es previsible y cuenta con capacidad para dialogar, se vuelve simultáneamente modelizante para el migrante pero también comprende al individuo activo con capacidad de decidir, actuar de diferentes maneras. ${ }^{26}$

La frontera para Lotman es un mecanismo bilingüe que traduce los mensajes externos al lenguaje interno de la semiosfera y a la inversa, elabora la nueva información y la adapta a las nuevas condiciones. El diálogo permite que entre las dos semiosferas (lugar de origen-lugar de llegada) haya ese intercambio de información con la consecuente generación de semiosis o sentidos; al respecto, señala Lotman que "tanto la historia de la autodefinición cultural, la nominación y el trazado de las 
fronteras del sujeto de la comunicación, como el proceso de construcción de su contraparte - del 'otro'-, son uno de los problemas fundamentales de la semiótica de la cultura".27

La diferencia de entre la cultura como unidad supraindividual y las unidades supraindividviudales de orden inferior (del tipo "hormiguero") está en que, al ingresar en todo como una parte, la individualidad particular no deja de ser un todo, Por eso la relación entre las partes no tiene un carácter automático, y supone cada vez una tensión semiótica y colisiones que adquieren a veces un carácter dramático. ${ }^{28}$

La cultura es un conjunto de relaciones textuales, dotada de significación para sus miembros que regula la vida y las interacciones de todos los miembros de la sociedad, funciona para Lotman como una unidad total y con fronteras semióticas adaptativas, el migrante está dotado de procesos de significación de dos culturas, generando una gran semiosfera donde dialogan y se confrontan dos cosmovisiones, que suman rasgos, pero que también se confrontan y contradicen de manera simultánea, lo que lo lleva a un proceso dinámico entre la integración y desintegración en su vida.

La semiosfera es un espacio delimitado con respecto del espacio que lo rodea, que sería el espacio extra-semiótico, divididos por una frontera de puntos que pertenecen a ambos espacios, que actúa como filtro $\mathrm{y}$ traductor. Esta traducción se articula dando sentido a la realidad extra-semiótica; es decir, otorga sentido dentro de algunos de los sistemas semióticos. Para Lotman la frontera "es la suma de todos los traductores -filtros- bilingües pasando a través de cuales un texto que se traduce a otro lenguaje (o lenguaje) que se halla fuera de la semiosfera". ${ }^{29}$

Para tener contacto el migrante entre una cultura y otra se tiene que pasar a través de los filtros para poder ser traducido al lenguaje de su cultura de origen, la frontera une dos esferas de la semiosis, desde la posición de la autoconciencia semiótica. Lotman, hace la división del espacio cultural entre centro y periferia, y plantea que la zona de la periferia es más sensible a los cambios, debido a su inestabilidad fronteriza y a la carencia de normas rígidas que la guíen; por el contrario, en el centro existe una constante estructuralidad, como resultado de esta situación, 
el cambio proviene casi siempre de esta zona periférica por su mayor impredictivilidad. La dialéctica del campo cultural y la semiosfera se da en el continuo movimiento entre centro y periferia.

El proceso de significación se da dentro de una convención social. Proceso que se da de una manera no natural, en la que los significados se dan de acuerdo con los conceptos y de contexto de la sociedad en la que se están presentando, es así como el significado de los discursos no está directamente relacionados con la verdad, sino que son construcciones de significados creados por una sociedad en particular, en un contexto cultural determinado.

La frontera actúa también como un elemento de organización y estructuración semiótica, no sólo organiza: es espacio dentro y fuera de ella, sino establece los elementos de la semiosis que se relacionan en un contexto determinado. La valoración de los espacios interior y exterior no es significativa, "significativo es el hecho mismo de la presencia de la frontera. ${ }^{30}$

La frontera filtra la penetración de lo externo hacia lo interno. y al filtrarlos los elabora y adapta a su interior. La frontera es un lugar donde se negocia procesos de integración, un lugar bilingüe que promueve adaptaciones, reelaboraciones y traducciones que territorializan un complejo colectivo, receptores "filtros" que recibe y descodifica lo a lo semiótico. La frontera presupone una zona de intersección y resistencia de fuerzas que los espacios oponen uno a otro. A Lotman le interesa la dificultad de la traducción de una parte no interceptada de una lengua a otra, porque es allí donde se produce los mayores problemas de construcción del sentido.

La intersección de la periferia produce rápidos cambios semióticos, porque captura espacios culturales particulares (extra semióticos) y las entidades que funcionan como traductores se distribuyen por la frontera, y funcionan como traductores en los límites del sistema, porque poseen el don especial de pertenecer a dos mundos.

Este proceso es el que experimenta el migrante al tener una cultura de origen y empieza a insertarse a otra cultura habla dos lenguajes, tiene dos culturas y le permite estar en la periferia actuando como traductor de una y otra cultura; son muchos los factores que determinan qué elementos de sus cultura nueva va a conservar y cuáles va a desechar, desde su psicología personal hasta elementos contextuales o de traducibilidad; pueden ir desde el uso de determinados términos, así como la adopción de costumbres, tradiciones, creencias, etcétera. Sin embargo, la cultura

30 Ibid., p. 29. 
no totalmente rígida, por lo cual existe un núcleo y una periferia. En el núcleo se disponen aquellos nombres que expresan los elementos más característicos de la cultura; por lo tanto menos bilingües y estáticos. El núcleo corresponde a los sistemas semióticos dominantes y la periferia a los fragmentos de sistemas o textos aislados; al respecto, menciona Lotman: "las estructuras nucleares segregan un sistema de metalenguajes con los cuales no sólo se describe a sí misma, sin que también al espacio periférico de la semiosfera dada entonces encima de la irregularidad del mapa semiótico real, se construye el nivel de unida ideal de éste. ${ }^{31}$

El proceso de transformación no es exclusivo del migrante, sino la población de acogida también sufre una transformación, lo que da lugar, de forma más o menos explícita, a reacciones desde la acogida de buena forma, hasta actitudes racistas y xenófobas; desde percibir al inmigrante como un intruso o peligro del que hay que protegerse, o como una persona que viene a enriquecer su cultura. En este marco, los inmigrantes desarrollan vínculos sociales y culturales junto a nexos económicos y laborales que hacen que muchos de ellos se "imaginen" a sí mismos como parte de una comunidad en los países a los cuales emigran, pero no de cualquier comunidad, sino de una comunidad emigrante que reproduce y recrea los patrones culturales y formas simbólicas de sus comunidades de origen. Esta construcción imaginaria se basa en un conjunto de relaciones y transacciones de todo tipo, que se dan en el marco de un sistema transnacional de redes sociales y capital cultural, las cuales conforman el nicho interpersonal del individuo, y contribuyen a su propio reconocimiento como individuo y a su imagen como miembro de una comunidad y sujeto de un tejido social.

Este proceso es lo que define la complejidad del fenómeno de la migración, que de manera dinámica y simultánea impacta al migrante y al contexto donde se desenvuelve.

Las comunidades migrantes definen y construyen un sentido de pertenencia y dependencia con las redes, más fuerte y profundo que el de los respectivos Estados nacionales involucrados con la migración. Se trata de la configuración de un sentido de pertenencia. En este sentido, se hace referencia a la transnacionalización (en el sentido de comunidad más allá de las fronteras nacionales tanto del estado original, pero también del estado al que se llega); de esta forma, los emigrantes residentes en el país de destino mantienen e incrementan su importancia y vínculos con sus comunidades de origen, aún después de su asentamiento legal, estable y definitivo.

31 Ibid., p. 26-30. 
Toda traducción lleva implícita la carga cultural, como es el caso de los migrantes que llevan traducciones semióticas que involucran semiosferas distintas (diferentes universos semióticos) en cualquier nivel; es necesario asumir que este tipo de traducción es necesariamente una semiótica intercultural.

La traducción, en el caso de la migración, involucra los lenguajes y textos comprendidos en la cultura y es compleja por la diversidad y características de esos lenguajes. Puesto que entre los lenguajes de la cultura rige un principio de intraducibilidad y las traducciones pueden ser:

a) Las traducciones interculturales que son los filtros traductores que permiten que elementos de otra cultura significan al inmigrante cuando ha realizado proceso de una traducción intercultural.

b) "La dimensión intersemiótica de la cultura resulta de la concurrencia parcial de los signos de los lenguajes (sistemas sígnicos). Se da a través de la interacción entre los diversos sistemas sígnicos que conforman un espacio semiósico. En dicho espacio se observa la transposición de unidades mínimas de significado, que van de un sistema semiótico a otro a partir de un contexto determinado de enunciación.

Es el camino que realiza el inmigrante al momento de intentar, y conseguir, el "traslado del significado" de un sistema sígnico a otro. Cada sistema semiótico supone la presencia de formas de estructuración del significado, así como de organización del sentido.

Lo intersemióticas, en el caso de los inmigrantes. es un proceso de semiosis que permite la circulación del significado a partir de un conjunto de adecuaciones estructurales, mediante el traslado de un sistema semiótico a otro a través de estrategias, lo que es un traslado de significados.

Lo extra semiótico es para Lotman "la descripción estructural se construye sobre la base de distinción, en el objeto que se describe elementos del sistema y nexos que permanecen invariantes En el caso de cualquier transformación homorfa del objeto... A ella se contraponen los elementos extra semióticos que se distinguen por la inestabilidad e irregularidad"32.

Lotman introduce el término alosemiótico para indicar el espacio que está por fuera de la semiosis y que, para tansitar en el campo de la significación, debe pasar por un traductor filtro bilingüe. Es decir, lo 
propio y ajeno, el mundo y la cosa no se tocan directamente, necesitan de una tercera zona de la experiencia que oficie de traductor filtro. A ello se denomina mecanismo de frontera.

Lo alosemiótico no puede pertenecer a ese espacio semiótico, es extrasistémico; esto implica, que determinados elementos se encuentren en el núcleo o más próximos a la periferia en un determinado sistema semiótico.

La adecuación de la traducción intercultural del migrante depende de las competencias desarrolladas para interpretar (traducir) los códigos de ambas culturas, y por las condiciones de conservación y transmisión de los textos.

\section{Resultados}

A partir de las categorías desarrolladas en la investigación, se dio la tarea de analizar los resultados de la investigación y se presenta el modelo de la Gran semiosfera del migrante

El migrante académico convive con dos semiosferas de manera simultánea, la semiosfera de la Ciudad de México y la semiosfera de su país originario: Argentina, Cuba, Colombia, Chile, España y Uruguay. El mecanismo a través del cual logra la semiosis son los filtros traductores que contribuyen a comprender los signos y significación de cada una de las semioferas, las traducciones pueden ser interculturales e intersemióticos; también existen elementos alosemióticos o intraducibles que no son comprensibles para el inmigrante y se vuelven extrasemióticos. Todo lo anterior nos confirma la naturaleza dinámica y compleja del fenómeno de la migración y es un acercamiento a la realidad empírica del migrante.

\section{Discusión}

Los estudios migratorios deben considerar, para abordar el fenómeno desde la perspectiva compleja, como punto de partida al actor que experimenta el proceso que es el migrante, y no los países para su análisis e impacto ; el migrante vive una realidad dinámica atravesada por múltiples factores y de manera simultánea cambia de manera permanente así como el entorno a donde vaya, actúa y participa en dos o más países en su calidad de transnacional y produce procesos de semiosis atravesado por fronteras físicas y simbólicas, que le obligan a ser bilingüe entre dos semiosferas y a emplear traducciones para comprender, adaptarse y en su lugar integrarse, siendo un proceso nunca acabado que requiere reconocer y comprender los signos de la cultura de acogida, una je- 
rarquización en los significados y símbolos que definen lo que decide mantener de su cultura de origen y una producción de sentido nuevo que se ve reflejada en acciones dotadas de interculturalidad; todo ello implica dejar de lado concepciones tradicionales como la asimilación, que implica negar sus raíces y su texto original y que tiene fundamento en los intereses políticos y económicos del Estado-nación.

\section{Crítica de resultados}

El alcance de la propuesta de esta investigación se limita al estudio de caso de nueve migrantes hispanoamericanos, que laboran en la actualidad en el ámbito académico y en la misma institución de educación superior; sin embargo, su análisis permite abrir nuevas investigaciones relacionadas con el fenómeno de la migración en torno a derechos humanos, lo que pone en énfasis su derecho a mantener su cultura original, condiciones jurídicas que contemplen su realidad transnacional y las aportaciones a sus dos naciones.

Las investigaciones disciplinarias de migración se enfocan en métodos que sólo observan un nivel de la realidad; el transnacionalismo y la semiótica lotmiana lo estudian desde la perspectiva compleja del migrante, debido que estudian de manera simultánea su relación con su país de origen y el de acogida; es transcultural porque tiene un carácter multidimensional y multirreferencial a través de reconocer la complejidad empírica del migrante que asume que el ser humano ha sufridos cambios exponenciales a través del tiempo, espacio y experiencia, que lo hace transcultural y dinámico; por lo tanto, es imposible abarcar su totalidad.

Los estudios de migración complejos son transdisciplinarios, buscan la pluralidad y quitan la autoridad académica disciplinaria individual y lo otorga a colectivos disciplinarios. 


\section{Referencias}

Arango, Joaquín, "Las Leyes de las Migraciones de E. G. Ravenstein, cien años después", en Revista Española de Investigaciones Sociales (REIS), 1985, pp. 7-26.

Bauman, Zymunt, Globalización, consecuencias humanas, Buenos Aires, FCE, 2001.

Blanco, Cristina, “Transnacionalismo. Emergencia y fundamentos de una nueva perspectiva migratoria”, en Papers, 2007, pp 13-29.

Clifford, James, Dilemas de la cultura, Barcelona, Gedisa, 2001.

De Juan, Artola, México país de migración, México, Siglo XXI, 2015.

Faist, Thomas, The Volume and Dinamics of International Migration and Transnational Social Spaces, Londres, Oxford University Press, 2000.

Garduño Oropeza, Gustavo. Zuñiga Roca, María Fernanda, "La semiótica de Lotman en la caracterización conceptual y metodológica de la organización como cultura”, en Revista de Ciencias Sociales, 2005, pp. 217-236.

Glick Shiller, Nina, Basch, Linda y Blanc-Szanton, Cristina, Transnationalism: A new analytic framework for understanding migration, New York, Columbia, 2001. 


\title{
CREACIÓN DE LA CIUDADANÍA \\ DESDE EL ECOSISTEMA DE LA \\ PRENSA DEL MÉXICO \\ INDEPENDIENTE (1820-1829)
}

\author{
Tatiana Valdez Bubnova \\ Laura Campos Millán \\ Emiliano Canto Mayén \\ El Colegio de Morelos
}

\section{Introducción}

Desde una perspectiva diacrónica y sincrónica nos proponemos estudiar, con base en tres textos de la prensa de los primeros años del México independiente, los ensayos incipientes de construcción de un concepto de ciudadanía. Para este propósito, consideramos a la prensa independiente como el ecosistema social en el cual se gestaron algunos modelos de las funciones ciudadanas. A partir de lo anterior, sostenemos que, en concordancia con el modelo de Edgar Morin, el ecosistema social de la nueva prensa nacional de la década de 1820 produjo una dinámica de morfogénesis, que resultó de la catástrofe del fin del régimen virreinal y de sus prácticas relativas a la opinión pública en la prensa. ${ }^{33}$ Sugerimos que observar este periodo, a través de procesos de morfogénesis, permite identificar la acción de las fuerzas catalizadoras del orden, el desorden y la organización de la nueva práctica periodística de la época.

Este trabajo es una aproximación a una problemática de índole histórica, con base en algunos postulados de la Teoría de la complejidad. La emancipación en el año de 1821 de la Nueva España y el surgimiento de la entidad política conocida como México, dio pauta a un proceso de reacomodos que podría calificarse como un periodo de morfogénesis. Este término se refiere, en el modelo de Edgar Morin, a aspectos de la

33 A decir de Víctor Gayol, la guerra de independencia generó un cambio en la labor de los letrados que, en la Nueva España, ejercieron el periodismo puesto que la contienda los obligó a tomar una posición política. Víctor Gayol, "Escritores cortesanos y rebelión. La breve respuesta de los letrados a los sucesos de 1810 en México”, en Marta Terán y José Antonio Serrano Ortega, coords., Las guerras de independencia en la América Española, México, El Colegio de Michoacán, Universidad Michoacana de San Nicolás de Hidalgo, CONACULTA/INAH, 2010, p. 149. 
caracterización de las dinámicas propias de la integración de las organizaciones sociales o humanas, que interactúan en un entorno, y forman un ecosistema urbano con componentes naturales, sociales y económicos. ${ }^{1}$

Por etapas o lapsos de morfogénesis, en el ámbito de la historia política o social, deben entenderse las coyunturas, en las cuales ciertas condicionantes sistémicas de una sociedad generan desorden y condiciones para el surgimiento de nuevas pautas o alternativas. ${ }^{2}$ Esta postura, inspirada en la teoría de la complejidad, tiene a su favor el hecho que permite, a los estudiosos e intérpretes del pasado humano, superar visiones que corren el riesgo de considerar la historia en blanco y negro y que suelen calificar a ciertos lapsos como de decadencia o apogeo.

La noción de morfogénesis abarca, en nuestro punto de vista, los fenómenos de cambio social desde una perspectiva amplia. En muy rara ocasión, los cambios sociales o políticos se efectúan de forma drástica e inmediata; en cada momento de la historia confluyen prácticas heredadas que, siguen influyendo de un modo u otro en las acciones y decisiones de los individuos e instituciones. Sin embargo, la degradación o debilitamiento de las usanzas o leyes permiten el surgimiento y consolidación de hábitos inéditos o contestatarios que, con el paso del tiempo, se fortalecerán hasta el punto de suplantar los modos previos.

En este sentido, la ruptura con el dominio de la corona española, que se registró en septiembre de 1821, abrió las puertas a un largo y conflictivo proceso de experimentación política, cuyos avatares, progresiones y retrocesos conformaron el cuerpo político del Estado nación mexicano. Para verificar lo anterior, basta con echar un vistazo a la crónica del devenir sociocultural de los primeros decenios de la historia patria, en la cual se sucedieron imperios y repúblicas centrales y federales en un cúmulo de asonadas y rebeliones militares.

En una intervención tan breve, es imposible efectuar un repaso pormenorizado siquiera de los principales acontecimientos registrados en los primeros años de la historia política; por ello, es imperioso apuntar que, en los albores de la independencia, la discordia e inestabilidad internas estuvieron muy lejos de aplacar el entusiasmo reinante entre los individuos que, pese al caos en la conformación del poder político,

1 La ecología urbana consiste en un enfoque de origen antropológico, que se propone investigar el interjuego de la cultura y la ecología a medida que las poblaciones humanas se adoptan a su(s) ecosistema(s). Thomas Barfield, Diccionario de Antropología, México: Siglo XXI, 2000, 40.

2 Edgar Morin, El Método I. La naturaleza de la naturaleza, trad. de Ana Sánchez en colab. de Dora Sánchez, Madrid, Cátedra, 2001, 35, pp. 68-69. 
idearon y propusieron alternativas para el surgimiento de estados de opinión que encaminaron a los antiguos vasallos y súbditos hacia una sociedad moderna y ciudadana. ${ }^{3}$

El espacio predilecto, para ventilar las ideas sostenidas por los letrados del siglo XIX en México, fue la prensa. ${ }^{4}$ Proponemos que este espacio emergió como un ecosistema renovado y en ebullición, gracias a la coyuntura gubernamental y al término de las censuras eclesiásticas que, anteriormente, pesaban sobre la producción impresa en la Nueva España. ${ }^{5}$ Antes de la guerra y declaración de Independencia, los pocos periódicos publicados en la Nueva España salieron a la luz después de una autorización previa, de una revisión de su contenido por parte de las autoridades eclesiásticas y medraron o sobrevivieron gracias al sostén económico del virrey o su corte. ${ }^{6}$ Es decir, que, sin ser plenamente oficiales, las columnas de las publicaciones periódicas de la época virreinal se irguieron como bastiones de la ortodoxia religiosa y de la defensa y elogio de las autoridades monárquicas.

Estas condiciones o reglas del juego variaron luego de la escisión política de 1821. Si bien el decoro, la religión católica y la vida privada de los individuos se mantuvieron como áreas vetadas o prohibidas para toda intrusión por parte de los escritores públicos, ${ }^{7}$ los periodistas pudieron opinar por primera vez de las decisiones del gobernante en turno y calificar los aciertos y errores de su administración. ${ }^{8}$ Además, en vista de que el sentimiento de identidad y pertenencia nacionales se hallaban muy lejos de esbozarse y adoptarse por la mayoría de pobladores del nuevo país, los periodistas recién erigidos y los procedentes

3 Este entusiasmo movió a los políticos de la época a considerar que México se transformaría en una tierra propicia para la llegada de inmigrantes extranjeros. Otto Berninger, Inmigración en México, 1821-1857, México, Secretaría de Educación Pública, 1974, pp. 22 y 35.

4 Fausta Gantús y Alicia Salmerón, Prensa y elecciones. Formas de hacer política en el México del siglo XIX, México, Instituto Mora/Instituto federal Electoral, 2014, 21.

5 Manuel Suárez Rivera, "La imprenta de Luis Abadiano y Valdés: Un acercamiento al mundo tipográfico decimonónico", en Laura Suárez de la Torre, coord., Estantes para los impresos. Espacios para los lectores. Siglos XVIII-XIX, México, Instituto Mora/Consejo Nacional de Ciencia y Tecnología, 2017, pp. 99-106.

6 Laurence Coudart, "En torno al correo de lectores de El Sol (1823-1832): Espacio periodístico y opinión pública", en Cristina Gómez Álvarez y Miguel Soto, coords., Transición y cultura política. De la colonia al México independiente, México, Universidad Nacional Autónoma de México, 2004, pp. 67-69.

7 Leonardo Martínez Carrizales, Tribunos letrados. Aproximaciones al orden de la cultura letrada en el México del siglo XIX, México, Universidad Autónoma Metropoitana-Atzcapozalco, 2017, p. 41.

8 Edward Said, Representations of the Intellectual, Nueva York, Random House, 1996, p. 11. 
del periodismo monárquico, se sintieron con el deber y obligación de debatir y proponer programas de adoctrinamiento y trazar las directrices y atributos del ciudadano mexicano ideal. ${ }^{9}$

El vaivén de la nación en formación alentó y retroalimentó las interacciones de la prensa de opinión política que fundaron personajes como José Joaquín Fernández de Lizardi, Florencio Galli y Francisco Íbar, entre otros, puesto que al desencadenarse una avalancha de luchas por el poder fue natural, que la libertad de expresión que este ambiente produjo, que se fomentara que un grupo de letrados manifestase su apoyo u oposición al modo en que se llevaban las riendas del gobierno del nuevo país. ${ }^{10}$

En este trabajo, sugerimos que estos esfuerzos de la prensa terminaron por convertirse en la energía catalizadora de un nuevo orden. Este orden no estaba diseñado de antemano, sino que fue determinado, a posteriori, a partir de las propias condiciones de desorden que trajo consigo la catástrofe independentista. A continuación, abordamos la cuestión de la determinación de un orden.

Introducimos la noción de orden a posteriori con la finalidad de comprender el proceso de formación de un ecosistema como una organización regulada por reglas. A través de la noción de juego de lenguaje, sostenemos que el debate periodístico en discusión generó las interacciones que fraguaron la formación de un tipo de orden: un ecosistema que integra la construcción de un concepto de ciudadanía. Además, expondremos los elementos actuantes en la formación de este ecosistema. Por último, sugerimos el empleo de las herramientas teóricas de la complejidad, que nos permite dar un tratamiento original de los eventos históricos, que puede trasladarse en reflexiones que relacionen circunstancias del pasado con la actualidad.

\section{Determinación de orden a posteriori}

De acuerdo con Morin, ${ }^{11}$ las condiciones singulares, que se presentan en una catástrofe dan lugar al surgimiento del desorden, pero, al mismo tiempo, son condiciones catalizadoras para el surgimiento del orden.

9 En esta ocasión, nos centraremos en las figuras de José Joaquín Fernández de Lizardi, Florencio Galli y Francisco Ibar, periodistas fundacionales de las publicaciones de opinión política en el México independiente.

10 Entre las primeras publicaciones políticas del México independiente, se encuentran La Gaceta del Gobierno de México, Semanario Político y Literario, Gaceta Imperial de México y El Farol.

11 Edgar Morin, El Método I., Madrid, Cátedra, 2001, p. 68. 
Esto se debe a que la catástrofe propicia interacciones entre los "elementos, cuerpos, objetos y fenómenos", involucrados en el evento catastrófico que, eventualmente, pueden dar origen a fenómenos de organización. ${ }^{12}$

Una de las tesis centrales de la formación de orden a partir de un evento catastrófico, es que el orden naciente obedece reglas, las cuales son necesarias para el mantenimiento del sistema creado, pero no están dadas de antemano, sino que son el resultado de las interacciones propiciadas por el desorden provocado por la catástrofe. En el caso que nos ocupa, el surgimiento de un nuevo orden social posterior a la lucha de independencia, podemos ayudarnos de la noción de orden dentro de un juego de lenguaje, para entender cómo contribuye la formación del concepto de ciudadanía en la conformación de este orden social. La noción de orden la encontramos desarrollada en las Investigaciones filosóficas ${ }^{13}$ de Wittgenstein.

\section{Juegos de lenguaje, ecosistemas y orden a posteriori}

Un juego de lenguaje puede ser considerado como un sistema, en tanto que está organizado a partir de las reglas de la gramática de ese juego, ${ }^{14}$ que no obedecen ni corresponden a instancias superiores o independientes del sistema, sino que surgen y se definen por el uso que hacen de ellas los seres humanos que participan en el juego. ${ }^{15}$ En este sentido, las reglas son producto de la actividad humana. La gramática de un juego de lenguaje es responsable del orden dentro del sistema, por lo que el orden así generado no responde a una instancia independiente del propio sistema, sino que es el resultado de la formación de convenciones. ${ }^{16}$ La historia natural del ser humano es la historia de la formación de convenciones; es decir, la historia de la institución de prácticas entendidas como formas regulares de comportamiento público infundado y no justificado. ${ }^{17}$

Si bien la práctica de un juego de lenguaje está determinada por su gramática y no tiene otro fundamento más allá de la convención, sólo es posible dentro de un armazón conformado por la realidad física del mundo. ${ }^{18}$ Sobre este armazón se generan y cohesionan distintas formas

12 Ibid., p. 69.

13 Ludwing Wittgenstein, Investigaciones filosóficas, México, Universidad Nacional Autónoma de México, 2003, p. 69.

14 Ibid., p. 23-25, 39-41, 133.

15 Ibid., p. 73-74, 105, 201.

16 Ibid., p. 275 y 331.

17 Ibid., p. 209, 211 y 301.

18 Ibid., p. 143-144 y 523. 
de vida. ${ }^{19}$ Un sistema regulado por una gramática es un sistema regulado por un orden, que surge a partir del actuar humano; es decir, a partir de las interacciones entre las acciones humanas. En este sentido, un sistema regulado por una gramática es un sistema regulado por un orden a posteriori. La construcción, transformación y eventual anulación de un sistema regulado por este tipo de reglas convencionales, es el resultado de la formación, transformación y eventual anulación de conceptos. ${ }^{20}$ Construir un concepto es introducir una conexión regular entre acciones dentro de un juego de lenguaje. Transformar un concepto es alterar estas conexiones regulares anteriormente establecidas. Anular un concepto consiste en perder completamente dicha conexión regular entre las acciones.

Proponemos que un ecosistema puede considerarse un juego de lenguaje siempre y cuando se cumplan dos condiciones: (i) se trata de ecosistemas en los que se organizan seres humanos y (ii) el empleo de palabras tiene un papel principal en esa organización. Dadas estas condiciones, sugerimos que el encuentro propiciado por el debate periodístico entre Íbar, Fernández de Lizardi y Galli, dio paso a las interacciones que fraguaron la formación de un tipo de orden a posteriori: un ecosistema que integra la construcción de un concepto de ciudadanía. Este ecosistema no se formó aisladamente, sino que, como cabe esperar de un evento catastrófico y de las fuerzas catalizadoras de orden, desorden y organización que echa a andar, la formación del ecosistema de la prensa influyó y fue influido por otros ecosistemas.

Aquí cabría recalcar las maneras en las cuales comenzaron a convivir dos ecosistemas que, a partir de entonces, serían inseparables. El del Estado mexicano, con sus cambios de gobierno y su lucha política, junto con el del periodismo de opinión. Los actores de ambos espacios compitieron y reaccionaron entre sí en un juego de intereses y oposiciones muy particulares. A partir de 1824, en el país el gobierno puede restringir las libertades de la prensa si considera que ésta sobrepasa o viola los límites de lo conveniente mientras que, por su parte, los escritores públicos pueden presionar a un caudillo o gobernante al tacharlo de tiránico, antipatriótico o injusto. La prensa, como contrapeso y el gobierno como censor serán las dos figuras predominantes durante el periodo estudiado y, a su favor, puede anotarse que la Constitución de 1824 indicó que al Congreso de la Unión le correspondería fomentar la ilustración y velar por la libertad

19 Una forma de vida es un conjunto de actividades humanas instituidas como prácticas infundadas que pertenecen a la historia natural del ser humano. Ibid, 39-41, 25-26, 517.

20 Wittgenstein, Ibid., pp. 31, 199, 285, 319. 
de expresión, mientras que los periódicos de la época dieron cabida a reflexiones sobre las obligaciones del ciudadano, que muy difícilmente hallarían una proyección similar en la época contemporánea.

Esta relación de simbiosis entre los políticos y periodistas desencadenó choques y enfrentamientos a causa de la naturaleza candente de la administración pública. ${ }^{21} \mathrm{El}$ mismo debate que fue detonado por los roces entre algunos actantes en estos ecosistemas traslapados derivó en el surgimiento de estados de una nueva conformación de la opinión pública ${ }^{22}$ y la toma de posición de los participantes de esta polémica.

A continuación, presentamos algunos de los principales elementos presentes en la construcción del concepto de ciudadanía propiciado por el debate períodistico del que Íbar, Fernández de Lizardi y Galli fueron protagonistas. Con base en estos elementos, sugeriremos finalmente, que se cumplen las condiciones para conformar un ecosistema que integra el concepto de ciudadanía.

\section{Elementos presentes en la construcción del concepto de ciudadanía en el ecosistema de la prensa 1820-1827}

Entre los componentes presentes en la construcción del ecosistema de la prensa, consideramos algunos textos que suelen estudiarse, en la actualidad, más por su historia editorial, sus valores estéticos o importancia dentro de la obra completa de su autor. Se trata de ensayos, poemas y relatos en prosa, algunos de los cuales son fuentes imprescindibles para la reconstrucción y análisis de los discursos políticos del pasado. En este tenor, historiadores como Elías Palti han abordado el periodismo cultural y literario como auxiliar en la construcción de la legitimidad política en el México del siglo XIX. ${ }^{23}$

21 Si a las organizaciones parlamentarias nos aproximamos, en los primeros cincuenta años de nuestra historia nacional hubo cuatro congresos constituyentes, catorce legislaturas del Senado, veinte ordinarias y una extraordinaria de la Cámara de Diputados, una Junta de Representantes y dos de Notables. Si se suma el número de nombramientos expedidos para presidentes de la república, senadores y diputados constituyentes, propietarios y suplentes, tenemos que se giró un total de 4,792 designaciones. Cecilia Noriega Elío, "Los grupos parlamentarios en los congresos mexicanos, 1810-1857. Notas para su estudio", en Beatriz Rojas, comp., El poder y el dinero. Grupos y regiones mexicanos en el siglo XIX, México, Instituto Mora, 1994, p. 122.

22 A decir de Gayol, los letrados de las postrimerías del virreinato, consistían en extensiones de los ámbitos cortesanos y eclesiásticos motivo por el cual escribían para las ceremonias oficiales y religiosas. Gayol, Escritores cortesanos, México, El Colegio de Michoacán, Universidad Michoacana de San Nicolás de Hidalgo, CONACULTA/INAH, 2010, pp. 150-152.

23 Elías Palti, La invención de una legitimidad: razón y retórica en el pensamiento mexicano del siglo XIX: un estudio sobre las formas del discurso político, México, Fondo de Cultura Económica, 2015, pp. 30-33. 
Proponemos que desde el enfoque de la prensa como un ecosistema social estos textos son parte de la tecnología de la información de una época. La inclinación de algunos escritores a participar en los debates ideológicos y políticos que les son contemporáneos nos permiten ofrecer una lectura del lenguaje de la ciudadanía que los artífices del concepto difundieron en la Ciudad de México, durante la primera década de independencia, sirviéndose del soporte que les proporcionó la tecnología del periodismo literario de la década que nos ocupa.

Fuente descartada por algunos analistas literarios, a causa de su artificio artístico y los historiadores poco afectos a las letras, el periodismo literario de los años posteriores a la independencia de México ofrece a los interesados en el discurso político una rica veta de análisis. A causa de esto, citaremos en el presente texto algunas composiciones que expusieron las opiniones e ideas de sus autores acerca de la ciudadanía, el gobierno y la participación política de los mexicanos.

En este escrito se presentan algunos de los principales ejes temáticos que tuvo el lenguaje de la ciudadanía en las publicaciones periodísticas de carácter literario. Expondremos parte de los más destacados debates que se ventilaron en las páginas de estas publicaciones; la función que los escritores asignaron a la literatura y a su labor creativa en aquella época de transformaciones políticas. En segundo término, se expondrán también los derechos y obligaciones que otorgaron en sus escritos al ciudadano.

Los autores en torno a los que se concentrará este estudio son José Joaquín Fernández de Lizardi, Florencio Galli y Francisco Ibar. Estos editaron respectivamente los periódicos Conversaciones del payo y el sacristán (1825), El Iris (1826) y El Celaje (1829). Se ha decidido retomar a esta tríada de autores por sus diversos orígenes: mientras uno es considerado el primer escritor connotado del México independiente, Íbar fue un maestro pintor y Galli un periodista de origen itálico, desterrado por su participación política y militar en Europa.

A pesar de las diferencias entre estos sujetos, sus ideas acerca de la literatura, la ciudadanía y la educación se encauzaron dentro de un debate en el que primaron los paralelismos y afinidades sobre de las discordancias y antagonismos.

\section{La misión regeneradora del escritor}


Francisco Íbar, maestro pintor que a fines del periodo virreinal había trabajado en la decoración del santuario de Guadalupe y en el túmulo funerario de la reina María de Braganza y Borbón, ${ }^{24}$ comenzó a editar a mediados de 1829 El Celaje. Esta publicación esgrimió argumentos de inspiración popular y mostró la concepción de Íbar del héroe ciudadano. El Celaje no estuvo dirigido a un público erudito, sino al gremio de artesanos, en el cual el escritor-pintor jugaba un papel influyente. ${ }^{25}$

Los contenidos ideológicos a los que Íbar dio espacio en El Celaje consistieron en ensayos que aleccionaban a sus lectores en lo que Rosanvallon ha calificado como la religión de la democracia; es decir, "la celebración de una mítica sociedad de iguales". ${ }^{26}$ En este sentido, el artista plástico redactó ensayos acerca de la historia de los símbolos clásicos de la República romana, dando su versión acerca del origen y significado del gorro frigio, de las fasces, entre otros objetos. ${ }^{27}$ También, Íbar efectuó traducciones de un artículo titulado "Política", tomado de la Encyclopédie moderne publicada en 1829 en París, ${ }^{28}$ y en donde se lee:

Cuando por el solo ascendiente de su voluntad privada, un ciudadano lucha contra la voluntad general hay aquí oposición; este estado es la consecuencia necesaria de un sistema republicano $[. .$.$] La anarquía no existe sino cuando un ciudadano$ quiere destruir o modificar por la fuerza el gobierno existente; pero no es en la democracia donde aparecen estos funestos ambiciosos; el ciudadano no posee en él, ni el crédito ni la fortuna, ni clientes, ni proletarios que son los instrumentos indispensables de estas catástrofes políticas. ${ }^{29}$

De esta manera, Íbar imagina un ciudadano que lucha como él, desde la construcción de conceptos, que conformó una oposición floreciente en una democracia. La línea editorial trazada en El Celaje de Íbar se explicó en el artículo "Escritores", publicado el 15 de agosto de 1829, aniversario

24 Petición de Francisco Íbar para que se le termine de pagar el trabajo de unos cuadros que hizo para el santuario de Nuestra Señora de Guadalupe, Ciudad de México, 1820, AGN. Indiferente virreinal, templos y conventos, caja 4785/9864/54, exp. 005, 1 y Francisco Íbar, profesor del arte de pintura de esta capital, sobre la construcción de la pira funeraria a la reina María Ignacia Francisca de Braganza y Borbón, Ciudad de México, 1819, AGN, Instituciones coloniales, Inquisición, vol. 1468/13287/1, exp. $1,1$.

25 Francisco Íbar, "Introducción”, en El Celaje, México, $1^{\circ}$ de agosto de 1829, pp. 1-3.

26 Pierre Rosanvallon, La consagración del ciudadano, México, Instituto Mora, 1999, p. 10.

27 Francisco Íbar, "El gorro de la libertad", en El Celaje, México, $1^{\circ}$ de agosto de 1829, p. 3.

28 Anónimo, "Política", en El Celaje, México, 12 de agosto de 1829, pp. 25-30.

29 Ibid., pp. 25-26. 
del natalicio de Napoleón. Este ensayo consiste en un verdadero manifiesto de principios, en el cual el pintor plasmó sus ideas acerca de la misión del escritor en la recién creada República mexicana. ${ }^{30}$

Comienza el texto afirmando que todo escritor tiene un compromiso solemne con la justicia, puesto que aquel que se dedica a las letras tiene necesariamente que elevar la voz en contra de la opresión y sufrimiento de sus prójimos. Luego, al elogiar la superioridad intelectual del artífice de la palabra, Íbar asegura que sus trabajos deben dirigirse a conseguir el bien público. Siguiendo el aforismo de que el arte debe educar divirtiendo, el redactor de El Celaje cree que:

Un poema, un drama, un romance que pinte vivamente la virtud, modela al lector sin que él lo sienta sobre los personajes virtuosos que él hace obrar; ellos le interesan, y el autor ha persuadido a la moral sin hablar de ella. ${ }^{31}$

Azuzando a los trabajadores de la palabra, Íbar propone que una suerte de fábula moralizante es un recurso de primer orden para formar ciudadanía. En este punto culminante, el autor ensalza a la pobreza que suele perseguir a los que se dedican a las letras, puesto que, según Íbar, difícilmente un individuo próspero y feliz podría identificarse con la situación de los que sufren. El literato suele tener la desgracia

De estar descontento de todo el mal que se hace en su patria, a fin de que sus escritos contengan rasgos varoniles que despierten la atención de sus lectores: es necesario que estos rasgos sean fuertemente pronunciados, pues que, es necesario que hieran orejas soberbias y endurecidas. Orador del mayor número, es decir, de la multitud de los desgraciados, es necesario que la melancolía madre de la piedad, presida a sus toques un poco sombríos y los haga más tiernos. ${ }^{32}$

Como se podrá inferir de estos fragmentos, en los que se parafrasea al francés Bernard le Bovier de Fontenelle, ${ }^{33}$ el escritor es para Francisco Íbar un adalid de la justicia y de la democracia y, cual si se tratara de una víctima propiciatoria, sus avatares son un sacrificio en aras de la mejoría del pueblo.

30 Anónimo, "Escritores", en El Celaje, México, 15 de agosto de 1829, pp. 38-40.

31 Idem.

32 Idem.

33 Escritor francés, nacido en 1657 y fallecido en 1757, fue autor de Nuevos diálogos con los muertos y Conversaciones acerca de la pluralidad de los mundos, entre otras obras de índole filosófica. 
Pese a las interacciones y fricciones que, en el punto de convergencia del ecosistema editorial (ver lámina 1), tuvo Íbar con José Joaquín Fernández de Lizardi —el segundo llegó a decir que quién había metido en la cabeza del pintor el volverse periodista,$-{ }^{34}$ el Pensador Mexicano compartió ciertas opiniones con el editor de El Celaje en cuanto a la función de los escritores. Estos elementos demuestran que, para los primeros años de la Independencia, es válido hablar de un discurso político compartido tanto por tirios como troyanos.

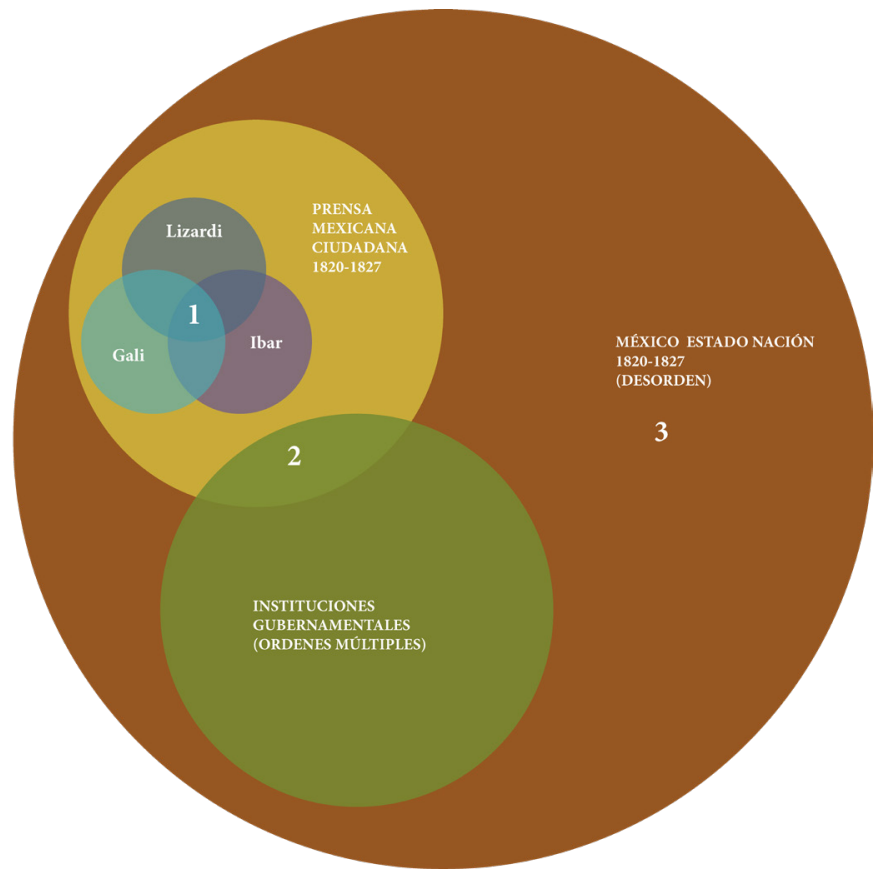

1 Interacciones: el pensador mexicano, el mosaico, el celaje.

Conflicto: polémicas, periodísticas.

Morfogénesis: prensa de opinion y oposición política mexicana.

2 Interacciones: conflictos politico-sociales $>$ morfogénesis de una prensa ciudadana, pero con censura editorial político (Art. 50 Constitución De 1824).

34 "Venid acá, pintorcillo necio y atrevido, ¿quién diablos os ha metido en la cabeza que sois literato, cuando no habéis saludado al musa musae? ¿Pensáis que sabéis algo por que tenéis cuatro libritos franceses que no entendéis? ¡Desgraciado!, los libros sin los principios elementales de la literatura y sin talento despejado, solo sirven para hacer orgullosos, charlatanes y eruditos a la violeta como vos, quien cada vez descubre su ignorancia más y más". José Joaquín Fernández de Lizardi, Obras 13, México, Universidad Nacional Autónoma de México,1968, p. 61. 
3 Sucesos (Diacronía): Construcción De La Nación (Instituciones gubernametales y ciudadanas) > Suceción De Gobernates (Revuelta De Santa Anna, Iturbide (Arresto 1824), Nuevos Roles Ciudadanos $>$ Guadalupe Victoria, Libertad De Prensa (Periodismo De La Nación Independiente), Constitución Federalista De 1822.

Lámina 1. Los ecosistemas nacional y de la prensa ciudadana. Se muestra aquí que en parte las interacciones fueron afectadas con el artículo 50, de la Constitución de 1824, que estableció los límites políticamente aceptables de la opinión impresa.

Más convergencias que conflictos se derivan de los escritos de Galli, pues no entró en polémicas con el pensador ni con el pintor.

Las principales convergencias de Fernández de Lizardi con Íbar se expresaron en el ensayo "Escritores", aparecido en El Correo Semanario de México del 27 de diciembre de 1826. En este escrito de El Pensador Mexicano, Lizardi retomó algunas ideas del abate Guillaume-Thomas Raynal ${ }^{35}$ y de El Espectador Sevillano, periódico redactado en España por Alberto Lista de 1809 a 1810.

Dice Fernández de Lizardi que el escritor es una suerte de magistrado, ya que tiene por funciones ilustrar a sus semejantes, combatir los abusos y advertir los defectos de los gobernantes. En este tenor, afirma que los literatos han servido de vehículos de la sabiduría y, por ello, han civilizado a los pueblos bárbaros, adoptando así, en su modelo de integración ciudadana, un rol determinado y determinante en la reproducción del modelo.

En contraste con Íbar, el novelista recalca que los gobiernos deben sostener y alentar, pero no influir o determinar la labor de los escritores. Fernández de Lizardi saca a colación la decadencia romana para censurar a los políticos que se burlan y se declaran sus enemigos. Como voceros, o más bien modeladores de la nueva opinión pública, están entonces los escritores, quienes, a decir de Fernández de Lizardi, "tienen por oficio hacer bien a los hombres, gobernándolos e instruyéndolos". ${ }^{36}$ Resalta nuevamente el papel determinante, pero no determinado, de los escritores como factor de gobernanza, el cual hoy nos puede parecer ingenuo. Por último, el escritor ideal según el Pensador, juega un papel importante en la promulgación de las leyes puesto que son "los escritos de los sabios, [los] que forman la opinión pública e ilustran, confirman o corrigen al gobierno". ${ }^{37}$

En la lámina 2 podemos ver un esquema de los procesos de la morfogénesis de las prácticas periodísticas del periodo, que fueron determinadas por los cambios en los modelos de gobierno propios de la década de 1820 .

35 Filósofo francés nacido en 1713 y fallecido en 1796, fue autor de La historia de las dos Indias y La Revolución de América.

36 Fernández de Lizardi, Obras 13, México, Universidad Nacional Autónoma de México,1968, p. 61.

37 Ibid., pp. 97-99. 
Por su parte, y en concordancia con Íbar y Fernández de Lizardi, pero con peor suerte en este ecosistema de la prensa ciudadana, Florencio Galli intentó ilustrar en sus artículos a sus lectores acerca de materias como el republicanismo, la importancia de una instrucción pública que fortaleciera a los hombres y liberara de la superstición a las mujeres. ${ }^{38}$ Todo lo antedicho, a decir de Paula A. Sprague, "con el objeto de contribuir a una sociedad más justa y equilibrada". 39

Lámina 2. Morfogénesis de las prácticas periodísticas de la década de 1820 .

Este afán de Galli por propagar conocimientos útiles que transformaran positivamente la vida de sus lectores, lo empujó a publicar un folleto sobre economía rural mexicana en $1825,{ }^{40}$ hecho que demuestra que en la práctica este individuo compartía la convicción de Fernández de Lizardi y de Íbar, acerca de la función del literato en la nación recién fundada. Sin embargo, su acción ciudadana desde la prensa le valió la expulsión de la nación naciente, permitiéndonos definirlo duramente, como un inversionista de energía intelectual, que pasó a ser residuo del ecosistema que hemos antes mencionado.

Esta visión ideal que promovió la imagen de un escritor público que se desenvolviera como una suerte de apóstol y patriarca de la república ya ha sido apuntado por algunos autores. En México, Jorge Ruedas de la Serna indica que al reflexionar sobre su labor escritural, los artífices de la palabra se sabían partícipes en el proyecto de construcción nacional. ${ }^{41}$ Por su parte, Jorge Myers, al repasar el movimiento y producción literarios en el Río de la Plata durante las décadas de 1820 a 1830, consideró que la literatura se legitimó como difusora de valores cívico-morales que se proponían regenerar a una sociedad originalmente

\footnotetext{
38 Sostenía Galli, que la educación impartida a los hombres y a las mujeres debía ser exclusiva y especializada, puesto que "siendo desigual la constitución de los dos sexos, una misma educación no es propia para ambos. La elasticidad del hombre tiene en el espíritu, la mujer la tiene en el corazón, y mientras el uno sube a las causas con más penetración, la otra sondea los efectos con más sensibilidad. Téngase este principio por base en el sistema de educación, y no se tema no dar a cada sexo lo que le corresponde". Florencio Galli, “Educación moral”, en El Iris, México, 27 de mayo de 1826, pp. 60-62.

39 Paula A. Sprague, El Europeo, Barcelona, 1823-1824, Prensa, modernidad y universalismo, España, Iberoamericana, 2009, p. 58.

40 Luis Schneider, "La primera revista literaria del México independiente", en Claudio Linati; Florencio Galli y José María Heredia, eds. El Iris, periódico crítico y literario, México, Universidad Nacional Autónoma de México, 1986, xxvi.

41 Jorge Ruedas de la Serna, coord., La misión del escritor. Ensayos mexicanos del siglo XIX, México, Universidad Nacional Autónoma de México, 2014, p. 8.
} 
monárquica. ${ }^{42}$ En los autores abordados, se confirman estos preceptos, ya que escribieron que la poesía, la narrativa y el ensayo podrían servir como una herramienta didáctica y transformadora; es decir, el arte puesto al servicio de la naciente patria mexicana se proponía adoctrinar a los individuos, ciudadanos en ciernes, en las nuevas formas de expresión, participación y socialización republicanas.

El término de 'ciudadanía' fue un elemento discursivo que se desenvolvió en el periodismo literario mexicano de la primera década de la vida independiente de esta nación. En aquel periodo, la palabra 'ciudadano' irrumpió por completo en el debate periodístico y esta eclosión abrupta conllevó desde sutiles matices hasta drásticas radicalizaciones. De manera sorprendente, el concepto de ciudadano se otorgó desde fechas muy tempranas a un conglomerado de individuos más amplio del que podría haberse creído en un principio; así, en Guadalajara, La Estrella Polar publicó, el año de 1822, que el deseo de alcanzar la libertad política penetró "en las chozas de los más pobres ciudadanos" y los motivó a sublevarse en contra de sus reyes. ${ }^{43}$ En este tono combativo, que enfrentaba al ciudadano moderno con el súbdito, destacó Florencio Galli, participante en un movimiento armado a principios de la década de 1820 en Italia. Galli había integrado también las filas del ejército liberal en Cataluña, durante el trienio liberal. Derrotadas estas sublevaciones, en 1825 se radicó en la República mexicana, donde colaboró con el poeta José María Heredia y el dibujante y litógrafo, Claudio Linati, en el periódico literario El Iris.

Tanto para Galli, como para sus compañeros de redacción, la ciudadanía era una condición inherente del individuo, puesto que el originario de Carrú consideraba que los monarcas eran meros ciudadanos que habían conseguido, de una manera u otra, una corona. También, haciendo una profesión de principios, este italiano indicó que el mejor empleo de la pluma de un ciudadano era "defender el honor de su patria”. Más adelante, el desterrado ubicó el surgimiento de esta categoría política en la antigüedad griega, cuando relató que las leyes, base de la opulencia, felicidad y de las victorias de Grecia, obligaban a los habitantes de la Hélade a ser buenos ciudadanos.

En concordancia con Galli, Heredia y Linati se mostraron como furibundos republicanos e hicieron del ciudadano un modelo consumado de heroísmo y de obediencia. Así, Claudio Linati enunciaba que la

42 Jorge, Myers, "La cultura literaria del periodo rivadaviano: saber ilustrado y discurso republicano", en Fernando Aliata y María Lía Munilla Lacasa, Carlos Zucchi y el neoclasicismo en el Río de la Plata, Argentina, Instituto Italiano de Cultura de Buenos Aires/EUDEBA, 1998, pp. 33 y 37.

43 “Derecho público", en La Estrella Polar, Guadalajara, 15 de noviembre de 1822, núm. 4, p. 26.

162 
inviolabilidad de la casa de un ciudadano era lo más sagrado en una república y que la función de los archivos, del gobierno y de los tribunales era salvaguardar los "intereses más preciosos de los ciudadanos propietarios, comerciantes y manufactureros”. Por su parte, José María de Heredia, consideró que el respeto a las autoridades era "un deber sagrado del ciudadano", y cuando se publicó la supresión de los títulos nobiliarios, el poeta nacido en Cuba, solicitó a aquellos subscriptores de El Iris a los que se había privado de sus carácter noble que les enviaran sus nombres y apellidos de ciudadanos, más propios para la sociedad republicana que aquel "ropaje gótico que los cubría" hasta entonces.

Mayor textura y complejidad alcanzó la reflexión hecha por el Pensador Mexicano acerca de quién podía y debía ser ciudadano en la república recién instaurada. Prueba de esto se halla en su decimosexta conversación del Payo y el Sacristán, diálogo que Fernández de Lizardi publicó en mayo de 1825. En este coloquio un par de personajes se entretienen redactando la Constitución política de una república imaginaria.

En primer lugar, el Payo propone que sean ciudadanos todos los nacidos en el territorio nacional y, de inmediato, le rebate el Sacristán, que dice que esas son "vejestorias" y un "plagio de la Constitución Española” y propone, a continuación, que se conceda el carácter de ciudadano a todos los extranjeros del mundo con la condición que "de cualquier modo" sean útiles a la República. Posteriormente, el Payo y el Sacristán deciden que su modelo de los derechos del ciudadano prescribirá libertad, igualdad, seguridad y propiedad, que goza a su vez del derecho a elegir y ser elegidos "a proporción de su mérito, capacidad y servicios de la patria."

Más adelante, la constitución utópica ordena que los ciudadanos se distingan de los que se hallan fuera de esta categoría con bandas y plumas de colores blanco y azul. Igualmente, se conforma la categoría de "ciudadanos eclesiásticos" en la cual se hallarían los frailes; también se concede el título de ciudadanas a las señoras y a los pobres, quienes usarían las plumas, trajes y bandas de ciudadanos por medio de la concesión de un diploma expedido por los gobernadores estatales. Otros artículos redactados por el Payo y el Sacristán en su Carta Magna se refieren a la pérdida de la ciudadanía; en este rubro, en nada innovan los personajes de Fernández de Lizardi, puesto que uno perdía su ciudadanía cuando se le procesaba por delitos “infames”, cuando se carecía de oficio o ejercicio honesto de vivir, se estaba incapacitado física o moralmente, se debía al erario público o se era un briago consuetudinario. 
Por su parte, Francisco Íbar tenía una idea más moral que política de lo que implicaba ser ciudadano, ya que en las primeras páginas de $\mathrm{El} \mathrm{Ce}$ laje este artista postulaba que la ciudadanía era una consecuencia lógica

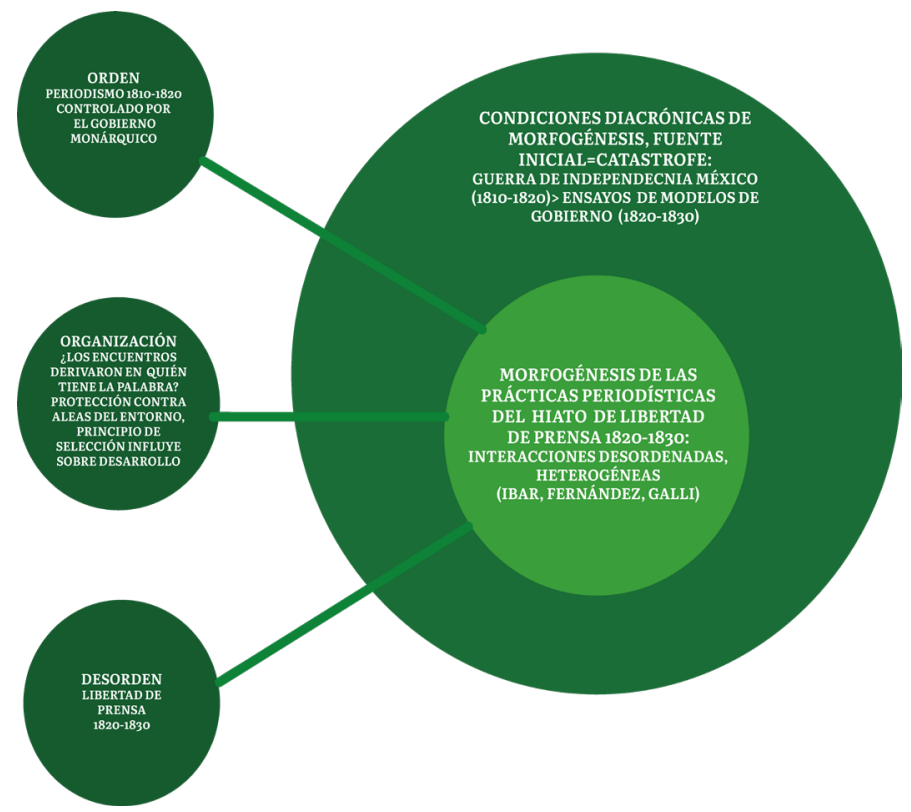

de ser buen hijo, mejor esposo y excelente padre. En otros términos, la ciudadanía era una cualidad del sexo masculino y consistía en proyección al espacio público de una vida privada ejemplar que, a causa de la educación, jamás se dejaría subyugar ni mucho menos ser reducida a la condición de "esclavos tributarios".

De este repaso, se puede afirmar que nuestros tres escritores consideraban a la ciudadanía como una categoría que otorgaba simultáneamente derechos civiles y políticos. Estos capacitaban a cada integrante de la nación a gozar de las libertades de expresión y de pensamiento, de la impartición de justicia y les confería la posibilidad de participar en el ejercicio del poder, como autoridad o como elector. Ahora, si bien el ciudadano era por excelencia un individuo con garantías, este se hallaba inscrito dentro de una comunidad más amplia, regida por las mismas leyes, y a decir de Fernández de Lizardi, Galli e Íbar, tenía una misión vital para el mantenimiento de la patria. Aquí se hace evidente una particularidad del periodismo literario de este periodo, puesto que los temores de un próximo intento de reconquista por parte de España, hicieron que el carácter de ciudadano se transformara en ocasiones en 
un llamado implícito a tomar las armas en defensa de la emancipación política de México. Este clamor, en favor de la militarización, se manifiesta sin rubor en Claudio Linati y en Florencio Galli, quienes al darle cima a una serie de ensayos sobre la educación, instaron a la creación de colegios militares y de escuelas politécnicas que dotaran a la República mexicana de oficiales e ingenieros militares.

Después de la revisión de estos escritos, constatamos la presencia de elementos determinantes para la configuración del ecosistema de la prensa de la década de 1820. A continuación esbozamos un modelo de explicación de la configuración de este ecosistema.

\section{Conclusiones}

El evento catastrófico de la lucha independentista propició encuentros que originaron interacciones, las cuales dieron paso a fenómenos de organización incipientes. Uno de estos fenómenos lo encontramos en la discusión protagonizada por Íbar, Fernández de Lizardi y Galli. A través de sus interacciones, materializadas en sus publicaciones periódicas, podemos presenciar uno de los primeros atisbos de formación de la conciencia ciudadana de una nación.

Si las interacciones entre Íbar, Fernández de Lizardi y Galli pueden ser consideradas relacionantes, entonces podemos tratarla como "generadoras de formas y de organización” de sistemas perdurables. En nuestro caso, se trata del ecosistema de la prensa, el cual, a su vez, opera en la conformación del ecosistema mayor de la nación mexicana. La contribución de las interacciones relacionantes entre Íbar, Fernández de Lizardi y Galli a la organización del ecosistema de la prensa estuvo centrada en la formación de un concepto de ciudadanía.

Si bien las consideraciones para construir este nuevo concepto de ciudadanía eran diversas entre estos tres periodistas, uno de los aspectos en los que podemos ejemplificar con claridad la formación de este concepto está justamente en las nuevas reglas para la aplicación del concepto. En esta discusión se puso en juego la relación entre el término 'ciudadanía' y las acciones que es correcto realizar ante el uso de esa palabra. En este sentido, Íbar consideró que la ciudadanía se extendía sólo a los varones irreductibles a esclavos tributarios; por lo que sería incorrecto hablar de ciudadanía y dirigirse a una mujer. En cambio, para Fernández de Lizardi, la ciudadanía debía extenderse a cualquier persona, sólo que en grados: en virtud de su "mérito y capacidad de servicios a la patria"; por lo que, 
hablar de ciudadanía y dirigirse a una viuda sería correcto, pero no sería correcto dirigirse a un briago consuetudinario. A diferencia de Íbar y Fernández de Lizardi, Galli consideró que la ciudadanía era una condición inherente al individuo, por lo que hablar de ciudadanía y dirigirse a un varón ejemplar, a una viuda o a un briago consuetudinario, sería correcto.

A partir de la discusión incipiente entre estos tres periodistas, que la catástrofe de la lucha de independencia reunió, podemos observar cómo las interacciones propiciadas por esta reunión aleatoria dieron paso a la construcción de un concepto fundamental para la naciente nación mexicana: el concepto de ciudadanía. En la medida en que el ecosistema de la prensa no se formó de manera aislada y en virtud de que el concepto de ciudadanía era de interés para otros ecosistemas en formación, es de esperar que las restricciones al concepto; es decir, sus reglas de aplicación, no fueran el resultado sólo de las interacciones en el interior del ecosistema de la prensa. Las organizaciones políticas sucesivas del ecosistema socio-político del México de la década 1820 fueron variables que permitieron una parcial independencia del ecosistema de la prensa de ese momento, debido a que la variable dependiente de la tecnología de la información escapó al control del Estado en este periodo.

El enfoque aquí empleado nos permite ver cómo la degradación del orden monárquico generó espacios de oportunidad en los que las fuerzas del desorden, en forma de una sucesión aleatoria de organizaciones políticas diversas, catalizaron fenómenos de organización, que en nuestro estudio de caso implicaron el fortalecimiento de la prensa ciudadana. Se puede agregar que, desde una perspectiva actual, el ecosistema de la prensa pudo apropiarse de una de las funciones que ahora comparte con el Estado: la formación de conciencias. 


\section{Referencias}

\section{Hemerografía}

El Celaje, Ciudad de México, 1829.

La Estrella Polar, Guadalajara, 1822.

El Europeo, Barcelona, 1823-1824.

El Iris, Ciudad de México, 1826.

\section{Bibliografía}

Barfield, Thomas, Diccionario de Antropología, México, Siglo XXI, 2000.

Berninger, Otto, Inmigración en México, 1821-1857, México, Secretaría de Educación Pública, 1974.

Fernández de Lizardi, José Joaquín, Obras, México, Universidad Nacional Autónoma de México, 1968.

Galli, Florencio, Memorias sobre la guerra de Cataluña en los años 1822 y 1823, por don Florencio Galli, edecán del jeneral [sic] Mina, Barcelona, Imprenta de A. Bergnes, 1835.

Gantús, Fausta y Salmerón, Alicia, Prensa y elecciones. Formas de hacer política en el México del siglo XIX, México, Instituto Mora-Instituto Federal Electoral, 2014.

Gayol, Víctor, "Escritores cortesanos y rebelión. La breve respuesta de los letrados a los sucesos de 1810 en México", en Las guerras de independencia en la América Española, coordinado por Marta Terán y José Antonio Serrano Ortega, 149-163, México, El Colegio de Michoacán, Universidad Michoacana de San Nicolás de Hidalgo, CONACULTA/INAH, 2010.

Coudart, Laurence, "En torno al correo de lectores de El Sol (1823-1832): Espacio periodístico y opinión pública”, en Transición y cultura política. De la colonia al México independiente, coordinado por Cristina Gómez Álvarez y Miguel Soto, México, Universidad Nacional Autónoma de México, 2004.

Marshall, T.H., Class, Citizenship and Social Development. Essays by T.H. Marshall, Westport, Greenwood, 1973.

Martínez Carrizales, Leonardo, Tribunos letrados. Aproximaciones al orden de la cultura letrada en el México del siglo XIX. México, Universidad Autónoma Metropolitana-Atzcapozalco, 2017.

Morin, Edgar, El método I. La naturaleza de la naturaleza, Traducción de Ana Sánchez en colaboración con Dora Sánchez García, Madrid, Cátedra, 2001. 
Myers, Jorge, "La cultura literaria del periodo rivadaviano: saber ilustrado y discurso republicano", en Carlos Zucchi y el neoclasicismo en el Río de la Plata de Fernando Aliata y María Lía Munilla Lacasa, 31-48, Argentina, Instituto Italiano de Cultura de Buenos Aires/EUDEBA, 1998.

Noriega Elío, Cecilia, "Los grupos parlamentarios en los congresos mexicanos, 1810-1857, Notas para su estudio", en El poder y el dinero. Grupos y regiones mexicanos en el siglo XIX, compilado por Beatriz Rojas, México, Instituto Mora, 1994.

Palti, Elías José, La invención de una legitimidad: razón y retórica en el pensamiento mexicano del siglo XIX: un estudio sobre las formas del discurso político, México, Fondo de Cultura Económica, 2015.

Pocock, J.G.A., "The Ideal of Citizenship since Classical Times”, en Theorizing Citizenship, editado por Ronald Beiner, 29-52, Albany, State University of New York Press, 1995.

Rosanvallon, Pierre, La consagración del ciudadano, México, Instituto Mora, 1999.

Rueda de la Serna, Jorge, coord., La misión del escritor. Ensayos mexicanos del siglo XIX, México, Universidad Nacional Autónoma de México, 2014.

Said, Edward, Representations of the Intellectual, Nueva York, Random House, 1996.

Schneider, Luis Mario, "La primera revista literaria del México independiente" en El Iris, periódico crítico y literario por Claudio Linati; Florencio Galli y José María Heredia, XXV-CIX, México, Universidad Nacional Autónoma de México, 1986.

Sprague, Paula A., El Europeo (Barcelona, 1823-1824): Prensa, modernidad y universalismo, Edición facsimilar, prólogo de Carmen Riera, España, Iberoamericana, 2009.

Suárez Rivera, Manuel, "La imprenta de Luis Abadiano y Valdés: Un acercamiento al mundo tipográfico decimonónico", en Estantes para los impresos. Espacios para los lectores. Siglos XVIII-XIX coordinado por Laura Suárez de la Torre, México, Instituto Mora/Consejo Nacional de Ciencia y Tecnología, 2017.

Wittgenstein, Ludwing, Investigaciones filosóficas, México, Universidad Nacional Autónoma de México, 2003. 


\title{
LA RADIODIFUSIÓN UNIVERSITARIA EN COAHUILA: ACCIÓN DISCURSIVA RADIOFÓNICA PARA LA DIVULGACIÓN DE LA CIENCIA
}

\author{
Jorge Sadi Durón \\ Universidad Autónoma de Coahuila
}

\section{Introducción}

El presente artículo es parte del trabajo de mi tesis doctoral, la cual aborda cinco de las seis estaciones de radio universitarias que existen en dos de las regiones más importantes del estado: la sureste y la laguna. La investigación parte del paradigma de la complejidad y la interdisciplinariedad, con el sustento epistemológico de la teoría de sistemas complejos de García y la epistemología Genética de Piaget, de las cuales no abordaremos a profundidad por cuestiones de espacio, ya que, en sí mismas, son suficientes para un artículo aparte. A continuación nos adentraremos un poco sobre la radiodifusión en México, para llegar a Coahuila y sus radiodifusoras universitarias, que son de carácter público y social según la ley federal de telecomunicaciones y radiodifusión. El marco teórico de referencia está fundamentado principalmente en Bourdieu y la teoría de la acción social; de Habermas y la teoría de la acción comunicativa, ${ }^{44}$ por lo que conceptos como habitus, campo y acción son comunes en el texto, sin pretender ser exhaustivos. Espacio social, tan bien definido y circunscrito, nos atrevemos a llamarle el campo de la radiodifusión universitaria, donde se desarrolla acción comunicativa mediada y mediatizada para construir conocimiento y difundirlo o divulgarlo en forma de discursos con una racionalidad comunicativa, para una audiencia heterogénea; es decir, se construye una "radio cultura", a partir de la acción discursiva radiofónica. La intención

44 Jürgen Habermas, Teoría de la acción comunicativa II, Crítica de la razón funcionalista, México, Taurus Humanidades, 1992. 
de este artículo es situarnos en la situación actual de la radiodifusoras universitarias en Coahuila y su habitus de producción que incluye a la divulgación de la ciencia como tarea sustantiva, poco abordada.

\section{Contexto radiofónico}

La radiodifusión en México tiene un lugar importante en el marco referencial de información y conocimiento de sus habitantes. Es un medio de comunicación que en México cumple más de 90 años y aunque no está en su auge, es una opción confiable y de fácil asequibilidad. Representa el segundo lugar en penetración de medios con 72\% del consumo en México, y su papel en el imaginario informativo lo podemos ejemplificar con lo ocurrido durante el sismo del 19 de septiembre de 2017, en la ciudad de México, que ante la falla de la red de telefonía móvil, la radio en sitios públicos sirvió como referente noticioso de fácil acceso y alta confianza. ${ }^{1}$

Como un primer paso debemos situar a la radio desde la ley mexicana. Existe en la Ley Federal de Telecomunicaciones y Radiodifusión, la figura de concesión única y cinco clasificaciones que son asignadas al concesionario según su uso, como lo marca en el titulo cuarto, capítulo primero, artículo 67 de acuerdo a sus fines: de Carácter Público, Social, Comunitaria, Comercial y Privada. ${ }^{2}$ Estas radios que son una alternativa a la programación recurrente y los contenidos de las concesionadas de carácter comercial, se les denomina bajo la ley federal de telecomunicaciones y radiodifusión como radios de concesión única de carácter público, por un lado para las Universidades públicas y radio de concesión única de carácter social, en el caso de las asociaciones civiles, que en nuestro caso detentan las radios de universidades privadas. ${ }^{3}$

Sobre la historia de la radio, hay literatura básica necesaria que nos permite saber que hace su aparición gracias a los esfuerzos de científicos, empresarios, entusiastas de la comunicación a distancia, y a múltiples inventos de finales del siglo XIX y principios del siglo XX. Nombres como Marconi, Sarnoff, Fassenden, Lee de Forest, entre otros, son los orígenes de la radiodifusión.4 Según Romo Gil (1989), la radiodifusión se puede dividir en etapas: "1.-Radio-difusión; 2.- Radio imitación; 3.- Radio-espectáculo; 4.- Radio music news; 5.- Radio tocadiscos; 6.- Radio-comu-

1 Lilia Corona, "La radio en México toma un nuevo aire", en Expansión, México, jueves 15 de febrero, 2018, recuperado de $<$ http://bit.ly/2OUH7RW >

2 Ley Federal de Telecomunicaciones y Radiodifusión, Cámara de Diputados, México, 2018, recuperado de <http://bit.ly/33xBOel >, visitado el 13 de 08 de 2019, pp. 36-37.

3 Idem.

4 María Cristina Romo Gil, Introducción al conocimiento y práctica de la Radio, Guadalajara, Jalisco., DIANA / ITESO, 1989. p. 39 
nicación." 5 En esta vertiente de poner etapas, podríamos estar asistiendo a la séptima, la "hiperradio", o radio-internet y radio por internet, debido a la importancia de esta plataforma y sus implicaciones, sobre todo en la comunicación alternativa, que escapa de las regulaciones legales de los países y de los "cercos ideológicos". Pero no es nuestra intención entrar a ese debate o discusión, pero debemos señalarlo por su importancia.

La radio en México la podemos rastrear desde inicios de 1921, aunque sus origines exactos siempre se disputan entre el centro del país y el norte. Todo esto como parte del auge de la tecnología inalámbrica que permite la comunicación a distancia sin cables y de modo instantáneo. Los albores de la radiodifusión son experimentos esporádicos y fugaces. ${ }^{6}$ Esto nos lleva a un comentario que es pertinente desde la óptica del campo de la radiodifusión en México. Fue la radio comercial la que se estableció, al igual que en los Estados Unidos, la primera opción de radiodifusión, que de manera semipermanente transmitía con regularidad. Es a partir de la XEW que los patrones y las prácticas radiofónicas en México se regularizan y el habitus de la radiodifusión se "profesionaliza" desde lo comercial; la radio se inserta en la cotidianidad para alcanzar sus metas publicitarias y comerciales. ${ }^{7}$

La radio educativa aparece el 30 de noviembre de 1924 con Radio educación, "la primera radiodifusora educativa y cultural de México", aunque de modo intermitente, siendo ahora una institución de gran trayectoria e incide en la forma de hacer radio educativa en México. Es en 1968 cuando comienza un nuevo ciclo, dependiendo de la Dirección General de Educación Audiovisual de la SEP. La Hora nacional aparece el 25 de julio de 1937 a través de la estación XEDT, emisora del extinto Departamento Autónomo de Prensa y Publicidad (DAPP), dependiente del Ejecutivo Federal, ahora dependiente de Secretaría de Gobernación y "corresponde a la Dirección General de Radio Televisión y Cinematografía, coordinar la producción y transmisión de los programas de La Hora Nacional". 9

5 Idem.

6 Fernando Mejía Barquera, "Historia miníma de la Radio en México (1920-1996). Escenarios \& Convergencias”, México, en Revista de Comunicación y Cultura 1, Marzo-Mayo, 1-26, 2007, disponible en $<$ http://bit.ly/2ORNDsu>.

7 Idem.

8 Radio Educación “Acerca de Radio Educación”, página web, Méxic, 2019, disponible en <http://bit. ly/2YIMKaa>, consultada el 13 de 08 de 2019.

9 La Hora Nacional "Historia de la Hora Nacional”, Página Web, México, 2019, 85-96, actualizada 29 01 2019, disponible en <http://bit.ly/2H9BJ7c>, consultada el 13 de 08 de 2019. 
Otro instituto de interés para la radiodifusión no comercial es el Instituto Mexicano de la Radiodifusión (IMER), "el medio público federal de comunicación radiofónica con mayor número de emisoras a nivel nacional con 18 emisoras en el país, 17 terrestres y 1 virtual (por internet), más 39 canales digitales". ${ }^{10}$ Fue fundada por decreto presidencia el 23 de marzo de 1983, con la finalidad de producir radiodifusión de "interés público" y operar las radiodifusoras que pertenecen a la federación que están a cargo de la SEP. En Coahuila llega como "La poderosa" en AM, por $1520 \mathrm{khz}$ y FM en el $103.9 \mathrm{mhz}$, en la ciudad de Acuña. A partir de esta investigación nos enteramos que en Saltillo se enlaza la B grande de las 7 pm y se retransmite su señal por la frecuencia de la Radio universitaria de la Narro, en AM por $1220 \mathrm{khz}$, pero eso no consta en su página oficial.

La radio indigenista (el hoy llamado Sistema de Radiodifusión Cultural Indigenista -SRCI-), fue sustentado como un proyecto a través de la creación del Instituto Nacional Indigenista en $1979 .{ }^{11}$ El proyecto era un esfuerzo del estado por usar la radio como vehículo educativo y de comunicación que desde los medios de comunicación (como punta de desarrollo) serviría para "impulsar la libre expresión" de las comunidades y el fomento de su cultura y lengua, además de ayudar a las labores del Instituto Nacional Indigenista (INI); así, el gobierno dota de todo el equipo y capacitación, para que los pueblos originarios tomen el uso del equipo y generar contenidos educativos para la población, orientado a las necesidades de información y conocimiento que no cubrían los medios regionales. ${ }^{12}$ El proyecto se convirtió en una parte muy importante en las regiones donde se tiene una radiodifusora, para el 2003 en el gobierno de Vicente Fox, se convertiría en la Comisión de los Derechos Indígenas (CDI) y se visibilizó una creciente demanda y cambios a la forma de producir y hacer los contenidos de las radios indigenistas y su programación. ${ }^{13}$

A 2018 el SRCI en la página web del CDI, informa que "comprende veinte emisoras que transmiten en la banda de amplitud modulada y siete más en la banda de frecuencia modulada operadas, cuatro de ellas, con la participación de niños y niñas mayas en los albergues de Yucatán." ${ }^{4}$

10 Instituto Mexicano de Radiodifusión (IMER). "Quiénes somos", Página Web, México, 2019, actualizada en 2019, disponible en <http://bit.ly/2z0t5n4>

11 "Indigenista, I. N. I. La radio Indigenista" en M. A. Rebelil Corelia, A. R. Alva de la Selva, y I. Rodriguez Zárate, Perfiles del Cuadrante, México, Trillas, 2005. pp. 85-96.

12 Ibid.

13 Inés Cornejo Portugal, "La radio cultural indigenista en México: dilemas actuales", en Revista Mexicana de Ciencias Políticas y Sociales, 52-209, 2010, pp. 55-62.

14 Comisión Nacional para el Desarrollo de los Pueblos Indígenas, Sistema de Radiodifusoras Culturales Indigenistas, 2019, "I. Antecedentes", Página Web, México, recuperado de <http://bit.ly/2KzoeQb>. 


\section{La radio universitaria}

Por otro, lado la radio universitaria aparecería con Radio UNAM en 1937, lo que daría inicio a la radio universitaria que tendría un desarrollo lento en comparación a la radio comercial, ya que de 1937 a 1985 apenas había 15 radiodifusoras universitarias repartidas en AM y FM en México, "cubriendo 14 localidades del país" ${ }^{15}$ La radio universitaria de la UNAM desde su inicio en AM, hasta la actualidad en ambas frecuencias AM y FM, se convertiría en el referente cultural y de divulgación de la ciencia para las otras radios universitarias y culturales de México. Como dice Florance Toussaint "las características de la radiodifusión obedecen a la línea de cada universidad y por eso las emisoras no pueden ser iguales, aunque todas pertenezcan a una casa de educación superior". ${ }^{16}$

Eso podemos fundamentarlo en Bourdieu, cuando habla del trabajo de Foucault sobre los artistas y los trabajos de los productores culturales, y sus semejanzas estructurales, que al mismo tiempo deben ser estudiadas como fenómenos particulares vinculados a su tiempo, "ninguna obra existe por si misma" y "lo que los productores culturales tienen en común es un sistema de referencias comunes, de referentes comunes, en pocas palabras, algo parecido a lo que evocaba antes con el nombre de espacio de las posibilidades". ${ }^{17}$ Bourdieu hace referencia al "campo de posibilidades"18 del que Foucault trazó, para llevarnos precisamente a su teoría de la acción social, en donde dentro del "espacio social", se forman campos, y que dentro de ellos se puede clasificar a los sujetos.

Dentro del espacio social de México, es la radiodifusión universitaria un campo de relaciones entre individuos e instituciones que interactúan y tiene un habitus que se ha conformado desde lo social, psicológico y biológico. Los números respecto a la presencia de las radios universitarias en los diferentes estados del país varían de una fuente a otra. Así, en 2018, según datos de la Asociación Nacional de Universidades e Instituciones de Educación Superior la (ANUIES), había más de 40 radios uni-

15 Florance Toussaint, La Radiodifusión Universitaria Nacional: 50 años de persistencia, en M. A. Rebeil Corella, A. R. Alva de la Selva, \& I. Rodríguez Zárate, Perfiles del Cuadrante, experiencias de la radio, México, Trillas, 2005, p. 84.

16 Op. cit., p. 84

17 Pierre Bourdieu, Razones Prácticas, sobre la teoría de la acción, Barcelona, Anagrama. 1997, p. 56.

18 Op. cit., p. 99. 
versitarias a lo largo de la república mexicana ${ }^{19}$ (no aparecen las radios universitarias de Coahuila), también aparecen las del Sistema Nacional de Productoras y Radiodifusoras de las Instituciones de Educación Superior (SINPRIES), donde había un total de 65 radios registradas. ${ }^{20} \mathrm{La}$ anteriormente llamada SINPRIES, ahora Red de Radios Universitarias de México (RRUM), según un reportaje de 2018, indicaba que tenía 35 radiodifusoras en su red y tienen reuniones de trabajo e intercambio de experiencias y material. ${ }^{21}$ En su página principal, nos indica que son 22 sus afiliadas a lo largo del país y que se "espera una presencia mayor ya que en México existen más de 75 Universidad e Institutos que cuentan con emisoras por antena y online". 22

Actualmente, el listado de radiodifusoras en AM y FM que existen en México, al 12 de febrero de 2019, según el Instituto Federal de Telecomunicaciones y Radiodifusión son un total de 2027 títulos de Concesión para Radio. De ahí 1637 son FM y 390 son AM. Las radios universitarias tienen 89 títulos de concesión o permiso, de los cuales 79 son para FM y 10 en AM; 19 son concesiones sociales, 11 a universidades privadas (con su razón social u otra) y dos a asociaciones civiles de institutos tecnológicos (Tijuana y Celaya), que dependen de la SEP.

Algunas universidades tienen más de una frecuencia, como la Universidad de Guadalajara (la que más tiene) con nueve estaciones distribuidas en diferentes municipios del estado; le sigue la Universidad Autónoma del Estado de Hidalgo con cinco; la Universidad de Guanajuato con cuatro; Baja California, la Autónoma de Morelos, la de Yucatán, Sonora, Sinaloa, San Luis Potosí y Puebla tienen tres; de Chihuahua, Chapingo y Autónoma de Coahuila tienen dos. El resto tienen una concesión. ${ }^{23}$ En total son 50 instituciones educativas públicas y privadas que tienen una o más radiodifusoras universitarias en AM y FM en el país, desde Baja California hasta Yucatán. Pero, en el listado de agosto de 2019 ya aparece Radio Tec de Saltillo, con el título de permiso, pero sin renovación para

19 Asociación Nacional de Universidades e Instituciones de Educación Superior, 2018, "Listado Radios Universitarias por Región", Página Web, México, recuperado de $<$ http://bit.ly/2MXKhlg $>$.

20 Marina Vazquéz Guerrero y Macarena Parejo Cuellar, "La divulgación científica a través de la radio universitaria en España y México", en Razón y Palabra (91), 2015, p. 675.

21 "Red de radios universitarias de México celebra tercer encuentro La rectora de la UAIS, María Guadalupe Ceceña, estuvo como invitada especial en este evento", El debate, 1 de junio, 2018, disponible en $<\mathrm{http}: / /$ bit.ly/2YOSPCd $>$.

22 Red de Radios Universitarias de México, “Nosotros”, Página Web, México, 2019, disponible en: $<$ http://bit.ly/2N3WODS $>$.

23 Instituto Federal de Telecomunicaciones y Radiodifusión IFT, a. "Listado de Radiodifusoras AM yFM" , archivo en línea, Instituto Federal de Telecomunicaciones, México, IFT, 2019, disponible en $<$ http://bit.ly/2N8kUNP $>$. 
concesión; ${ }^{24}$ incluso en entrevista nos dijeron que el trámite se ha detenido del todo. Así que podemos contar 51, aunque no sabemos si existen otras radiodifusoras en el país con situaciones semejantes.

\section{Método y Metodología}

Para investigar el habitus de la acción comunicativa de la radiodifusión universitaria en Coahuila, en cuanto a las prácticas de producción de programas y productos radiofónicos de divulgación de la ciencia, fue necesario elaborar una estrategia metodológica de tipo interdisciplinario, que permitiera abordar las interacciones sociales de primer nivel y de segundo nivel, así como observar la acción social y la acción comunicativa en sus procesos de mediación y mediatización con los agentes de la acción discursiva radiofónica. Esto nos lleva a estudiar las relaciones con los agentes del campo de la ciencia, la divulgación y la radiodifusión, dentro de un campo compartido, y que vemos como una comunidad de práctica en donde todos coinciden. Esto es lo que también denominamos (desde Bourdieu) habitus de la radiodifusión universitaria. Desde la cotidianidad de estas prácticas del campo se construye el discurso de divulgación de la ciencia. El cómo se construye, fue interés de esta investigación; no el producto terminado de segundo nivel. Así que recurrimos a una estrategia interdisciplinar y hermenéutica que ofrece el análisis del discurso, desde sus variantes de Análisis Crítico del Discurso (ACD) y el Análisis Mediato del Discurso (AMD).

Los métodos de investigación de corte hermenéutico sirven para interpretar realidades humanas complejas; en nuestro caso, sistemas complejos. Por tanto, se requiere de un acercamiento que tome en cuenta desde lo sociológico según Bourdieu, el campo, el agente (su trayectoria y capitales) y el habitus, entendidos en el marco de su desarrollo cotidiano como acción social, ${ }^{25}$ que observamos desde lo comunicativo y lingüístico con Habermas ${ }^{26}$ como acción comunicativa, o competencia comunicativa en el entorno mediato, ${ }^{27}$ a partir de su racionalidad comunicativa propia que identificamos desde la epistemología genética

24 Instituto Federal de Telecomunicaciones y Radiodifusión IFT, b. "Listado de Radiodifusoras AM yFM, archivo en línea, Instituto Federal de Telecomunicaciones, México, IFT, 2019, disponible en $<$ http://bit.ly/2N8kUNP>.

25 Pierre Bourdieu, Cosas Dichas, Barcelona, Gedisa, 2000.

26 Jürgen Habermas, Teoría de la acción comunicativa I, Racionalidad de la acción y racionalización social, México, Taurus Humanidad, 1999.

27 Ron Scollon, Acción y texto: para una comprensión conjunta del lugar del texto en la inter (acción) social, el análisis mediato del discurso y la acción social, en R. y Wodak, Métodos de Análisis Crítico del Discurso, Barcelona, edisa, 2003, pp. 205-266. 
como construcción del conocimiento, ${ }^{28}$ con Piaget y García, ${ }^{29}$ y la psicología social con Vigotsky, así como también su mediación ${ }^{30}$ (acción discursiva entendida desde sus cogniciones y esquemas de acción) y desde la comunicación como su mediatización ${ }^{31}$ (resultante de las herramientas culturales, físicas y de los signos) y su resultante, lo hemos designado como acción discursiva radiofónica, sea de primer nivel (entre los agentes) o de segundo (de los agentes a los radioescuchas), en búsqueda de la divulgación de la ciencia en un enfoque sistémico desde García. ${ }^{32}$ El Análisis Mediato del Discurso desde el Análisis Crítico del Discurso (ACD), nos ayuda a amalgamar metodológicamente todo: "El análisis mediato del discurso (AMD) comparte los objetivos del ACD, pero traza unas estrategias... a un enfoque sobre las acciones sociales mediante las cuales producen los actores sociales las historias y los hábitos de sus vidas cotidianas...Es decir, el AMD se centra más en la acción social que en el discurso o en el lenguaje". ${ }^{33}$

Esta investigación es explicativa, ya que "su objetivo último es explicar por qué ocurre un fenómeno y en qué condiciones se da éste" ${ }^{34}$ A partir de estudio de casos múltiples: unidades estudiadas desde la investigación ideográfica: "implica descripción amplia, profunda del caso en sí mismo". ${ }^{35}$ Así un estudio como el que llevamos a cabo de cinco casos en particular, es adentrarnos en cada radiodifusora como grupo o campo de acción social.

Las personas seleccionadas fueron por "criterio lógico", esto implica trabajar todos aquellos casos que reúnan algún criterio predeterminado de importancia; ${ }^{36}$ también llamado muestreo intencionado, al ser el investigador quien decide por su juicio, los elementos representativos para ser estudiados $^{37}$. Fueron 21 entrevistas con informantes clave que laboran en las radios universitarias de Coahuila y son parte de la nómina, incluyendo colaboradores que aunque no dependen de la radio, se adscriben de

28 Jean Piaget, La equilibración de las estructuras cognitivas. Problema central del desarrollo (Quinta Edición), México, Siglo XXI Editores, 1998, pp. 109.

29 Rolando García, El conocimiento en construcción, Barcelona, España, Gedisa, 2000, pp. 90.

30 Leontiev Vigotsky, Pensamiento y lenguaje. Teoría del desarrollo cultural de las funciones psíquicas, (M. M. Rotger, Trad.), Madrid, España, Pléyade, 1977.

31 Friedrich Krotz, "Mediatization: A concept With Wich to Grasp Media and Societal Change", en L. Kunt, y S. Livingstone, Mediatization, concepts, changes, consequences, USA, Peterlang, 2009, pp. 87.

32 Rolando García, Sistemas Complejos, Conceptos, método y fundamentación epistemológica de la investigación interdisciplinaria, Barcelona, España, 2006, Gedisa, pp. 66.

33 Ron Scollon, Acción y texto: para una comprensión conjunta..., op. cit., p. 206.

34 Daniel Behar Rivero, Metodología de la Investigación, Ediciones Shalom, Argentina, 2008, p. 18.

35 Manuel Muñiz, Estudios de caso en la investigación cualitativa, División de Estudios de Posgrado,

Universidad Autónoma de Nuevo León, Facultad de Psicología, México, 2010, p. 1.

36 Carlos Sandoval Casilimas, La investigación Cualitativa, Bogotá, Colombia, 1996, p. 124.

37 Daniel Behar, op. cit., p. 53. 
manera voluntaria a ella. Seleccionando a los que hacen divulgación de la ciencia o hablan de temas científicos en sus programas o producen cápsulas, spots o entrevistas a forma de microprogramas para ello. Técnicas utilizadas: 1.- La entrevista abierta semiestructurada: para el análisis del sujeto (agente) y sus relaciones en el campo y el habitus. De aquí, el discurso se analiza con base a los criterios y observables que surgen a partir de nuestro marco teórico-metodológico. Se empleó grabación de audio por ser menos intrusiva. Se partió de una guía con tópicos y preguntas orientadoras. Para la trayectoria de los agentes, su posición en el campo, la descripción de las prácticas laborales, profesionales, interacciones, etcétera; 2.- cuestionario de preguntas abiertas para recolección de datos generales y que nos den una aproximación a sus referentes conceptuales y de valores para poder hacer un esbozo de su trayectoria social. Así obtendremos resultados de dos fuentes que nos permitirán cruzar datos.

El habitus y la interacción social y construcción de la acción comunicativa en la producción de divulgación de la ciencia, a través de la radiodifusión universitaria, permitirá observar de modo activo y abierto las relaciones entre los sujetos del sistema complejo dentro de un campo específico y su habitus. Los sistemas complejos a estudiar, a partir del recorte de una realidad nacional, son en este caso las universidades que tienen un sistema de radiodifusión, y su papel como productores de conocimiento como discurso para divulgación de la ciencia; esto en el estado de Coahuila, donde la problemática se presenta.

En las investigaciones que existen, respecto de divulgación de la ciencia en radios universitarias, a la fecha, no hay datos sobre esta perspectiva, y menos sobre la radiodifusión universitaria del estado de Coahuila, en ninguna tenemos datos sobre su procesos de producción y programación de conocimiento. Esos procesos creativos, mediados y mediatizados a partir de la racionalidad comunicativa de los agentes del campo de la radiodifusión universitaria, es precisamente lo que buscamos conocer. En este avance preliminar daremos algunos datos sobre la conformación de estas radios, el contexto donde operan, apenas un atisbo de la trayectoria social de sus agentes y de la presencia, en cuanto a divulgación de la ciencia que tienen. 


\section{Estado de la cuestión.}

La información sobre radiodifusión y en particular del estado de Coahuila es muy limitada, es realizada en su mayoría por la Universidad Autónoma de Coahuila, desde Saltillo por la Facultad de Ciencias de la Comunicación, y en Torreón por la Facultad de Ciencias Políticas y Sociales; el siguiente en aportar es la Universidad Iberoamericana, plantel Laguna. ${ }^{38}$ Los anteriores en su mayoría por trabajo de cuerpos académicos y otros individuales, y según Hinojosa, las líneas de investigación en comunicación en el Noreste del País van encaminadas a "medios tradicionales", ${ }^{39}$ (mayormente TV y prensa), perspectivas de periodismo, organizacionales, y hay una tendencia hacia las nuevas tecnologías e internet, pero "aún sin consolidarse". Los datos más recientes son de los ya citados, Carabaza, Sadi y Carabaza et al.

De Sadi tenemos dos textos, el que aborda el concepto sobre Comunicación Alternativa, aplicado a la radio "estudiantil" de Coahuila, que hace la una ruptura epistemológica identificándola y diferenciándola de la radio universitaria institucional..$^{40}$ El otro texto es sobre radio cultural, un diagnóstico de consumo de medios por parte de los estudiantes de la Universidad Autónoma de Coahuila, Unidad Torreón, 14 unidades académicas, para un total de 756 estudiantes hombres y mujeres, que sobre consumo de radio el $25.66 \%$ de los que contestaron escuchan radio FM. De la radio cultural, el $23.4 \%$ sí escuchan radio no comercial, y son las universitarias, Radio Universidad 89.5 FM, con un 9.3\%, Frecuencia UAL 98.7 FM con el 1.7\%, las más recordadas por los encuestados. ${ }^{41} \mathrm{En}$ Carabaza (2008) la información es sobre las radiodifusoras existentes en el cuadrante de Saltillo y un resumen de su contexto histórico, así como de algunos datos simples sobre la programación. ${ }^{42}$

38 Julieta Carabaza, Andrea Aguilar y Blanca Chong, La investigación en Comunicación en Coahuila, Saltillo, Universidad Autónoma de Coahuila, 2011.

39 Lucila Hinojosa, Blanca Chong y Juan Olvera, "Las Ciencias de la Comunicación en el Noreste de México: Una mirada a la institucionalización del campo", en C. Morado y L. Hinojosa, Las Ciencias Sociales en el Noreste de México (31-58), México, Facultad de Filosofía y Letras, Universidad Autónoma de Nuevo León, 2015, p. 43.

40 Jorge Sadi Durón, La radio universitaria estudiantil, la comunicación alternativa, México, El autor, UNAM, Maestría, 2006.

41 Jorge Sadi Durón, "Diagnóstico de Audiencia Radiofónica Cultural en la Comarca Lagunera 2016”, en B. y Chong López, Problemáticas de la Región y la nación desde la Laguna, 96-128, México, Universidad Autónoma de Coahuila, 2017, pp. 108-116.

42 Julieta Carabaza, "La radiodifusión en la Región Sureste de Coahuila", en J. y Carabaza, Voces, textos e imágenes, México, Universidad Autónoma de Coahuila/ Facultad de Ciencias de la comunicación, 2008, pp. 223-259. 
En cuanto a los avatares de divulgar ciencia en México, Márquez (2003) nos da una perspectiva muy clara de las principales problemáticas que atraviesa la divulgación de la ciencia y la técnica en México y de dónde resumimos que: 1.- Falta una política de estado sobre divulgación de la ciencia en México; 2.- Existe escasez de recursos económicos destinados a la divulgación de la ciencia y la tecnología; 3.- La falta de reconocimiento formal (social, académico, etc.) a las tareas de divulgación de la ciencia y la técnica. Esto a nivel estructural. A nivel medios de comunicación y divulgadores: A.- Falta de comprensión de la importancia de la divulgación de la ciencia; B.- La falta de índices o parámetros de evaluación de los productos de la divulgación de la ciencia y la técnica y de los propios divulgadores; C.- La baja profesionalización de los divulgadores de la ciencia y la técnica; y D.- La escasa capacidad para crear y operar en equipos multidisciplinarios. ${ }^{43}$

En cuanto a la divulgación de la ciencia en radio, específicamente en la radiodifusión universitaria, el estudio más cercano a lo que estamos realizando, es el de Vázquez y Parejo Cuellar, que estudian de manera cuantitativa la producción de radio sobre divulgación de la ciencia en México y España, en donde indicna que a 2015 hay 23 radios universitarias en México que tienen contenidos de divulgación de la ciencia, de 65 que estaban registradas en el Sistema Nacional de Productoras y Radiodifusoras de Instituciones de Educación Superior (SINPRIES) ${ }^{44}$. Asimismo, indican que el promedio de las radios mexicanas es de 1.85 programas por emisora, inferior a los productos de España que se promedian en 2.4. En México la suma de programas realizados por estas 23 emisoras es de 74 formatos diferentes, ${ }^{45}$ pero no aborda el habitus de la producción ni la interacción de los agentes y sus características.

Este marco histórico y legal nos lleva a pensar en las prácticas de producción radiofónica desde el medio y su contexto; que responden por un lado a la especificidad del medio, su lenguaje, y modalidad, a las necesidades de producción: conforme a los objetivos y funciones de su modalidad y sus fines. A su auto denominación; a su conformación histórica y social; a sus recursos técnicos, humanos y económicos; y a

43 Ernesto Márquez Nerey, "Estudio diagnóstico sobre la divulgación de la ciencia en México", en Cultura Científica y Cambio Social, México, SOMEDICYT, 2003, pp. 1-15.

44 Marina Vazquéz Guerrero y Macarena Parejo Cuellar, "La divulgación científica a través de la radio universitaria en España y México”, en Razón y Palabra, número 91, 2015, p. 675.

45 Idem., p. 675-677. 
sus conocimientos propios sobre la radiodifusión como medio y como lenguaje y la interacción de sus agentes, así como de las instituciones que las sostienen legal, económica, administrativa y moralmente.

\section{El habitus de la radiodifusión universitaria. Aproximación teórica}

El marco teórico es una plática interdisciplinaria con los autores que manejan "la acción" como parte fundamental de sus investigaciones: Bourdieu y la acción social, Habermas y la acción comunicativa, y Piaget y sus esquemas de acción. Ellos son nuestro sustento teórico, desde la teoría de la acción social que implica para nosotros: habitus y campos sociales principalmente; ${ }^{46}$ la teoría de la acción comunicativa y la racionalidad comunicativa ${ }^{47}$ y la teoría cognitiva de las equilibraciones,${ }^{48}$ con la construcción del conocimiento a partir de esquemas de acción.

Para descifrar los mecanismos de la racionalidad comunicativa dentro del campo de la radiodifusión universitaria, por parte de los agentes que producen y programan radio, tomaremos la ayuda de Jensen y sus planteamientos teóricos sobre la comunicación humana y sus 4 niveles: 1.-cuerpo y herramientas, 2.-tecnología, 3.-metatecnologías, 4.-computación ubicua o internet de las cosas. ${ }^{49}$ Asimismo el concepto de Krotz sobre mediatización, ${ }^{50}$ pensado desde la producción y programación de la radio y sus agentes. Pero también de como se da la mediación a partir de la radiodifusión de los sujetos entre sí y para otros. Esto a partir del lenguaje radiofónico como objeto mediador o "Sistema mediatizante" 51 entre el agente y la construcción del "discurso" radiofónico para la divulgación de la ciencia, por "parte de un grupo que lo ostenta" 52 como "acción social" 53 en la "acción mediata" 54 de su entorno. El discurso es acción también y podemos analizar el discurso como plática y práctica mediata cotidiana y como productos radiofónicos.

46 Pierre Bourdieu, Razones Prácticas, sobre la teoría de la acción, Barcelona, España, Anagrama, 2003, pp. 90.

47 Jürgen Habermas, Teoría de la acción comunicativa I, Racionalidad de la acción y racionalización social, México, Taurus Humanidad, 1999, p. 76.

48 J. Piaget, B. Inhelder, R. García, \& J. Vonéche, Epistemología genética y equilibración, Madrid, Editorial Fundamentos, 1981.

49 Karl Jensen, La comunicación y los Medios, Metodologías de investigación cualitativa y cuantitativa (M. Sánchez-Ventura, trad.), México, Fondo de Cultura Económica, 2014, pp. 16-24.

50 Krotz, op. cit., 2009, p. 93.

51 Vigotsky, op. cit., 1977, p. 65.

52 Van Dijk Teun, "La multidisciplinariedad del análisis crítico del discurso: un alegato en favor de la diversidad", en Wodak, Ruth; Meyer, Michael, Métodos de análisis crítico del discurso, Barcelona,Gedisa, 2003, pp. 143-176.

53 Ruth Wodak y Michael Meyer, comp., Métodos de Análisis Crítico del Discurso, Barcelona, Gedisa, 2003, pp. 286.

54 Scollon, op. cit., pp. 189. 
Entenderemos que a las prácticas cotidianas y convencionalizadas de la construcción del discurso radiofónico para la acción comunicativa radiofónica resumiéndolas como: acción discursiva radiofónica, sea en texto o hablada. La podemos pensar desde los niveles de Jensen e identificamos dos tipos inicialmente, en un primer nivel entre los agentes del campo para su entendimiento entre sí, como productores, programadores, guionistas, locutores, directivos, etcétera; y en un segundo nivel, para las audiencias desde el discurso radiofónico hablado. La retroalimentación del público hacia los agentes es parte importante y ésta se da de forma interpersonal a través de teléfono y de redes sociales, que son comunicación de primer y tercer nivel.

Con esto abarcamos los procesos de producción (o construcción), circulación y difusión del discurso. El tercer nivel sería la comunicación a través de internet, como plataforma principal de comunicación. Nosotros no planeamos analizar los discursos de segundo nivel ni los de tercero. Vamos a analizar los de primer nivel; es decir, quedarnos en el discurso entre agentes y sus prácticas cotidianas de acción discursiva radiofónica, de construcción de conocimiento para la acción comunicativa desde su campo particular y su habitus, con cierta racionalidad inherente.

Partiendo desde el concepto de la cibercultur@ ${ }^{55}$ como estrategia de comunicación, información y conocimiento, nos permite entablar este diálogo entre el marco teórico y el epistemológico, del cual emerge la construcción del conocimiento, por un lado sobre la comunicación interpersonal, mediática, entre otras; por otro, el accionar de los sujetos pensado desde lo social (y cultural), lo cognitivo, físico o material.

Sostenemos que la comunicación es acción social y en sí acción comunicativa, además de discurso y prácticas estructuradas desde los dominios social (y cultural) psicológico y biológico. Entendemos en esta investigación al sujeto como un ente biopsicosocial, circunscrito y estructurado desde lo biológico, psicológico y sociológico (o socio-antropológico). Explicando esto, debemos entender que en primera instancia existen condiciones de posibilidad de acción y comunicación, las cuales identificamos desde lo biológico como fisiológicas o de posibilidad, ${ }^{56}$ que permiten al sujeto sobrevivir e interactuar con otros semejantes a

55 Margarita Mass, José Azmorrutia, Patricia Almaguer, Laura Gonzalez, Manuel Meza, Sociocibernética, Cibercultur@y Sociedad, México, CEIICH-UNAM, 2012,pp. 317

56 J. Piaget, B. Inhelder, R. García, y J. Vonéche, Epistemología genética y equilibración, Madrid, Editorial Fundamentos, 1981 y Jensen, Karl. Brun, La comunicación y los Medios, Metodologías de investigación cualitativa y cuantitativa (M. Sánchez-Ventura, Trad.), México, Fondo de Cultura Económica, 2014, p. 44. 
su situación física. En segundo plano desde lo psicológico con una serie de estructuras cognitivas o esquemas, que como condiciones o posibilidades de comunicación, a partir de la acción, permiten al sujeto construir el conocimiento por los mecanismos de asimilación-acomodación y de desequilibración y equilibración, ${ }^{57}$ a partir de cierta racionalidad comunicativa, a partir del lenguaje que surge de la propia estructura cognitiva y del contacto social, desde lo simbólico. ${ }^{58}$

En un tercer plano desde lo social, como agente de un campo, con un habitus de prácticas, aseveraciones, "razones de ser", herencias, presunciones y conocimientos adquiridos en la doxa de sentido común, a través de una trayectoria social y capitales propios de cada sujeto, que está inmerso en una sociedad bajo cierta cultura particular. ${ }^{59}$ Este participa como agente del campo en que se establece dentro del espacio social, y ese campo le estructura y reestructura, y el agente a su vez reestructura y estructura el campo en su acción social e interacción con otros agentes.

El eje teórico es entonces la acción del sujeto en lo bio-psicológico, lo social y comunicativo, con base en una estructura biológica, cognitiva, social y cultural, que es flexible y en constante cambio, pero estable. Esta investigación se sostiene desde el constructivismo con la epistemología genética de Jean Piaget ${ }^{60}$ así como la teoría de los sistemas complejos de García $^{61}$ y el modelo general de la equilibración de Piaget. ${ }^{62}$ Nos sirven para dar cuenta de cómo construimos el conocimiento desde los individuos, entre ellos y a partir de lo social, en nuestro contexto cotidiano.

Pensando en el entorno social desde los sistemas complejos, en este caso son las universidades como sistema complejo. Dentro del sistema existen subsistemas en donde se encuentran los medios u organismos o departamentos de comunicación universitarios y, entre ellos, en particular, el campo de la radiodifusión universitaria. Esto en cada universidad, como sistema complejo, tiene un campo de la radiodifusión universitaria, con sus propias características como medio, sus prácticas, habitus e interacciones sociales, y los modos y maneras de transmitir información a través del lenguaje radiofónico, y construir discursos de conocimiento mediatizados y mediados para la transmisión, con una

57 Piaget et al., op. cit., 1981, p. 100.

58 Habermas, op. cit., 1999, p. 165.

59 Pierre Bourdieu, Capital cultural, escuela y espacio social, México, Siglo XXI editores, 2008, y Pierre Bourdieu, Razones Prácticas, sobre la teoría de la acción, Barcelona, , Anagrama, 1997.

60 Jean, Piaget, El nacimiento de la inteligencia en el niño, Barcelona, Biblioteca de Bolsillo, 2000.

61 Rolando García, Sistemas Complejos, Conceptos, método y fundamentación epistemológica de la investigación interdisciplinaria, Barcelona, Gedisa, 2006.

62 Piaget et al., op. cit., , 1981, p. 21. 
finalidad, ya sea sobre divulgación de la ciencia o cualquier otro tema. Este espacio social, bien definido y circunscrito nos atrevemos a llamar "el campo de la radiodifusión universitaria", donde se desarrolla acción comunicativa mediada y mediatizada para construir conocimiento y difundirlo o divulgarlo en forma de discursos con una racionalidad comunicativa, para una audiencia heterogénea; es decir, se construye una "radio cultura", a partir de la acción discursiva radiofónica.

A partir de esta plática interdisciplinaria, definimos a la radiodifusión siguiendo, a Romo "desde lo técnico" y "lo simbólico": es un medio electrónico, que transmite señales de audio a un público heterogéneo y masivo que comparten entre sí el interés de escucharlo, a través de la palabra hablada y la escucha, a partir de signos y significados convencionalizados a través del tiempo, con la característica de que necesita una estructura formal y compleja para funcionar adecuadamente. "La radiodifusión es un sistema porque tiene objetos definidos que son sus componentes o sus partes, con atribuciones o funciones específicas que se relacionan entre sí manteniendo unido el sistema". ${ }^{33}$

Entendemos desde Habermas ${ }^{64}$ al proceso de construcción del mensaje o discurso comunicable en una interacción posible (de uno a uno o de uno a muchos), como acción comunicativa. Asimismo, la racionalidad comunicativa, es cierta lógica particular de ese entorno ${ }^{65}$ (sistema y subsistemas), que marca las pautas, valores y le da forma y fondo al discurso en su elaboración mental, su construcción articulada como mensaje y en su decodificación al recibirlo o cómo pensamos que será recibido; es decir, desde sus procesos de producción, circulación y recepción. En la radiodifusión, a partir del posicionamiento sistémico y de la acción comunicativa, podemos situar que el lenguaje radiofónico es una parte del sistema y existe una racionalidad comunicativa de la acción comunicativa radiofónica.

Para poder describir la forma en la que se construye el mensaje o discurso de divulgación de la ciencia en las radiodifusoras, debemos pensar en la lógica de los sujetos que interactúan dentro del sistema. Debemos circunscribir el habitus, resumido en las prácticas, valores, trayectoria y el contexto de los participantes de dicho acto, en un espacio social determinado a partir de él, y que por, acción de dichas prácticas y la interacción de sus agentes, el campo y su habitus se reestruc-

63 Romo, op. cit., 1989, p. 14.

64 Jürgen Habermas, Teoría de la acción comunicativa: complementos y estudio previos, México, Rei, 1993.

65 Habermas, op. cit., 1999, 1992, 1993. 
tura constantemente. Para ello emplearemos los conceptos de "campo" de Bourdieu ${ }^{66}$ para circunscribir ese "espacio" que no es solamente un sitio, sino es un tiempo y un contexto. También empleamos el concepto de habitus desde el mismo autor, para dar cuenta de esas prácticas "estructurantes y estructuradas" que los agentes (sujetos) llevan a cabo dentro del campo como "estructuras objetivas, independientes de la conciencia y de la voluntad de los agentes, que son capaces de orientar o de coaccionar sus prácticas o sus representaciones".67

La teoría del habitus de Bourdieu es compatible con la de la acción comunicativa de Habermas; ambas unen el análisis crítico y el análisis mediato del discurso, que en el siguiente artículo plantearemos para explicar la recolección, codificación y análisis de datos de esta investigación.

Asimismo, en palabras de Bourdieu que nos ayudan a vincularlo desde la epistemología genética de corte constructivista, es que el propio Bourdieu declara que si él tuviera que "caracterizar su trabajo en dos palabras" se llamaría "costructivism structuralism o de structuralism constructivism"; es decir, constructivismo estructuralista o estructural constructivismo, muy diferente a "Sassure o a Levi-Strauss".68 Esto explicado por él en su libro Cosas Dichas dice así: "Por constructivismo, quiero decir que hay una génesis social de una parte de los esquemas de percepción, de pensamiento y de acción que son constitutivos de lo que llamo habitus, y por otra parte estructuras, y en particular de lo que llamo campos y grupos, especialmente de lo que se llama generalmente las clases sociales". ${ }^{69}$

Las condiciones sociales de los sujetos que comunican y hacia quién se comunican, dentro de un sistema y bajo las reglas de un campo, parten de la trayectoria de esos agentes y sus capitales, que desde Bourdieu, identificamos como capital social, económico, cultural, simbólico y político. ${ }^{70}$ Bourdieu les llama "poderes fundamentales" son "disposiciones" que se adquieren por la posición que ocupan dentro del "universo social" y es un "sense of one place" que posiciona a las personas, en su "lugar" dentro del sistema y los subsistemas, y a partir de ahí se construye el habitus de los agentes, como dice Bourdieu "Así los agentes son distribuidos en el espacio social global, en la primera dimensión según el volumen global de capital

66 Pierre Bourdieu, op. cit., 1997.

67 Pierre Bourdieu, op. cit., 2000, p. 127.

68 Idem.

69 Idem.

70 Pierre Bourdieu, op. cit., 2000, p. 177. 
que poseen bajo diferentes especies, y, en la segunda dimensión, según la estructura de su capital; es decir según el peso relativo de las diferentes especies de capital, económico y cultural, en el volumen total de su capital".71

Por tanto en la radiodifusión el lugar que ocupan los diferentes agentes, tiene su "lugar" como productor, programador, locutor, director, etcétera, el capital que se tiene le provee de ciertas formas de entender o de "percibir" la realidad de ese "espacio social", ese campo de acción, y bajo esas condiciones reproduce ciertas condiciones y "visiones del mundo", tomándolas como "naturales", "y se puede aún explicar en términos sociológicos lo que aparece como una propiedad universal de la experiencia humana, a saber el hecho que el mundo familiar tiende a ser taken for granted, percibido como evidente. ${ }^{72}$

Los agentes están en cada puesto por su trayectoria social (en muchos casos) y a partir del campo se hacen de su puesto y función radiofónica. Así, el habitus cae dentro de este sentido común (doxa), de ese conocimiento empírico que se desarrolla dentro del campo y como fruto de los capitales intrínsecos y de las interacciones sociales y de la propia construcción del sujeto. Es una relación dentro del espacio social y del campo.

Sobre la mediatización técnica la definiremos siguiendo a Krotz (2009), ya que este concepto es diferente pero complementario al concepto de la mediación. Entonces entenderemos en esta investigación como mediatización: Las articulaciones de la tecnología y el uso que se le da y como se conforman las prácticas sociales a partir de su uso ${ }^{73}$. Es decir, cómo producimos mensajes a partir de la mediatización de la radiodifusión, la práctica desde el habitus de una tecnología electrónica, eléctrica, que emplea elementos análogos y digitales, para grabar, editar, reproducir y transmitir voz (bajo ciertos criterios específicos de fonogenia), música y efectos de sonido; además de elementos convencionalizados a partir del uso del medio (fade in, fade out, fondeo, cortinillas, puente, ráfaga, voz en off, audio frio, etcétera).

El lenguaje y su configuración social es con lo que se articulan los elementos de la mediatización; es decir, "las herramientas y los signos" es donde a partir idioma propio y el de la radiodifusión; es decir, de la mediación del lenguaje radiofónico, como parte de los esquemas cognitivos (capital simbólico y cultural) de la radiodifusión, construimos la información discursiva para las audiencias y para los propios sujetos dentro del medio. 
Así enlazamos en la mediatización, lo que dice Bourdieu con respecto del capital cultural entendido desde el constructivismo, como "construcción de conocimiento", que está "basado en la acción" y "el hábito de los poseedores" que fueron "acumulando" en su entorno y en los diversos campos de acción, el conocimiento adquirido como capital cultural de la radiodifusión es visible en la mediatización, y se revela en las prácticas cotidianas a través del tiempo, de cada agente, así: "el capital cultural es un tener transformador en ser, una propiedad hecha cuerpo que se convierte en una parte integrante de la "persona", un hábito. Quien lo posee ha pagado con su "persona", con lo que tiene de mas personal: su tiempo". ${ }^{74}$

Así, a partir del capital cultural, y la mediatización y el uso del lenguaje aprendido (radiofónico, coloquial o de divulgación de la ciencia) usaremos como enlace para el lenguaje mediador, la visión de Lev S. Vigotsky del "sistema mediatizante" (al que llamaremos objeto mediador, para facilitar el manejo del mismo) desde la intervención de la mediación del lenguaje y los objetos para mediatizar (signo + herramienta). La mediación por el lenguaje la vemos como "función psicológica superior, o conducta superior, al referirnos a la combinación de herramienta y signo en la actividad psicológica" ${ }^{35}$ ya que la principal función del lenguaje es la comunicación el contacto social ${ }^{76}$. Todo esto es compatible con la acción comunicativa y la racionalidad Comunicativa de Habermas.

Para dar cuenta de la comunicación mediática e interpersonal en el sentido de transmisión de mensajes, entiéndase de radiodifusión, y diferenciarla de la interacción social y del contacto interpersonal, usaremos las definiciones de comunicación, su mediación y sus niveles desde la perspectiva de Klaus Bruhn Jensen, quien maneja 4 niveles, que en nuestras propias palabras resumimos como cara a cara (uno a uno), medios de comunicación tradicionales (uno a muchos), medios a través de internet (muchos a muchos) y el internet de las cosas. ${ }^{77}$

Nos referimos en esta investigación como acción discursiva radiofónica a la acción comunicativa dentro de 3 niveles de comunicación en del campo social y las interacciones sociales: operativizando el término de acción comunicativa de Jürgen Habermas y en conjunto con la epistemología genética constructivista de Piaget — desde los esquemas de acción-que es "piedra fundacional"78 de su teoría. La "implicación

74 Pierre Bourdieu, "Los tres estados del capital cultural", en Revista Sociológica, Año 2, Otoño (5), 1-6., 1987, p.2.

75 Vigotsky, op. cit., p. 89.

76 Vigotsky, op. cit., p. 26.

77 Jensen, op. cit., 2014, p. 16-24.

78 García, op. cit., 2000, p. 78. 
entre acciones" es un nombre que se le asignó a las inferencias, y es la base de una "lógica de la acción", que precede a la "lógica" que se desarrolla con el lenguaje. ${ }^{79}$ Así, el ser humano, desde su nacimiento, es un organismo entendido como una totalidad biológicamente estructurada, como un sistema abierto, y cuya perduración (conservación) depende de sus interacciones con el medio ante el cual tiene posibilidades de actuar, y eses actuar, aunque limitado, son "los esquemas de acción”. García plantea que Piaget adoptó como categoría básica inicial a la acción, la cuál sería la piedra fundacional del constructivismo epistemológico. ${ }^{80}$

A su vez, inserta u observable en la acción social en Campos, de la teoría de los campos sociales de Bourdieu como el proceso (acción) de construir y producir un mensaje estructurado, con base en el conocimiento previo (y nuevo) del sujeto. Así la interacción del humano con el entorno está mediada por: 1.- Las estructuras organizativas y 2.- Las invariantes funcionales del intelecto ${ }^{81} \mathrm{y}$ añadimos que con coherencia y racionalidad comunicativa como dice Habermas, ${ }^{82}$ para un público determinado desde la plataforma bio-psico-social del sujeto, que se interrelaciona socialmente o que interactúa con otros sujetos y objetos, dentro de un sistema y sus respectivos subsistemas. ${ }^{83}$

Esto sucede en un campo de acción, realizado por ciertos agentes, que los estructuran desde su habitus como lógica de actuación en la que están inmersos y en un contexto determinado por su entorno. ${ }^{84}$ Con el lenguaje como "sistema mediatizador" llamado por nosotros "objeto mediador", que surge de la crítica y ampliación de la teoría de Piaget por parte de Vigotsky, ${ }^{85}$ así el sujeto (agente) construye discursos para la radio, desde su racionalidad comunicativa, atendiendo a su habitus, bajo las premisas que el propio campo le ha establecido y que ha aprendido desde su formación en el campo y la academia; es decir, su capital simbólico. Para mayor claridad cito a Jurgën Habermas textualmente: "Este concepto de racionalidad comunicativa...tiene un habla argumentativa en que diversos participantes superan la subjetividad inicial de sus respectivos pun-

79 Jean Piaget, El nacimiento de la inteligencia en el niño, Barcelona, Biblioteca de Bolsillo, 2000, p. 100.

80 Idem., pp. 97-98.

81 Idem., pp.14-15.

82 Habermas, op. cit., 1999, p. 56.

83 García, op. cit., 2000, p. 90.

84 Bourdieu, op. cit., 1997, p. 66.

85 Vigotsky, op. cit., p. 89. 
tos de vista y merced a una comunidad de convicciones racionalmente motivada se aseguran a la vez de la unidad del mundo objetivo y de la intersubjetividad del contexto en que desarrollan sus vidas". ${ }^{86}$

Así la racionalidad comunicativa tiene que ver no sólo con capacidad de construcción propia e individual del conocimiento, sino también al consenso no sólo en términos de acuerdos, sino de incorporación de los saberes, diría Piaget, en procesos de asimilación y acomodación que permiten el avance dentro de la construcción del conocimiento. Citando a Habermas: "Llamamos racional a una persona que interpreta sus necesidades a la luz de los estándares de valor aprendidos en su cultura; pero sobre todo, cuando es capaz de adoptar una actitud reflexiva frente a los estándares de valor con que interpreta sus necesidades. Los valores culturales, a diferencia de las normas de acción, no se presentan con una pretensión de universalidad". 87

De esta manera con base en las interacciones sujeto-objeto, sujeto-sujetos, entendemos la acción comunicativa como el pilar de la construcción del conocimiento, que es posible gracias a las invariantes del conocimiento del sujeto que como ente bio-psico-social, desarrolla y ejecuta desde los estadios más primitivos de la infancia hasta la edad adulta; en el caso particular de esta investigación, la construcción del conocimiento que se genera para divulgación científica.

\section{Estudio regional desde la teoría de sistemas y sistemas complejos}

Al hablar de una investigación sobre un fenómeno, partiendo de la epistemología genética de Piaget y la teoría de los sistemas complejos de García, nos lleva a hacerlo desde el paradigma de la complejidad. Parte de la tarea de esta investigación es conceptualizar y delimitar el universo de estudio, por lo cual, es pertinente definir conceptos que por ser tan obvios o de uso frecuente, pasamos por alto, como lo es el concepto de región, que en esta investigación usamos desde un posicionamiento de teoría de sistemas y que es parte de la "moderna o nueva geografía." 8

Esto es pertinente, porque vamos a hablar de dos regiones que son muy importantes en México y en particular del estado de Coahuila de Zaragoza: la sureste y la laguna. Así lo afirma Carabaza; Aguilar y Chong (2011), al platicar sobre el estado de Coahuila, destacan que es el

86 Jürgen Habermas, Teoría de la acción comunicativa I, Racionalidad de la acción y racionalización social, México, Taurus Humanidad, 1999, p. 27.

87 Idem., p. 39.

88 José Manuel Mateo Rodriguez y Manuel Bollo Manent, La región como categoría geográfica, México. UNAM-CIGA, 2016, p. 41. 
[...] tercer estado más grande del país[...]dividido en 5 regiones geoeconómicas con características muy particulares tanto en su economía, como patrones culturales[...]En cada una de estas regiones destacan una o dos ciudades que concentran la mayor actividad económica, política, social, educativa y mediática. ${ }^{89}$

El estado de Coahuila de Zaragoza, según cifras del Instituto Nacional de Estadística Geografía e Informática, representa el 7.73\% del territorio nacional, su población es $90 \%$ urbana y $10 \%$ rural, las actividades económicas se concentran en su mayoría en los sectores de la industria (la manufacturera principalmente) y servicios, es decir: secundario (53.6\%) y terciario (43.9\%); la aportación al producto interno bruto (PIB) nacional representa el 3.4\%. El promedio de escolaridad de la entidad es de 9.9 años; el total de su población es de 2954915 habitantes, que equivale al 2.5\% del total del país. Saltillo tiene 807, 537 habitantes y Torreón 679288 . Ambas son las dos poblaciones con mayor número de habitantes en Coahuila. ${ }^{90}$

Ambas regiones, han tenido una cierta rivalidad (desde la Laguna) que puede rastrearse "en papel" desde el 6 de octubre de 1988, donde se plantea la creación del "Estado de la Laguna", que engloba parte de Durango y Coahuila, en dónde enfatizan entre otras cosas: el pretendido abandono de la región por la lejanía de los centros de los gobiernos estatales...limita la celeridad de los trámites administrativos... por lo reducido de los recursos económicos que esos gobiernos y de la federación destinaban a la Comarca Lagunera, porque antes preferían invertirlos en las ciudades capitales. ${ }^{91}$ Son algunos de los reclamos de esta propuesta con un fuerte empuje desde los empresarios "laguneros". Entonces, esa rivalidad está cimentada en general desde lo político-económico, más que entre las comunidades.

En cuanto a lo identitario, algunas de estas diferencias, se pueden notar al fuerte sentido de autoidentidad de los "laguneros" y los valores que lo identifican: "trabajadores" y "orgullo lagunero"; por ello, antes que definirse por el topónimo de su municipio, se utiliza el de la región: "Laguneros", esto porque las personas de los municipios que integran la Laguna de Durango y la Laguna de Coahuila confluyen en "lugares,

89 Julieta Carabaza, Andrea Aguilar y Blanca Chong, La investigación en Comunicación en Coahuila, Saltillo, Universidad Autónoma de Coahuila, 2011, p. 7.

90 Instituto Nacional de Estadística y Geografía INEGI, México en Cifras: Coahuila de Zaragoza, México. 2019, consultado en <http://bit.ly/2OWATB4>.

91 José Luz Ornelas López, "Breve reflexión histórica sobre la creación de los Estados: A propósito de la quimera Estado de la Laguna”, (10-41), en Chong López, Blanca y Ornelas López, José Luz (coord.), Problemáticas de la región y la nación desde la Laguna, Cuerpo Académico Sociedad, Comunicación y Cultura, FCPyS-UA de C, 2017, p. 10. 
costumbres, tipo de entretenimiento, deporte, religión, celebraciones, cultura, etc"; además de tener en común el autodenominarse como "gente alegre, responsable, fiestera", etcétera. ${ }^{92}$

Saltillo es el centro de la zona Sureste y ha sido siempre catalogada de una ciudad "cerrada" con gente de un alto "conservadurismo, apatía y cerrazón social”, arraigado desde la época porfirista; según el historiador Javier Villareal Lozano93 esta ciudad de 442 años de edad, es la capital de Coahuila y según Beltrán, características propias de los Saltillenses son ser una sociedad "conservadora" y con una marcada "separación de clases sociales... cierta aristocracia", pero también está presente la cultura tlaxcalteca. ${ }^{94}$

En el ámbito de la oferta de medios de comunicación en Coahuila, según el Instituto Federal de Telecomunicaciones y Radiodifusión (IFT) en cuanto a Radio y TV, existen 65 concesiones otorgadas en el Estado para televisión, de las cuales 4 son de tipo público y 1 social. Saltillo tiene 14 de las cuales 3 son de carácter público y las demás comerciales. Torreón tiene 15 de ahí 1 es de carácter público. En radiodifusión son 103 concesiones de Radio AM (11) y FM (92); de ahí 29 son de tipo público, social y permisos (no hay comunitarias). En Saltillo hay 16 estaciones de ahí 3 en $\mathrm{AM}$ y el resto en FM, 4 de tipo público, social y permiso y 11 comerciales. En Torreón 17 estaciones, 2 en AM y 15 en FM, de ahí 6 de tipo público y social.95 En las dos ciudades se concentra la mayor parte de las estaciones de radio, seguidas de Piedras Negras y Acuña.

\section{Los sistemas radiofónicos de Coahuila. La radio universitaria en Saltillo y Torreón}

Según Sadi, en el cuadrante del FM en la comarca lagunera, de 25 concesionarios en Frecuencia Modulada, existen seis que son "no comerciales"; es decir, de concesión de tipo pública o social, que dependen de

92 Blanca Chong López; Hilda Georgina Hernández Alvarado; Roberto López Franco; Juan Carlos, Hernández; José Luz Ornelas López y Alfredo Morales, “Torreón en el identitario de lo Lagunero”, en Hilda Georgina Hernández Alvarado, coord., Como La Laguna ninguna. Identidades y redes semánticas naturales, Cuerpo Académico Sociedad, Comunicación y Cultura, FCPyS-UA de C., 2012, p.43-55.

93 Rios, Armando. “¿Cómo ven los visitantes a los saltillenses”, enVanguardía, 25 de julio, versión Web, disponible en <http://bit.ly/2P9nc1Q>, 2017.

94 Esther Beltran Rosa, "El ser social saltillense", en Vanguardia, 2017, disponible en <http://bit.ly/ 2YOWnEi $>$.

95 Instituto Federal de Telecomunicaciones y Radiodifusión IFT,b. "Listado de Radiodifusoras AM yFM”, archivo Excel en línea, Instituto Federal de Telecomunicaciones, México, IFT, 2019), disponible en $<$ http://bit.ly/2N8kUNP $>$. 
universidades o de asociaciones civiles o de gobiernos municipales o estatales, de las cuales son pertenecientes a universidades cuatro de las que nos interesan, tres ubicadas en Torreón. ${ }^{96}$

En la ciudad de Saltillo, en el rubro de las radios culturales, existen cinco radiodifusoras: una cultural, la del gobierno del estado y tres universitarias, todas de instituciones públicas.

La oferta cultural o alternativa en la radiodifusión en México es aún muy baja con respecto a la oferta comercial, en todo el país existen 2027 títulos de concesión para radiodifusión, 1448 son de radio comercial y de ahí 579 son concesiones públicas, sociales, sociales comunitarias, permisos e indigenistas. ${ }^{97}$ Esta diferencia es histórica y se ha ido acortando poco a poco. Pero aún así la legislación permite a la radio comercial, obtener recursos y lucrar con su concesión, y mientras las "otras radios" no pueden hacerse de recursos que no sean los que asigne la propia institución o asociación civil.

\section{Limitaciones del método}

Realizamos 21 entrevistas semiestructuradas (para análisis del discurso) y 21 cuestionarios de preguntas abiertas para datos de corte general, valorativos y que nos den una pista sobre su trayectoria social y capitales. Cubrimos cinco de las seis radiodifusoras universitarias de AM y FM de Coahuila, distribuidas en Saltillo (3) y en Torreón (3). Entrevistas a los directivos, jefes de departamento, operadores, locutores, productores y programadores de cinco de las seis radiodifusoras universitaria en Coahuila, lo nos permitió un acercamiento a las prácticas cotidianas de producción y programación radiofónica y en particular a la producción para divulgación de la ciencia, que es uno de los pendientes de producción de las radios universitarias, cuando creeríamos debiera ser una constante.

Las entrevistas buscan abarcar categorías de análisis que hemos mencionado anteriormente: Habitus / acción mediata, divulgación de la ciencia, lenguaje radiofónico, acción comunicativa/racionalidad comunicativa. Lo que nos interesa es: 1.-Quién detenta el poder en la práctica discusiva de divulgación de la ciencia: ¿quién produce?, ¿los científicos, los radiodifusores - periodistas- o existen divulgadores especializados?

96 Jorge Sadi Durón, "Diagnóstico de Audiencia Radiofónica Cultural en la Comarca Lagunera 2016", en B. y Chong López, Problemáticas de la Región y la nación desde la Laguna, Torreón, Coahuila, México, Universidad Autónoma de Coahuila, 2017, p. 101.

97 Instituto Federal de Telecomunicaciones y Radiodifusión IFT, a. "Listado de Radiodifusoras AM yFM”, Archivo Excel en línea, Instituto Federal de Telecomunicaciones, México, IFT, 2019, disponible en $<$ http://bit.ly/2N8kUNP>. 
2.- Cómo se da la interacción entre los agentes tanto radiodifusores como científicos o divulgadores, buscando si las prácticas y definir si existen prácticas de interdisciplinariedad como comunidad emergente; 3.- El origen y la selección de las fuentes de información y conocimiento al momento de elaborar productos radiofónicos (es conocimiento surgido de investigaciones propias y de la región o es divulgación de alguien más); 4.- Quien decide que se dice y el cómo se hará el discurso, los temas, etcétera. 5.- La libertad de los agentes y la apertura de la radiodifusora para crear y distribuir el discurso de divulgación de la ciencia.

Algunas de las limitantes de la metodología de esta investigación, son fundamentalmente que dependemos de los discursos de los agentes y su memoria. La observación directa es limitada, ya que la producción además de escasa es volátil; es decir, no tienen fechas exactas u horarios en los que se pueda coincidir para observar directamente los momentos exactos de las prácticas de producción. La ventaja fue que en el acercamiento a los diversos actores, se cubrieron todas las áreas de operación, producción, programación e incluso dirección de las estaciones de radio universitaria. Tuvimos así una oportunidad única de ver una misma realidad desde los diversos puntos de vista organizacionales y jerárquicos.Por tanto, se complementan y se puede reconstruir con base a los discursos y la complementariedad de los productos radiofónicos escuchados, así como a los videos "posteados" en redes sociales, dónde se ve directamente la acción y práctica radiofónica durante la transmisión.

Confiamos en que gracias al método del análisis del discurso y análisis mediato del discurso, podremos organizar de modo coherente y articulado, lo que se dice, lo que se hace y lo que se dice que se hace, con lo que no se dice que se hace.

Algunos aspectos que arrojan de manera preliminar los cuestionarios y algunos detalles de la observación y acercamiento al campo de la radiodifusión universitaria.

\section{De la investigación}

Como ya hemos referido la divulgación de la ciencia en la radiodifusión de Coahuila, es un espacio social en el que confluyen tres campos: la radiodifusión, la academia (ciencia) y la administración universitaria. La investigación buscó en el campo de la radiodifusión universitaria en Coahuila y se centró en los agentes de la producción, 
programación y transmisión de contenidos en radiodifusión, incluidos en algunos casos colaboradores que explícitamente dicen hacer divulgación de la ciencia, sean remunerados o no.

En la ciudad de Torreón, Coahuila, la radio universitaria tienen presencia en tres universidades, 1 pública y 2 privadas a saber: 1.- La radio de la Universidad Autónoma de Coahuila: "89.5 FM Radio Universidad", de carácter público 2.- La radio de la Universidad Autónoma de la Laguna: “98.7 FM Frecuencia UAL” de carácter privado (concesión de tipo social) y la Radio de la Universidad Milennium internacional: "101.9 FM Milennium Internacional” de carácter privado.

En la ciudad de Saltillo, tres estaciones todas de universidades públicas: 1.-El instituto Tecnológico de Saltillo con "Radio Tec XHINS 100.1 FM". 2.- La segunda es "XESAL 1220 KHZ AM Radio Universidad Agraria” de la Universidad Autónoma Agraria Antonio Narro y por último 3.- La Radio de la Universidad Autónoma de Coahuila "104.1FM Radio Universidad”. La única estación que tuvimos que sacar de la investigación fue Milenium Internacional, al presentar reiteradas negativas para su estudio y al enterarnos que sólo una persona que opera y trabaja en ella de manera esporádica y sin horarios definidos. El rector de la institución que también es director de la radio, no fue posible contactarlo, y la universidad fue renuente a dar información al respecto. Por otro lado, debemos destacar que la Universidad Autónoma de Coahuila contempla a sus dos radiodifusoras como parte del "Sistema Universitario de Radio", que las engloba, pero también le da un carácter particular y de red, comparten algunos programas, producciones y contenidos como spots, cápsulas, música, un organigrama similar, funciones, entre otros aspectos.

\section{Hallazgos preliminares}

Además de los consabidos problemas sobre recursos económicos y humanos para producir divulgación de la ciencia, hay además una falta de sistematización y de interacción o trabajo interdisciplinario entre los que producen discursos de radio y los que tienen el conocimiento de la ciencia.

Los divulgadores capacitados son normalmente escasos, o no participan en radio (por falta de tiempo, interés o estímulo), o no dominan el lenguaje radiofónico, no están capacitados para ello y actúan de modo empírico. Es decir, no hay una interdisciplinariedad para generar discursos de divulgación de la ciencia en radio, y las practicas de construcción de conocimiento para divulgación de la ciencia en radio son, 
generalmente, producto de la buena voluntad del científico que llega a participar en la radio, o del interés de la radio por tener material; eso y la invitación que se hace a los científicos, investigadores, docentes y personal de la universidad, aunque no sea fructífera siempre.

El trabajo de guionismo es prácticamente inexistente, se reduce a una escaleta (lista de pasos a seguir en el programa en vivo) y la construcción del guion literario (el de contenido) sólo está en manos del científico o del productor del programa que colabora en la estación. El productor de la estación suele ser sólo una guía que aconseja en aspectos de locución y cuando hay más acercamiento, de cierto tratamiento periodístico al discurso del científico, pero sin ir más allá; es decir, consejos sobre "cómo decir" algo de su discurso que no se entiende y cómo debe decirse en radio. Esto no es en todos los casos, pero la generalidad, es que quien produce es quien se responsabiliza de su discurso y no hay un trabajo más que de acompañamiento ocasional, cuando lo hay.

El departamento de producción (o los productores) se relegan a satisfacer necesidades de grabación y edición de audios. Programación a mantener el orden de los spots oficiales, y los horarios de los programas y música, no a desarrollar un "discurso lógico" de programación de la radio. En gran parte de los casos, los operadores deciden que música es la que sale al aire; es decir, programan. También toman la decisión del orden, variedad y cantidad de las "capsulas de ciencia" que aparecen, (cuando las hay); ellos a su libre albedrio disponen, transmiten o no, los contenidos de divulgación de la ciencia (o cualquier otro) de los bloques de spots. Otra constante es que los trabajadores realizan más de una función de la que su "puesto" le asigna, y la remuneración es la misma. En algunos casos, incluso no hay un organigrama claramente definido dentro de la radio, salvo el puesto del director.

Los esfuerzos de los distintos departamentos se enfocan exclusivamente en sus funciones primarias y en el día a día, con cierta planeación derivada de las agendas de efemérides, culturales, sociales, entre otras, de la universidad. No hay un departamento especialmente designado para "producir y divulgar la ciencia" dentro de las estaciones. En el mejor de los casos hay una persona o dos, asignadas a hacer labores de divulgación, y concentrada en un programa o dos, y/o en hacer cápsulas o entrevistas en el mejor de los casos, y sin recursos asignados para ello. Esto se convierte en un esfuerzo extraordinario y no en una actividad recurrente y planificada. 
Los agentes saben que es escasa la divulgación de la ciencia, son conscientes de la necesidad de dar a conocer las investigaciones de sus respectivas Universidades, pero la respuesta es similar en todas: faltan recursos (económicos y humanos), tiempo, contacto con los departamentos de la universidad dedicados a ello (cuando los hay) y de acercamiento a los científicos. Sólo que no hay esos acercamientos, muchas veces es la misma falta de recursos y tiempo o por la dinámica de la radiodifusión que no se detiene, o por el desanimo o desinterés de las áreas de ciencia, tecnología o los científicos que no fructifican estos esfuerzos. Las prácticas de producción están desligadas de la interdisciplinariedad para construir conocimiento, y está a nivel de participación ocasional y de buena voluntad.

La agenda de eventos científicos de cada escuela o facultad, es el principal motor de las producciones sobre divulgación de la ciencia de los programas de contenido, más parecido a periodismo radiofónico. La capsula informativa (conceptual y descriptiva) y la entrevista, son los dos formatos más recurrentes para la producción y programación de la divulgación de la ciencia; y por supuesto las producciones de intercambio con otras universidades o de organismos externos como Radio Canadá, Radio UNAM, Radio Educación, etcétera, y forman parte de redes de colaboración como La Red de Radios Universitarias de México (RRUM, Antes SINPRIES), aunque mucho del material no es propiamente divulgación, sino programas de corte educativo dónde se tocan temas de ciencia, muy valiosos e interesantes, pero a nivel general, al estilo del "sabías qué..." y otros esquemas de "datos interesantes".

Los entrevistados, en su mayoría las autoridades universitarias no ven a la radio como un recurso importante, sino más como un gasto administrativo, o una actividad extra de la universidad a modo de difusión de la cultura exclusivamente, o como "rockola".

Los trabajadores de la radiodifusión, están conscientes del papel y la importancia del medio de comunicación para con la sociedad y de que los universitarios, (científicos, estudiantes, docentes, administrativos, autoridades) deberían estar más comprometidos o inmiscuidos en ella. No sólo ser audiencia, sino también participar activamente. Les desconcierta en muchos casos la escasa importancia que le procuran las autoridades y en algunos casos hasta el alejamiento o el desinterés, así como de la falta de un acercamiento de los demás departamentos incluidos los de divulgación de la ciencia. 
Los principales valores señalados por los 21 entrevistados en el cuestionario aplicado antes de la entrevista semiestructurada, presentó los siguientes datos: la muestra incluyó 11 mujeres y 10 hombres, en su mayoría estudiaron a nivel licenciatura 15, en maestría cinco, y preparatoria uno, la carrera más frecuente fue comunicación 14 de 21 . Han estado trabajando en medios públicos específicamente Radio 16 de 21, y 5 en varios medios. Las edades oscilaron entre 26 a 74 años. La clase social más frecuente fue $\mathrm{D}+(6,800$ a 11,599 pesos de ingresos mensuales) ya que entrevistamos en mayoría puestos de jefaturas; la más alta $\mathrm{C}+(35,000$ a 84,000$)$ estuvo entre directivos y personal con mucha antigüedad y la más baja $\mathrm{D}(2,700$ a 6,799) en los operadores.

Debemos aclarar que muchos de los que trabajan en radio, combinan sus actividades con otros trabajos y tomaron los ingresos como matrimonio de base, eso no refleja el sueldo individual. El estado civil: 11 casados, nueve solteros y un divorciado.

En cuanto a valores personales y profesionales, los más recurrentes fueron: honestidad, responsabilidad, respeto y compromiso. Conocimientos del lenguaje radiofónico de básico a intermedio, y de divulgación de la ciencia básico a experto.

Organizacionalmente dos estaciones no tienen un organigrama definido. En todas las estaciones los miembros cumplen en su mayoría de dos a cuatro funciones extra de su puesto asignado.

\section{Conclusiones}

En este acercamiento podemos observar que los trabajadores de las radios universitarias tienen las nociones básicas sobre ciencia y su divulgación o periodismo científico, así como el conocimiento para desarrollar sus labores de radiodifusión. En algunos casos hace falta capacitación sobre cuestiones tecnológicas del uso de equipo y software, pero no es la regla general. Todos refirieron que hace falta más capacitación en general sobre temas de divulgación de la ciencia. Cada caso en particular es distinto, pero en cuanto a la planeación de la divulgación de la ciencia, desde la producción como un discurso ordenado e interdisciplinario y desde el lenguaje radiofónico, así como desde el lenguaje científico adaptado para su divulgación a los "no científicos", estructure estrategias de comunicación, información y conocimiento, para programar a manera de discurso integral de la programación de cada estación, que no se da. 
Las prácticas habituales de radiodifusión incluyen la multitarea; es decir, que los puestos asignados en el papel o el organigrama, suelen ser rebasados en su mayoría por la cantidad de funciones que se realizan. En otros casos, hay puestos que no se tienen cubiertos, por falta de personal o de recursos económicos para desarrollarlos, que se traduce en falta de equipo, material, y sobre todo tiempo. También podemos ver que en unos casos no se cuenta con un organigrama y las radiodifusoras dependen de los presupuestos de otros departamentos, con esto no hay libertad de asignar recursos para divulgación de la ciencia o casi cualquier otro tema.

La falta de tiempo, tiene que ver con las actividades propias de una estación como producir spots, cápsulas, preparar programación, apoyar a los colaboradores a grabar material para sus programas: vestidos, spots, capsulas y programas grabados para fechas posteriores (meterse en cabina, grabarlos y editar, no propiamente con el guion). No hay recurso humano designado exclusivamente a labores de divulgación de la ciencia. Sólo participaciones entusiastas en algunos casos.

La producción y programación se va en "automático", dedicar los pocos recursos a otras actividades que no sean las básica para sacar la estación en tiempo y forma con las exigencias legales y los compromisos propios de la estación, es complicado. Las reuniones de trabajo regularmente son en tiempos muertos o de comida. Las juntas son regulares, pero se tocan también temas administrativos y laborales. En cuanto a juntas de producción y programación, muchas veces se cae en los asuntos de agenda cultural como son: "efemérides", "campañas de concientización", "difusión cultural", "personajes históricos”, etcétera.

Algo que con la simple observación notamos es que no hay guionistas, hacer guiones cobra tiempo y recursos. El trabajo de producir discursos articulados desde la lógica del medio, corre por cuenta de los propios colaboradores de los programas (ajenos a la radiodifusora, y a la comunicación en general); es decir, entusiastas de la universidad y de instituciones externas.

El trabajo de preproducción es realizado generalmente fuera de la estación y los colaboradores llegan y graban de inmediato. Se hacen ajustes en cabina en cuestiones mínimas. Pero no hay trabajo interdisciplinario propiamente, sino que se trabaja en la marcha, en la producción. En postproducción sólo se dan últimos detalles o se cortan los errores. Esto da espontaneidad, pero no siempre es lo óptimo, sobre todo al trabajar lenguaje científico que puede ser rebuscado y complicado de explicar. Pero el 
peso de la producción de programas de radio, recae en la participación de colaboradores externos a la radiodifusora. Las estaciones con el personal que tienen, producen programas hasta donde les es posible.

En la realidad, el equipo de trabajo en las radiodifusoras es el mínimo requerido para poder operar y a veces por debajo del mínimo. Pero aún así se cumple con el trabajo de sacar las radiodifusoras adelante por el gusto de hacer radio y la responsabilidad con la universidad y los radioescuchas. Una característica en particular es que ninguna tiene un noticiero propio por los gastos que implica desarrollarlo. Mucho de lo que se produce son programas de corte educativo que abordan temáticas de interés desde la perspectiva de las ciencias que estudian esos fenómenos, (psicología: depresión; economía: impuestos; astronomía: hoyos negros; etcétera), pero no son propiamente de divulgación de la ciencia, sino que es periodismo científico o educativo, su valor radica en ser un acercamiento a la ciencia, aunque no se cumpla con el "divulgar" las investigaciones de los científicos locales. Pero eso no exenta de la necesidad de hacerlo.

En el caso de producciones externas que se obtienen por intercambio con otras radiodifusoras del país y del extranjero o de instituciones gubernamentales (CONABIO, UNAM, Radio Educación, IMER, Radio Canadá internacional, etcétera) son muchos de corte educativo, cultural, infantil, artístico, pero no propiamente de divulgación de la ciencia. En promedio los programas propios de divulgación de la ciencia van de uno a dos. Contando las capsulas como si fueran un programa tendríamos 3 , ya que es en cápsulas y en microprogramas de entrevistas, o en entrevistas convertidas en cápsulas, o como parte de programas de revista o temáticos, es donde se tiene mayor presencia de divulgación de la ciencia.

En los programas propiamente producidos por las escuelas y facultades o por las carreras de cada universidad, se tienen mayormente temas de agenda estudiantil y universitaria propios de su entorno; aunque también se tocan temas referentes a lo que estudian y ven en su contenido curricular. Aclaremos que en ese sentido hay un cierto acercamiento a la ciencia a partir de estos programas educativos que enseñan la construcción conceptual de la ciencia a partir de ciertos problemas y temáticas, pero, no son propiamente programas pensados y elaborados para la divulgación de los hallazgos de las investigaciones de la ciencia de las universidades en sí. Nos acercan a los investigadores, a modo de periodismo de la ciencia. Eso no les resta importancia, pero, no podemos incluirlos como "divulgación de la ciencia" sino que "tocan temas 
científicos" de la misma forma en que se hace el periodismo científico en los medios comerciales a modo de tópico y como una entrevista. En algunos programas se habla de temas científicos, dando datos "curiosos" o conocimientos referidos a la ciencia en la cotidianidad. Son acercamientos interesantes y útiles. Pero no es una constante, sino destellos.

En cuanto a la programación, podemos apreciar desde el primer acercamiento que no hay una planificación de la programación como discurso integrador de la estación de radio hacia el radioescucha. Se programa música en los espacios desocupados, pero en muchos casos son los operadores quienes toman la decisión de qué música programar con base, a cierto genero que va en esa hora. Los bloques de corte a spots, la principal preocupación son pasar y cumplir con los tiempos oficiales del Instituto Nacional Electoral (INE) y de gobernación (La hora $\mathrm{Na}$ cional, el programa del Consumidor, etcétera) y la identificación de la estación. A partir de ahí en la mayoría de las estaciones los operadores seleccionan que spots o cápsulas van a pasar, en que frecuencia. Pero los criterios de selección son: el gusto, la repetición y el tiempo.

El espacio designado a los programas si bien se busca que sea adecuado a la audiencia a la que se transmite, al no tener datos sobre quién escucha y a qué horas, el cálculo se hace con base en las llamadas telefónicas y interacción en redes que se tenga con los programas. A prueba y error y con la intuición radiofónica, y el sentido común, se proponen horarios y días de transmisión para los programas. Además de la disponibilidad de los colaboradores que hacen los programas. Falta una sistematización de la programación como discurso radiofónico. En las diversas estaciones de radio hay una variedad amplia de contenidos, y la música se programa pensando en la audiencia meta de las estaciones. Las barras programáticas varían de las que son, en su mayoría, musicales y las que tienen mayoría contenido hablado y las intermedias. El balance entre uno y otro tiene que ver con la cantidad de colaboradores que desarrollan programas en cada estación.

Existe conciencia de que es importante la divulgación de la ciencia y muchos expresan la falta de material y programas. El problema de la falta de recurso humano y a veces, de la indiferencia o apatía de los científicos para acercase a la radio, incluso del desconocimiento de la existencia del medio. Se les invita pero los científicos, incluso, no van a entrevistas. Hace falta incursionar en otra investigación sobre el porqué 
los científicos no quieren participar en la radio universitaria. Aunado a la apatía de algunas autoridades y la falta de recursos, la producción de la divulgación de la ciencia se vuelve complicada.

Esto es un acercamiento a la Radio Universitaria en Coahuila. Falta analizar el discurso que nos develará parte de las prácticas de producción, y programación de las radios universitarias de Coahuila a partir del habitus de sus acciones comunicativas y el discurso que construyen en su cotidianidad como acción discursiva radiofónica en la radio cultura.

\section{Referencias}

Almaguer Kalixto, P. E., Cibercultur@e Investigación-Acción Participativa: intersecciones metodólogicas para el desarrollo de comunidades emergentes del conocimiento Local. Estudios sobre las culturas contempóraneas $X I X(37), 2013$, pp. 129-164.

Behar Rivero, Daniel S. Metodología de la Investigación. Ediciones Shalom. Argentina, 2008.

Beltrán Rosa Esther, El ser social saltillense, Vanguardia, 2017, http://bit.ly/2YOWnEi.

Bourdieu, Pierre, Razones Prácticas, sobre la teoría de la acción, Barcelona, Barcelona, España, Anagrama, 2003.

, Cosas Dichas. Barcelona, España: Gedisa, 2000.

, Capital cultural, escuela y espacio social (octava edición ed.), México, Siglo XXI editores, 2008.

, Razones Prácticas, sobre la teoría de la acción, Barcelona, España, Anagrama, 1997.

, Los tres estados del capital cultural, Revista Sociológica, Año 2, Otoño, (5), 1-6, 1987.

Carabaza, J., La radiodifusión en la Región Sureste de Coahuila. En J. Carabaza, Voces, textos e imágenes (págs. 223-259). Saltillo, Coahuila, México: Universidad Autonoma de Coahuila/ Facultad de Ciencias de la comunicación, 2008. 
Carabaza, Julieta., Aguilar, Andrea., \& Chong, Blanca. La investigación en Comunicación en Coahuila. Saltillo, Universidad Autónoma de Coahuila, 2011.

Chong López, Blanca; Hernández Alvarado, Hilda Georgina; López Franco, Roberto; Hernández, Juan Carlos; Ornelas López, José Luz y Morales, Alfredo. Torreón en el identitario de lo Lagunero. (43-57) en Hernández Alvarado, Hilda Georgina (Coord.), Como La Laguna ninguna. Identidades y redes semánticas naturales, Cuerpo Académico Sociedad, Comunicación y Cultura, FCPyS-UA de C, 2012.

Cornejo Portugal, I., La radio cultural indigenista en México: dilemas actuales, Revista Mexicana de Ciencias Políticas y Sociales, 52(209), 2010, pp. 55-62.

Corona, Lilia, "La radio en México toma un nuevo aire", Expansión, México Jueves 15 de febrero, 2018, recuperado: http://bit.ly/2OUH7RW.

"Red de radios universitarias de México celebra tercer encuentro La rectora de la UAIS. María Guadalupe Ceceña, estuvo como invitada especial en este evento", Debate, Los Mochis, 01 de junio, 2018, recuperado $<$ http://bit.ly/2YOSPCd $>$.

García, Rolando, El conocimiento en construcción, Barcelona, España,Gedisa, 2000.

García, Rolando, Sistemas Complejos, Conceptos, método y fundamentación epistemológica de la investigación interdisciplinaria, Barcelona, Gedisa, 2006.

Habermas, Jürgen. Teoría de la acción comunicativa II, Crítica de la razón funcionalista. México: Taurus Humanidades, 1992.

, Teoría de la acción comunicativa: complementos y estudio previos, México, Rei, 1993.

Teoría de la acción comunicativa I, Racionalidad de la acción y racionalización social, México, Taurus Humanidad, 1999.

Hinojosa, Lucila., Chong, Blanca., y Olvera, Juán, "Las Ciencias de la Comunicación en el Noreste de México: Una mirada a la institucionalización del campo", en C. Morado y L. Hinojosa, Las Ciencias Sociales en el Noreste de México, (31-58), Monterrey, Facultad de Filosofía y Letras, Universidad Autónoma de Nuevo León, 2015.

Instituto Federal de Telecomunicaciones y Radiodifusión IFT, a., "Listado de Radiodifusoras AM yFM." Archivo en línea, Instituto Federal de Telecomunicaciones, México, IFT, 2019, recuperado en http://bit. ly/2N8kUNP Revisado 20022019. 
, b., "Listado de Radiodifusoras AM yFM.", Archivo en línea, Instituto Federal de Telecomunicaciones, México, IFT, 2019, recuperado en http://bit.ly/2N8kUNP Revisado 12 de 08 de 2019.

Indigenista, I. N. I.. La radio Indigenista. en M. A. Rebelil Corelia, A. R. Alva de la Selva y I. Rodriguez Zárate, Perfiles del Cuadrante (85-96), México, Trillas, 2005.

Instituto Nacional de Estadística y Geografía INEGI, México en Cifras: Coahuila de Zaragoza. México, 2019, recuperado en http://bit.ly/2OWATB4.

Jensen, Karl. Brun, La comunicación y los Medios, Metodologías de investigación cualitativa y cuantitativa, M. Sánchez-Ventura, trad., México, Fondo de Cultura Económica, 2014.

Krotz, Friedrich, Mediatization: A concept With Wich to Grasp Media and Societal Change, en L. Kunt, y S. Livingstone, Mediatization, concepts, changes, consequences, USA, Peterlang, 2009.

Ley Federal de Telecomunicaciones y Radiodifusión, Cámara de Diputados, México, 2018, recuperado en http://bit.ly/33xBO, 2019.

Márquez Nerey, Ernesto, Estudio diagnóstico sobre la divulgación de la ciencia en México, Cultura Científica y Cambio Social (págs. 1-15), México, SOMEDICYT, 2003.

Mejía Barquera, Fernando, "Historia miníma de la Radio en México (1920-1996)", Escenarios y Convergencias. México, Revista de Comunicación y Cultura (1), Marzo-Mayo, 1-26., 2007, recuperado en <http://bit.ly/2ORNDsu>.

Muñiz Manuel, Estudios de caso en la investigación cualitativa, División de Estudios de Posgrado Universidad Autónoma de Nuevo León,Facultad de Psicología, México, 2010, pp. 1-8

Mateo Rodriguez, José Manuel y Bollo Manent, Manuel, La región como categoría geográfica, México,UNAM-CIGA, 2016.

Ornelas López, José Luz. Breve reflexión histórica sobre la creación de los Estados: A propósito de la quimera Estado de la Laguna, (10-41), en Chong López, Blanca y Ornelas López, José Luz, coord., Problemáticas de la región y la nación desde la Laguna,Cuerpo Académico Sociedad, Comunicación y Cultura, FCPyS-UA de C, 2017.

Piaget Jean, Inhelder B., García R., y Vonéche J., Epistemología genética y equilibración. Madrid. Editorial Fundamentos, 1981.

, La equilibración de las estructuras cognitivas. Problema central del desarrollo, México, Siglo XXI Editores, 1998. 
, El nacimiento de la inteligencia en el niño, Barcelona, España,Biblioteca de Bolsillo, 2000.

Instituto Nacional Indigenista, INI "La Radio Indigenista" en Rebelil Corelia, Alva de la Selva y Rodriguez Zárate, coord., 2005, Perfiles del Cuadrante, México, Trillas, 2005, 85-96.

Rios, Armando, “Cómo ven los visitantes a los saltillenses”, en Vanguardía. 25 de Julio, versión Web en http://bit.ly/2P9nc1Q, 2017.

Romo Gil, María, Cristina, Introducción al conocimiento y práctica de la Radio, Guadalajara, Jalisco, DIANA / ITESO, 1989.

Scollon, Ron, "Acción y texto: para una comprensión conjunta del lugar del texto en la inter(acción) social, el análisis mediato del discurso y la acción social", en R. \&. Wodak, Métodos de Análisis Crítico del Discurso, págs. 205-266, Barcelona, Gedisa, 2003.

Sandoval Casilimas, Carlos, La investigación Cualitativa, Bogotá, Colombia,1996.

Sadi Durón, Jorge, Diagnóstico de Audiencia Radiofónica Cultural en la Comarca Lagunera 2016, en B. y Chong López, Problemáticas de la Región y la nación desde la Laguna, 96-128, Torreón, Coahuila, Universidad Autónoma de Coahuila, 2017.

, La radio universitaria estudiantil, la comunicación alternativa, México, Tesis de Maestria, UNAM, 2006.

Toussaint, Florance, La Radiodifusión Universitaria Nacional: 50 años de persistencia, en M. A. Rebeil Corella, A. R. Alva de la Selva y I. Rodríguez Zárate, Perfiles del Cuadrante, experiencias de la radio, 8084, México,Trillas, 2005.

Vazquéz Guerrero, Marina y Parejo Cuellar, Macarena, La divulgación científica a través de la radio universitaria en España y México, Razón y Palabra (91), 2015, pp. 669-686.

Vigotsky, Leontiev, Pensamiento y lenguaje, Teoría del desarrollo cultural de las funciones psíquicas, M. M. Rotger, trad., Madrid, Pléyade, 1977.

, El desarrollo de los procesos psicologicos superiores, Barcelona, Crítica, Grupo Editorial Grijalbo, 1978.

Van Dijk, Teun, La multidisciplinariedad del análisis crítico del discurso: un alegato en favor de la diversidad, en Wodak, Ruth; Meyer, Michael. Metodos de Analisis Critico del Discurso, Barcelona, Gedisa, 143-176, 2003. 
Wodak, Ruth y Meyer Michael, comp., Métodos de Análisis Crítico del Discurso, Barcelona, Gedisa, 2003, pp. 286.

\section{Electrónicas}

ANUIES, Asociación Nacional de Universidades e Instituciones de Educación Superior, 2018, "Listado Radios Universitarias por Región”. Página Web, México, recuperado de $<$ http://bit.ly/2MXKhlg $>$.

CDI, SCRI, Comisión Nacional para el Desarrollo de los Pueblos Indígenas, Sistema de Radiodifusoras Culturales Indigenistas, 2019, "I. Antecedentes", Página Web, México, recuperado de <http://bit. ly/2KzoeQb>.

IMER, Instituto Mexicano de Radiodifusión, 2019, “Quiénes somos”, Página Web, México, actualizada 01 junio 2019, <http://bit.ly/2z0t5n4>.

La Hora Nacional, "Historia de la Hora Nacional", Página Web, México, 2019, actualizada 2901 2019, recuperado <http://bit.ly/2H9BJ7c>

RRUM, Red de Radios Universitarias de México, “Nosotros”, Página Web, México, 2019, recuperado <http://bit.ly/2N3WODS>

Radio Educación, “Acerca de Radio Educación”, Página Web, México, 2019, $<$ http://bit.ly/2YIMKaa> 


\title{
ELEMENTOS PARA EL ESTUDIO Y ANÁLISIS DE LAS ORGANIZACIONES DESDE LA PERSPECTIVA DE LOS SISTEMAS DINÁMICOS COMPLEJOS
}

\author{
Pablo Guerrero Sánchez \\ Universidad Autónoma del Estado de Morelos \\ José Guerrero Grajeda \\ Universidad Nacional Autónoma de México
}

\section{Una primera aproximación}

Una convicción de quienes escribimos este artículo radica en que, si se está interesado en conocer algún sector de lo real -material o social-, las matemáticas pueden ser una herramienta de gran ayuda en muchos casos, aunque, por otro lado, asumimos las críticas de quienes se oponen a esta visión, que argumentan, entre otras cosas, que el objeto de estudio de las ciencias físicas o biológicas difiere cualitativamente del de las ciencias sociales, cuestión de la que nos ocuparemos más adelante. Por ahora, analizaremos algo acerca del contexto universitario, tanto a nivel nacional como global, desde el punto de vista de la teoría y los estudios organizacionales, en específico de las teorías de la ambigüedad, el nuevo institucionalismo sociológico y su andamiaje teórico epistemológico y metodológico como sistemas flojamente acoplados, tratando de construir un maridaje entre las teorías emanadas de las ciencias sociales en general, los estudios organizacionales en particular y finalmente, la construcción de un modelo matemático interpretativo de forma operacionalizada.

\section{De la teoría de la organización a los estudios organizacionales}

La teoría de la organización tiene una conceptualización teórico metodológica y una base epistémica, la cual abarca varios niveles y escuelas de análisis, para precisarlas, haremos un breve recuento de ellas para entender su desarrollo. En primer lugar, se encuentra la administración 
científica que busca la eficiencia en los procesos a partir de los tiempos y movimientos, según los estudios de Taylor, Coriat, Durand, Fredman y Mouzelis, desarrollados a lo largo del siglo pasado. ${ }^{1}$ Por otro lado se encuentra la escuela de las relaciones humanas, que implica la lógica de los sentimientos en el proceso de la organización, según las apreciaciones de, entre otros, Mayo, Roethlisberger y Dickson, Desmarez, Mouzelis y Guillepie. La escuela de la burocracia, que observa el problema de la racionalidad y la formal legal como estructura normativa, es el aspecto que desarrollaron Weber, Merton, Crozier y Blau. La escuela del comportamiento que analiza la racionalidad limitada, de acuerdo con Simon en El comportamiento administrativo y otros autores, como March con su obra The Business firm as a political coalition, de 1989 y del mismo autor y Cyert, con A Behavioral Theory of the Firm; y además, Simon, con su obra La nueva ciencia de la dirección gerencial. Otra escuela importante, que toma en cuenta la necesidad de analizar el contexto como parte fundamental de las acciones de un sistema abierto a partir de la contingencia, es la línea de los estudios de Woodward, Pugh y otros con su libro, Dimensions of Organization Structure; en esta corriente destacan además, Hickson, Hinings y Turner, Burns y Stalker así como Lawrence y Lorch. Finalmente, el efecto de las necesidades de liderazgo y las internas, aunadas a los tipos de motivaciones en lo que se llamó las nuevas relaciones humanas fue lo que trataron Mazlow y McGregor.

El desarrollo de estos puntos de vista a lo largo del tiempo constituyó un marco teórico conceptual con un objetivo estructural, funcionalista y también multidisciplinario para la caracterización del análisis de las organizaciones desde el punto de vista prágmático. Esta visión, en la práctica trató de resolver problemas específicos presentados durante la primera mitad del siglo XX que, no obstante, tuvieron ciertas consecuencias en función de la ausencia de crítica de la teoría aplicada en función principalmente de las relaciones de poder y la cultura. Por lo tanto, el marco analítico planteó nuevos retos y esquemas interpretativos, así como retos epistemológicos, teóricos y metodológicos, aunados a la lectura de nuevas disciplinas que se sumaron al estudio de las organizaciones desde diversos niveles y enfoques.

1 Las referencias se encuentran en la bibliografía. N. del E. 


\section{De la teoría de la organización a los estudios organizacionales}

La teoría crítica de aplicación de la teoría de la organización nace desde el punto de vista del poder como mito racionalizado e instrumental, según tratan Ibarra y Montaño, se suma la disciplina de la Sociología y el tema del conflicto de acuerdo con Mouzelis, y se integra la ambigüedad, más que la certidumbre como distingue Merton. El tamaño es un factor central, tal como reconoce Pfeffer y comienza a formularse una división entre los propios críticos y analíticos de la organización, a partir de la validez de los estudios respecto del enfoque de análisis y las metodologías, de acuerdo con Donaldson. Así, se incorpora el elemento subjetivo humano, acuñado por Reed, y la diferenciación entre un sistema en equilibrio determinado por un sistema dinámico complejo. El sujeto, ahora es considerado también como oportunista y con una naturaleza económica en la búsqueda de su propio beneficio, tal como señala Williamson. Pero, además, se suma el efecto de los valores a partir de la cultura según DiMaggio y Powell,como elementos más bien interpretativos de la ambigüedad, el significado simbólico de las decisiones y las estructuras, así como de los procesos e interacciones, como acuñaron Chanlat y Bédard, pero también se reconoce la naturaleza del objeto/sujeto de estudio entre las ciencias exactas y las ciencias sociales, de acuerdo con lo que señaló Silverman. Los elementos del sistema pueden ser vistos, además, como poseedores de múltiples lógicas, necesidades y objetivos, así como entre coaliciones, por lo que se reconoce que están flojamente acoplados, como observó Zey-Ferrell. ${ }^{2}$ Finalmente, Weick reconoce en sus postulaciones la importancia de la motivación y las creencias.

\section{La epistemología en el cambio de lo concreto a lo complejo y dinámico}

Luego de este recorrido se puede advertir que la teoría de la organización, por lo tanto, es mayoritariamente positivista, ${ }^{3}$ objetiva, realista y con relaciones humanas deterministas; por lo que su metodología es nomotética ${ }^{4}$ basada en el método científico y estudia a los individuos, los objetivos, los procesos, las reglas, el ambiente y las estructuras de forma cuantitativa. Los estudios organizacionales tratan, por su parte, de explicar más que

2 M. Zey-Ferrell, "Criticisms of the dominant perspective on organizations", The Sociological Quarterly, 1981, p. 185.

3 El positivismo afirma que todo conocimiento deriva de la experiencia, basada en conocimientos y hechos reales, respaldada por el método científico. $\mathrm{N}$ del E.

4 La nomotética significa "propuesta en forma de ley" y se usa en distintas disciplinas como filosofía, antropología, sociología y psicología con diferentes significados. N. del E. 
determinar, el factor ambigüo subjetivo, de forma cualitativa, valorativa, psicoanalítica es decir, inconsciente, desde una perspectiva del poder político y las coaliciones internas por lo que tiene un enfoque voluntarista. Todo ello bajo un enfoque nominalista, ${ }^{5}$ por lo que la realidad se considera construida socialmente a partir del significado subjetivo que opera al interior de grupos sociales específicos, por lo que es eminentemente antipositivista y relativista de forma nomotética.

Dentro de este marco de ideas, el análisis de las organizaciones sociales estudia no sólo a las empresas sino a otro tipo de entidades como lo son las organizaciones no gubernamentales, el gobierno en sí mismo, los partidos políticos y las instituciones de educación superior, puesto que todas ellas son suceptibles de ser analizadas por este amplio marco metodológico epistémico y teórico nutrido de forma multidisciplinar en un diálogo acumulativo. La caracterización de las universidades, en particular, expresa la necesidad de la aplicación de diversas disciplinas que expliquen la dinámica de las organizaciones a partir de sus niveles de análisis, así como de sus estructuras fundamentales y múltiples objetivos, por lo que las teorías de la ambigüedad, a partir de el nuevo institucionalismo sociológico, ofrecen el marco interpretativo de los sistemas flojamente acoplados. Dicho marco explica que los diversos elementos del sistema tienen un comportamiento en el tiempo a partir de sus diversos intereses lógicos en lo que se podría denominar una anarquía organizada que posee una lógica interna interpretativa, a partir de las dinámicas que se desarrollan en función de los objetivos, actores, estructuras, valores y niveles de poder.

\section{Los cambios universitarios de los últimos tiempos}

Los distintos movimientos sociales han generado cambios que, a nivel internacional han introducido reformas y han transformado los sistemas universitarios sustentados en el concepto de universidad de investigación6, producto de la era industrial y basada en el conocimiento disciplinar, bajo

5 Doctrina filosófica según la cual todo lo que existe es particular. El nominalismo niega la existencia de los universales tanto de manera inmanente como trascendente. Otra palabra para designarlo es el particularismo. N. del E.

6 Peter Manicas, "La educación superior al borde del precipicio" en Inayatullah Sohail y Jennifer Gidley, La universidad en transformación. Perspectivas globales sobre los futuros de las universidades, Ediciones Pomares, Barcelona, 2003, pp. 41-53. 
cuyos supuestos se premia el trabajo académico especializado mientras "la excelencia en la enseñanza y el más amplio 'modelamiento del carácter' del estudiante aparecen en un segundo plano, a menudo muy pobre"?

Este modelo cobró fuerza a partir de las dos últimas décadas del siglo $\mathrm{XX}$, en el marco de la llamada globalización, ${ }^{8}$ su cara más visible es la revolución informática, sustentada en los avances tecnológicos de la era digital.

Tal vez el producto más conspicuo de esta era de cambios acelerados sea - en el ámbito de la educación superior - la creación de las llamadas "instituciones de conveniencia", cuyo producto más reconocibles es el de la universidad virtual, su soporte tecnológico es "la red", que se ha convertido en la herramienta y lugar de intercambio de información más importante de nuestro tiempo. Lo que, entre otras cosas, ha permitido abaratar los costos de la docencia e investigación universitarias y ha cambiado de manera importante el rol del profesor en la enseñanza. ${ }^{10}$

Estos hechos se ubican en un entorno en el que el Estado, fuente principal de financiamiento de las universidades estatales, ha iniciado en las últimas décadas un proceso de disminución de subsidios ${ }^{11}$ que, entre otros cambios, ha obligado a las instituciones universitarias a buscar recursos financieros en fuentes alternativas, por lo regular, en empresas o autogenerando sus recursos. Este nuevo panorama también ha obligado a las universidades a adoptar esquemas tendientes a satisfacer las demandas del mercado, ${ }^{12}$ lo que, por supuesto, ha provocado reacciones que van, desde la creación de nuevas instituciones o la adopción, por parte de las existentes, de estrategias que permitan posicionarse de manera ventajosa en el nuevo contexto. Claro que no faltan diversas reacciones críticas respecto del proceso de mercantilización universitaria, en tanto que éste, se enfoca principalmente en que los alumnos desarrollen habilidades y competencias específicas, más que en una formación integral de éstos, en

7 Philip Spies, "Las tradiciones de la universidad y el desafío de la transformación global" en Inayatullah Sohail y Jennifer Gidley, La universidad en transformación. Perspectivas globales sobre los futuros de las universidades, Ediciones Pomares, Barcelona, 2003, pp. 27-40.

8 En un documento editado por la Organización para la Cooperación y Desarrollo Económico, Technology and the Economy: The Key Relationships, se define globalización como "un conjunto de condiciones en las que una creciente fracción del valor y de la riqueza son producidas y distribuidas a nivel mundial a través de un sistema de redes privadas interconectadas", 1992, p. 210.

9 Deane Neubauer, "¿Seremos incluidos en el futuro? Reflexiones de un profesional de la educación superior" en Inayatullah Sohail y Jennifer Gidley, La universidad en transformación. Perspectivas globales sobre los futuros de las universidades, Ediciones Pomares, Barcelona, 2003, pp. 54-71.

10 Michael Skolnik, "La universidad virtual y el profesorado" en Inayatullah Sohail y Jennifer Gidley, La universidad en transformación. Perspectivas globales sobre los futuros de las universidades, Ediciones Pomares, Barcelona, 2003, pp. 72-87.

11 Peter Manicas, op. cit., p.45.

12 Deane Neubauer, op. cit., pp.55-56. 
la que el conocimiento sea la prioridad, la condición indispensable para enfrentar con éxito la complejidad de los problemas planteados en los ámbitos de la tecnología y las ciencias de nuestro tiempo.

Dado que el proceso de globalización es de proyección mundial, México no podía escapar a su impacto (el hecho más visible es el conocido paso del Estado Benefactor al Estado Evaluador ${ }^{13}$, con sus sistemas de estímulos al desempeño y programas, en los que la obtención de recursos para becas, infraestructura y viajes depende de la presentación de proyectos que deberán ser evaluados y aprobados). Aunque la geografía e historia de nuestro país lo ubican como un caso especial, pues, por un lado, comparte un Tratado de Libre Comercio, así como una conflictiva y enorme frontera con los Estados Unidos de Norteamérica, país donde residen algunas de las universidades más "prestigiosas" del mundo — las de la Liga Ivy, por ejemplo ${ }^{14}$ - y que, además, está a la vanguardia del desarrollo tecnológico, como es natural para un país que nació con la mirada puesta en el futuro ${ }^{15}$.

El problema es que México, a su vez, forma parte de Hispanoamérica, con cuyos países miembros comparte historia y cultura, y en el ámbito específico de las universidades estatales incluye una tradición centenaria de luchas antisistémicas ${ }^{16}$ entre las que destacan las de la autonomía y la gratuidad. ${ }^{17}$ En este contexto, nos interesa mencionar el caso de la Universidad Autónoma de la Ciudad de México (UACM), dado que se trata de un caso único, en el que opera el concepto de igualdad, tan importante para quienes luchan desde la oposición política de izquierda. Esta homogeneidad se materializa en la igualdad de salarios de los profesores, independientemente del grado académico que posean o de su desempeño, así como por el ingreso por sorteo de los alumnos, sin que deban aprobar

13 Hugo Casanova Cardiel, Políticas y gobierno de la educación superior en América Latina, coord. Hugo Casanova Cardiel, Coruña, Netbiblio, 2002, p.249-250.

14 Philip Spies, op. cit., p. 30.

15 "Una sociedad se define esencialmente por su posición ante el tiempo. Por razón de su origen y de su historia intelectual y política, los Estados Unidos son una sociedad orientada al futuro [...] El norteamericano vive en el límite extremo del ahora, siempre dispuesto a saltar hacia el futuro. El fundamento de la nación no está en el pasado ni en el porvenir. Mejor dicho: su pasado, su acta de fundación fue una promesa de futuro y cada vez que los Estados Unidos regresan a su origen, a su pasado, redescubren el futuro". Octavio Paz, "Posiciones y contraposiciones: México y Estados Unidos”, en Obras Completas, Fondo de Cultura Económica, México, Tomo 8 (1978), 2006, p. 448

16 Cabe aclarar que en el caso de los Estados Unidos de Norteamérica también existen este tipo de luchas con una larga tradición. Al respecto puede consultarse, por ejemplo, Theodore Roszak et. al., La contestación universitaria, Ediciones Península, Madrid, 1973.

17 Axel Didriksson, "La universidad diferente: presente y futuro de la universidad de América Latina y el Caribe", en Inayatullah Sohail y Jennifer Gidley, La universidad en transformación. Perspectivas globales sobre los futuros de las universidades, Ediciones Pomares, Barcelona, 2003, pp. 213-250. 
previamente un examen de admisión, lo que, en términos probabilísticos, significa que todos los aspirantes tienen la misma posibilidad de ingreso, independientemente de su origen y sus conocimientos.

\section{Propósito general}

Establecer un lenguaje común entre los estudios organizacionales y las ciencias físico-matemáticas, que permita formular un modelo matemático inicial del tipo:

$$
M(t ; A i, A e) \text {, }
$$

donde $\mathbf{t}$ es una variable temporal, la variable Ai, representa a los actores internos considerados como los más relevantes (académicos, autoridades, etc.), mientras que Ae representa a los actores externos (gobiernos estatales y federal y organismos internacionales).

Este modelo dinámico - en tanto que depende del tiempo-, deberá, como todo modelo, dar cuenta de su objeto de estudio y funcionar como herramienta para el análisis y la toma de decisiones en las instituciones públicas de educación superior de México.

\section{Sistemas sociales y universidades públicas}

Nuestro punto de partida es la sociedad mexicana, a la que consideraremos como nuestro universo. Definimos entonces:

Sistema social: es un sector de la sociedad constituido por:

1.Un conjunto de individuos-actores agrupados en coaliciones formadas por individuos con intereses compartidos, que pertenecen a un espacio $\mathbf{X}$.

2. Un operador dado por el conjunto de reglas formales e informales que regulan las relaciones entre los individuos que integran las coaliciones, así como las relaciones entre coaliciones.

3. Un objetivo-meta que consiste en resultados preestablecidos, producto de la actividad de los individuos-actores, que pertenecen a un espacio $\mathbf{Y}$. 
En forma esquemática tenemos:

$$
\begin{aligned}
& K: X \leftrightarrow \rightarrow Y \\
& \mathrm{~K}(\mathrm{c}) \leftrightarrow \rightarrow r,
\end{aligned}
$$

Esquema 1

donde:

$K \equiv$ operador,

$\boldsymbol{c} \equiv$ vector de coaliciones de individuos - actores $\left[\mathrm{c}_{1}, \mathrm{c}_{2}, \ldots, \mathrm{c}_{\mathrm{n}}\right] \mathrm{y}$

$\boldsymbol{r}(\boldsymbol{t}) \equiv$ vector de resultados $\left[\mathrm{r}_{1}, \mathrm{r}_{2}, \ldots, \mathrm{r}_{\mathrm{k}}\right]$, donde éstos están asociados con un tiempo específico.

Veámoslo en el contexto de las universidades públicas. Tenemos:

Individuos-actores $\equiv$ [autoridades, trabajadores académicos, trabajadoresadministrativos, estudiantes] $\equiv$ $\left[\mathrm{c}_{1}, \mathrm{c}_{2}, \mathrm{c}_{3}, \mathrm{c}_{4}\right]$.

Operador $\equiv[$ legislación universitaria + reglas no escritas $] \equiv \mathbf{K}$.

Objetivo-meta $\equiv$ producir con calidad [ nuevas investigaciones, nuevos académicos, nuevos desarrollos tecnológicos, difusión-divulgación del conocimiento ] $\equiv$ $\left[\mathrm{r}_{1}, \mathrm{r}_{2}, \mathrm{r}_{3}, \mathrm{r}_{4}, \mathrm{r}_{5}\right]$.

Nuestro esquema 1 podemos interpretarlo como sigue: la aplicación del operador $\mathrm{K}$ al vector $\mathrm{c}$, produce un vector de resultados $\mathrm{r}$, o bien, estamos ubicados en un universo racional donde opera una lógica de tipo consecuencial ( $\mathrm{P}$ implica Q o, a una acción corresponde una respuesta predeterminada).

Cabe decir que este esquema podemos aplicarlo a una amplia variedad de situaciones. Por ejemplo, si K representa las leyes de la gravedad newtoniana, $\mathrm{X}$ nuestro sistema solar y $\mathrm{x}$ el vector cuyos elementos son los planetas, entonces la aplicación de $\mathrm{K}$ produce el movimiento conocido de los planetas alrededor del Sol y nos permite determinar la posición de éstos, dada por el vector $y$, en un instante de tiempo determinado, ya sea del pasado o del futuro. 
Como se observa, hemos elegido un ejemplo que corresponde al dominio de la física, y la pregunta ahora es: ¿Qué sucede cuando pasamos al campo de las sociedades humanas y nos planteamos de entrada el problema, digamos, del poder en los términos de varios autores clási$\cos ?^{? 18}$ Esto es, si tenemos una situación en la que un individuo o un grupo trata de obtener una respuesta de otro individuo o grupo al interior de una comunidad $\mathrm{X}$, mediante la aplicación de una estrategia $\mathrm{K}$ que deberá afectar sus intereses? Es claro que esto es perfectamente aplicable al caso de las universidades públicas mexicanas, puesto que entre las distintas clases o coaliciones de individuos se dan juegos de poder motivados, por ejemplo, por la búsqueda de posiciones o recursos. Bajo este supuesto, nuestro esquema 1 difícilmente resulta aplicable, pues aún en el caso de sociedades totalitarias - piénsese en las descritas de forma sombría pero magistral en las obras de Orwell, Bradbury o Huxley, por ejemplo-, en las que el control de los individuos intenta controlar la totalidad de sus actividades vitales, sin embargo, siempre latente, existe la posibilidad de la rebelión, pues los individuos que conforman la especie humana son, en el sentido que aquí nos interesa, más complejos que los objetos inertes del sistema planetario, o que los integrantes de otras especies vivas, cuyos códigos genéticos los encaminan a actuar, en un sentido predeterminado.

Necesitamos, entonces, enriquecer nuestro esquema inicial con el propósito de que nos permita tratar adecuadamente problemas no abarcables en las fronteras de un universo racional en el que opera una lógica de tipo consecuencial. Para superar esto, planteémonos el siguiente escenario:

Un espacio $\mathbf{X}$ tal que si $\mathbf{x}_{1}$ y $\mathbf{x}_{2}$ son elementos "cercanos" (su distancia es pequeña en algún sentido) en $\mathbf{X}$, resulte que sus respuestas $\mathbf{K}\left(\mathbf{x}_{1}\right)$ y $\mathbf{K}\left(\mathbf{x}_{2}\right)$ sean muy "distantes" en $\mathbf{Y}$. Un esquema más adecuado en este contexto es:

$$
\begin{gathered}
\mathrm{K}: \mathrm{X} \leftrightarrow \mathrm{Y} \\
\mathrm{K}\left(\mathrm{x}_{1}\right), \mathrm{K}\left(\mathrm{x}_{2}\right) \leftarrow \rightarrow \mathrm{y}_{1}, \mathrm{y}_{2} \text {, con } \\
\mathrm{d}\left(\mathrm{K}\left(\mathrm{x}_{1}\right), \mathrm{K}\left(\mathrm{x}_{2}\right)\right) \text { pequeña y } \mathrm{d}\left(\mathrm{y}_{1}, \mathrm{y}_{2}\right) \text { muy grande. }
\end{gathered}
$$

Esquema 2

18 Véase, por ejemplo: A. Ayuzabet de la Rosa, "Poder, ambigüedad e institución: re-pensando la concepción tradicional de las relaciones de poder en el análisis organizacional”, en Administración y Organizaciones, Universidad Autónoma Metropolitana, 2007, pp. 11-29. 
Esta situación, que es común en matemáticas, (por ejemplo cuando $\mathbf{X}$ es el conjunto de los números reales y $\mathbf{K}$ representa a una función con discontinuidades), también es recurrente en muchas aplicaciones de las matemáticas al análisis y resolución de problemas reales y aquí proponemos aplicarla al ámbito social, específicamente al análisis de la dinámica organizacional en el marco de las instituciones públicas de educación superior. Al respecto, supongamos que $\mathbf{X}$ es el conjunto de académicos de una universidad pública y $\mathbf{K}$, las reglas de un programa de estímulos. En este caso, la aplicación de $\mathbf{K}$ (instrumento racional que, de diversas formas "dirige" el tipo de actividades de quienes se sujeten al programa), tiene como propósito (respuesta esperada) el aumento de la productividad académica. Ahora bien, los académicos ubicados en este contexto pueden adoptar (como hacen en la práctica) respuestas de distinto tipo: a) asumir los términos del programa en cuestión y buscar la manera de sacar de ello el mayor provecho; b) rechazar los términos del programa y luchar contra su imposición, o bien, asumir alguna variante ubicada entre las dos anteriores.

Un análisis que intente dar razón del tipo de respuesta de los académicos deberá necesariamente considerar distintas variables: origen social, posición ideológica, religión, tipo psicológico, situación familiar, etc.; esto es, toda respuesta es función de un conjunto de variables pero, en última instancia, encarna un acto de libertad que, en muchos casos, puede llevar a quien lo toma a una situación de enfrentamiento con el sistema, ello a pesar del papel de domesticación y adiestramiento que imponen por las instituciones (escuelas, hospitales, iglesias, empresas), aún en el caso de sociedades democráticas, como bien lo ha expuesto Michel Foucault, entre otros autores.

Por supuesto, podemos volver aún más complejo nuestro ejemplo, si consideramos que un mismo individuo puede proporcionar diferentes respuestas en tiempos distintos, o bien que en una universidad actúan otros grupos o coaliciones (subconjuntos de $\mathrm{X}$ ) que, como hemos supuesto, están dados por trabajadores, administrativos, autoridades y estudiantes, todos con intereses propios, lo cual convierte al sistema en un sistema flojamente acoplado, en el que los intereses de un grupo no son necesariamente coincidentes (o no del todo) con los de otro, lo que a nivel organizacional da lugar a conflictos de intereses y dinámicas complejas donde difícilmente puede hablarse de respuestas predeterminadas. 


\section{Conclusión}

Pensamos que lo anterior es suficiente para mostrar que nuestro esquema 2, en el que la aplicación de un operador $\mathrm{K}$ puede dar lugar a respuestas muy distintas por parte de los elementos cercanos de un universo o conjunto $\mathrm{X}$, es perfectamente aplicable al caso social, $\mathrm{y}$, en específico, al caso de las universidades públicas mexicanas. Si bien la teoría de la organización ha usado un marco teórico conceptual positivista, no se reflejó en el diseño analógico interpretativo de los estudios de caso, sin embargo, tratamos de evidenciar diversas relaciones entre elementos del sistema, así como una construcción de interpretaciones de los sistemas dinámicos, desde el punto de vista de las Matemáticas y la Física, valiéndonos tan sólo la estadística y los modelos económicos.

Los estudios organizacionales, por su parte, no reflejan un puente interpretativo más allá de la subjetividad y los estudios de caso, sin embargo, en este primer acercamiento intentamos tender puentes epistemológicos interpretativos, no sólo para el estudio de las organizaciones, sino para las Ciencias Sociales, Naturales y exactas, como la Física y las Matemáticas. Los sistemas dinámicos y los sistemas complejos explican, por lo tanto, expresiones de la realidad del comportamiento interno de las organizaciones con variables que pueden ser susceptibles de ser analizadas e interpretadas de forma rigurosa, pero que, además, explican las dinámicas internas y los comportamientos en el tiempo, más allá del equilibrio o puntos de estabilidad, que pueden modificarse y cambiar por ligeras variaciones de las condiciones en el sistema, tanto internas como externas; de tal forma, los sistemas dinámicos explican variaciones que pueden modelarse a partir del cambio de los sistemas de ecuaciones diferenciales.

Las variables que intervienen en la lógica de las organizaciones pueden ser operacionalizadas de forma heurística a través de ecuaciones lineales, pero también, a partir de ecuaciones no lineales que expliquen y den cuenta de la complejidad de los elementos del sistema; esta primer interpretación puede, no sólo explicar las dinámicas y condiciones así como el comportamiento, sino predecir los cambios futuros del sistema, y las nuevas realidades organizacionales que se presentan a partir de la contingencia, en ocasiones, con ligeras variaciones en las condiciones del sistema y los actores involucrados. 


\section{Referencias}

Desmarez, P., "La sociología industrial, heredera de la termodinámica del equilibrio" en I. Colado y L. Montaño, Teoría de la organización: Fundamentos y controversias, México, Universidad Autónoma Metropolitana, 1986, pp. 27-38.

Didriksson, Axel, "La universidad diferente: presente y futuro de la universidad de América Latina y el Caribe", en Inayatullah, Sohail y Gidley, Jennifer, La universidad en transformación. Perspectivas globales sobre los futuros de la universidad, Ediciones Pomares, Barcelona, 2003, pp. 213-250.

DiMaggio, P.,y Powell, W., “The iron cage revisited: institutional isomorphism and collective rationality in organizational fields", en American Sociological Review , 48(2), 1983, pp. 147-160.

Donaldson, L., Contingency Theory, Cambridge, Darmouth, 1995.

Durand, C., El trabajo encadenado. Organización del trabajo y dominación social, Madrid, Hernan Blume, 1979.

Fredman, G., "Dos grandes doctrinarios del progreso”, en M. Rosim, Historia del pensamiento administrativo, México, Universidad Autónoma Metropolitana 1985, pp. 225-273.

Guillepie, R., Manufacturing Knowledge, London, Cambridge University Press, 1993.

Haykin, Simon, Neutral Networks and Learning Machines, Pearson Publisher, Chicago, 2008.

Lawrence, P., Lorch, Organización y ambiente, Editorial Labor, Madrid, 1973.

Manicas, Peter, "La educación superior al borde del precipicio," en Inayatullah, Sohail y Gidley, Jennifer, La universidad en transformación. Perspectivas globales sobre los futuros de la universidad, Ediciones Pomares, Barcelona, 2003.

March, J., Cyert, R, A Behavioral Theory of the Firm, New Jersey, Prentice Hall, 1963.

, Simon, H., Teoría de la Organización, Barcelona, Ediciones Ariel, 1969.

, “The Business firm as a political coalition”, en J. March, Decisions and organizations, New York, 1989, pp. 101-115.

, A primer on Decision Making, New York, The Free Press, 1994.

Mayo, E., Problemas humanos de una civilización industrial, Buenos Aires, Nueva Visión, 1972. 
Mazlow, A., Motivation and personality, New York, Harper \& Row Publishers, 1970. McGregor, D., El aspecto humano de las empresas, México, Editorial Diana, 1973. Merton, R., Teoría y estructuras sociales, México, Fondo de Cultura Económica, 2002. Mouzelis, N., Organización y Burocracia, Barcelona, Ediciones Península, 1975. , “Organización y burocracia”, en N. Mouzelis, Problemas Humanos de la civilización industrial, Buenos Aires, Nueva Visión, 1975, pp.105-129.

Neubauer, Deane, “ ¿Seremos incluidos en el futuro? Reflexiones de un profesional de la educación superior", en Inayatullah, Sohail y Gidley, Jennifer, La universidad en transformación. Perspectivas globales sobre los futuros de la universidad, Barcelona, Ediciones Pomares, 2003.

Paz, Octavio “Posiciones y contraposiciones: México y Estados Unidos", en Obras Completas, Fondo de Cultura Económica, México, Tomo 8 (1978), 2006.

Pfeffer, J., Nuevos rumbos en la teoría de la organización. Problemas y posibilidades. México, Oxford University Press, 2000.

Pugh, D., et al. "Dimensions of Organization Structure". en Administrative Science Quarterly, 1968, pp. 65-105.

, Hickson, D., Hinings, R., Turner, C., "The context of organization structures", Administrative Science Quarterly, 1969, pp. 91-114.

Roethlisberger, F., Dickson, W., Management and the worker, Massachusetts, Harvard University Press, 1996.

Rosa, A. Ayuzabet de la, "Poder, ambigüedad e institución: re-pensando la concepción tradicional de las relaciones de poder en el análisis organizacional", en Administración y Organizaciones, Universidad Autónoma Metropolitana, 2007, pp.11-29.

Roszak, Theodore et al., La contestación universitaria, Ediciones Península, Madrid, 1973.

Silverman, D., Teoría de las organizaciones, Buenos Aires, Nueva Visión, 1975. Simon, H., La nueva ciencia de la dirección gerencial, Buenos Aires, El Ateneo, 1982. , El comportamiento administrativo, Buenos Aires, Aguilar, 1988.

Skolnik, Michael, "La universidad virtual y el profesorado", en Inayatullah, Sohail y Gidley, Jennifer, La universidad en transformación. Perspectivas globales sobre los futuros de la universidad, Barcelona, Ediciones Pomares, 2003, pp. $72-87$. 
Spies, Philip, "Las tradiciones de la universidad y el desafío de la transformación global", en Inayatullah, Sohail y Gidley, Jennifer, La universidad en transformación. Perspectivas globales sobre los futuros de la universidad, Barcelona, Ediciones Pomares, 2003.

Taylor, F., Principios de la Administración Científica, México, Herrero Hermanos, 1983.

Weber, M., Economía y Sociedad, México, Fondo de Cultura Económica, 1992.

Weick, K., "Educational Organizations as Loosely Coupled Systems" en Administrative Science Quarterly,1976, pp.1-19.

Williamson, O., Las instituciones económicas del capitalismo, México, Fondo de Cultura Económica, 1989.

Woodward, J., "Management and technology", en D. Pugh, Organization Theory, Londres, Penguin Books, 1975, pp. 56-71.

Zey-Ferrell, M., "Criticisms of the dominant Perspective on Organizations", The Sociological Quarterly,1981, pp. 181-205. 


\title{
COMPLEJIDAD HUMANA EN LAS \\ ORGANIZACIONES: UN TEMA POCO \\ CONSIDERADO EN EL ESTUDIO \\ ORGANIZACIONAL
}

\author{
Luis Canek Ángeles Tovar \\ El Colegio de Morelos
}

\section{Introducción}

No es novedad hoy en día que se hable de un paradigma de la complejidad para la generación de nuevo conocimiento en las distintas disciplinas existentes, ya que ahora es mayormente aceptada la idea de que lo complejo se encuentra en gran parte de la vida de las personas. En el caso de los estudios de la organización esto no es diferente, a lo largo de los años se han dedicado a analizar y generar conocimiento sobre la gran diversidad de organizaciones existentes, a través de una amplia variedad de perspectivas teóricas, las cuales han mostrado que las organizaciones pueden considerarse como sistemas complejos, haciendo que sea vista como un elemento inherente en prácticamente cualquier organización.

Derivado de ello, el tema de la complejidad en el ámbito organizacional es retomado en este documento, en el cual, mediante una metodología cualitativa de análisis de contenido, se genera una reflexión respecto a la complejidad humana en las organizaciones. La intención es presentar al lector por qué las organizaciones pueden considerarse como complejas y por qué es pertinente considerar el tema de los aspectos humanos en las organizaciones, como elementos que las vuelven aún más complejas de lo que ya son. Para desarrollar lo anterior el texto se divide de la siguiente manera.

Se inicia abordando el tema de la complejidad para tener una idea más clara de qué implica y por qué actualmente es de gran utilidad. Posteriormente, se escribe sobre la relación entre la complejidad y las organizaciones, no sin antes dejar en claro por qué es relevante el estudio de las organizaciones. Luego de ello, se expone la complejidad humana en ellas, el por qué es adecuado tomar en cuenta a los seres humanos 
como entes complejos al interior de las organizaciones, para explicarlo, se retoman aportaciones de una corriente llamada antropología de las organizaciones que presenta diversos aspectos inherentes del ser humano, los cuales evidencian la naturaleza compleja de las personas. Por último, se ofrece la conclusión respectiva.

\section{Una perspectiva diferente para generar conocimiento}

Por mucho tiempo, al menos hasta la mitad del siglo XX, la generación de conocimiento en gran variedad de ciencias y disciplinas existentes, se ha enfocado en alcanzar explicaciones sumamente puntuales de los fenómenos estudiados; es decir, se ha buscado una especie de "perfección" para entender lo que pasa en el mundo, crear teorías que ofrezcan saberes de amplio alcance (por no decir universales). Aunque en las llamadas ciencias "duras" lo anterior podría parecer adecuado, conforme han pasado los años, es un hecho que la manera de hacer investigación (especialmente en las ciencias sociales) y por ende de obtener conocimientos, se ha modificado debido a que se está trascendido el paradigma ${ }^{19}$ de la simplicidad, dominante en la generación de conocimiento, por un largo período.

En ese sentido, de acuerdo con Morin, ${ }^{20}$ hablar de un paradigma de la simplicidad conlleva la intención de otorgar un orden al universo, concretar el conocimiento en leyes o principios de aplicación general, los cuales al final llegan a separar aquello que está interrelacionado o unificar lo diverso en aras de poner en términos simples el saber obtenido. Esa simplicidad provoca una exclusión de lo que es difícil de entender, la incertidumbre, la ambigüedad y las contradicciones; ${ }^{21}$ dicho de otra manera, la simplicidad se sostiene en cuatro pilares dentro de la llamada ciencia "clásica", 22 que permitían obtener certeza al generar conocimiento. El primero es el orden, que apunta a lograr un mundo regido por leyes sumamente deterministas, sin flexibilidad. El segundo, es el principio de la separabilidad, que conlleva el descomponer los fenómenos en elementos simples para poder analizarlos, eso busca evitar la ambigüedad y la complejidad. El siguiente pilar es el de la reducción,

19 Un paradigma puede entenderse de dos formas, en palabras de Kuhn: 1) Como un conjunto de creencias, valores, técnicas que son compartidos por los integrantes de un grupo. 2) Como ejemplos compartidos para resolver problemas que enfrentan los grupos sociales, esto ya que los ejemplos compartidos ofrecen la posibilidad de obtener conocimiento de forma empírica, el cual posteriormente es aceptado y distribuido por la comunidad. Thomas, Kuhn, La estructura de las revoluciones científicas, México, Fondo de Cultura Económica, 1971.

20 Edgar Morin, Introducción al pensamiento complejo, Barcelona, Gedisa, 1990, p. 120.

21 Edgar Morin, Ciencia con consciencia, Barcelona, Anthropos, 1982, p. 98.

22 María Da Concienção, Para comprender la complejidad, México, Multiversidad Mundo Real Edgar Morin, 2007, p. 45. 
traducida en describir los fenómenos, pero transformándolos en cantidades para que puedan medirse cuantitativamente. En cuanto al último pilar, este es el predominio de una lógica inductiva-deductiva; es decir, las cosas deben explicarse con base en la razón, todo aquello que no se pueda explicar de esa forma no debe ser considerado por la ciencia.

Por lo anterior, Ashby ${ }^{1}$ menciona que, a mediados del siglo XX, muchos científicos de la época, en esencia, se habían dedicado a estudiar sistemas considerados como simples, o al menos que podían ser analizados con relativa facilidad, debido a sus pocos elementos. Tal paradigma de la simplicidad si bien ha sido de "utilidad" durante mucho tiempo para abordar temas relevantes, hoy en día ya no parece ser el adecuado para seguir generando conocimientos de mayor alcance, ahora se considera un nuevo paradigma para realizar investigación, el de la complejidad. Pero ¿qué es la complejidad? De forma breve el término, de acuerdo con el Diccionario de la Real Academia Española (RAE), ${ }^{2}$ se deriva del concepto de complejo, que implica estar compuesto por varios elementos, ser complicado (difícil de comprender) y ser la unión de dos o más cosas que forman una unidad. Por ello, es posible decir que lo complejo es un concepto que cuenta tanto con una dimensión objetiva (debido a que implica la unión de elementos muy diferentes), como con una subjetiva (porque es difícil de entender). ${ }^{3}$

Evidentemente, entender mejor la Complejidad implica ir más allá de la definición de la RAE, por ello, Da Concienção, ${ }^{4}$ con base en contribuciones de Morin, Le Moigne, Ciurana y Motta, entre otros autores destacados en el tema, presenta algunos elementos para comprender de forma más amplia la Complejidad:

- Existen diferentes niveles de complejidad que depende de cada fenómeno, por ejemplo, entre más abierto es un sistema, generalmente la complejidad será mayor. De igual forma, si se estudia un fenómeno natural como un terremoto existirá cierto grado de complejidad, pero no tanto como al estudiar ciertos comportamientos humanos como la violencia.

\footnotetext{
1 Ashby Ross, Introducción a la cibernética, Buenos Aires, Nueva Visión, 1956.

2 s.v. 'Complejidad', 'complejo', Diccionario de la Real Academia Española en línea https://dle.rae. es/?id=A1JK3tM (consultada el 2 de noviembre de 2019).

3 José Solana, "El concepto de complejidad y su constelación semántica", en Complejidad y Ciencias Sociales, Sevilla, Universidad Internacional de Andalucía, 2013, p. 90.

4 María Da Concienção, op. cit., p. 99.
} 
- No es lo mismo complejidad que complicado, ${ }^{5}$ esto último se puede dividir en partes para ser estudiado y eso permite comprenderlo más fácilmente. Por el contrario, lo complejo no puede ser separado, ya que sus múltiples elementos siempre están interrelacionados y son, a la vez, dependientes e independientes.

- Lo complejo conlleva incertidumbre tanto práctica como teórica.

- Aquello que es complejo no es previsible, debido a todos los elementos que interactúan no hay margen para predecir con exactitud qué pasará.

- Los fenómenos complejos no están regidos por leyes universales, pues son inestables e imprevistos.

- Un fenómeno complejo sobrevive gracias a que cuenta con una auto organización, es decir, tiene la capacidad de trabajar su información internamente para regenerarla, modificarla y finalmente generar nuevas formas de organización, además están en interacción con el medio ambiente.

- Lo complejo se relaciona con lo inacabado, un fenómeno complejo normalmente se encuentra transformándose constantemente.

- Algo que es complejo resulta al mismo tiempo dependiente y autónomo, esto ya que es afectado por su entorno, pero también el fenómeno complejo se organiza por sí mismo.

- Cualquier fenómeno complejo presenta emergencias debido a la imprevisibilidad las cuales pueden afectar o beneficiar el funcionamiento del sistema.

- Lo complejo no busca tener un equilibrio, ello debido a su naturaleza cambiante e inestable que deriva en desconocer cómo se comportan esos sistemas tan dinámicos (complejos).

- Aquello que se considera complejo se encuentra en una tensión entre la libertad y el determinismo, a pesar de no ser previsibles y muy dinámicos, generalmente los fenómenos complejos son relacionados con determinismos de la naturaleza.

5 Lo complicado es un aspecto de la complejidad de acuerdo con Edgar Morin, El método II: La vida de la vida, Madrid, Cátedra, 1983. 
A estos elementos es posible agregar otros mencionados por Luhmann, ${ }^{6}$ quien es un autor que se ha referido a la Complejidad, para él, y dejar otras fuera dicho tema tiene que ver con las relaciones, las posibilidades, la contingencia y las probabilidades. Un sistema se considera más complejo de acuerdo a la cantidad de relaciones que establezca, entre mayores sean, la complejidad es más alta, derivado de esas múltiples relaciones se presentan situaciones contingentes o no contempladas que afectan al sistema. Por ello, Luhmann considera un sistema como una estructura de relaciones, la cual debido a su gran número se ve obligada a reducir la complejidad a través de elegir algunas relaciones y dejar otras fuera, en ciertos momentos.

De igual forma, Morin 7 presenta algunas ideas que permiten conocer más sobre la noción de complejidad. Menciona la inclusión de dos términos en teoría excluyentes; el orden y el desorden, esto ya que uno puede contribuir al surgimiento del otro, por más paradójico que eso parezca, por eso existe una relación entre ambos dentro de los fenómenos complejos. También hace mención a considerar la complejidad a nivel humano, es decir los diversos elementos que influyen en el accionar de las personas día a día. Por otra parte, afirma que existen muchos tipos de complejidad, en cualquiera existen contradicciones, estas últimas deben considerarse no como errores, sino como hallazgos que permiten estudiar una capa más de la realidad percibida. Aunado a todo lo anterior, afirma que se requiere tener una visión multidimensional, pues la unidimensionalidad ofrecerá aportes parciales y “pobres" sobre los fenómenos a estudiar; aunque aclara que un punto clave es entender la incapacidad de obtener un saber total de los fenómenos complejos, pero eso no impide ampliar el conocimiento sobre ellos. Si se busca definir de manera breve a la complejidad (a pesar de lo irónico que eso suene) lo dicho por Morin resulta ilustrativo; "La complejidad es una noción cuya primera definición no puede ser sino negativa: la complejidad es lo que no es simple".

Es así, que el acercarse a una perspectiva donde la complejidad es un elemento esencial para generar conocimiento en gran variedad de temas, se ha convertido en una herramienta más que adecuada en nuestros tiempos. En este punto, cabe mencionar que considerar la complejidad para realizar investigación no es algo reciente, para Simon ${ }^{9}$ los

6 Niklas Luhmann, “Temporalización en complejidad”, Introducción a la teoría de sistemas, México,

Universidad Iberoamericana, 1996, pp. 176.

7 Edgar Morin, Introducción al pensamiento complejo, México, Gedisa, 1998, p. 98.

8 Edgar Morin, Ciencia con consciencia, Barcelona, Anthropos, 1984, p. 87.

9 Simon Herbert, Las Ciencias de lo artificial, Granada, Comares, 2006, p. 56. 
antecedentes se observan desde finales de la Primera Guerra Mundial, cuando se aceptaba la idea de que el todo es más que la simple suma de sus elementos, esto tenía una tendencia anti reduccionista y, al mismo tiempo, daba cabida a una visión holística. Posteriormente, llegó la cibernética y la teoría de sistemas generales, así como diversas posturas que tienen a la complejidad como un elemento relevante, entre ellas se encuentran los sistemas complejos adaptativos, la teoría del caos o los algoritmos genéticos. Por eso, se asegura que la complejidad, con el paso del tiempo, se ha convertido en algo que las diversas ciencias consideran "como una característica clave del mundo en que vivimos y de los sistemas que coexisten en nuestro mundo". ${ }^{10}$

De acuerdo con Solana, ${ }^{11}$ lo que resalta de esas nuevas ideas enfocadas en la complejidad, no es el estudiar sistemas complejos, pues eso ya se hacía antes, sino abordar a la complejidad per se, de esto se desprende que Morin mencione que, para generar un nuevo paradigma basado en la complejidad, es necesario construirlo con base en un conjunto de nuevas visiones, conceptos, descubrimientos y reflexiones, las cuales con el tiempo convergerán para mejorar la perspectiva de este pensamiento.

Estamos en una batalla incierta y no sabemos aún quién la llevará adelante. Pero podemos decir, desde ya, que si el pensamiento simplificante se funda sobre la dominación de dos tipos de operaciones lógicas: disyunción y reducción, ambas brutalizantes y mutilantes, los principios del pensamiento complejo, entonces, serán necesariamente los principios de distinción, conjunción e implicación. ${ }^{12}$

El mismo Solana ${ }^{13}$ destaca que Edgar Morin es un referente en cuanto al tema de la complejidad, entre otras cosas por su intención de construir una teoría compleja de la organización, partiendo de la idea de que la organización sólo puede concebirse de una forma adecuada si se le ve desde una perspectiva compleja. Precisamente, esto último da pie al siguiente apartado del documento, la relevancia de estudiar a las organizaciones actuales, haciendo uso de una perspectiva donde la complejidad es aceptada como elemento clave en el análisis.

10 Ibid., p. 216.

11 Solana, op. cit., p. 92.

12 Edgar Morin, Introducción al pensamiento complejo, op. cit., p. 110.

13 Solana, op. cit., p. 145. 


\section{Complejidad en las organizaciones. La relevancia del estudio de las organizaciones}

Antes de considerar la pertinencia de utilizar un enfoque complejo para el estudio de las organizaciones, primero es necesario plantear por qué es importante analizarlas. En ese sentido, se sabe que las organizaciones actualmente son esenciales en la vida de todos los seres humanos, sin ellas, la vida como la conocemos actualmente no sería posible, ya que se requiere tanto de empresas (de todos los tamaños), como de gobiernos, organizaciones civiles, cooperativas, hospitales, escuelas, universidades, prisiones, funerarias, equipos deportivos, gimnasios, etc. Realmente, es prácticamente imposible no tener algún tipo de relación con al menos una organización, aunque generalmente las personas interactúan con varias de ellas, por ejemplo, una persona puede tener relación con el proveedor de internet o de servicios telefónicos, con los supermercados o mercados para comprar alimentos y otros productos o servicios, con la organización (u organizaciones) donde labora, así como con organizaciones dedicadas al entretenimiento (equipos deportivos, cines, teatros, museos), por mencionar algunas. Entonces las organizaciones están en todos lados, como se expresa en las siguientes líneas:

Nacemos dentro de organizaciones, somos educados por ellas y la mayor parte de nosotros consumimos buena parte de nuestra vida trabajando para organizaciones. Empleamos gran parte de nuestro tiempo libre gastando, jugando, y rezando en organizaciones. La mayoría de nosotros morirá dentro de una organización, cuando llegue el día del entierro la organización más grande de todas -el Estado- deberá otorgar su permiso oficial. ${ }^{14}$

Ahora, ¿por qué hay tantas organizaciones? Debido a que, por medio de ellas, es como los seres humanos pueden alcanzar gran variedad de objetivos que de manera individual no sería posible lograr, además, gracias a su existencia, las personas son capaces de otorgar un cierto orden a sus actividades cotidianas, de ahí la idea de que se les puede concebir "como el principal vehículo por el cual, sistemáticamente las tareas de nuestra vidas son racionalizadas, planeadas, articuladas, sintetizadas, más eficientes y ordenadas, y administradas por expertos". ${ }^{15}$ Así, con el paso del tiempo, ha resultado claro que las organizaciones influyen, en mayor o menor medida, en las actividades cotidianas de cualquier sociedad, razón por la cual el analizarlas y generar conocimiento so-

14 Etzioni Amitai, Organizaciones modernas, México, UTEHA, 1986, p. 1.

15 Scott Richard, Institutions and Organizations, California, Sage, 2008, p. 5. 
bre ellas para comprenderlas, se vuelve necesario en busca de mejorar su funcionamiento y contribuir a resolver los problemas que enfrentan pues, en teoría, las organizaciones tienen la capacidad de generar beneficios para la sociedad que las rodea. Perrow ${ }^{16}$ resume esta visión en la siguiente frase: "ya que vivimos en una sociedad organizacional, casi cualquier cosa que podamos aprender acerca de las organizaciones nos ayuda a sobrevivir entre y dentro de ellas".

Con todo esto, resulta evidente por qué es relevante estudiar las organizaciones en la actualidad, tal es la importancia de hacerlo, que existen varios campos de conocimiento para analizarlas a través de diversas perspectivas teóricas, destacándose dos, la teoría de la organización y los estudios organizacionales. Ambos campos cuentan con distintas corrientes de pensamiento que estudian temas presentes en cualquier organización y que dan cuenta de la amplia cantidad de elementos que conforman a las organizaciones. En ese sentido, la teoría de la organización, sustentada en obtener información con técnicas cuantitativas y en un enfoque económico, aborda temas como las relaciones informales al interior de las organizaciones, la influencia del medio ambiente en el funcionamiento de la organización, los procesos para la toma de decisiones, las estructuras formales y reglas establecidas en cada organización, así como las necesidades y motivaciones para influir en el comportamiento de las personas.

Por su parte, dentro de los Estudios Organizacionales, basados en análisis cualitativos y bajo una perspectiva social, recuperan tópicos como las redes organizacionales, el nuevo institucionalismo, el poder, el cambio organizacional, la cultura organizacional, análisis estratégico, el psicoanálisis en las organizaciones, la ambigüedad organizacional, aprendizaje organizacional y la antropología de las organizaciones. Tantos temas por abordar en el estudio de las organizaciones son, en parte, consecuencia de las numerosas formas de organización que existen hoy en día, ${ }^{17}$ las cuales difieren de las existentes anteriormente y que provocan no poder distinguir un modelo único de organización, sino más bien, de organizaciones posmodernas, muy diferentes unas de otras, ${ }^{18}$ por ello, se afirma, desde hace tiempo, que "se acabó la certidumbre, si alguna vez existió, acerca de

16 Charles Perrow, "La historia del Zoológico o la vida en el arenal organizativo", en Control e ideología en las organizaciones, Salaman, Graeme y Kenneth, Thompson, México, Fondo de Cultura Económica, 1984, pp. 293-314.

17 Heydebrand Wolf, "New organizational forms", en Work and occupations, vol. 16, n. 3, 1989, pp. 323-357.

18 Antonio Barba y Pedro Solís, Cultura en las organizaciones. Enfoque y metáforas de los estudios organizacionales, México, Vertiente, 1996, p. 65. 
lo que son las organizaciones". ${ }^{19}$ De ahí que, de acuerdo con De la Rosa y Contreras, ${ }^{20}$ las corrientes adscritas a los estudios organizacionales permiten pasar a un análisis donde se busca anteponer:

Lo local a lo universal, lo particular a lo general, lo relativo a lo absoluto, el caos al orden, la ambigüedad a la claridad, la multirracionalidad a la uniracionalidad, la acción al determinismo, la confrontación al consenso, lo subjetivo a lo objetivo, lo cualitativo a lo cuantitativo, la comprensión a la explicación y la interpretación diversa a la aseveración.

Esa manera "diferente" de estudiar a las organizaciones se realiza con la firme intención de contribuir a la comprensión de la complejidad existente en las organizaciones ${ }^{21}$ por medio de la mutirracionalidad ${ }^{22}$ pues, como menciona Morin, actualmente se requiere acercarse a una perspectiva compleja, y más en el caso de las organizaciones, por su relevancia para la vida moderna de los seres humanos. Como es posible deducir, cualquier organización está conformada por una gran cantidad de elementos interrelacionados, distribuidos en muchos de los temas que han sido abordados por cada una de las diversas perspectivas de la teoría de la organización y los estudios organizacionales. Si bien este último campo de conocimiento, ya cuenta con una visión de colaboración entre disciplinas para generar conocimiento organizacional (transdisciplina), considerar como tal la Complejidad para analizar organizaciones parece más que adecuado para avanzar en la comprensión de la complejidad en ellas.

\section{Complejidad y organizaciones}

En el ámbito del estudio de las organizaciones, el relacionar la complejidad se deriva en principio de concebir a las organizaciones como sistemas abiertos, desde una perspectiva sistémica, donde existe relación con un medio ambiente el cual influye en ellas, pero, al mismo tiempo, las organizaciones pueden influir en él. Un aspecto importante en opinión de Descamps, ${ }^{23}$ es que los sistemas cuentan con diversos "componentes", entre ellos, el humano, que puede recuperarse, ya sea a nivel 19 Stewart Clegg y Cynthia Hardy, "Introduction. Organizations, organization and organizing", en Handbook of organization studies, Clegg, Stewart, Hardy, Cynthia y Nord, Walter, London, Sage, 1996, p. 131.

20 Ayuzabet de la Rosa y Julio Contreras, "El partido político: entre la ciencia política y los estudios organizacionales", en Polis, vol. 3. n. 2, 2007, pp. 17-67.

21 Guillermo Ramírez et al., "Estudios Organizacionales y Administración. Contrastes y complementariedades: caminando hacia el eslabón perdido, Forum doctoral, 201, 3, pp. 7-53.

22 Antonio Barba, "Administración, teoría de la organización y estudios organizacionales. Tres campos de conocimiento, tres identidades", en Gestión y estrategia, año 21, n. 44, 2013, julio/diciembre, pp.139-152.

23 Patrick Descamps, Compexité des organisations et management de la transformation, Monee, Éditions universitaires européenenes, 2016, p. 20. 
microscópico (individual), misión o macroscópico (social). La intención del enfoque sistémico es analizar un sistema de forma total, junto con su dinámica y complejidad inherente ${ }^{24}$, por esa razón se requiere considerar los diversos subsistemas que lo conforman. 1) Estructural, donde se encuentran el organigrama, la descripción de las tareas, los objetivos, las políticas y las estrategias (aspectos formales). 2) Psicosocial, incluye los comportamientos, actitudes, motivaciones, relaciones entre las personas ya sean formales o informales con sus respectivos conflictos y tensiones. 3) Cultural, se le relaciona generalmente con la cultura organizacional, tomando en cuenta la misión, razón de ser de la organización, los valores y las creencias compartidas por los integrantes. 4) Técnico, que son todos los recursos y herramientas requeridos para el funcionamiento de una organización. ${ }^{25}$

El hecho de considerar a las organizaciones como sistemas abiertos que contienen diversos elementos que interactúan constantemente entre ellos, es suficiente para pensar que cualquier organización, independientemente de su tamaño, es compleja, sin embargo, hay otros aspectos contextuales a nivel global que incrementan la complejidad de las organizaciones y por ende de su estudio. En ese sentido Descamps ${ }^{26}$ presenta lo que considera nuevos paradigmas que obligan a las organizaciones a mantenerse en constante cambio para lograr adaptarse y sobrevivir. El primero es la internacionalización de los mercados, es decir las organizaciones, especialmente con fines económicos, buscan tener presencia en cada vez más lugares alrededor del mundo, lo cual deriva en ser afectadas por más elementos de su ambiente, aumentando la complejidad en ellas. El siguiente es la globalización y regionalización, dos términos opuestos pero complementarios, que coexisten e incluso interactúan. El primero es similar a la internacionalización, tener una apertura, aunque no sólo de mercados, sino también, de costumbres, culturas, tendencias, ideas, tecnologías, etc. Mientras que el segundo es esencialmente lo contrario, la existencia de un mundo cerrado a las influencias externas, ya sean culturales, económicas, sociales, políticas, etc. El tercer paradigma es un enfoque intercultural, como consecuencia de la globalización/internacionalización, en este sentido, es lógico reconocer la existencia de múltiples culturas en cada lugar, algo necesario para que las organizaciones con

24 Jöel de Rosnay, El Macroscopio, Madrid, Editorial AC, 1977, p. 87.

25 Michel Bédard, Roger Miller, "L'evolution des connaissances scientifiques en administration: les principaux courants théoriques", La gestion des organizations. Une approche systémique, conceptuelle etstratégique, Michel Bédard, Roger Millerdir, Montréal, Chenelière/McGrawHill, 1995, pp. 24-129.

26 Patrick Descamps, op. cit., p. 80. 
presencia en diversos países puedan lograr lazos de colaboración entre personas con culturas sumamente diferentes. Entonces, las organizaciones son sistemas complejos ya no sólo por los elementos que las conforman y por la influencia de elementos de su entorno inmediato, sino también por todo aquello que les afecta de manera amplia, debido a los cambios contextuales a nivel mundial.

Así, las organizaciones pueden ser vistas como sistemas complejos funcionando alejados del equilibrio ${ }^{27}$ y con ciertas características ${ }^{28}$ que las distinguen de sistemas simples: son abiertas y se conforman de un gran número de elementos, ${ }^{29}$ de estos todos interactúan entre ellos de forma no lineal, por lo tanto, cada elemento puede influenciar o ser influenciado por los demás, derivando en que cada elemento desconoce generalmente el comportamiento del sistema completo. De esta forma, acercarse a un paradigma de la complejidad para el estudio de las organizaciones es adecuado, pues permite lograr beneficios, ${ }^{30}$ como nuevas maneras de concebir a las organizaciones, generar nuevos conceptos y principios para comprender gran número de fenómenos ocurridos en ellas, desafiar los conocimientos aceptados anteriormente, basados en una perspectiva simplista o reduccionista. Con este "nuevo" paradigma es posible pensar en las organizaciones como lugares donde conviven orden y desorden, disonancias y armonías, razón y sin razón, todos ellos conceptos inicialmente contradictorios entre sí, pero que coexisten simultáneamente la mayor parte del tiempo. ${ }^{31}$ Esta manera de pensar en ellas, abre la brecha para adentrarse en un estudio de las organizaciones más profundo, con aportaciones más aterrizadas a la "realidad" de cada organización, pues no se debe olvidar que todas las organizaciones, desde la perspectiva de los estudios organizacionales, son distintas unas de otras, son únicas y por ello el conocimiento generado no puede generalizarse, sino atribuirse a cada una de las organizaciones, o grupos de ellas que son analizados.

Con base en lo expuesto, hasta el momento es claro el por qué comienza a existir un acercamiento, dentro de los estudios de la organización, a un paradigma (en construcción) de la Complejidad, tomando en

27 Steve Maguire et al., "Complexity science and organizations studies", Handbook of organizations studies, Stewart, Clegg; Cynthia Hardy; Thomas Lawrence y Walter Nord eds., London, Sage, 2006, p. 78.

28 Paul Cilliers, Complexity and postmodernism: Understanding Complex Systems, London, Routledge, 1998, p. 96.

29 Esta característica es debatible ya que dentro del campo de los estudios organizacionales, la cantidad de elementos que conforman una organización no es condicionante para concebirla como compleja, organizaciones pequeñas y con un número no muy amplio de elementos también son complejas, en esencia ya que se conforman de seres humanos, quienes son complejos en sí mismos.

30 Steve Maguire et al., op. cit., pp. 123.

31 Jorg Etkin, Gestión de la complejidad en las organizaciones, Argentina, Granica, 2017, p. 90. 
cuenta sus múltiples elementos, mediante gran diversidad de perspectivas teóricas, sin embargo, hay uno ${ }^{32}$ que generalmente no es considerado, al menos no de manera explícita, el ser humano. Es precisamente este tema el abordado a continuación.

\section{Complejidad del ser humano en el estudio de las organizaciones}

Dentro de los múltiples elementos que integran las organizaciones, los seres humanos son por sí mismos complejos, esto ya que cada persona se conforma de una gran variedad de aspectos tanto fisiológicos, como psicológicos y sociales. En ese orden de ideas, dos perspectivas para iniciar con el abordaje de la complejidad del ser humano, son la filogénesis y la ontogénesis, ambas derivadas de las ciencias humanas y que ofrecen la oportunidad de conocer elementos básicos del ser humano como especie y de forma individual. "A grandes rasgos la filogénesis permite distinguir las similitudes del ser humano con otros seres vivos pero al mismo tiempo muestra las diferencias que hacen a la especie humana única", ${ }^{3}$ el ser humano a nivel fisiológico se distingue por su posición bípeda, que fue el detonante para más adelante lograr una liberación de la mano y el desarrollo del pulgar oponible, aspectos que a su vez desencadenaron en una mejora de las capacidades cerebrales permitiendo la creación de utensilios y herramientas para cazar y sobrevivir. La filogénesis también contempla la genética a través del llamado ADN o ácido desoxirribonucleico, el cual permite conocer cómo se transmite la información para la construcción de las células que conforman a las personas ${ }^{34}$ biológicamente hablando. De igual forma se considera el sistema nervioso compuesto de millones de neuronas que permiten los pensamientos abstractos y la creatividad, que es una característica diferenciadora ante las demás especies que habitan el planeta. Otro aspecto único en los seres humanos es el lenguaje y la palabra, pues, aunque los demás seres vivos logren comunicarse con sonidos o movimientos,

32 A pesar de que en este punto se menciona a las personas que forman parte de una organización como elementos, en realidad el ser humano no puede ser reducido a una concepción cosificante como esta, por el contrario, es un ser viviente sumamente complejo. La intención de referirlo así, es, simplemente, para mantener una "coherencia" con la idea de organización como sistema abierto compuesto de elementos.

33 Luis Ángeles, Leticia, Morales, "La filogénesis y la ontogénesis como perspectivas auxiliares para el Análisis Organizacional que contribuya a trascender la concepción de las personas como "objetos": casos SNI y UAM", Análisis Organizacional (n. especial 2016), p. 1337.

34 L. Cavalli-Sforza, W. Bodmer, "Conceptos básicos de genética”, en Genética de las Poblaciones Humanas, Cavalli-Sforza L. y Bodmer W., España, Omega, 1981, pp. 5-39. 
ninguno cuenta con algo siquiera parecido al lenguaje humano, ${ }^{35}$ además, a través de este las personas estructuran su realidad, otorgan un significado subjetivo a sus vidas cotidianas.

Ahora, respecto a la parte Ontogenética, en esencia expone los elementos que permiten la construcción de la identidad de cada ser humano tanto a nivel social como individual; por eso, de inicio, un punto clave es considerar el desarrollo de las personas desde su infancia misma, partiendo de la idea que cada una de ellas es única en un sentido subjetivo. Otro aspecto relevante son las emociones, las cuales pueden abordarse por medio del psicoanálisis, enfocado en sumergirse en el análisis de la realidad interior de las personas, en la que la sexualidad y el placer son importantes para la construcción de la personalidad. ${ }^{36}$ También se toma en cuenta la influencia de los otros, concretamente en la construcción de la identidad de los individuos, de acuerdo con Levi-Strauss, ${ }^{37}$ por medio de relaciones de reciprocidad es posible que los grupos sociales influyan en los comportamientos humanos individuales y sociales. Por último, en la ontogénesis el lenguaje también es de suma relevancia, pero ahora visto desde una perspectiva subjetiva en donde, a través de este, se construyen las relaciones interpersonales que permiten llegar a un punto sustancial de la identidad de cada persona: el reconocimiento de los otros. Toda persona, para dar sentido a su existencia, requiere del reconocimiento de otros, sin él, es muy complicado integrarse a cualquier sociedad de forma adecuada.

Con base en las perspectivas filo y ontogenética es posible responder, al menos de manera abreviada, a la pregunta de ¿quién es el ser humano en las organizaciones que nos rodean?

De forma sintética podemos afirmar que es un ser vivo sumamente complejo por la amplia variedad de elementos (fisiológicos y psíquicos) que lo conforman como especie y como individuo (en sociedad), por ello no se le puede concebir de ninguna manera como una máquina o herramienta, ya que si bien existen máquinas que pueden ser complejas por su gran cantidad de elementos, hasta el día de hoy no cuentan con un verdadero pensamiento propio, con sentimientos, con subjetividad, con irracionalidad, etc. ${ }^{38}$

35 Georges Gusdorf, La palabra, Buenos Aires, Ediciones Galatea Nueva Visión, 1957, p. 75.

36 Sigmund Freud, Cinco conferencias sobre psicoanálisis, Madrid, Amorrortu Editores, 2016, p. 96.

37 Claude Lévi-Strauss, Introducción a Mauss. Sociología y antropología, Marcel Mauss, Madrid,

Editorial Tecnos, 1950, pp. 13-42.

38 Luis Ángeles y Leticia Morales, op. cit., p. 1349. 
Con lo presentado en líneas recientes, parece claro que el ser humano es complejo, pero no lo es solamente por sus aspectos relacionados con lo fisiológico y la construcción de la identidad social-individual, también por la existencia de otros aspectos humanos. En ese sentido es adecuado retomar las aportaciones hechas por una corriente de pensamiento adscrita a los estudios organizacionales y conocida como antropología de las organizaciones $(\mathrm{AO}) .^{39}$ Lo que destaca a la $\mathrm{AO}$ es su énfasis en poner al ser humano como un "elemento" sustancial para el funcionamiento de cualquier organización, aunado a ello, cuenta con una aproximación transdisciplinaria donde existe participación amplia de una gran diversidad de perspectivas teóricas, que retoman aportaciones hechas para comprender a los seres humanos:

La antropología que queremos aspira a estimular el nomadismo, a eliminar las fronteras y a la hibridación. La historia de las ciencias en general y la historia de las ciencias humanas en particular llevan el sello de los pioneros, quienes al plantear nuevas preguntas, inventan disciplinas y trazan nuevos territorios. ${ }^{40}$

Otro aspecto por el cual se destaca la $\mathrm{AO}$, son sus orígenes, ya que se crea como una respuesta para hacer frente a las definiciones inadecuadas del ser humano que durante muchos años han invadido todo tipo de organizaciones en el mundo, las cuales se sustentan en la existencia de un homo economicus. En otras palabras, se piensa que las personas en las organizaciones son seres con capacidades cognitivas ilimitadas, que les permiten conocer todas las alternativas y soluciones posibles a los diversos problemas que se presenten. De eso se despende apreciarlos como seres completamente racionales y cuyos intereses son meramente económicos y dirigidos meramente para optimizar resultados benéficos para la organización. Entonces la AO, nace como una perspectiva alternativa encaminada a modificar las visiones reduccionistas del ser humano, pues aun en la actualidad se le llega a concebir como recurso,

39 Es necesario aclarar que la antropología de las organizaciones a la que se hace referencia en el presente documento, es una visión francesa que difiere de la americana o inglesa. Estas últimas se enfocan exclusivamente en abordar la cultura y los aspectos humanos que ella conlleva, mientras que la francesa desglosa esos aspectos para dar cabida a algunos, que no siempre suelen tomarse en cuenta cuando se habla de cultura, por ejemplo, en la cultura no se habla de sentimientos, de deseos y pulsiones, estos elementos sí son retomados por los autores franceses impulsores de la antropología de las organizaciones.

40 Jean François Chanlat, Ciencias Sociales y Administración. En defensa de una antropología general, Colombia, Fondo Editorial Universidad EAFIT, 2006, p. 66. 
herramienta o capital. Esto deriva en la "existencia" de personas aculturales, ahistóricas, apolíticas, asociales, faltas de moral y que no expresan sentimientos, no muestran emociones y carecen de vida psíquica. ${ }^{41}$

El hecho de permitir la existencia de ese tipo de visones sobre el ser humano, contribuye a olvidar aspectos inherentes al mismo, por mencionar un ejemplo, se llega a desconocer que las personas cuentan con afectividad a través de la cual expresan sentimientos como la envidia, los celos, el egoísmo, la paranoia, el enojo, etc.; todos, presentes en cualquier momento al interior de cualquier organización y que tienen mayor o menor impacto en el funcionamiento de cada persona y de la organización misma. De esta forma, en síntesis, hablar de la AO francesa implica, entre otras cosas, comprender el comportamiento de los seres humanos en las organizaciones, analizándolos bajo un contexto organizacional. ${ }^{42}$

Recordando que son las miembros de la organización el verdadero sustento de estas últimas (sin ellas no podrían existir), estudiarlos dentro de las organizaciones parece sumamente acertado para continuar avanzando en la comprensión más profunda del mundo organizacional, que como se ha observado es muy complejo. En opinión de Chanlat ${ }^{43}$ la AO busca de igual forma recordar cuál es la esencia del ser humano, debido a que hacerlo puede contribuir a realizar análisis más profundos de las organizaciones en las temáticas que se requieran, ello como consecuencia de retomar aspectos inherentes del ser humano, los cuales están siempre presentes en las organizaciones, independientemente de su tamaño, estructura u objetivos; y los cuales permiten explicar ciertos fenómenos organizacionales que de otra manera no sería posible. Dichos aspectos a grandes rasgos son los siguientes: ${ }^{44}$

- Los seres humanos son actores sociales en relación con otros

- Son sujetos en acción, con deseos, sueños y ambiciones

- Portan identidades que se construyen tanto individualmente como en sociedad

41 Jean François Chanlat, "Lagir humain selon "la théorie de l'agence: une critique anthropologique", Les études critiques en management : une perspective française, Golsorkhi, D., Huault, I. y Leca, B., eds. Québec, Les Presses de l’université Laval, 2009, p. 200.

42 Jean François Chanlat, "Anthropologie des organisations", Encyclopédie des ressources humaines, Allouche, Vuibert, 2012, p. 102.

43 Jean François Chanlat, Ciencias Sociales, op. cit., p. 100.

44 Cfr. Jean François, Chanlat las ha desarrollado ampliamente en sus escritos "Anthropologie des organisations"; "Hacia una antropología de la organización" y Ciencias Sociales y Administración. 
- Son actores-sujetos que están en busca de significados que den sentido a su existencia

- Son sujetos arraigados a un espacio y tiempo

- Son sujetos encarnados, es decir, son de carne y hueso, que pueden moverse, actuar, tocar, sentir, sentir placer o sufrimiento

- Son sujetos que se rigen por principios éticos

- El ser humano es un ser al mismo tiempo genérico (como especie) y singular (como individuo)

- Es un ser activo y reflexivo pues son capaces de pensar y actuar, no sólo de responder a estímulos

- Es un ser de palabra, que requiere de ella para dar sentido a su realidad y comunicarse con los otros

- Las personas son seres con deseos y pulsiones

- Son seres simbólicos, por ello son importantes los signos, imágenes, metáforas, emblemas, historias, mitos, etc.

- El ser humano es tanto sujeto como objeto de su ciencia (las ciencias humanas)

- El ser humano es un ser de experiencias vividas

Así, la $\mathrm{AO}$ puede sintetizarse como una perspectiva que pone en la mesa del estudio organizacional una serie de aspectos inherentes al ser humano, que permiten confirmar lo complejo que es y, por ello, lo pertinente que resulta el paradigma de la Complejidad dentro del estudio de las organizaciones. Al final, no se puede negar que las personas son actores sociales, interactuando entre ellas, son sujetos que cuentan con la capacidad de tomar decisiones y realizar acciones de forma autónoma, personas con identidad, tanto social como individual, quienes se encuentran siempre en una búsqueda de significados que otorguen sentido a su día a día, personas que viven en un espacio y tiempo específicos, seres con la posibilidad de hacer múltiples actividades, con sentimientos, capaces de moverse, actuar, tocar, observar, conocer, sentir placer o sufrir y, también, son sujetos que siguen principios éticos. 
Gracias a lo expuesto en el presente apartado, se considera que, si las organizaciones están conformadas por seres humanos, es lógico tener en cuenta los diversos aspectos humanos para aprender más sobre la complejidad en ellas. Sin embargo, desafortunadamente, esos aspectos por lo general, no son considerados en el análisis organizacional. Es cierto que, a través del tiempo, se han tomado en cuenta las aportaciones de diversas corrientes como las relaciones humanas, las nuevas relaciones humanas, el comportamiento organizacional, la cultura organizacional, las teorías de la ambigüedad, el poder en las organizaciones, las redes organizacionales, por mencionar algunas; las cuales, indirectamente hacen referencia a los aspectos humanos retomados por la $\mathrm{AO}$, pero ese es precisamente el punto. Se abordan temas relacionados, pero el ser humano, directamente en la organización, no es analizado a través de sus aspectos inherentes, ello a pesar de la importancia que representa considerar todos esos matices que, aunque no sean "observables", siempre están presentes. En la práctica, fuera de las ciencias humanas que por su naturaleza se dedican al estudio de las personas, la complejidad humana queda relegada del análisis organizacional. ¿Cuántos estudios en este ámbito se apoyan en las ciencias humanas de forma amplia? ¿Cuántos tienen al ser humano como el actor principal en el análisis? Realmente, son muy escasos los que lo hacen.

Aun no se ha hecho conciencia sobre el potencial que ofrece el aprender sobre la complejidad humana a través de las aportaciones ofrecidas por la $\mathrm{AO}$ y por las ciencias humanas, pues es necesario aclarar que la AO no intenta profundizar en cada aspecto humano, sino recordarlos y ponerlos sobre la mesa, para que cada investigador se adentre en la respectiva ciencia humana (psicología, sociología, antropología, etc.), que generó originalmente conocimiento sobre cada aspecto humano. Hacerlo, incentiva la transdisciplinariedad, ayudando a explicar un mayor número de fenómenos en las organizaciones complejas de hoy.

\section{La pertinencia de considerar la complejidad humana en el estudio de las organizaciones}

Es un hecho que se ha ido avanzando en la comprensión de la gran variedad de organizaciones que rodean a las sociedades modernas, sobre todo ahora que hay mayores acercamientos a un paradigma de la Complejidad, acorde con la naturaleza de las organizaciones como sistemas complejos. Pero resulta paradójico que, si cualquier organización se integra por personas (es el único "elemento" que no varía 
en ninguna), prácticamente no se esté analizando la complejidad del ser humano al interior de las organizaciones. Si bien, es posible generar conocimientos sin retomar los aspectos inherentes del ser humano, como se ha realizado por muchos años, se considera que es pertinente hacerlo con cierta constancia, ya que de esa manera será posible obtener saberes de un mayor número de fenómenos acontecidos en las organizaciones que se relacionan directamente con temas como el lenguaje, los símbolos, la ética, las experiencias de vida, los sentimientos, los deseos, las pulsiones, la afectividad, etcétera. Dejar fuera del análisis la complejidad humana llevará, en el largo plazo, a un estancamiento en el camino de la construcción de un paradigma de la complejidad, útil para el estudio de las organizaciones. Al final, este documento extiende la invitación, a que, incluso los especialistas en campos de conocimiento que no se dedican al estudio de todo tipo de organizaciones (economía, ciencias políticas, derecho, administración, educación, por mencionar algunos), consideren la complejidad humana para generar nuevos conocimientos que enriquezcan aún más sus respectivas perspectivas teóricas. Es necesario aclarar, antes de terminar, que en ningún momento se trata de "glorificar" al abordaje de los aspectos humanos en las organizaciones, ni intentar que éstos sean la única temática a revisar de ahora en adelante, no es así, la intención es, simplemente, contribuir a que se conozca otra manera de plantear la complejidad en las organizaciones.

\section{Referencias}

Ángeles, Luis y Morales, Leticia, "La filogénesis y la ontogénesis como perspectivas auxiliares para el Análisis Organizacional que contribuyan a trascender la concepción de las personas como "objetos": casos SNI y UAM”, Análisis Organizacional, n. especial, 2016, pp. 1323-1375.

Ashby, Ross, Introducción a la cibernética, Buenos Aires, Nueva Visión, 1956.

Barba, Antonio y Solís, Pedro, Cultura en las organizaciones. Enfoque y metáforas de los estudios organizacionales, México, Vertiente, 1996. 
Barba, Antonio, "Administración, teoría de la organización y estudios organizacionales. Tres campos de conocimiento, tres identidades", Gestión y estrategia, año 21, n. 44, 2013, pp. 139-152.

Bédard, Michel y Miller, Roger, "L'evolution des connaissances scientifiques en administration: les principaux courants théoriques", La gestion des organisations. Une approche systémique, conceptuelle et stratégique, Bédard, Michel y Miller, Roger dirs., Montréal, Chenelière/ McGrawHill, 1975, pp. 24-129.

Cavalli-Sforza, L. y Bodmer, W. “Conceptos básicos de genética”, Genética de las Poblaciones Humanas, Cavalli-Sforza, L. y Bodmer, W., España, Omega, 1981.

Chanlat, Jean François, Ciencias Sociales y Administración, En defensa de una antropología general, Colombia, Fondo editorial Universidad EAFIT, 2006.

Chanlat, Jean François, "Lagir humain selon "la théorie de l'agence: une critique anthropologique", Les études critiques en management: une perspective française. Golsorkhi, D., Huault, I. y Leca, B. eds., Québec, Les Presses de l'université Laval, 2009.

Chanlat, Jean François, "Anthropologie des organisations", Encyclopédie des ressources humaines, Allouche, Vuibert, 2012.

Chanlat, Jean-François, "Hacia una antropología de la organización”, Gestión y política pública, vol. 3, n. 2., 1994, pp. 317-364.

Cilliers, Paul, Complexity and postmodernism: Understanding Complex Systems, London, Routledge, 1998.

Clegg, Stewart y Hardy, Cynthia, "Introduction. Organizations, organization and organizing", Handbook of organization studies, Clegg, Stewart, Hardy, Cynthia y Nord, Walter, London, Sage, 1996.

Concienção Da, María, Para comprender la complejidad, México, Multiversidad Mundo Real Edgar Morin, 2007.

Descamps, Patrick, Compexité des organisations et management de la transformation, Monée, Éditions universitaires européenenes, 2016.

Etkin, Jorge, Gestión de la complejidad en las organizaciones, Argentina, Granica, 2017.

Etzioni, Amitai, Organizaciones modernas, México, UTEHA, 1986.

Freud, Sigmund, Cinco conferencias sobre psicoanálisis, Madrid, Amorrortu Editores, 2016. 
Gusdorf, Georges, La palabra, Buenos Aires, Ediciones Galatea Nueva Visión, 1957.

Heydebrand, Wolf, New organizational forms, Work and occupations, 16 (3), pp. 323-357, 1989.

Kuhn, Thomas, La estructura de las revoluciones científicas, México, Fondo de Cultura Económica, 1971.

Lévi-Strauss, Claude, Introducción a Mauss. Sociología y antropología, Marcel Mauss, Madrid, Editorial Tecnos, 1950, pp. 13-42.

Luhmann, Niklas, "Temporalization of complexity", en Sociocybernetics, Geyer, Felix y Van der Zouwen, Johannes, eds., London, Martinus Nijhoff, Vol. 2, pp. 95-111, 1978.

Luhmann, Niklas, Introducción a la teoría de sistemas, México, Universidad Iberoamericana/Anthropos, 1996.

Maguire, Steve; Mckelvey, Bill; Mirabeau, Laurent y Öztas, Nail “Complexity science and organizations studies", Handbook of organizations studies, Clegg, Stewart; Hardy, Cynthia; Lawrence, Thomas y Nord, Walter, eds. London, Sage, 2006.

Morin, Edgar, Introducción al pensamiento complejo, Barcelona, Gedisa, 1990.

Perrow, Charles, "La historia del Zoológico o la vida en el arenal organizativo", en Control e ideología en las organizaciones, Salaman, Graeme y Kenneth, Thompson. México, Fondo de Cultura Económica, 1984, pp. 293-314.

Ramírez, Guillermo, Vargas, Germán y Rosa de la, Ayuzabet, "Estudios Organizacionales y Administración. Contrastes y complementariedades: caminando hacia el eslabón perdido", Forum doctoral, 3, 2011, pp. 7-53.

Rosa de la, Ayuzabet y Contreras, Julio, "El partido político: entre la ciencia política y los estudios organizacionales”, Polis, 3 (2), 2007, pp. 17-67.

Rosnay de, Jöel, El Macroscopio, Madrid, Editorial AC, 1977.

Scott, Richard, Institutions and Organizations, California, Sage, 2008.

Simon, Herbert, Las Ciencias de lo artificial, Granada, Comares, 2006.

Solana, José, "El concepto de complejidad y su constelación semántica", Complejidad y Ciencias Sociales, Ruíz, Esteban y Solana, José, Sevilla, Universidad Internacional de Andalucía, 2013. 
Proyecto realizado con financiamiento de la Secretaría de Educación Pública, Subsecretaría de Educación Superior, Dirección General de Educación Superior Universitaria.

Convenio registrado bajo el número 0708/19.

Este programa es público, ajeno a cualquier partido político. Queda prohibido el uso para fines distintos a los establecidos en el programa. 


\section{( (9)}

Transdisciplinariedad, Complejidad y Educación

fue arbitrado bajo el sistema de dobles pares

ciegos y se editó en El Colegio de Morelos.

Av. Morelos Sur 154 esq. Amates, Col. Las Palmas, Cuernavaca, 62050, Morelos, México. (01 777) 318 0125, $3180126,3180127,3180130$

www.elcolegiodemorelos.edu.mx

Para su formación se usó la familia

tipográfica Minion. 